Júlio César Riccó Plácido da Silva

\title{
O PAPEL DA LINGUAGEM FOTOGRÁFICA EM PROCEDIMENTOS DE PROJETO DE PRODUTO
}

Tese apresentada à Faculdade de Arquitetura e Urbanismo da Universidade de São Paulo para obtenção do título de Doutor

Área de concentração: Design e Arquitetura

Orientadora: Prof. ${ }^{\text {a }}$ Dr. ${ }^{\text {a }}$ Cibele Haddad Taralli

EXEMPLAR REVISADO E ALTERADO EM RELAÇÃO À VERSÃO ORIGINAL, SOB RESPONSABILIDADE DO(A) AUTOR(A) E ANUÊNCIA DO(A) ORIENTADOR(A).

$A$ versão original, em formato digital, ficará arquivada na Biblioteca da Faculdade.

São Paulo, 02 de julho de 2018 
Autorizo a reprodução e divulgação total ou parcial deste trabalho, por qualquer meio convencional ou eletrônico, para fins de estudo e pesquisa, desde que citada a fonte.

e-mail: julioricco@usp.br

\section{Júlio César Riccó Plácido da Silva}

Graduado em Publicidade e Propaganda pela Universidade do Sagrado Coração em 2006 e Mestrado em Artes visuais pela Universidade Estadual Paulista de São Paulo em 2014.

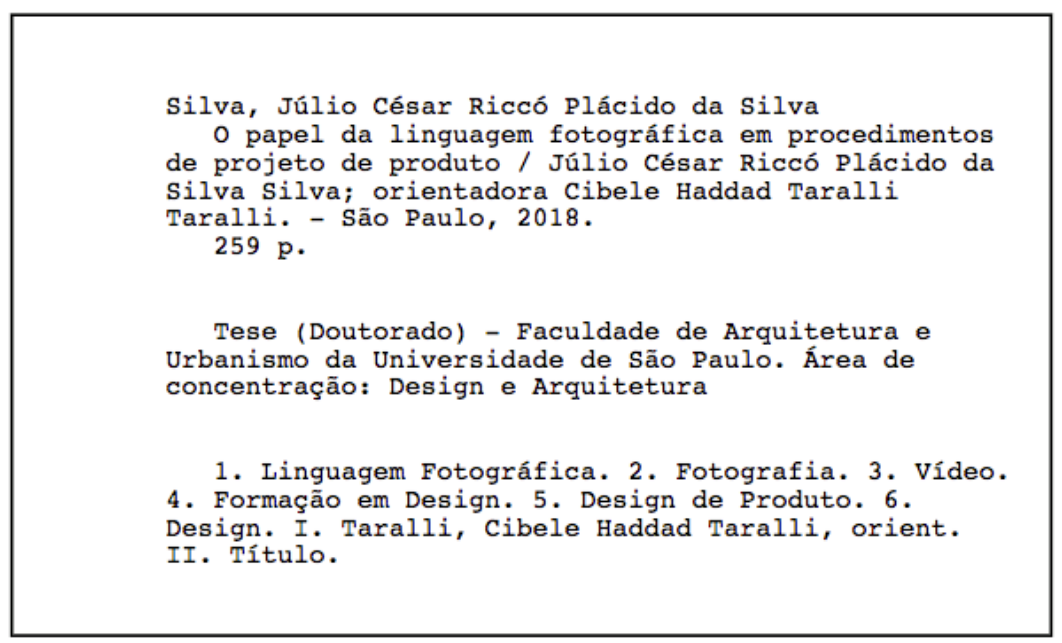

Elaborada eletronicamente através do formulário disponível em: 〈http://www.fau.usp.br/fichacatalografical>

\section{Q


Dedico este trabalho a meus pais, José Carlos Plácido da Silva e Rosa Maria Riccó Plácido da Silva, por todo amor incondicional, por me terem incutido todos os valores que achavam importantes e por me tornarem na pessoa que sou hoje. 


\section{Agradecimentos}

Aos meus pais, José e Rosa e irmão João, por serem grandes incentivadores de todas as minhas jornadas e por criarem essa sede de conhecimento.

Ao Conselho Nacional de Desenvolvimento Científico e Tecnológico (CNPq) pelo recurso financeiro concedido na modalidade de Bolsa de Doutorado sob o processo n. ${ }^{140200 / 2015-0}$, responsável pelo financiamento da pesquisa e por acreditarem na relevância do trabalho.

A Prof. ${ }^{a}$ Dr. a Cibele Haddad Taralli, pela confiança em mim depositada, sempre pronta e gentil e por acreditar na importância desta pesquisa.

Ao Prof. Dr. João Bezerra de Menezes e Prof. Dr. Artur Simões Rozestraten pela contribuição durante o Exame Geral de Qualificação.

Aos professores da USP com os quais tive o privilégio de cursar disciplinas durante o doutorado, Prof. Dr. Wagner Souza e Silva, Prof. ${ }^{a}$ Dr. ${ }^{a}$ Daniela Kutschat Hanns, Prof. ${ }^{a}$ Dr. ${ }^{a}$ Cristiane Aun Bertoldi, Prof. Dr. Carlos Egídio Alonso e Prof. ${ }^{a}$ Dr. ${ }^{a}$ Myrna Nascimento. Aos funcionários da secretaria e da biblioteca, pela gentileza e ajuda, sempre que necessário.

Ao meu irmão Prof. Dr. João Carlos Plácido da Silva e a cunhada Prof. a Ms. Valéria Ramos Friso, pela amizade e presença constante em minha vida, pelas sugestões e apoio acadêmico. Ao meu sobrinho Max Benjamim Friso Plácido, por seu enorme carinho.

Aos professores e alunos que participaram da pesquisa de campo e do questionário digital.

A amiga Simone Priscila Marciano Melz, que tão gentilmente revisou meu projeto inicial, pelo apoio e paciência dispensada no inicio do processo e nos artigos escritos em conjunto.

A colega de turma e amiga Prof. a Ms. Maria do Rosário Gonçalves Mira, pelas incríveis discussões acadêmicas, pessoais e pela parceria em artigos desenvolvidos. E a todos amigos da pós-graduação, com quem tive o prazer e privilégio de conviver durantes esses anos e que tornaram parte desta jornada.

Ao grande amigo e fotógrafo Filipe Berndt, que acompanhou todo o processo e dedicou seu tempo em nossas conversas sobre o projeto, e aventuras fotográficas, colaborando e incentivando a pesquisa. 
À Ana Carolina Perez por sua contribuição na revisão de todo o conteúdo da pesquisa.

Aos amigos de corrida, Aline Taba, Edson Hideki Hashimoto e Fernanda Hatsue Nakasato, que me ensinaram nesse período da pesquisa a conhecer um novo estilo de vida e incentivaram a criar a paixão por esse esporte.

E agradeço a Deus, pelo maravilho presente que é a vida! 
"I've got this light

I'll be around to grow

Who I was before

I cannot recall"

[Eddie Vedder - Long Nights] 
SILVA, J. C. P. O papel da linguagem fotográfica em procedimentos de projeto de produto. Tese apresentada à Faculdade de Arquitetura e Urbanismo da Universidade de São Paulo para obtenção do título de Doutor na área de concentração de Design e Arquitetura.

Aprovado em: 22/05/2018

Tese apresentada como requisito parcial para obtenção do grau de Doutor pelo Programa de Pós-Graduação em Design Arquitetura e Urbanismo da FAU - USP. Aprovada pela Comissão Examinadora abaixo assinada.

\section{Banca examinadora}

Prof. ${ }^{a}$ Dr. ${ }^{a}$ Clice T. S. Mazzilli Instituição: FAU - USP Julgamento: Aprovado

Prof. Dr. Wagner S. e Silva Instituição: ECA - USP Julgamento: Aprovado

Prof. Dr. Osmar V. Rodrigues Instituição: UNESP Julgamento: Aprovado

Prof. Dr. Jofre Silva Instituição: UFRJ Julgamento: Aprovado

Orientador

Prof. ${ }^{\text {a }}$ Dr. ${ }^{\text {a }}$ Cibele H. Taralli Instituição: FAU - USP Julgamento: Aprovado 


\section{RESUMO}

SILVA, J. C. P. O papel da linguagem fotográfica em procedimentos de projeto de produto. 2018. 259p. Tese (Doutorado: Design e Arquitetura) - Faculdade de Arquitetura e Urbanismo, Universidade de São Paulo, SP, 2018.

A tese parte da premissa de que a linguagem fotográfica constitui recurso adicional e pertinente para aplicação no projeto de produto, representando uma ferramenta potencial para uso desde a pesquisa e captura ${ }^{1}$; a manipulação; e o tratamento de imagens para o design de produto, considerado da concepção à viabilização da ideia, e também na comunicação de resultados projetuais. Considera-se que esta linguagem colabora no design de produto, para a criação, a visualização e a compreensão das ideias, por meio de imagens pertinentes ao projeto, ao lado das demais técnicas e meios de representação usuais como sketches, desenho técnicos, protótipos e outros.

O universo da pesquisa versa sobre a formação em Design, realizando primeiro levantamentos bibliográficos sobre, as aplicações da linguagem fotográfica no processo de projeto de produto; passando pelas origens e influências conceituais e pedagógicas para o ensino de design de produto exercidas pela Bauhaus e pela Escola de Ulm; apresentando em seguida uma síntese do levantamento e da caracterização de técnicas, recursos e aplicações da fotografia e do vídeo no projeto de produto, procurando identificar a contribuição e os usos da linguagem fotográfica na construção e desenvolvimento gradual e sistemático de ideias, considerando a transmissão; a conservação, documentação e a memória, e a prospecção de conceitos e configurações (formais, geométricas, e experimentais em e através de imagens). Considera-se que estas trazem ao designer oportunidade diferencial para o projeto, colaborando para a ampliação de seu repertório imagético e de capacidades abstrativas na aplicação das ferramentas - analógicas e digitais considerando o projeto, analise, avaliações de projeto de produto.

Em seguida através de pesquisa qualitativa de campo realizada com professores de cursos de graduação em Design, no Estado de São Paulo, traça um panorama sobre o que eles entendem sobre a linguagem fotográfica; como aplicam as novas tecnologias no processo de projeto, e quais as estratégias de ensino são

\footnotetext{
${ }^{1} \mathrm{O}$ significado captura é utilizado na atualidade no lugar de registro com o efeito de capturar algo no sentido de diversas tomadas de enquadramento possíveis que as ferramentas possam realizar. A ação de registrar foi investigada por Barthes (1984) na década de 60.
} 
adotadas. Do ponto de vista dos alunos, através de levantamento quali e quanti, se percebeu o que eles conhecem a respeito, e em quais disciplinas ou recursos didáticos são abordados aspectos da linguagem fotográfica no ensino de projeto de produto.

Constata-se que muitas vezes seu avanço não é percebido ou incorporado na estrutura educacional do ensino superior em de Design, quando se consideram os meios, recursos e procedimentos para o projeto de produto.

Os levantamentos realizados colaboraram para a formulação de uma proposição de conteúdos sobre linguagem fotográfica nos cursos de graduação de design com o foco considerando a sua contribuição para o projeto de produto. A importância do estudo está em identificar, por meio de pesquisa documental e entrevistas, quais são os aspectos mais relevantes do emprego da linguagem fotográfica no ensino do designer de produto na região do Estado de São Paulo, simulando projeções e perspectivas futuras em premissas para a formação de disciplinas de Linguagem Fotográfica na graduação em Design de Produto.

\section{Palavras-chave}

Linguagem fotográfica, fotografia, vídeo, formação em design, design de produto, design. 


\section{ABSTRACT}

SILVA, J. C. R. P. The role of the photographic language in product design procedures. 2018. 259p. Doctoral dissertation (Manor in Design and Architecture), Faculdade de Arquitetura e Urbanismo, Universidade de São Paulo, SP, 2018.

The present thesis is based on the premise that the photographic language constitutes an additional and relevant resource for application in product design, representing a potential tool to be used in research and capture; manipulation; and image processing for product design, considered from the conception to the viability of the idea as well as in the communication of project results. This language is considered to collaborate in the product design for the creation, the visualization, and the understanding of ideas, through images that are pertinent to the project, along with other common techniques and means of representation such as sketches, technical drawings, prototypes etc.

The research is about design training, starting with bibliographical surveys on the applications of the photographic language in the product design process; addressing the Bauhaus and the School of Ulm origins and conceptual and pedagogical influences for the teaching of product design; and presenting a synthesis of the survey and characterization of techniques, resources, and applications of photography and video in product design, aiming to identify the contribution and uses of the photographic language in the construction and gradual and systematic development of ideas, considering transmission, preservation, documentation and memory, and exploration of concepts and configurations (formal, geometric, and experimental in and through images). These are considered to provide the designers with a differential opportunity for the project, collaborating to expand their repertoire of images and abstract capabilities in the application of analog and digital tools considering the design, analysis, and product design evaluations.

Then, by means of qualitative field research conducted with professors of undergraduate courses in Design, in the state of São Paulo, the research traces a panorama on what they understand about the photographic language; how they apply new technologies in the design process, and which teaching strategies are adopted. From the students' point of view, by means of a qualitative and quantitative survey, it was possible to observe what they know about it, and which disciplines or 
didactic resources approach aspects of the photographic language in the teaching of product design.

Notes that its advance is often not recognized or incorporated in the educational structure of the Higher Education in Design taking into account the means, resources, and procedures for product design.

The surveys conducted have contributed to the formulation of a proposition of contents about photographic language in undergraduate courses of design with the focus considering your contribution to the design of the product.

The importance of this study is to identify, by means of documentary research and interviews, the most relevant aspects of using the photographic language in the teaching of the product designer in the State of São Paulo, simulating projections and future perspectives in premises for the creation of disciplines on Photographic Language in the graduation in Product Design.

\section{Keywords}

Photographic language, photography, video, design training, product design, design. 


\section{LISTA DE ABREVIATURAS}

apud: (do latim: junto a; em) citado conforme, segundo - indica a fonte de citação cap.: abreviatura de capítulo

et al.: et alii (masculino) indica que existem mais autores citados

ex.: abreviatura de exemplo

fig.: abreviatura de figura

p.: abreviatura de página

pp.: abreviatura de páginas

\section{LISTA DE SIGLAS}

2D: bidimensional

3D: tridimensional

ABERGO: Associação Brasileira de Ergonomia

ABRA: Escola de Arte e Design

BA: Centro Universitário Belas Artes

CAD: Projeto auxiliado ao computador

CFE: Conselho Federal de Educação

CG: Computação Gráfica

CNPq: Conselho Nacional de Desenvolvimento Cientifico e Tecnológico

CV: Comunicação Visual

DCH: Design Centrado no Humano

DCN: Diretrizes Curriculares Nacionais

DCU: Design Centrado no Usuário

DI: Desenho Industrial

ECA: Escola de Comunicação e Artes

e-MEC: Cadastro da Educação Superior do Ministério da Educação

ESDI: Escola Superior de Desenho Industrial

ESPM: Escola Superior de Propaganda e Marketing

ETEC: Escola Técnica Estadual

FAAP: Fundação Armando Alvares Penteado

FACAMP: Faculdade de Campinas

FAU: Faculdade de Arquitetura e Urbanismo

FIB: Faculdades Integrada de Bauru 
FPA: Faculdade Paulista de Artes

FMU: Faculdades Metropolitanas Unidas

HD: Parte do computador onde são armazenados os dados

HCD: "Human-Centred Design" (Design Centrado no Humano)

HFG: "Hochschule für Gestaltung" (Escola de Design de UIm)

ICSDI: "International Council of Societies of Industrial Design" (Conselho Internacional das Organizações de Design Industrial)

IED: Instituto Europeo Di Design - São Paulo

IES: Instituição de Ensino Superior

ISO: Sensibilidade de superfícies fotossensíveis

LEI: Laboratório de Ergonomia e Interfaces

LF: Linguagem fotográfica

MACKENZIE: Universidade Presbiteriana Mackenzie

MAM: Museu de Arte Moderna de São Paulo

MASP: Museu de Arte de São Paulo

MAUÁ: Instituto Mauá de Tecnologia

MEC: Ministério da Educação

MOCAP: Captura de movimento

MOCKUP: Modelo em escala ou tamanho real de um projeto ou dispositivo

RA: Realidade Aumentada

RV: Realidade Virtual

SAGA: Escola de Computação Gráfica

SENAC: Serviço Nacional de Aprendizagem Comercial

SESC: Serviço Social do Comércio

SP: São Paulo

UCD: "User-Centered Design" (Design Centrado no Usuário)

UNESP: Universidade Estadual Paulista

UNIARA: Universidade de Araraquara

UNIMONTE: Centro Universitário Monte Serrat

UNISO: Universidade de Sorocaba

UNIFATEA: Centro Universitário Teresa D’Ávila

UNINOVE: Universidade Nove de Julho

USC: Universidade do Sagrado Coração

USP: Universidade de São Paulo 


\section{LISTA DE FIGURAS}

Figura 1 - Lucia Moholy, "Silver coffee and tea service with alcohol-fuelled warmer by Marianne Brandt, 1924" - foco no conjunto de utensilios, documentação realizada em estúdio para valorização dos objetos

Figura 2 - Georg Muche, "Still Life in Glass, 1921/22" - composição dos

objetos de elementos materiais para estudo de reflexos em estúdio.

Figura 3 - à esquerda, Paul Citroen, "Big City (Metropolis), 1923" montagem de diversas imagens no desenvolvimento de uma composição única.

Figura 4 - à direita, László Moholy-Nagy, "Photoplastic, 1925" montagem de diversas imagens no desenvolvimento compositivo da imagem.

Figura 5 - Light-Space Modulator, Réplica 1970. Dispositivo para experimentação de efeitos da luz em movimento..

Figura 6 - Série de experimentos: "Von Grader und Kreis zu Hiperbolóide und Kugel", para a aula de Joost Schmidt na oficina de escultura.

Figura 7 - Paleta de cores gerada através de software de imagem.

Figura 8 - Exemplo de um dos maiores bancos de imagens que disponibilizam diversas mídias através de planos mensais.

Figura 9 - A brincadeira de criança utilizando um carro de brinquedo possibilitou a ideia de desenvolvimento de sketches de um aspirador de pó

Figura 10 - Motion Capture

Figura 11 - Mapa de imagens relacionadas com o queijo Serrano.......

Figura 12 - Moodboard de mapeamento de Mercado, a estética e os comentários dos usuários de produtos de limpeza, por Tom Harper......

Figura 13 - A partir de uma referência de uma imagem de borboleta foi gerado o conceito para o desenvolvimento de sketches de uma cadeira.....

Figura 14 - Desenvolvimento de fone de ouvido usando mídia mista: fotografia e caneta.

Figura 15 - A sequência de imagens abaixo apresentam todas as 
etapas mais importantes no desenvolvimento de uma mesa (Tavalone), com a utilização de resina, grade de ferro, pernas de aglomerado revestidas com resina em varias dimensões.

Figura 16 - A imagem explodida do fone de ouvido, produto abaixo, apresenta detalhadamente todas as peças que fazem parte do produto.......

Figura 17 - Análise sobre suporte de objetos na bicicleta, fotografadas por James Bartlett, apresentando as improvisações/soluções

Figura 18 - Três opções posturais da cadeira: (a) ereto (b) reclinado e (c) inclinação para frente.

Figura 19 - Planos anatômicos 88

Figura 20 - Janela de controle para realizar a captura. 90

Figura 21 - O uso de dois monitores é recomendado, principalmente para o registro das categorias de interação.

Figura 22 - Imagem de totem digital realizada em estúdio fotográfico com inserção de figura humana em software de tratamento digital.

Figura 23 - Totem digital e figura humana inserida em ambiente de possível instalação do produto.

Figura 24 - Interface do software Flir tools, com diversas capturas realizadas para análise.

Figura 25 - Imagem térmica sofrendo possíveis analises através do software Flir tools

Figura 26 - Termografia do corpo-de-prova em metal........................... $\quad 95$

Figura 27 - Termografia do corpo-de-prova em silicone......................... 95

Figura 28 - Princípio de triangulação fotométrica................................... 97

Figura 29 - Estratégias para aquisição de conjuntos de imagens.......... 97

Figura 30 -: Imagens carregadas no sistema VisualSFM....................... 98

Figura 31 - Restituição fotogramétrica - nuvem de pontos.................... 99

Figura 32 - Edição e correção da nuvem de pontos - MeshLab............ 99

Figura. 33 e 34 - Captura e análise digital, com agachamento (inicial e final) Plano Sagital 101

Figura 35 - interface do software Kinovea para análise de situações capturadas em vídeo. 102

Figura 36: Experiência de Sutherland (1972) com malhas poligonais 
complexas no processo de modelagem da carroceria.......................... 105

Figura 37 - Representação esquemática da geração de holograma..... 109

Figura 38 - O Dreamoc da RealFiction - projetor holográfico................ 110

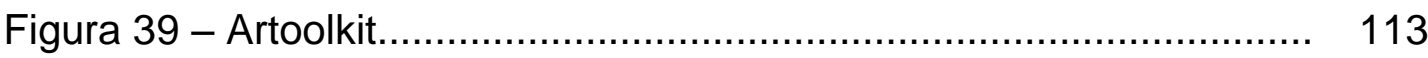

Figura 40 - Carro virtual (esquerda) ao lado de uma maquete real........ 115

Figura 41 - Fluxograma da elaboração da tese com rebatimento ao

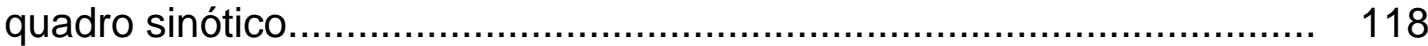

Figura 42 - Esquema sobre a coleta de dados quali e quanti................. 119

Figura 43 - Tipos de dados da entrevista episódica.............................. 124

Figura 44 - Nuvem de palavras....................................................... 135

Figura 45 - Relações entre os elementos estruturantes....................... 136

Figura 46 - Elementos estruturantes da análise............................... 137

Figura 47 - Exemplo de codificação do documento............................... 138

Figura 48 - Categorização Design Análise............................................. 139

Figura 49 - Categorização Design de Produto..................................... 140

Figura 50 - Categorização Design Investigação................................... 140

Figura 51 - Categorização ensino.................................................. 141

Figura 52 - Categorização Ferramentas......................................... 142

Figura 53 - Categorização Linguagem Fotográfica.............................. 142

Figura 54 - Categorização Representação......................................... 143

Figura 55 - Categorização Tecnologia............................................. 144

Figura 56 - Diagrama considerado para a proposta de desenho de conteúdos e práticas para planos de ensino........................................... 206

Figura 57 - Interdisciplinaridades com as disciplinas da área............... 211

Figura 58 - Competências representacionais, projetual e relacional..... 212 


\section{LISTA DE QUADROS}

Quadro 1 - Classificação de técnicas de reconstrução tridimensional....... 106

Quadro 2 - Comparação entre as técnicas de reconstrução tridimensional...... 106

Quadro 3 - Forças e fragilidades da entrevista episódica.......................... 123

Quadro 4 - Codificação e categorização................................................. 134

Quadro 5 - Sugestão de inserção da linguagem fotográfica nos eixos de conhecimento para o Design............................................................ 213

Quadro 6 - Síntese das propostas - linguagem fotográfica para o design

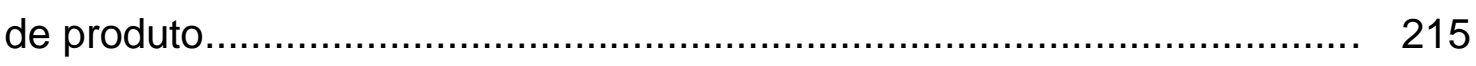




\section{LISTA DE GRÁFICOS}

Gráfico 1 - Porcentagem de aceitação dos alunos ao "Termo de Consentimento Livre e Esclarecido"

Gráfico 2 - Contagem de instituições de Ensino Superior e Cidade com alunos participantes

Gráfico 3 - Semestre letivo de cada participante.

Gráfico 4 - Respostas sobre a oferta da disciplina de Fotografia ou

Vídeo - (questão fechada)

Gráfico 5 - Nome das disciplinas oferecidas nas instituições de ensino.

Gráfico 6 - Você utiliza da linguagem da fotografia e do vídeo nos projetos do curso?.

Gráfico 7 - Respostas para a questão: A linguagem fotográfica e do vídeo pode desenvolver papel preponderante no processo de projeto?....

Gráfico 8 - Você utiliza a linguagem fotográfica e do vídeo em outras aplicações dentro do curso?

Gráfico 9 -Você acredita que o sistema digital (fotografia e vídeo) viabiliza e agiliza no desenvolvimento do projeto de design na atualidade?.

Gráfico 10 - Já realizou algum curso ou workshop de fotografia ou de vídeo em outra instituição? 


\section{SUMÁRIO}

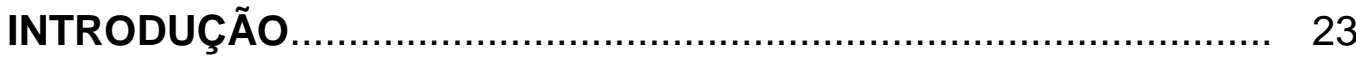

APRESENTAÇÃO DESTE VOLUME.......................................... 25

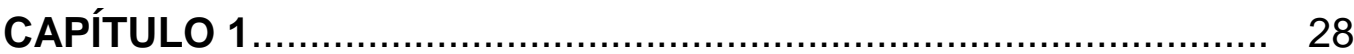

1. CARACTERIZAÇÃO GERAL DA PESQUISA................................. 29

1.1 Objeto da pesquisa................................................................ 29

1.2 Problema fundamental............................................................... 29

1.3 Relevância e originalidade.............................................................. 29

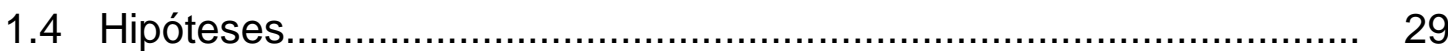

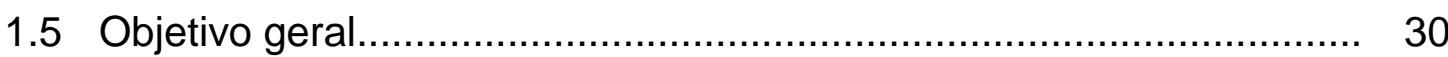

1.5.1 Objetivos específicos.............................................................. $\quad 30$

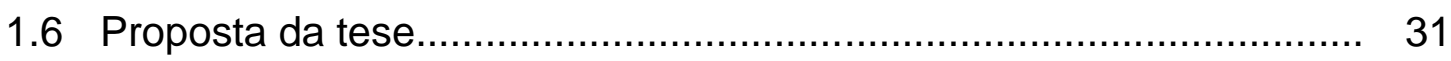

1.7 Introdução ao estudo................................................................ 31

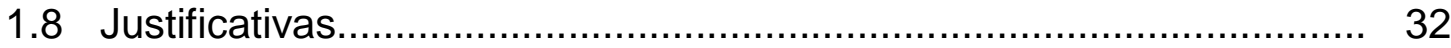

1.9 Definições de conceitos................................................................... 34

1.10 Procedimentos da pesquisa de campo.............................................. 34

1.11 Eticidade da pesquisa.................................................................... 35

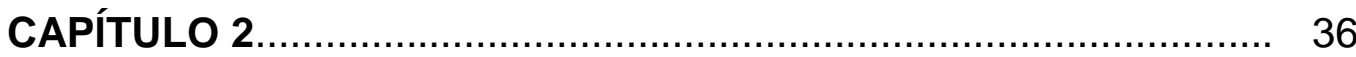

2. DESENHO INDUSTRIAL - DESIGN: ALGUMAS COLOCAÇÕES SOBRE O CAMPO DO PROJETO DE PRODUTO.......................... 37

2.1 O Designer - formação e atividade profissional.................................. 39

2.2 Colocações iniciais sobre projeto para Design de produto e as ferramentas. 42

2.3 O projeto, os produtos e a complexidade contextual e configuracional.. 44

2.4 Alguns aspectos sobre métodos projetuais e o ensino de Design de

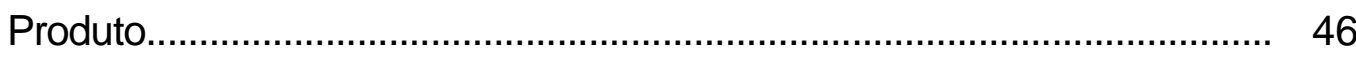

2.5 O ensino da metodologia e as ferramentas..................................... 48

2.6 Linguagem fotográfica e representação para o Design de Produto.... 51

2.7 Linguagens, representação e percepção visual................................ 52

2.8 A fotografia e o vídeo como ferramenta de representação................. 55

2.9 A linguagem fotográfica............................................................ 57

2.10 A linguagem fotográfica e a formação do designer de produto........... 58

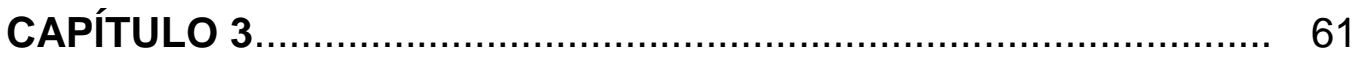

3. AS PRINCIPAIS ESCOLAS E SUAS REFERÊNCIAS PARA A 
FORMAÇÃO DOS DESIGNERS.

3.1 Bauhaus - Aspectos históricos....................................................... 62

3.2 Valorização da documentação e criação do objeto............................. 65

3.3 Breve histórico da Escola de ULM................................................... 71

3.3.1 A oficina de fotografia e vídeo na Escola de Ulm............................. 73

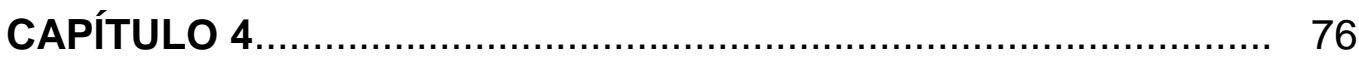

4. PRINCIPAIS USOS DA FOTOGRAFIA NO PROCESSO DE PROJETO E NA ATUAÇÃO EM DESIGN........................................ 77

4.1 Pesquisa e criação................................................................... 78

4.2 Referência visual..................................................................... 78

4.3 Uso no processo criativo de projeto de produto................................. 83

4.4 Documentação das fases de processo de projeto.............................. 84

4.5 Imagens técnicas....................................................................... 85

4.6 Análise e pesquisa de uso ............................................................ 86

4.7 Análise através do vídeo........................................................... 89

4.8 Análise e prospecção de uso....................................................... 91

4.9 Recursos recentes - Introdução................................................... 92

4.9.1 Termográfica infravermelha........................................................ 92

4.9.2 Fotogrametria digital........................................................... 96

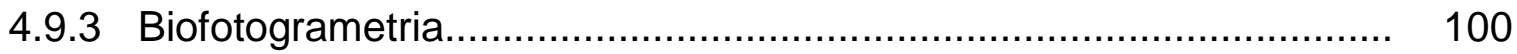

4.9.4 Escaneamento Tridimensional................................................. 104

4.9.5 Holografia .................................................................... 108

4.9.6 Realidade aumentada............................................................ 111

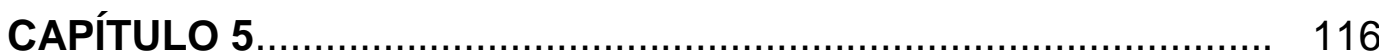

5. PROCEDIMENTOS ADOTADOS - PESQUISA DE CAMPO............. 117

5.1 A escolha do método adequado a pesquisa.................................... 118

5.2 Dados necessários para o levantamento......................................... 119

5.3 Acesso às instituições de ensino................................................... 119

5.4 Técnica de coleta de dados........................................................ 120

5.5 Entrevista episódica com docentes............................................... 120

5.6 Entrevista Piloto.......................................................................... 123

5.7 Questionário on-line com alunos................................................. 125

5.8 Questionário piloto online............................................................. 127 
5.9 Sobre os métodos para coleta de dados:

128

5.10 Transcrição das entrevistas e sistematização dos questionários........ 128

5.11 Técnicas de tratamento dos dados.................................................. 129

5.12 Percurso metodológico da pesquisa com o software Atlas.TI............. 130

5.13 Componentes do software......................................................... 132

5.14 Organização dos dados das entrevistas e questionários.................... 133

5.15 Organização e categorização através do software Atlas.ti.................. 134

5.16 Inferências e interpretação dos resultados....................................... 138

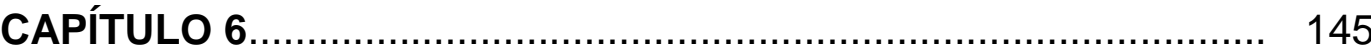

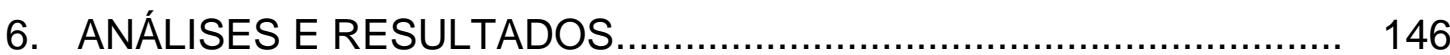

6.1 Mudanças fundamentais do papel da fotografia no processo projetual, contextualizada na evolução da tecnologia........................ 146

6.2 O emprego da fotografia e do vídeo como meios tecnológicos para recurso projetual no Design de Produto............................................. 151

6.3 Como o conhecimento técnico sobre linguagem fotográfica é aplicada por docentes no campo do Design de Produto.

6.4 A ferramenta fotográfica e de vídeo é utilizada no campo do Design de Produto

156

6.5 A fotografia e o vídeo geram interferências nas ações dos processos de projeto e nos processos de representação.

6.6 As diversas técnicas de representação contribuem para que o designer otimize a atividade projetual.

6.7 As diversas técnicas de captura e manipulação de imagem oferecidas e a disposição no ensino de Design de Produto, no Design de Análise e no Design de Investigação.

6.8 As diversas técnicas de captura e manipulação de imagem oferecidas e a disposição no ensino de Design de Produto; no Design de Análise e no Design de Investigação

6.9 Há necessidade do aluno estar familiarizado com as diversas ferramentas para a produção de imagem

6.10 De que forma a fotografia e o vídeo tem sido aplicados como suporte nos processos e procedimentos em Design de Produto; no Design de Análise e no Design de Investigação 
6.11 A linguagem fotográfica no design perdeu o seu papel fundamental de fomentar e socializar a comunicação e informação nos processos de projeto.............................................................. 185

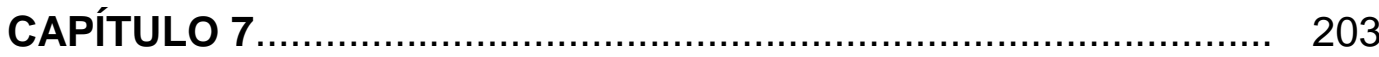

7. PREMISSAS PARA FORMATAÇÃO DE DISCIPLINA E CONTEÚDOS SOBRE LINGUAGEM FOTOGRÁFICA..................... 204

7.1 Elementos de destaque para a proposta de disciplina sobre Linguagem Fotográfica aplicada ao projeto de produto............................................ 207

7.2 Elementos para a proposta de distribuição de conteúdos de linguagem fotográfica nas disciplinas dos cursos de Design de

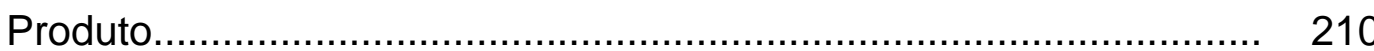

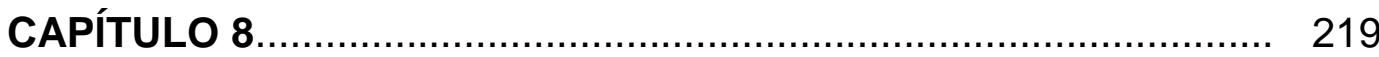

8. CONSIDERAÇÕES FINAIS .................................................... 220

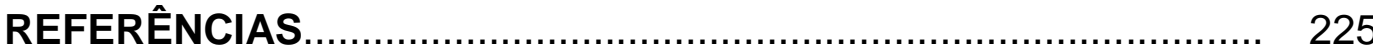

APÊNDICES 


\section{INTRODUÇÃO}

No processo de criação de produtos industriais, o designer utiliza diversos procedimentos metodológicos e criativos, bem como ferramentas e técnicas para o desenvolvimento de suas ações.

Sobre as tecnologias e técnicas contemporâneas, o aprimoramento ou as inovações advindas dos recursos digitais disponibilizam ao profissional da área, recursos, instrumentos e procedimentos, oriundos da linguagem fotográfica, que oferecem possibilidades de tratamento, manipulação e uso de imagens facilitadoras e qualitativas para o processo de projeto.

$\mathrm{Na}$ formação do designer, pode ser observado que o método projetual é a espinha dorsal no desenvolvimento de novos projetos. Assim, quanto ao Design de Produto, é possível constatar que nas ações pedagógicas para o exercício de projeto, na graduação, os estudantes são orientados, tradicionalmente, para o desenvolvimento e o uso de métodos fundamentados em fases sequenciais e contínuas ou experimentais. A partir do consenso acerca dos fundamentos do design no campo de produto, assim como no meio profissional e acadêmico, observa-se que a variedade e quantidade de métodos existentes vêm acompanhadas de relevante evolução nos procedimentos para o projeto.

Igualmente verifica-se que há um incremento nas pesquisas direcionadas às práxis do projeto, que tem progressivamente se revelado essencial para geração de inovação e incorporação de novas tecnologias, em função das respostas que consideram as soluções práticas de design, e não somente daquelas demandadas pelo mercado e que envolvem, por exemplo, questões técnicas, estéticas, culturais, geográficas, ecológicas, históricas e políticas de forma integrada.

Recentemente, parte dos designers considera outras visões e metodologias, introduzindo contribuições das mais diversas áreas do conhecimento e incorporando novas perspectivas e tendências tecnológicas do e para o campo profissional e acadêmico. Contudo, cada designer, na atividade projetual, introduz recursos e/ou usa meios disponíveis já experimentados, como softwares para desenho, imagens fixas ou em movimento, que ora são auxiliares na representação do processo criativo do produto, ora são instrumentos de trabalho que concorrem para a viabilização da ideia e seu desenvolvimento. 
No processo de projeto e seu desenvolvimento, a fotografia e o vídeo, os sistemas de produção e manipulação de imagens, bem como suas técnicas, entre outros, são considerados suportes do projeto de design. A fotografia e o vídeo, como ferramentas auxiliadoras no processo de projeto, vêm sendo marcados por diversos aprimoramentos técnicos, que em um processo de evolução no tempo, visaram à reprodução fiel da realidade e foram acompanhados por mudanças tecnológicas que incorporaram gradativamente a automatização do aparelho e dos recursos fotográficos, em detrimento da relação ser humano versus máquina.

Pode-se afirmar que muitos designers já utilizam instrumentos computacionais e digitais para o estudo, na realização e na concretização de seus projetos. Entre tais instrumentos, a fotografia e o vídeo podem assumir função auxiliar, porém, essencial como meio participante das atividades do designer, não apenas no processo criativo, passando também pelas etapas de desenvolvimento e finalização do projeto.

O estudo bibliográfico investigou os conhecimentos e as diversas habilidades que o designer adquire ao incorporar a linguagem fotográfica no processo de projeto, assim como mapeou seus múltiplos usos na área do Design de Produto. Logo, uma das indagações que surgiu no presente estudo é como selecionar o material e os dados de natureza conceitual e teórica (literatura especializada), bem como as informações empíricas (instituições de ensino de Design de Produto - docentes e alunos); para responder às questões da pesquisa (considerado o tempo e o acesso). Estes procedimentos iniciais constituíram etapa fundamental necessária, obtendo informações que direcionaram a execução dos levantamentos de campo, com dados consistentes e atualizados, sobretudo relacionados a atividade das instituições de design, e as ferramentas atualizadas de linguagem fotográfica (softwares e hardwares) para a atuação em Design.

Nessa perspectiva, considera-se que essas ferramentas, que historicamente desempenharam e ainda assumem papel significativo nos processos de projeto em Design, atualmente têm sido subutilizadas pelos profissionais da área de Produto.

É um instrumento que possibilita ao designer empregar recursos e expressões imagéticas importantes e qualitativas para o projeto, podendo colaborar para desenvolver um procedimento constitutivo da imagem (e da ideia) desde 0 início do projeto. Considera-se, também, que os recursos da linguagem fotográfica disponibilizam outras possibilidades de trabalho/manipulação de imagens bi e 
tridimensionais, que extrapolam o seu uso tradicional na representação e comunicação do projeto e do produto, e que podem alterar o modo e a frequência do seu emprego nas fases e nos resultados do projeto.

Diante dessas colocações, a pesquisa tem por objetivo destacar a importância de os designers conhecerem os fundamentos e as práticas de uso das tecnologias emergentes aplicadas aos processos de projeto, dentre estas, em especial, a fotografia e o vídeo, em que pese, as diversas habilidades e competências já desenvolvidas em sua formação e atuação. Verifica-se que apesar do reconhecimento dessa importância, ainda são escassos os estudos científicos sobre o papel da fotografia no projeto de produto, carecendo de pesquisa sobre saberes técnicos e funcionais que podem ser identificados na formação do designer, nos relatos bibliográficos, examinando assim, sua importância como ferramenta auxiliar no processo de projeto.

Esta tese coloca e aborda as linguagens fotográficas no ensino de Design, no Estado de São Paulo, trazendo levantamentos bibliográficos e reflexões sobre as influências da fotografia no Design, considerando desde as escolas precursoras, discorrendo sobre estudos focados nas linguagens fotográficas e no projeto em Design de Produto; oferecendo uma atualização nos recursos e técnicas contemporâneas, o que torna possível a aplicação no Design.

Enfoca também, por meio de pesquisa qualitativa e quantitativa, como a fotografia tem sido considerada no ensino de Design, na opinião de docentes e alunos de instituições de ensino paulistas, através de levantamentos de campo. As respostas apontam na direção de proposta de inclusão de conteúdos e práticas sobre fotografia, em disciplinas e workshops, além de oficinas nos cursos de graduação que ofereçam meios e recursos para a formação plena em Design de Produto.

\section{Apresentação deste volume}

A disposição deste volume foi constituída por oito capítulos, seguidos pelas referências e apêndices.

O capítulo 1 trata da caracterização geral da pesquisa e inicia-se com colocações sobre o estudo e o contexto das áreas de conhecimento envolvidas (o Design de Produto e a linguagem fotográfica). Apresenta o problema fundamental, 
que norteou toda a investigação e sua relevância e originalidade para o campo. Neste capítulo, também se encontram as hipóteses (pressupostos) elucidadas em detalhes, os objetivos gerais e específicos, as variáveis norteadoras e uma breve introdução ao estudo, justificativas, definições de conceitos úteis à compreensão da pesquisa, os procedimentos iniciais tomados para a pesquisa, que estão detalhados no capítulo 5, e a eticidade da pesquisa.

Na sequência, o capítulo 2 proporciona uma revisão bibliográfica concisa, com o objetivo de situar o problema de pesquisa na literatura tanto clássica como atual, do campo de conhecimento do projeto de produto, finalizando com colocações sobre a importância do uso de ferramentas da fotografia e do vídeo no projeto, como uma das possibilidades de linguagem para o projeto e sua representação.

No capítulo 3 é analisado o histórico do Design e as características do seu desenvolvimento no campo de conhecimento e atuação ao longo do tempo, através de duas das principais e mais influentes escolas precursoras de Design do século 20 - a Bauhaus e a Escola de Design de UIm (HFG), que são analisadas na perspectiva de sua contribuição para a formação em Design. Tem o objetivo de resgatar, identificar as origens e as aplicações do uso da linguagem fotográfica na formação do profissional, através de pesquisa histórica das práticas envolvidas.

O capítulo 4 traz uma síntese do levantamento sobre meios, recursos e aplicações da fotografia no projeto de produto, procurando identificar a contribuição e os usos da linguagem fotográfica na construção, desenvolvimento gradual e sistemático de ideias, considerando a transmissão, a conservação, documentação e a memória, além da prospecção de conceitos e configurações (formais, geométricas, experimentais e através de imagens), que trazem ao designer, uma oportunidade de diferencial para o projeto, colaborando para a ampliação de seu repertório e de capacidades abstrativas na aplicação das ferramentas, considerando o projeto, análise e avaliações de projeto de produto.

O capítulo 5 apresenta os métodos de pesquisa de campo e a maneira como esta investigação foi estruturada através de estudos e pesquisas qualitativas e quantitativas, executadas por meio de entrevistas com docentes e alunos de instituições previamente localizadas e posteriormente selecionadas. Na sequência, é apresentado o quadro sinótico, que resume a estrutura metodológica da pesquisa, a estrutura da tese, os procedimentos e instrumentais adotados e desenvolvidos, que focam questões relevantes para a obtenção de dados que respondam aos aspectos 
e particularidades envolvidos no ensino de projeto de produto relacionado à linguagem fotográfica, que permeiam a hipótese desta tese.

No capítulo 6, são apresentadas análises, discussões e resultados obtidos com a aplicação dos métodos, de forma sintetizada, procurando ressaltar aqueles importantes. Apresenta o relato de dados e análises correspondentes aos subproblemas, onde buscou-se investigar o fenômeno, objeto deste trabalho para constituírem a formulação de diretrizes futuras para o ensino.

O capítulo 7 é dedicado às considerações e premissas para a formatação de disciplina para o campo, constituindo uma proposta para o ensino da Linguagem Fotográfica com a formatação de possíveis diretrizes para a disciplina e composição de laboratórios e ferramentais, sugerindo contribuições e continuidades na área.

O capítulo 8, destinado à conclusão final, apresenta os principais achados da pesquisa, dispostos nos capítulos 6 e 7, através de análises e aspectos destacados dos levantamentos, com confronto, comparação e contraste entre os casos estudados.

São apresentadas as reflexões, a partir de resultados gerais e outros correspondentes a cada subproblema, que foram extraídos da pergunta fundamental da pesquisa para obtenção de resultados finais, amplos, abrangentes e aprofundados.

$\mathrm{Na}$ sequência, os conteúdos seguintes considerados pós-textuais, apresentam as referências, trazendo a relação de todos os materiais bibliográficos consultados, citados ou complementares, utilizados na elaboração do trabalho. Os apêndices, material desenvolvido durante o processo, encerram este trabalho. 0 documentário e as entrevistas transcritas estarão agrupadas e armazenados em DVD que acompanha esta tese. 
CAPÍTULO 01 


\section{CARACTERIZAÇÃO GERAL DA PESQUISA}

\subsection{Objeto da pesquisa}

A linguagem fotográfica em instituições de ensino de Design de Produto

\subsection{Problema fundamental}

Quais são os fatores mais relevantes do emprego da linguagem fotográfica, nas fases de concepção e desenvolvimento de representações, em suas várias modalidades, que emergem de uma investigação de práticas de projeto de produto divulgadas na literatura especializada, em conhecimentos e práticas no ensino de Design de Produto no Estado de São Paulo?

\subsection{Relevância e originalidade}

A relevância e originalidade da tese encontram-se nas contribuições que a linguagem fotográfica pode desencadear na formação do designer por meio de técnicas, em um enriquecimento e ganho para sua atividade profissional, auxiliando como uma ferramenta de alto impacto nos processos de projeto.

\subsection{Hipóteses}

As hipóteses aqui apresentadas e que serão testadas na tese, constituem-se em conjecturas iniciais que tentariam responder aos subproblemas da pesquisa relatados a seguir:

A projetação compreendida como processo entre a criação e execução do método projetual pode-se valer de outros recursos, instrumentos metodológicos e aparatos. Considera-se que a ferramenta fotográfica e de vídeo constituem recurso válido e pertinente para o projeto de produto, visto que suas inovações técnicas e funcionais (tecnologias digitais) podem contribuir para o projeto da concepção e viabilização da ideia, ao lado daquelas usuais inerentes ao processo de projeto;

A área projetual prioriza os aspectos funcionais, estéticos, emocionais, simbólicos e tecnológicos entre outros, o que tem levado os designers a 
pesquisarem e implementarem novas técnicas para a manipulação, constituição e interpretação das imagens nas etapas de projeto. Assim, a linguagem fotográfica oferece recursos adicionais, diferenciais e indutivos para a criação no processo de projeto, ao lado dos sketches, desenhos técnicos, protótipos e outros; e

A atividade projetual considera aspectos contextuais e estruturais pertencentes a várias ciências e campos do saber e se utiliza de contribuições das áreas tecnológicas, em constante e rápida transformação, impactando ações, práticas e estudos no campo acadêmico e profissional do designer no Brasil. Observa que muitas vezes tal avanço não é percebido ou incorporado na estrutura educacional do ensino superior em Design, quando se consideram os meios, recursos e procedimentos para o projeto de produto.

\subsection{Objetivo Geral}

Pretende-se, ao longo da pesquisa, examinar o emprego das linguagens fotográficas em processos de criação e simulação de projeto de produto, procedimentos de busca de informações, testes e verificação, que emergem de práticas de projeto em relatos na literatura especializada em Design de Produto e em experiências notáveis nas instituições de ensino de Design de Produto também desta região.

\subsubsection{Objetivos específicos}

- Estudar o histórico do uso da fotografia e do vídeo no contexto da mudança dos meios analógicos para os digitais, no processo de projeto de produto;

- Verificar como a linguagem fotográfica vem sendo abordada e divulgada na literatura;

- Investigar na literatura, como a linguagem foi empregada em instituições que influenciaram o campo;

- Verificar como a linguagem fotográfica vem sendo empregada nas escolas de Design de Produto;

- Verificar o emprego das inovações tecnológicas da ferramenta fotográfica e de vídeo no processo de projeto; 
- Examinar quais as contribuições efetivas da linguagem fotográfica para a atividade do Designer de Produto.

\subsection{Proposta da tese}

A tese propõe, a título de colaboração, o aprimoramento e a proposição do desenvolvimento de uma disciplina de Linguagem Fotográfica para o Projeto de Produto, em cursos de Design de Produto, visando adequar a atual formação em práticas que pretendem fornecer aos estudantes, o embasamento de um sistema de informações que facilitem a aplicação da linguagem fotográfica, levando-os ao conhecimento e ao entendimento dos elementos que dão sustentação ao uso de ferramentas adequadas ao projeto, como resultado da investigação e com sentido de conclusão da tese.

\subsection{Introdução ao estudo}

Partindo do estudo das diversas modalidades que emergem de uma investigação de práticas de projeto, serão analisadas as técnicas da linguagem fotográfica e seu papel no processo de projeto.

Adota-se como pressuposto que as evoluções tecnológicas e a oferta de novos dispositivos e equipamentos impõem aos profissionais uma atualização constante e necessária, exigindo a implementação e o uso de novas técnicas em velocidade praticamente imediata. Para a expressão de uma concepção de produto, atualmente, utilizam-se instrumentos computacionais (softwares) para o estudo, a realização e a concretização de projetos.

Paralelamente a tais instrumentos, considera-se a importância do uso da fotografia e do vídeo, o seu papel significativo (histórico e atual) nos processos de design. Seus processos transformaram-se, em um espaço de tempo considerado curto demais, do analógico para o digital (analógico/mecânico x digital/eletrônico), de acordo com Machado (2013). No entanto, o que se vê hoje, é uma distância entre o designer e essa técnica, que oferece recursos qualitativos de captura, construção, tratamento e manipulação, além das já consagradas na divulgação de imagens no e para o projeto, proporcionadas pelas tecnologias digitais. 
Alguns dos aspectos a serem confirmados nesta pesquisa se referem à rápida inserção e à evolução dos processos digitais, ocorrendo em um primeiro momento o distanciamento na obtenção de conhecimento técnico e funções das ferramentas, devido ao processo de automatização, que incorporou diversos recursos que não necessitam ser mais manipulados, ou ainda, necessidade de conhecimentos aprofundados.

Assim, identifica-se a necessidade não só da apropriação da técnica pelos profissionais, mas de saberes e habilidades para interferência no sistema das ferramentas, fomentando a exploração de novas possibilidades além daquelas decorrentes de procedimentos tradicionais de constituição e simulação de imagens bi ou tridimensionais, representativas dos e nos processos de projeto.

A pesquisa permitirá que sejam validadas as hipóteses que propõem verificar como a ferramenta fotográfica está sendo utilizada e/ou introduzida nos métodos projetuais aplicados no desenvolvimento do produto. Para isso, serão consultadas referências bibliográficas, docentes e alunos de instituições de ensino do Estado de São Paulo. Essa investigação fornecerá subsídios para fundamentar a tese.

\subsection{Justificativas}

Levando em conta a escassez de documentos referentes ao assunto e a carência de pesquisas relacionadas à área do Design, a presente pesquisa tem por escopo, analisar e avaliar as diversas habilidades do designer, complementar as poucas iniciativas existentes no campo, bem como mapear as múltiplas e notáveis utilizações da linguagem fotográfica na área de design de produto.

Observa-se que o estudo da fotografia e do vídeo como instrumento para o Design, constitui instrumento e aporte necessário e justificado para o projeto, diante das novas perspectivas e ações que elas proporcionam, não só na documentação e comunicação, mas, sobretudo na manipulação, constituição e interpretação das imagens.

Constatando-se o papel significativo exercido pela fotografia e o vídeo para os profissionais de Design de Produto, verifica-se a urgência de uma atualização continuada em relação aos conhecimentos técnicos decorrentes das novas tecnologias, que possibilitem a disseminação de recursos e ferramentas já 
disponíveis, porém, muitas vezes subutilizadas, fazendo com que não sejam atingidas todas as suas capacidades.

Nesta pesquisa buscou-se uma aproximação junto aos docentes e alunos de instituições de ensino do Estado de São Paulo, por meio de uma investigação qualitativa e quantitativa de caráter fenomenológico-exploratório acerca das aplicações das ferramentas.

Por essa razão, cabem as considerações desse estudo, especialmente na averiguação sobre se estas técnicas estão agregadas à formação e presentes nas graduações de Design de Produto. Após esta averiguação, identifica-se que a relevância do projeto não está só na atividade projetual, mas, também, na formação do designer, pois colabora para a atualização e revisão dos conteúdos, dos meios e instrumentos implantados nos currículos de sua formação.

A pesquisa procura gerar oportunidades de inserção de conteúdos pedagógicos nas grades curriculares dos cursos de graduação em design, com habilidades e competências completas, abrangentes e atualizadas. Desta maneira a investigação contribui com o incremento de material substancial e referencial para a compreensão da aplicabilidade da linguagem fotográfica na contemporaneidade, incorporando as tecnologias digitais, além de verificar a interferência ou a colaboração no processo criativo da fase de projeto, e nos procedimentos metodológicos, na busca de informação (pesquisa), testes e verificação. Estudos comparados dos recursos, dispositivos e técnicas serão procedidos e analisados ao lado dos utilizados em outras linguagens tradicionais. Nota-se que a fotografia e o vídeo são de grande importância para a área do Design de Produto, pois oferece recursos adicionais e diferenciais para a criação, além de novas possibilidades expressivas no processo de projeto.

Cabe ressaltar a originalidade da proposta, já que este é um assunto pouco investigado no âmbito do Design de Produto. A proposta tem o potencial de contribuir para novos termos de compreensão da colaboração entre Design e a linguagem fotográfica. Espera-se que os resultados possam contribuir para que os docentes e designers ampliem seus conhecimentos e habilidades com o uso da linguagem fotográfica. 


\subsection{Definições de conceitos}

- Fotografia:

Tecnologia de criação de imagens por meio de exposição luminosa, fixandoas em superfícies sensíveis.

- Imagem (estática ou em movimento):

O termo está sendo usado, neste trabalho, com o sentido de representação visual obtido por qualquer forma visual de expressão da ideia.

- Linguagem fotográfica (LF):

Um conjunto de elementos, que somados, fazem 0as tecnologias da fotografia e do vídeo terem a capacidade narrativa, gerando uma linguagem própria com elementos que podem ser manipulados através de técnicas apropriadas para cada ferramenta.

- Representação:

Devido à ambiguidade do termo, será utilizado na pesquisa, com o sentido de assumir o lugar de quem representa não de forma idêntica, porém, análoga, através das atribuições de significados imputados.

- Vídeo:

Tecnologia de processamento de sinais para capturar, armazenar e transmitir ou apresentar uma sucessão de imagens (fotografia), com impressão de movimento.

\subsection{Procedimentos da pesquisa de campo}

Nesta pesquisa, buscou-se uma aproximação com os docentes e alunos de instituições de ensino do Estado de São Paulo, por meio de uma investigação qualitativa e quantitativa, de caráter fenomenológico-exploratório acerca das aplicações das ferramentas e empregando métodos de entrevistas (em profundidade 
semiestrutural, episódica - docentes e estruturada - alunos) e revisão de literatura relacionada ao campo.

Desta forma, a pesquisa trata de questões qualitativas em sua maior parte, uma vez que se vale de estudos e pressupostos de outros pesquisadores, principalmente de referências acadêmicas sobre o Design de Produto, em suas discussões e entrevistas semiestruturadas episódicas com docentes do campo. Trata também de dados quantitativos, coletados e mensurados para compor análises, conclusões e direcionamentos, como é o caso de entrevistas estruturadas digitalmente com alunos de Instituições de ensino do Estado de São Paulo.

\subsection{Eticidade da pesquisa}

Para o levantamento de dados nas instituições de ensino com docentes e alunos, foram tomados todos os procedimentos éticos e solicitada previamente, a autorização para o desenvolvimento dos estudos, esclarecendo que a pesquisa tem objetivo estritamente acadêmico e que a utilização dos dados ocorrerá apenas para a publicação da tese e de trabalhos científicos oriundos dela, sendo que as informações, tais como nomes e dados confidenciais, serão omitidos por meio de um procedimento de proteção da privacidade do participante, com sigilo total de todas as informações por ele cedidas.

Para a conduta prevista, por envolver a participação de seres humanos, foi utilizado o termo de consentimento livre e esclarecido e que atende à Resolução no 466/12-CNS-MS (apêndice c).

Desta forma todos os participantes concordaram em participar da pesquisa, dando permissão para que as informações, bem como imagens capturadas dos docentes em vídeo, fossem utilizadas na publicação acadêmica resultante desta tese. Todas as entrevistas com os docentes, contaram com o apoio, de gravação em áudio e vídeo, sendo que os locais utilizados para a realização das entrevistas, pertenciam às instituições de ensino. 
CAPÍTULO 02 


\section{DESENHO INDUSTRIAL - DESIGN: ALGUMAS COLOCAÇÕES SOBRE O CAMPO DO PROJETO DE PRODUTO}

O campo de estudos e propostas compreendidas neste trabalho, abrange 0 Design, nas habilidades e competências para o projeto de produto, incluindo as mais variadas modalidades de objetos e sistemas de objetos, considerando os meios para sua criação, desenvolvimento, produção e uso. Engloba assim, a diversidade de projetos, aplicações e usos, atividades, análises e avaliações, considerando a produção industrial que caracteriza e viabiliza este campo de atuação.

O foco destas colocações iniciais aborda conteúdos que versam sobre 0 ensino e a formação de Designers, além dos futuros profissionais que atuarão no campo do Design, com ênfase no projeto de produto. Não se trata de definir e estudar o campo, ou a terminologia, já bem desenvolvido e abordado por autores (como Maldonado, 1993; Bonsiepe, 2012 e 2015; Burdek, 2006; ICSDI, 2012, entre outros), mas de contextualizar aspectos relacionados à formação em Design, que tangenciam os meios e as ferramentas que colaboram para as práticas e o conhecimento nesta área.

A concepção de produtos vem acompanhando o desenvolvimento econômico e social, atendendo a demandas e expectativas da sociedade, ao mesmo tempo em que está relacionada a novos sistemas de produção industrial do país, utilizando (e acompanhando) avanços e conhecimentos científicos e tecnológicos obtidos ao longo dos anos (mesmo sendo o Design, uma atividade profissional recente e que depende e interage com várias, além das áreas tecnológicas).

Para as nações industrializadas e em processo de industrialização, o Design tem forte poder de inovação científica e competitividade, evidenciando o seu valor intrínseco, estratégico, ainda mais evidente e qualitativo quando ressaltadas as identidades em relação às diferenças socioculturais, e às necessidades, aspirações e demandas de cada usuário que devem ser analisadas de forma adequada no local da demanda do produto.

O termo 'Desenho Industrial' que caracterizou a implantação deste campo de conhecimentos e atuação no país vem sendo substituído (ou convive) cada vez mais com 'Design'. Pode-se dizer que na década de 1970, era consenso a conceituação de Desenho Industrial como a projetação de artefatos fabricados industrialmente por mediação de máquinas e de modo seriado, cuja função principal centra na 
projetação da forma de um produto, onde projetar a forma significa a organização, a integração e articulação de todos os fatores participantes do processo constitutivo da forma do objeto (MALDONADO, 1993).

Gonçalves (1981), numa visão mais restrita e ligada à produção, considera o Desenho Industrial como uma atividade meramente de cunho projetual, capaz de determinar a produção seriada dos objetos por intermédio de processos de planejamentos, de ordenações e de racionalização industrial.

Já o International Council of Societies of Industrial Design, que vem sistematicamente atualizando as definições do termo Design e do campo ao longo dos anos, amplia a noção e a abrangência desta atividade e relaciona a profissão em interação com outras, como expresso em 2012:

[...] uma atividade criativa (e projetual) cujo objetivo é estabelecer as qualidades multifacetadas de objetos, processos, serviços e seus sistemas em ciclos de vida completos. Portanto, Design é o fator central da humanização inovadora de tecnologias e o fator crucial de intercâmbio cultural e econômico. Assim, o Design é uma atividade que envolve um amplo espectro de profissões nas quais produtos, serviços, gráficos, interiores e arquitetura tomam parte. Juntas, essas atividades devem melhorar ainda mais - em consonância com outras profissões relacionadas - o valor da vida (ICSDI, 2012).

Ainda Bonsiepe (2014) esclarece que o Design, na atualidade, terá muito a contribuir, pois é, por definição, uma atividade inovadora com profunda inserção no sistema produtivo.

Considerando os aspectos produtivos dos produtos, Bonsiepe (2012) coloca que é indiscutível que a indústria necessita indispensavelmente do projetista industrial, principalmente pela capacidade que ele tem de resolver os problemas de produção, ou melhor, de fazer projetos que ajudem a resolver os problemas da produção, contribuindo para todo o processo de industrialização, colocando assim, que a atividade projetual melhora a cultura material e busca beneficiar a maioria da população. Mas o Design só pode contribuir para um processo de desenvolvimento quando é valorizado e aceito como um item de investimento. O mesmo autor enfatiza que se um país não tiver uma política consistente de industrialização, dificilmente perceberá a importância do Design como instrumento para o desenvolvimento. 
Bürdek (2006) identifica alguns problemas que o Design deverá sempre atender: visualizar progressos tecnológicos; priorizar a utilização e o fácil manejo de produtos; tornar transparente o contexto da produção, do consumo e da reutilização; promover serviços e a comunicação, mas também, quando necessário, exercer com energia a tarefa de evitar produtos sem sentido. Para atender estas questões, a atenção e o empenho do projetista industrial seguem, adotam e usam métodos de projeto, onde todos os fatores que o determinam são levados em conta como: os funcionais, os culturais, tecnológicos e econômicos. O mesmo autor coloca que existe igualmente um grande esforço para integrar métodos científicos nos processos de projeto, de forma a serem aceitos pela indústria, que diferentemente da arte, precisa de experimentação prática e atualização constante, pois no processo evolutivo surgem novos matérias e tecnologias.

Ressalta-se que a concepção de objetos na atualidade depende de várias ferramentas tecnológicas, que podem colaborar em todo o processo de projeto e seus desdobramentos (avaliações, análises, entre outras atividades decorrentes de uso e aplicação de produtos). Deste modo, a metodologia do Design tem finalidades nítidas, como por exemplo, a de organizar o processo de projeto e de fornecer as ferramentas necessárias para sua viabilização.

Deste modo, a projetação, compreendida entre o método projetual e a sua execução, pode e deve se valer de outros instrumentos metodológicos e aparatos tecnológicos que auxiliam no processo de projeto, onde se inclui a fotografia e do vídeo.

\subsection{O Designer - formação e atividade profissional}

A formação em Design (de produto) hoje, no país, demanda a capacitação para a atuação num cenário produtivo consolidado e ao mesmo tempo em constante transformação. Deste modo, o designer é o profissional que se ocupa do Design para dar soluções aos projetos (ou tecnológicas e produtivas) que envolvem todo um processo de criação ao desenvolvimento, incluindo atividades de análise, aperfeiçoamento e pesquisa, para uma variedade produtos $^{2}$ (de pequeno a grande porte; complexos ou não), a fim de atender às necessidades da população (HSUANAN, 2017).

\footnotetext{
${ }^{2}$ As áreas de atuação do Designer de produto no contexto nacional: produtos de uso; máquinas e equipamentos em geral; produtos componentes de ambientes em geral; e artigos do lar.
} 
Carpes (2014), Bonsiepe (2015) e Hsuan-An (2017), cada qual discorrendo sobre a profissão e os campos de atuação, enumeram quais habilidades, conhecimentos e contribuições competem ao designer:

Para Carpes (2014) as habilidades exigidas são:

- Aptidão para identificar, analisar e solucionar problemas;

- Criatividade e desenvoltura prática;

- Responsabilidade em relação ao processo de desenvolvimento dos produtos e ao produto final;

- Bom nível de conhecimento geral, principalmente em relação às áreas de tecnologia, sociologia, comportamento e psicologia do consumidor;

- Capacidade de associação de ideias e conceitos; de comunicação, para facilitar o trabalho em equipe.

Bonsiepe (2015), considerando a possibilidade de atuação na indústria, coloca algumas das contribuições principais que o Designer deve fornecer para a empresa:

- Formular as especificações de uso de um produto;

- Elaborar cenários de uso para novos produtos e sistemas de produtos;

- Observar e analisar tendências do mercado;

- Interpretar as contribuições do marketing e traduzi-las em uma realidade tangível;

- Elaborar conceitos básicos (anteprojetos);

- Elaborar detalhes técnicos e formais;

- Elaborar propostas para o acabamento, cores, texturas e dimensão gráfica do produto;

- Participar da seleção dos materiais e processos de fabricação e de montagem (Design for assemby);

- Interpretar testes de usuários;

- Contribuir para criar a identidade pública da empresa;

- Avaliar a compatibilidade ambiental da proposta. 
Hsuan-An (2017) enfatiza a importância da formação para uma atuação em escala global (mundial), mencionando as competências e habilidades que deverão ser desenvolvidas:

- Capacidade criativa; domínio da linguagem (escrita e gráfica);

- Capacidade de trânsito interdisciplinar, visão sistêmica de projeto;

- Domínio da metodologia de projeto; conhecimento e visão do setor produtivo específico;

- Conhecimento da gestão de produção e da prática profissional;

- Conhecimento e visão dos diversos contextos e fatores determinantes de Design;

- Capacidade de trabalhar em equipe.

Além disso, ressaltam-se outras questões importantes como analisar o produto em situações reais de uso, melhorar suas características a partir do levantamento de dados em campo e diminuir o custo de produção para satisfazer às necessidades reais do usuário. Outro quesito está no pressuposto de que o designer possua sensibilidade estético-formal e saiba lidar com materiais e processos. Dessa maneira, o designer pode ajudar uma empresa a manter-se em um contexto de crescente concorrência (BONSIEPE, 2015).

Ressalta-se, após estas colocações, que a atuação básica principal, entretanto, é o projeto, no caso deste trabalho, de produtos. Bürdek (2006), abordando sobre o processo de projeto, menciona a importância em definir o problema (de projeto), determinar a tarefa, variáveis e restrições, enfatizando sobre a necessidade de adoção de método para enfrentar as tarefas.

Para Carpes (2015), as tarefas a serem realizadas geralmente passam pelas considerações sintetizadas a seguir: o levantamento de desejos, necessidades e expectativas dos consumidores, transformando-os em requisitos de projeto; a identificação e a consideração de fatores de influência no projeto, como custos, seleção de materiais, seleção de métodos de produção, segurança, ergonomia, tendências, meio ambiente, mercado consumidor e novas tecnologias; e a realização de desenhos detalhados e listas de peças, que podem ser feitas em software de CAD (projeto auxiliado por computador). 
As mudanças tecnológicas vêm alterando profundamente e modificando substancialmente o contexto de atuação, demandando conhecimentos e práticas, conceituais e tecnológicas (hardware e software), bem como demandando novos métodos e instrumentações como coloca Bürdek (2006).

Entretanto, Bonsiepe (2012) critica e alerta para o fato da generalização da aplicação da informática nos trabalhos de projeto, pesquisa, produção, distribuição e gestão onde o designer atua. Com isso, pessoas que dominam apenas essas ferramentas consideram-se capazes de elaborar projetos e conceber sistemas complexos, dispensando a formação teórico-conceitual que deveria reger o uso desses recursos (BONSIEPE, 2012).

Hsuan-An (2017) coloca que a vocação para essa área exige aspectos que vão além das ferramentas e que seguem primeiramente alguns requisitos, tais como o domínio de desenho, a visão espacial, a criatividade, o senso estético e a vontade de adquirir conhecimento. $O$ autor menciona igualmente a necessidade de conhecimentos artísticos, culturais, ergonômicos, sociais, ecológicos, psicológicos e históricos para o exercício pleno da profissão.

Todas estas visões dos autores conduzem para a formação de um designer com amplo conhecimento do campo (e de áreas correlatas) e domínio de habilidades fundamentais para $\circ$ projeto de produto, que não prescindem do entendimento e da habilidade no manejo de ferramentas auxiliares para a projetacão e de meios de representação, como é o caso da fotografia e do vídeo enfocada neste trabalho.

\subsection{Colocações iniciais sobre projeto para Design de Produto e as ferramentas}

O processo de projeto inclui um conjunto de métodos, procedimentos, conceitos de trabalho e regras que vêm sendo abordados na literatura por diversos autores, compreendendo modos específicos de proceder individualmente ou equipes de profissionais, que inclui várias etapas, prévia e racionalmente determinadas. Esta visão não exclui possibilidades exploratórias advindas de processos cognitivos associativos ou por similaridade, ou outros mecanismos criativos favoráveis à concepção de produtos inovadores, inéditos, mas que de certa forma também constituem métodos e colaboram para os procedimentos projetuais. Silva (2014) enfatiza que cada método projetual possui um conjunto de etapas ou fases 
constituídas de micro ou macroestruturas, de técnicas particulares ou mais apropriadas, advindas das próprias influências, de experiências acumuladas e de contribuições das outras áreas do conhecimento humano.

Ao projetar, o designer concebe uma ideia para algum objeto e a expressa através de meios de representação e expressão, depois viabilizada por meio de processos produtivos em forma de um corpo físico (CARPES, 2014 APUD ROOZENBURG; EEKELS, 1995). Este trabalho passa por um processo de desenvolvimento individual ou por uma equipe, contando com o auxílio de meios técnicos, e ferramentas auxiliares (como desenho e simulações gráficas manuais ou digitais; fotos, vídeos e filmes; softwares de imagem e prototipagem, entre outros), através do qual a ideia de produto é transformada em informação na forma de requisitos, que são convertidos em informações representadas em formas de descrição de um produto (CARPES, 2014). Assim, o projeto pode ser descrito não necessariamente em desenhos técnicos, mas pode ser elaborado através do auxílio de outras ferramentas que proporcionam outras modalidades de imagens.

Uma breve abordagem sobre os termos "método", "metodologia" e "processo", encontradas na literatura, podem auxiliar nas conceituações e na diferenciação entre eles. O dicionário Michaelis (2009, n.p.) expõe significados pertinentes: o "Método" pode ser definido como "conjunto dos meios dispostos convenientemente para alcançar um fim e especialmente para chegar a um conhecimento científico ou comunicá-lo aos outros", "ordem ou sistema que se segue no estudo ou no ensino de qualquer disciplina", "maneira de fazer as coisas; modo de proceder"; "Metodologia" pode ser definida como "estudo científico dos métodos"; "Processo" pode ser definido como uma "série de ações sistemáticas visando a um certo resultado", "ação ou operação contínua ou série de ações que ocorrem de uma maneira determinada".

Para Pazmino (2015), os métodos de Design são procedimentos passíveis de serem ensinados, e consequentemente aprendidos e repetidos; são comunicáveis e auxiliam o designer no processo de projeto. Os métodos representam as diversas ações que o designer utiliza e combina no processo de Design e que envolvem instrumentos de planejamento, coleta, análise e síntese, caracterização dos instrumentos materiais com a qual o Design trabalha. Assim, ele é o caminho para se atingir uma finalidade, podendo ser entendido como um composto de várias técnicas. 
Considera-se que o método de projeto para o Designer não é absoluto nem definitivo; pode ser modificado, caso ele encontre outros valores objetivos que melhorem o processo (MUNARI, 1998). O autor ainda alerta que no campo do Design não se deve projetar sem um método, pensar de forma artística, procurando a solução de imediato, pois o método pressupõe uma série de operações necessárias, distribuídas em ordem lógica, tendo como objetivo alcançar o melhor resultado, sem ser algo absoluto e definitivo. Coloca também, que pode ser modificado caso sejam descobertos outros valores que melhorem o projeto.

O uso da metodologia permite ao designer, conceituar propostas, selecionar e se apoiar em procedimentos, organizar dados e informações, resolver problemas, dominar processos abstratos, conhecer, compreender e aprender possibilidades dos recursos das técnicas e ferramentas junto às linguagens.

As técnicas são meios auxiliares para a solução dos problemas e podem estimular o processo criativo ou facilitar a visualização dos elementos de uma análise: pode ser uma habilidade, um conhecimento, uma experiência. Para ser aplicada, pode fazer uso de ferramentas, passos ou procedimentos estruturados e sistemáticos (PAZMINO, 2015).

As ferramentas são meios que existem para apoiar a realização das atividades do processo de projeto e desenvolvimento de produtos. Para Bomfim (1995), são instrumentos físicos ou conceituais que têm origem em diversas ciências. Pazmino (2015) coloca também, que são recursos que controlam inputs para obter outputs e são aplicadas em um momento específico do trabalho, com o objetivo de auxiliar o designer nas tarefas.

Considera-se que atualmente, com a expansão e a abrangência ampliada do campo de atuação em Design, é necessário se munir de ferramentas auxiliares ou centrais à aplicação de novos métodos, ou atualizar aqueles já consolidados, com a intenção de abarcar as complexidades inerentes às novas demandas projetuais, visando criar soluções (RESENTE; SILVA, 2016).

Para tanto, além de entender os métodos, metodologias e processos, é importante compreender o nível de complexidade envolvida no projeto de produtos, usando conhecimentos e habilidades em prol de soluções projetuais reais.

\subsection{0 projeto, os produtos e a complexidade contextual e configuracional}


A complexidade é uma questão que tem sido cada vez mais pesquisada e discutida, e há muitas definições para retratá-la, como "[...] complexidade, entendese um sistema composto de muitos elementos e estruturas, cujas inter-relações condicionam e redefinem continuamente o funcionamento do todo" (CARDOSO, 2012, p. 25). Vassão (2010) considera que a complexidade existe a partir do momento em que se dá conta da grande quantidade de relações entre as informações.

Os atuais problemas projetuais complexos não podem mais ser resolvidos sem atividade de pesquisa prévia ou paralela (BONSIEPE, 2011), pois, na atualidade, a tendência é a de enfrentamento de problemas muito intricados, demandando que o designer disponha de uma série de informações acerca de cada problema isoladamente e das interações e fluxos entre os dados, para maior segurança no projeto.

Esta condição não é nova e aparece já na década de 1960, com Alexander (1964), apontando que os problemas de Design estavam se tornando cada vez mais complexos e que os designers deveriam apoiar-se em métodos que os ajudassem a reduzi-los, minimizando critérios subjetivos, por meio de uma racionalidade no processo de projetar.

Mais recentemente, Bürdek (2006, p.226) adiciona outras variáveis que caracterizam os problemas e as soluções, afirmando que "[...] o mundo, cada vez mais complexo, não pode ser mais dominado pelo designer individualmente [...]", sendo que as melhores soluções costumam vir do trabalho em equipe e em rede, fato corroborado por Cardoso (2012).

Pazmino (2015) menciona diferentes níveis de complexidade de produtos, de acordo com características funcionais, semânticas, de usabilidade, fabricação, tecnologia, entre outras Assim, os produtos podem ser de baixa complexidade ou simples, de média complexidade e de alta complexidade ou sistêmica. (PAZMINO, 2015).

Para Filho (2006), é de fundamental importância compreender as conceituações de níveis de complexidade configuracional, tecnológica e de fabricação do produto industrial, para o exercício profissional.

Já Bonsiepe (2015), diz que a complexidade e a diversidade dos problemas envolvidos em um projeto, seja ele de baixa ou alta complexidade, vêm ampliandose rapidamente, com o aumento do número de variáveis envolvidas no processo do 
projeto e produção de objetos, caracterizando processos projetuais que demandam recurso, meios e ferramentas capazes de contribuir para as soluções e resultados. Outros autores reconhecem estas características, relacionando a complexidade com a metodologia projetual: "[...] esteve sempre presente no discurso projetual, mas ligada principalmente ao número de componentes do problema, sejam peças ou disciplinas envolvidas" (VAN DER LINDEN; LACERDA, 2012, p. 88).

Portanto, para Carvalho e Monte (2017) um dos pontos importantes e que devem ser destacados é o da existência de mudanças relevantes nos modos de procedimento projetuais advindas da evolução tecnológica contemporânea, que se refletem na demanda de uso e de domínio conceitual e técnico de recursos e ferramentas atualizadas, sendo a fotografia e o vídeo uma destas.

\subsection{Alguns aspectos sobre métodos projetuais e o ensino de Design de Produto}

Como mencionado, a difusão da metodologia usada no Design tem origem e se intensifica a partir dos anos de 1960, tendo por base métodos focados na divisão do processo em passos definidos, em diversas tarefas, sendo mais tarde considerados por diversos autores como uma discussão exagerada, denotando uma fase evidente da cientificação das atividades de projeto. Segundo Bürdek (2006) alguns autores que caracterizam esta fase são Morris Asimow (1962), que desenvolveu a chamada Morfologia do Design; Bruce Archer (1963/64,) que publicou Check Lists abrangentes determinando fortemente o processo de projeto; Christopher Alexander (1964), um dos pais da metodologia, que dirigia especialmente à problemática da forma e do contexto; John R. M. Ager e Carl V. Hays (1964), que se ocuparam com procedimentos de avaliação de alternativas de projeto; e Christopher Jones (1969) que promovia a metodologia em um contexto internacional.

Bruce Archer (1963) desenvolveu uma das primeiras descrições sistematizadas do processo projetual, estabelecendo modelos adaptáveis, através de processos de ampliações e modificações conforme as necessidades de cada situação de resolução de problemas.

A ênfase dos primeiros métodos de projeto de produtos tinha o intuito de colaborar para definir os requisitos dos produtos, concentrando-se em suas 
características e qualidades, estabelecendo sequências, etapas, feedback, tendo em vista abranger a totalidade das questões envolvidas e necessárias para a proposta e o projeto dos objetos. O que os distingue da situação anterior (no tempo), onde a concepção de produtos vinha de um método empírico baseado na observação, na experiência e nos experimentos que eram praticados desde a antiguidade, mas que se tornaram procedimentos sistemáticos no século $X X$, assim como já havia ocorrido anteriormente com outras ciências na Idade Média (CARPES, 2014).

Outra parte dos designers adota ou adapta metodologias, seguindo as mesmas linhas de pensamento da escola alemã Bauhaus (que será aprofundado no capítulo 03). Mais recentemente, outras visões e práticas vêm trazendo contribuições das mais diversas áreas do conhecimento, utilizando processos e procedimentos, novas tendências, mais relacionados a técnicas experimentais, como é o caso do Design Emocional ${ }^{3}$, classificado por Norman (2004) como visceral, comportamental e o Design Centrado no Humano.

$\mathrm{Na}$ atualidade, as mudanças tecnológicas e as necessidades vigentes, demandam abordagens voltadas ao indivíduo que ganha status de foco central do projeto em Design, filosofia que insere o usuário no centro do processo de desenvolvimento, deslocando o foco projetual dos objetos para as pessoas (RUBIN; CHISNELL, 2008). Chaves (2014) afirma, com fundamento em diversos pesquisadores e autores atuantes neste pensamento, que o Design Centrado no Usuário $^{4}$ é tanto uma filosofia quanto uma variedade de métodos, que pressupõem o envolvimento do usuário. A autora coloca que, juntamente com o aparecimento do Design Centrado no Usuário, outro conceito de maior abrangência, com aspectos parecidos, porém expandidos, denominada Design Centrado no Humano 5 (CHAVES, 2014), vem sendo utilizado em pesquisas e aplicado em projetos de produtos, passando do foco no objeto para o usuário.

Estas visões, com foco no usuário, demandam a capacitação do designer, para compreender as necessidades e solucioná-las, conferindo ao projeto do objeto maior identidade cultural e plena utilização. Alguns autores explicam que surgiram

\footnotetext{
${ }^{3}$ Não é o objetivo de a pesquisa abranger todas as metodologias aplicadas ao campo, mas reconhecê no ambiente de formação universitária.

${ }_{4} \mathrm{O}$ termo User-Centered Design (UCD), foi introduzido por Norman \& Draper (1986) no livro User-Centered System Design: New Perspectives on Human-Computer Interaction, em português o termo foi traduzido e é tratado em pesquisas como Design Centrado no Usuário

${ }^{5} \mathrm{O}$ termo Human-Centred Design (HCD), em português foi traduzido e é tratado em pesquisas como Design Centrado no Humano.
} 
no início da década de 50, quando o paradigma de produto passa a ser considerado um bem de consumo, informação e identidade, conforme ressaltado por Krippendorff (2000), e assim não se trata de um pensamento novo. O autor ainda afirma que este enfoque preocupa-se com a maneira com que as pessoas veem, interpretam e convivem com artefatos.

Outros colocam que estas manifestações têm origem em áreas como ergonomia, ciência da computação e inteligência artificial, baseado em técnicas que comunicam, interagem, enfatizam e estimulam 0 envolvimento de pessoas, adquirindo assim, o entendimento de desejos, necessidades e experiências, que normalmente, transcendem suas próprias percepções (GIACOMIN, 2012). Entretanto, é necessária uma metodologia eficaz e bem empregada, que permitirá ao profissional, desenvolver produtos que solucionem problemas, atendendo ao usuário.

Qualquer um dos métodos demanda o uso de meios e recursos auxiliares, mas fundamentais para a consecução de projetos, podendo representar diferencial qualitativo tanto nas proposições, na concepção de objetos, quanto nas etapas de desenvolvimento, execução ou fabricação, comunicação de resultados, como em processos de avaliação, análises e documentação. Assim, a instrumentação destes meios torna-se fundamental para atuação profissional e para a formação em Design, a partir de conhecimentos e práticas de conceitos e possibilidade de aplicação.

\subsection{0 ensino da metodologia e as ferramentas}

$\mathrm{Na}$ década de 60 registrou-se o auge da metodologia projetual, o de desenvolvimento de métodos e processos de projeto, como já abordado anteriormente, que se espelhou e disseminou nos processos de formação em Design (e vice versa).

No panorama da produção de objetos, o processo de criação de novos produtos industriais também exige a necessidade da utilização de diversos procedimentos metodológicos, criativos, ferramentas e técnicas para o desenvolvimento das ações do designer.

Considera-se que a aplicação da metodologia de projeto no ensino vem contribuindo de maneira sistemática, para formar a cultura material, melhorando a qualidade funcional e estética, utilizando recursos disponíveis. 
Entretanto, um dos grandes problemas no ensino da metodologia é a distância entre mundo acadêmico e mundo empresarial, principalmente nas soluções de problemas efetivos e a tempo real de ocorrência, devido à demanda, ao crescimento e mudança incessantes da sociedade. Soma-se a este quadro, a observação de que grande parte dos designers em formação considera as discussões sobre metodologia algo aquém da prática real ou esforço frustrante para cercear a criatividade de novas propostas, quando o que querem é "pôr a mão na massa" imediatamente, como ressalta Bonsiepe (2015). Adiciona-se a esta percepção, que este conhecimento e habilidade está ausente nas instituições de ensino e que os alunos estão sem base ou instrumentação do uso de ferramentas (como será aprofundado no capítulo 04).

Para que os designers tenham uma instrumentação adequada à aplicação e uso de novas ferramentas é necessário investigar a abrangência e a complexidade que envolve o ensino e consequentemente a grade curricular das instituições, considerando também as visões e práticas dos docentes envolvidos nas disciplinas.

Para Carvalho (2012), é necessário considerar que a grade curricular é um dos parâmetros de importância que devem ser investigados, visto que representa um dos elementos da metodologia do ensino enquanto organização e relacionamento das disciplinas na prática pedagógica. A autora coloca que questões voltadas aos currículos são importantes e decisivas para uma boa aplicação pedagógica e devem ser consideradas tanto para a elaboração, como para correções do curso.

As instituições de ensino são consideradas um dos pilares para a formação do designer e são estruturadas de maneira que possam contribuir para o desenvolvimento e valorização do campo profissional, gerando designers capacitados para atender as exigências nacionais e internacionais (CARVALHO, 2012).

Considerando as tecnologias, técnicas e ferramentas adequadas e demandadas para a construção do conhecimento e das habilidades necessárias para a formação em Design, o seu aprimoramento ou as inovações vindas dos recursos digitais, estabelecem ao profissional da área, procedimentos proativos em atualização constante, sequencial e continuado, e exigem implementação atualizada no tempo, além da manutenção dos recursos por parte das instituições de ensino superior. A evolução tecnológica demanda um esforço de atualização tanto em 
hardware quanto em software, das duas partes - as instituições de ensino e a comunidade escolar - que acabam interagindo com a pedagogia, o currículo, as instalações e equipamentos colocados à disposição da formação em Design.

A formação em Design de Produto passa pela aquisição e a instrumentação de conhecimentos e habilidades que envolvem experimentação, o exercício de projeto, a simulação de resultados, a pesquisa, análises e testes, em maior ou menor amplitude e profundidade, em consonância com os projetos pedagógicos e currículos das instituições superiores de ensino. Assim, o exercício do projeto é fundamental, incluindo métodos, procedimentos e estratégias.

Bürdek (2006) afirma que a teoria e metodologia do Design são reflexos objetivos dos esforços que se destinam a aperfeiçoar métodos, regras e critérios para que o Design possa ser pesquisado, avaliado e também melhorado. Contudo, independente dos métodos utilizados, cada designer na atividade projetual, introduz e usa linguagens, recursos e meios disponíveis ou já experimentados, como softwares para desenho, imagens fixas ou em movimento, que ora são auxiliares na representação do processo criativo do produto, ora são instrumentos de trabalho que concorrem para a viabilização da ideia, do seu desenvolvimento e da comunicação de resultados.

No processo de projeto e seu desenvolvimento, a fotografia, o vídeo, a tipografia, os sistemas de produção e manipulação de imagens e as técnicas publicitárias são considerados suportes do projeto de Design. A fotografia e o vídeo são marcados por diversos aprimoramentos técnicos, que procuraram atender as necessidades da sociedade e aumentar sua produção. Esses refinamentos visaram, num processo de evolução no tempo, a reprodução fiel da realidade e foram acompanhados de mudanças tecnológicas que programaram gradativamente a automatização do aparelho fotográfico e o domínio e autonomia na geração de imagem.

$\mathrm{Na}$ década de 90, a consolidação das mudanças tecnológicas dos sistemas eletrônicos para os digitais se espraiou em ferramentas, equipamentos, programas e recursos para a obtenção de informações, a socialização e a divulgação de conhecimentos e aprendizados, além da ampliação de possibilidades de meios de expressão e representação, trazendo outros conteúdos, demandas e exigências para a formação em Design, como colocadas por Morris (2010), que enfatiza também a necessidade do projetista ter uma larga bagagem de conhecimentos 
sobre as propriedades mecânicas, elétricas, térmicas, químicas, magnéticas e ópticas dos diferentes materiais, tradicionais ou novos, que impactam as tecnologias de produção e mesmo o modo de projetar objetos. A inserção de novas ferramentas auxiliares no processo de projeto (hardwares e softwares) traz a necessidade de inclusão no âmbito universitário e acadêmico, de medidas que favoreçam o preparo do aluno para trabalhar no contexto da sociedade contemporânea e dos sistemas informatizados de produção.

Logo, os designers, em diversos momentos do processo de projeto, incluem e utilizam conhecimentos e práticas advindas da observação, da percepção, da apreensão e de experimentações que podem ser otimizadas através das ferramentas fotográficas e do vídeo (consideradas neste trabalho como partes constituintes da linguagem fotográfica).

Pode-se considerar que muitos designers já utilizam instrumentos computacionais e digitais para o estudo, experimentação, realização e concretização de seus projetos. Dentre tais instrumentos, considera-se que a fotografia e o vídeo podem assumir função auxiliar, mas também essencial como meio participante das atividades do processo criativo para as etapas de desenvolvimento, finalização do projeto e auxiliando o dialogo com outras áreas.

Torna-se importante recuperar dados históricos sobre a inserção da disciplina Fotografia na grade curricular da escola de Design Bauhaus e HfG (ver capítulo 03), que influenciou inúmeros procedimentos de instrumentação em linguagens e representações do ensino no Brasil e em grande parte da América do Sul, colocando ainda, reflexões sobre novas possibilidades e estratégias de ensino que possam não apenas instrumentalizar o aluno dos cursos de Design para o uso da linguagem fotográfica, mas alargando as possibilidades e aplicações nos processos de projeto em Design.

\subsection{Linguagem fotográfica e representação para o Design de Produto}

A linguagem fotográfica como manifestação não verbal, utiliza-se de sinais que não possuem um código definido ou uma gramática rígida que determine seus procedimentos constitutivos. Portanto, a compreensão de seus sistemas possibilita ao sujeito, expandir a capacidade de ver e compreender melhor a mensagem visual.

Contudo, a natureza da linguagem fotográfica é a de representar fielmente o mundo e sua realidade, e ao mesmo tempo identifica-se uma vontade oposta em 
modificar a imagem real, introduzindo outros elementos e aspectos visuais, possibilitados por diversos recursos de linguagem.

Ferramentas fotográficas e de vídeo ampliam assim, a capacidade perceptiva, através da transposição do tridimensional para o bidimensional em um enquadramento selecionado pelo indivíduo e fixação em um suporte definido pelo operador 6 .

Desta forma, o conhecimento das possibilidades criativas e dos processos e técnicas da linguagem fotográfica são ferramentas essenciais para as fases de criação projetivas, análise, coleta de dados, manipulação e tratamento, principalmente daquelas que envolvem a apreensão e uso de representações visuais de documentação para o projeto.

Admite que a primeira hipótese da pesquisa é a de que a imagem fotográfica, antes de tudo, faz parte de uma linguagem e não uma mera representação, pois congrega os elementos de concepção e representação de caráter funcional que as constitui, agindo conjuntamente com os argumentos verbais e os seus próprios elementos de linguagem, que atuam de forma decisiva e qualitativa no ato de pensar, projetar e refletir sobre os sistemas e componentes, visualizar, destacar objetos e produtos isolados.

\subsection{Linguagens, representação e percepção visual}

São inúmeros os tipos de linguagens e todas elas demandam e compreendem formas de reflexão, ação e expressão. Desta forma, as linguagens se modificam e dão lugar ou convivem com outras.

Todas as linguagens trabalham com diversos níveis de percepção humana e seu domínio colabora para constituir um pensamento estruturado para a transmissão de ideias ou sentimentos, pretendendo uma comunicação. Códigos, técnicas e tecnologias e as sintaxes construtivas de cada linguagem são processos que devem ser observados para o seu emprego adequado e efetivo nas representações das imagens, podendo constituir um sistema.

\footnotetext{
${ }^{6}$ Durante todo o avanço tecnológico da fotografia a preocupação pelos meios técnicos de fixar a imagem em um suporte concreto, resultou em diversas pesquisas para o desenvolvimento de equipamentos de ampliação e posteriormente impressão automatizados.
} 
Para Durand (2004), todo pensamento humano é uma representação, isto é, passa por articulações simbólicas onde o imaginário constitui o conector entre ambas (DURAND, 2004). Deste modo, imagens mentais permitem diversas interpretações, por serem suscetíveis e dependerem de mecanismos que interferem no processo de codificação, provocados por diferentes níveis de percepção (ROSSI, 2014).

Para Gombrich (1999), quando não se consegue relacionar a imagem com um motivo localizado no mundo exterior, toma-se por uma ideia de um motivo que se acha no mundo interior do indivíduo. Mundo interior que pode ser externado por ferramentas. Porém, a passagem da superfície à interface, do óptico ao numérico, pressupõe outra ordem visual, alicerçada não num objeto, mas em um modelo e em suas regras formais de manipulação das ferramentas (FABRIS, 1998).

É possível compreender que as linguagens são utilizadas para moldar as percepções de como os objetos devem ser compreendidos nos aspectos do Design e da ideia dos produtos materiais. Deste modo, a fotografia e o vídeo, utilizam-se de códigos que atuam essencialmente na visão, sem conter necessariamente, um sistema ou código rigoroso que determine seus procedimentos sintáticos de linguagem.

No desenvolvimento do processo de projeto de produto, a linguagem fotográfica adquire também outros papeis como representação formal: de estudos analíticos, avaliativos e estruturais da investigação entre forma e conteúdo, além de explorações de acabamento, aparência, entre outros aspectos. Esta linguagem evolui e modifica seus significados tão depressa como qualquer outra (SUDJIC, 2010).

Representação é sempre diferente da realidade, é uma nova particularidade, uma reinterpretação que mascara e assume o "original", o de recortar o real, dirigindo a atenção somente para fatos que pretende transmitir (ROSSI, 2014). Ao utilizar a linguagem fotográfica, realizam-se escolhas conscientes ou não, omitindo ou selecionando determinados aspectos pelo enquadramento compositivo e gerador, propondo novos dados imagéticos. Walter Benjamin (1985) já alertava sobre a irresistível necessidade de possuir o objeto de tão perto quanto possível na imagem, ou melhor, na sua reprodução. 
Uma imagem é uma abstração ${ }^{7}$ complexa de altíssimo grau, transferindo uma aparência (que é a luz) para um aparato técnico ou outro suporte qualquer. Aptidão, que esquematiza e simplifica o mundo de quem a utiliza num ato mental que tem como instrumento operativo, a manipulação.

O produtor da imagem imita a forma exterior do objeto que está à sua frente e o espectador reconhece por essa forma, o assunto (GOMBRICH, 1999). Assim, o registro fotográfico e do vídeo captam não apenas a reprodução da forma exterior de um objeto, mas uma intenção de exprimir determinados aspectos privilegiados ou relevantes do mesmo. Nesse ponto, a fotografia e o vídeo diferem da possibilidade do cérebro humano de atribuir fidelidade na observação e na capacidade de reproduzir a informação visual.

A percepção visual também colabora e muito para o processo de projeto de produto, onde concretiza os sistemas de representação dos objetos, das coisas, da cultura material, artísticas, entre outros aspectos. As várias formas de percepção estão associadas ao sentido da visão que consiste na habilidade de detectar a luz e interpretar tais estímulos luminosos.

Entende-se que a natureza da percepção é complexa e pode ser considerada em conteúdo de várias áreas do conhecimento, já que seu campo é muito vasto. Mas o foco da tese recai sobre as características da percepção dos elementos da linguagem fotográfica e do vídeo, suas possibilidades e implicações na representação bi e tridimensional em suas diversas variáveis. Entende-se que o uso desta linguagem permite registrar aspectos fundamentais do mundo exterior do indivíduo (real e/ou projetado por ele).

Segundo Alonso (1994), indagar sobre o processo de percepção visual significa tentar compreender uma das partes fundamentais do processo geral da percepção, que supera o registro mecânico de estímulos, baseado unicamente em percepções visuais de componentes psicofisiológicos do sistema nervoso e o funcionamento mecânico do aparato sensorial.

Os mecanismos que interveem e consideram, além destes sistemas, o contexto sócio cultural de cada indivíduo (e da realidade), ampliando as possibilidades de manifestação e expressão a partir de um repertório particular,

\footnotetext{
${ }^{7}$ Abstração é uma ausência, pois tira-se algumas percepções como, o tato a presença a espacialidade, o entorno, reduzindo todas as possiblidades do ver.
} 
adquirido em experiências adquiridas e vivências que colaboram para construir os diversos modos de ver (e apreender), possibilitando perceber de forma distinta 0 mundo que nos rodeia, incluindo emoções e conhecimentos, interferem na experiência de perceber e se relacionar com o mundo exterior.

Os sistemas perceptivos e cognitivos despertam e deflagram imagens mentais, gerando diversas interpretações que dependem da capacidade e dos mecanismos atuantes e ativos no processo de codificação do sujeito.

O processamento da percepção visual e da representação são semelhantes: os dois sistemas estão sujeitos a transformações que alteram as informações recebidas e, desta forma, não captam as informações exteriores exatamente como elas são, e isso, sem dúvidas, será registrado e reverberado nas representações. (ROSSI, 2014).

Rossi (2014) ressalta que a percepção corresponde a um processo cíclico e evolutivo, pois a cada manifestação, cria-se novas emoções que vão condicionando e realimentando outras. Portanto, considera-se que o repertório atua de maneira determinante no desenvolvimento de nossas representações. Assim, a percepção visual é uma experiência complexa e que pode ser ampliada por meio de práticas apropriadas, com o uso da linguagem.

Embora o mundo físico possa ser apreendido por todo o sistema sensorial, o fenômeno da visão, pela dinamicidade existente no ato de olhar, é um dos aspectos fundamentais para que se possa perceber e relacionar com o mundo exterior. Através da captura da imagem (fotografia e vídeo) dos objetos e demais elementos do mundo real, ocorrem formas de representação ou comunicação.

Aceita-se que a imagem fotográfica e de vídeo, antes de tudo, é uma linguagem, pois congrega os elementos conceptivos e representativos de caráter funcional que as constitui, agindo conjuntamente com os argumentos verbais e os seus próprios elementos de linguagem, que atuam de forma decisiva e qualitativa no ato de pensar, projetar e refletir, visualizar, destacar objetos e produtos isolados ou inseridos em contextos socioculturais ou de uso e desempenho determinado.

\subsection{A fotografia e o vídeo como ferramenta de representação}

A fotografia é uma abstração da realidade, pois é realizada pela captura de um angulo diferente ao do olho humano, que não esgota as possibilidades de 
apreensão do espaço e dos objetos, possível mediante a descoberta da perspectiva, valorizando certos ângulos selecionados previamente, que asseguram uma identificação da realidade conforme um ponto de vista.

Assim, é visível a tensão na fotografia e vídeo, face suas possibilidades e facilidades de reprodutibilidade em relação aos outros meios de expressão, que a elege como sistema vantajoso e independente das habilidades manuais para o desenho do operador. Ao mesmo tempo, ao tornar tecnologicamente o registro cada vez mais automático, devido a inserção de novos recursos digitais, se colocam em choques constantes, as reflexões sobre a interferência decorrente dessa digitalização dos meios na capacidade abstrativa no processo criativo (projetual) e na produção do projeto em Design.

Soma-se a tal tensão, outros aspectos que reverberam também no campo do Design que tem valorizado e incorporado diversas disciplinas, de diferentes áreas de conhecimento, contribuindo para a formação e atuação profissional consonante com a expectativa de atendimento às demandas e características do mercado de produção e consumo; às necessidades e expectativas fundamentais dos cidadãos e da sociedade; e à pesquisa e desenvolvimento do país, ampliando disciplinas e atividades pedagógicas, ao mesmo tempo em que elimina outras fundamentais, na área de linguagem e representação dos currículos das instituições de ensino, sendo que grande parte das instituições não priorizam a utilização de novas ferramentas, devido ao alto custo de aquisição, manutenção e contratação de professores e técnicos especialistas.

A linguagem é um conjunto de proposições que não se transformam em respostas prontas para qualquer situação de projeto, mas que ao longo do processo estruturam-se em um raciocínio e instrumentalizam o uso técnico da ferramenta.

Neste contexto, tem-se perdido possibilidades de ampliação do uso da fotografia e do vídeo sem instrumentar as habilidades e favorecer experimentação prática na formação em projeto de produto, que usam outras formas expressivas e de utilização de linguagens no processo criativo de produto, na avaliação, na geração de alternativas, no desenvolvimento de modelos e protótipos e na representação do produto final, entre outras que se tornam emergentes dentro do campo.

É importante apontar que estes recursos derivados da linguagem estabelecem outras possibilidades de trabalho/manipulação de imagens bi e 
tridimensionais, que extrapolam o seu uso tradicional na representação e comunicação do produto e que podem alterar o modo e a frequência do seu emprego nas fases e nos resultados finais de projeto (como por exemplo, o uso de escaneamento tridimensional); a possibilidade de obtenção de informações confiáveis e fiéis sobre objetos físicos e o meio ambiente, através de processos de registro, medição e interpretação da imagem fotográfica (como a fotogrametria, biofotogrametria e metrologia).

A linguagem fotográfica e de vídeo são atos compositivos e representativos e atuam de forma determinante no ato de processar a imagem, agindo em conjunto com argumentos verbais rebatidos e expressos no plano bidimensional. Permitem processar uma serie de experiências; observações e análises com e sobre a imagem de objetos, ampliando as possibilidades de simular, testar, manipular o desenvolvimento gradual da experiência projetual. Considera-se aqui também, o seu uso em procedimentos de avaliação de objetos produzidos, modelados ou prototipados, sendo que em todas estas possibilidades constitui ferramenta auxiliar, mas fundamental no processo de aprendizagem nas disciplinas de projeto em Design.

Pensar nas transformações advindas dos processos de simulação interativa, que permitem antecipar o resultando real, físico, (reproduzi-lo e manipulá-lo), aspecto que gera uma transformação não apenas do conceito de representação como apresentado anteriormente, mas, sobretudo, da sua relação com o produto real (FABRIS, 1998).

Os procedimentos e técnicas da linguagem devem ser investigados, uma vez que os aperfeiçoamentos são constantes. Destaca-se a importância da evolução tecnológica no aspecto de representar aquilo que não é possível ver a olho nu.

Verifica-se assim, sua importância na formação em Design, fornecendo instrumentação técnica e atualizada na manipulação e no conhecimento dos dispositivos (equipamentos) e recursos embarcados e/ou em funcionamento acoplado, que colaboram para representar a criação e a visualização de objetos.

\subsection{A linguagem fotográfica}

A linguagem foi desenvolvida gradativamente por surgir no contexto da arte pictórica, sendo impregnada por ela ao imitar os temas de figuração da pintura, 
podendo-se citar também situações de imitação de caráter e efeitos do desenho (fotografismo).

A linguagem possibilita ao sujeito, expandir a capacidade de ver e entender a mensagem visual, envolvendo um contexto que vai além da simples visão. $A$ experiência do registro, seja ele fotográfico ou em vídeo, sempre foi vista como um fenômeno misterioso, por ter como suporte a impressão e a tela, que rapidamente gerava uma imagem do mundo visível, com aspecto real e verídico como o sentido da visão.

Contudo, a natureza original das ferramentas existentes, é a de representar fielmente o mundo e sua realidade devido a sua construção e programação. Ao mesmo tempo, identifica-se uma vontade oposta em modificar a imagem real, introduzindo outros elementos e aspectos visuais, possibilitados por diversos recursos de linguagem.

Destaca-se, no entanto, a importância da evolução tecnológica no sentido de representar aquilo que não é possível ver a olho nu. Por todo este conjunto de interinfluencias criativas, expressivas e técnicas, é importante frisar que a busca de soluções para o projeto orienta-se por uma lógica da descoberta que se faz nos momentos iniciais do projeto e que tem por necessidade o acesso a figuração imagética baseada na exploração da tecnologia da linguagem fotográfica e do vídeo como forma de retórica da figuração, auxiliando no raciocínio projetual e na forma do ver, observar, perceber, pensar, refletir e representar.

Verifica-se assim, sua importância na formação em Design, fornecendo instrumentação técnica e atualizada na manipulação e no conhecimento dos dispositivos (ferramentas) e recursos acoplados, que colaboram para representar e auxiliar no processo de geração de alternativas. No entanto, para identificar essa lacuna do conhecimento, buscou-se o estado da arte no que se refere ao uso das ferramentas fotográficas e de vídeo, detendo-se na aplicação de sua linguagem para seleção de alternativas projetuais e ampliação do repertório do designer.

\subsection{A linguagem fotográfica e a formação do Designer de Produto}

A linguagem fotográfica possibilita a construção e o desenvolvimento gradual e sistemático de ideias, considerando fases como a transmissão, a conservação, documentação e a memória, e a prospecção de conceitos e imagens, que traz ao 
designer oportunidade importante e qualitativa para o projeto, colaborando para a ampliação de seu repertório imagético e suas capacidades abstrativas.

Com as mudanças na instituição, além da inserção de diversos conhecimentos científicos e tecnológicos interdisciplinares inerentes ao projeto, buscou-se orientar e conduzir o Design para o futuro, retratando a vida moderna entrelaçada à tecnologia (FAGGIANI, 2006). Assim, o Design moldou-se e desenvolveu-se de acordo com a tecnologia de seu tempo. Uma destas tecnologias, foi a fotografia e posteriormente o vídeo, que com sua popularização, fez com que seus desenvolvedores mobilizassem esforços contínuos na busca incessante de aperfeiçoamentos do equipamento e de todo o processo fotográfico, do registro à impressão da imagem no papel, aprimorando não apenas a ferramenta ou técnicas especializadas, mas contribuindo para a construção de uma linguagem.

O aprimoramento da ferramenta e das possibilidades deu-se gradualmente no tempo, acompanhando o desenvolvimento que demandou atualizações constantes das teorias físicas, químicas e óticas colocadas em prática, exigindo dos profissionais mais conhecimentos a fim de manipular, atender as demandas e transmitir mensagens, representando ideias e conceitos, além de documentar e registrar imagens.

Nas últimas décadas, na passagem do formato fotoquímico para 0 eletrônico/digital, a fotografia e o vídeo passaram a ser utilizada incessantemente como ferramenta popular de grande potencial, para e em todas as áreas do conhecimento, sobretudo no Design de Produtos, ao mesmo tempo em que pôde minimizar a forma da captura da imagem com características diferentes.

As mudanças e avanços tecnológicos nos dispositivos e programas para fotografia e vídeo, colocam à disposição hoje, recursos imediatos de captura de imagem estática e em movimento, em mídias comuns e bem disseminadas na sociedade (como o celular e tablet), mas com outra qualidade quando comparado a processos fotográficos de equipamentos e programas e outros correlatos como o escaneamento, a termografia, que demandam investimentos próprios e também das instituições de ensino.

A linguagem fotográfica exige dos docentes, a transferência de conhecimentos tácitos que só podem ser adquiridos por meio da prática, necessitando do conhecimento por parte do profissional para gerar novas formas de 
aplicação para avaliação dos conceitos e técnicas, possibilitando ao aluno, assimilar sua aplicação e entender sua importância para obter melhores resultados.

É importante frisar, citando Escorel (2005), que são inúmeras e incessantes as possibilidades de renovar as tecnologias disponíveis para a reprodução, assim como quase infinita é a gama de materiais em que o profissional poderá imprimir (ou fabricar) suas decisões de projeto devido ao grande avanço tecnológico. Nesse sentido foi feito um levantamento sistemático da evolução e processos inventivos da linguagem fotográfica (Apêndice $F$ ), juntamente com um cruzamento de aspectos históricos da aplicação das ferramentas e aspectos históricos de uso pelo designer através de uma cronologia. Desta maneira com esse levantamento foi possível identificar a importância da investigação das duas escolas influenciadoras do ensino do Design nos pais.

Bauhaus e ULM, as mais importantes escolas do Design, expõem que a formação deste profissional não é apenas uma questão de técnica no sentido de aplicação de determinada fórmula ou conhecimento prático (VELA, 2010), tanto das ferramentas como de linguagens. Há, entretanto, a necessidade de conhecimento científico tanto no sentido do produto que se quer desenvolver, quanto do indivíduo que utiliza tal produto. $\mathrm{Na}$ estruturação curricular, essa visão global e integral de como se quer formar este profissional, uma colocando a Arte como mais importante, outra a técnica, marca as duas escolas e deve ser sempre lembrada como a base para a formação de um profissional qualificado (VELA, 2010).

Assim, cabe realizar investigações sobre as formas que as novas estruturas curriculares atuais, influenciadas pela experiência didática e recursos da Bauhaus e Escola de Ulm, foram modificando e estruturando currículos das escolas de Design, em relação aos avanços tecnológicos dessa ferramenta. 
CAPÍTULO 03 


\section{AS PRINCIPAIS ESCOLAS E SUAS REFERÊNCIAS PARA A FORMAÇÃO DOS DESIGNERS}

A linguagem fotográfica sempre esteve presente na formação em design, ora como meio de representação (de objetos, de eventos formativos - retratar, documentar e inventariar), ora como recurso criativo para o projeto e a ideação artística (narrativas poéticas).

Analisando o histórico do Design e as características do seu desenvolvimento com campo de conhecimento e atuação ao longo do tempo, duas das principais e mais influentes escolas precursoras de Design do século 20 - a Bauhaus e a Escola de Design de Ulm (HFG) são aqui analisadas na perspectiva de sua contribuição para a formação em design. Temos por objetivo resgatar, identificar as origens e as aplicações do uso da linguagem fotográfica e de vídeo na formação do profissional, através de pesquisa histórica das práticas envolvidas no uso da linguagem fotográfica, visando sustentar a reflexão e a análise das condições atuais e futuras para a adoção de possíveis abordagens para o ensino e a preparação completa desse futuro profissional.

\subsection{Bauhaus - Aspectos históricos}

A literatura e os autores que estudam, discorrem e abordam as atividades, o campo e a pesquisa em design já discutiram e analisaram a importância da escola da Bauhaus para a formação, cabendo neste trabalho, a reflexão sobre como a fotografia foi tratada, qual o seu papel nesta instituição pretendendo verificar o legado para a formação dos designers. Trata-se aqui de aprofundar de forma objetiva, os aspectos históricos da origem do design na instituição de ensino de graduação, com ênfase, sobretudo nas perspectivas da inserção do e no ensino da fotografia, como linguagem e representação no projeto e na produção de produtos.

Considera-se que a contribuição desta instituição já foi bem estudada e discutida na literatura, por sua importância na difusão de conhecimentos, gerando diversas influências no ensino, na pesquisa e na prática como protagonista de uma visão pedagógica do Design na época, que pode ser identificada até hoje. 
A escola ${ }^{8}$ inaugurada em 12 de abril de 1919, pelo diretor Walter Gropius (1883 - 1969), uniu artesões e artistas, integrando várias concepções de movimentos artísticos, tendo em vista a inserção e a adequação de produtos, peças de comunicação e de artes à produção em massa.

Esta instituição de ensino passou por três fases - a primeira em Weimar (1919 - 1925), com o fundador e diretor Walter Groupius; a segunda em Dessau (1925 - 1932), em 1928 com Hannes Meyer nomeado diretor, quando foram introduzidas novas disciplinas e oficinas, entre elas a Fotografia, Plástica, Psicologia e outras (BÜRDEK, 2006), atuando na forma de pensar a prática do design.

A fotografia passa a auxiliar na prática, como uma ferramenta artística e de documentação do processo de projeto. Em 1932 Meyer foi afastado e assumiu Ludwig Mies Van Der Rohe ${ }^{9}$; e a terceira em Berlim (1932 - 1933), por um breve período de tempo, onde foram encerradas as atividades por pressão nazista.

A constituição do perfil profissional se consolidou na Bauhaus como o estabelecimento dos princípios pedagógicos e concepções teóricas em torno da profissão, embora autores como Bürdek (2006) e Cardoso (2008) mencionem a pouca discussão ou quase nenhuma, em torno dos métodos de projeto. Depois outras escolas surgiram em vários países, seguindo os modelos de ensino e prática da Bauhaus, inclusive a Escola Superior da Forma (Hochschule fur Gestaltung $\mathrm{HfG}$ ), em Ulm na Alemanha.

O principal elemento de sustentação do ensino da instituição, segundo Bürdek (2006) era o curso básico, obrigatório para qualquer aluno. Este foi a contribuição mais significativa da Bauhaus para o ensino do Design tendo por objetivo "permitir ao ingressante $o$ autoconhecimento a assegurar a todos os alunos a compreensão de questões fundamentais de criação, que deveriam servir de base para o estudo ulterior da forma e para o aprendizado em oficinas" (WICK, 1989, p.87). Vila (2010) enfatiza que o curso surgiu para aproximar artistas e técnicos e como recurso.

Vila (2010) expõe que Itten, influente professor da Bauhaus e instrutor do curso básico, colocava que as disciplinas introdutórias deveriam estimular 0 potencial criativo dos alunos e desenvolver suas potencialidades, mas devido as

\footnotetext{
${ }^{8}$ Com a fusão entre a Escola de Artes Aplicada e a Escola de Belas-Artes, em Weimar, surgiu a Casa Estatal da Construção (Das Staatliches Bauhaus), conhecida por Bauhaus.

${ }_{9}$ Durante a terceira fase Van der Rohe deu continuidade a trajetória traçada anteriormente, mantendo a Bauhaus como uma academia de Arquitetura com algumas classes de Design, de pintura livre e de Fotografia (VELA, 2010).
} 
mudanças já mencionadas anteriormente, esta primeira fase passou a visar uma educação mais voltada para a conformidade, um senso comum, uma disseminação do saber em torno de princípios da forma e da produção de produtos.

Nesse sentido a posição de diversos autores aqui mencionados coloca a escola como formadora de questões fundamentais de criação; experimentações artísticas, técnicas e de tecnologias em design.

A Bauhaus preencheu conteúdos pedagógicos nos conceitos teóricos e práticos, familiarizando melhor o aluno no uso de materiais, processos de fabricação e de ferramentas auxiliares no processo de projeto (como a fotografia, e hoje o vídeo), e se considera que atualmente seja necessária uma retomada desse aspecto, questionando assim, a carência da variável tecnologia na linguagem e nos meios de representação, no desenvolvimento e aprimoramento das imagens na formação acadêmica do aluno de design.

A disciplina básica compreendia objetivamente a fotografia de produto de forma refinada com detalhes ricos em retratos superficiais e nuances de sombras mínimas no retrato bidimensional e também em objetos com grandes volumes (SIEBENBRODT; SCHÖBE, 2012).

$\mathrm{O}$ ano de 1929 marca a ruptura definitiva do desenvolvimento da fotografia como uma oficina paralela ao curso, fase que foi caracterizada, principalmente, pelo trabalho do fotógrafo Walter Peterhans (SIEBENBRODT; SCHÖBE, 2012). Peterhans desenvolveu suas atividades como docente de fotografia nos anos de 1929 a 1932, na Bauhaus de Dessau, e de 1932 a 1933, na de Berlim.

Percebeu-se, a necessidade da criação de uma disciplina específica no curso, para ampliar o horizonte perceptivo do estudante. No ano de 1930, a fotografia mostrou-se autônoma no currículo, enquanto em 1931 tornou-se um curso anual, sendo requisito necessário para a graduação em Design (SIEBENBRODT; $S C H O ̈ B E, 2012)$. A instituição investiu em equipamentos destinados à formação especializada e técnica, que incluíam um quarto escuro com ampliadores, uma série de projetores e instrumentos óticos ${ }^{10}$.

Mesmo com a inserção da oficina de fotografia como disciplina autônoma no currículo da Bauhaus e investimentos para sua concretização, nota-se através de dados históricos, sua subutilização no Design de Produto, em detrimento da sua

\footnotetext{
${ }^{10}$ Não relacionados e detalhados na literatura.
} 
contribuição para o avanço nas artes visuais, com usos exploratórios realizados pelos docentes Moholy-Nagy e Peterhans, que em um curto período de tempo influenciaram gradativamente o seu uso nos campos do Marketing, da Publicidade e do Design Gráfico.

Com a saída destes docentes a ferramenta ficou disponível para todos os cursos, mas sua instrumentação e uso foram diluídos nas disciplinas e explorados por professores e técnicos com experiências anteriores na prática e técnica deste dispositivo, sendo retomado e mantido o uso da imagem apenas como representação visual direta e documental dos objetos, atendendo aos campos da Publicidade, do Marketing, do Design Gráfico e do Design de Produto.

\subsection{Valorização da documentação e criação do objeto}

A fotografia manteve por um bom tempo um papel documental e de procedimento exploratório nas oficinas da Bauhaus. Em 1929, a ferramenta assumiu uma função integrativa dentro da instituição, adquirindo status de oficina em um dos departamentos (photo workshop), decorrente de reformulações da instituição ocorridas desde 1923 (Artand Technology - A new Unity), contribuindo para a disseminação da estética nas atividades formativas, apoiada em linguagens que buscavam ampliar as possibilidades da alfabetização visual (SIEBENBRODT; SCHÖBE, 2012).

A observação da documentação de imagens desenvolvidas pelos alunos na instituição, retratadas em bibliografia, apresenta-se com diversas influências estéticas e experimentais, dado o grau de possibilidades e conceitos possíveis com o uso da ferramenta, o que permitiu explorar a criatividade nas abordagens pedagógicas (SIEBENBRODT; SCHÖBE, 2012).

As publicações realizadas pela instituição com o uso da ferramenta variaram e apresentam retratos, documentação de trabalhos, composição de e do objeto, arquitetura, fotografia de produto (figura 1), utilização nas etapas do projeto, natureza morta (figura 2), fotografia de ambientes e o uso da imagem para montagens e foto colagens (figuras 3 e 4$)^{11}$.

\footnotetext{
${ }^{11}$ Ambas as possibilidades de abordagem seguiam por base conhecimentos dos docentes ligados a disciplina, sendo que a abordagem artística foi cada vez direcionada ao campo gráfico.
} 
Figura 1 - Lucia Moholy, "Silver coffee and tea service with alcohol-fuelled warmer by Marianne Brandt, 1924" - foco no conjunto de utensilios, documentação realizada em estúdio para valorização dos objetos.

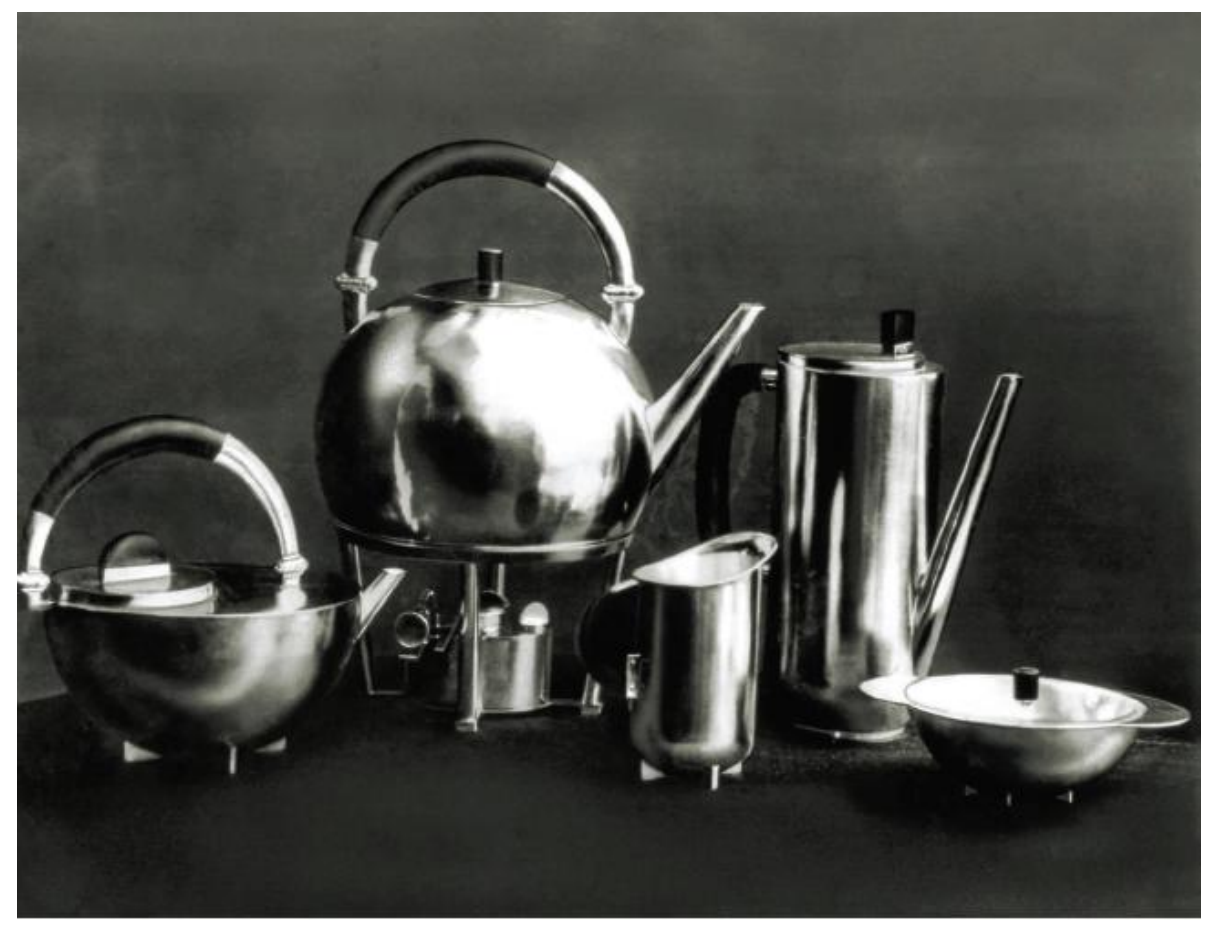

Fonte: Siebenbrodt; Schöbe, (2012, p. 207).

Figura 2 - Georg Muche, "Still Life in Glass, 1921/22" - composição dos objetos de elementos materiais para estudo de reflexos em estúdio.

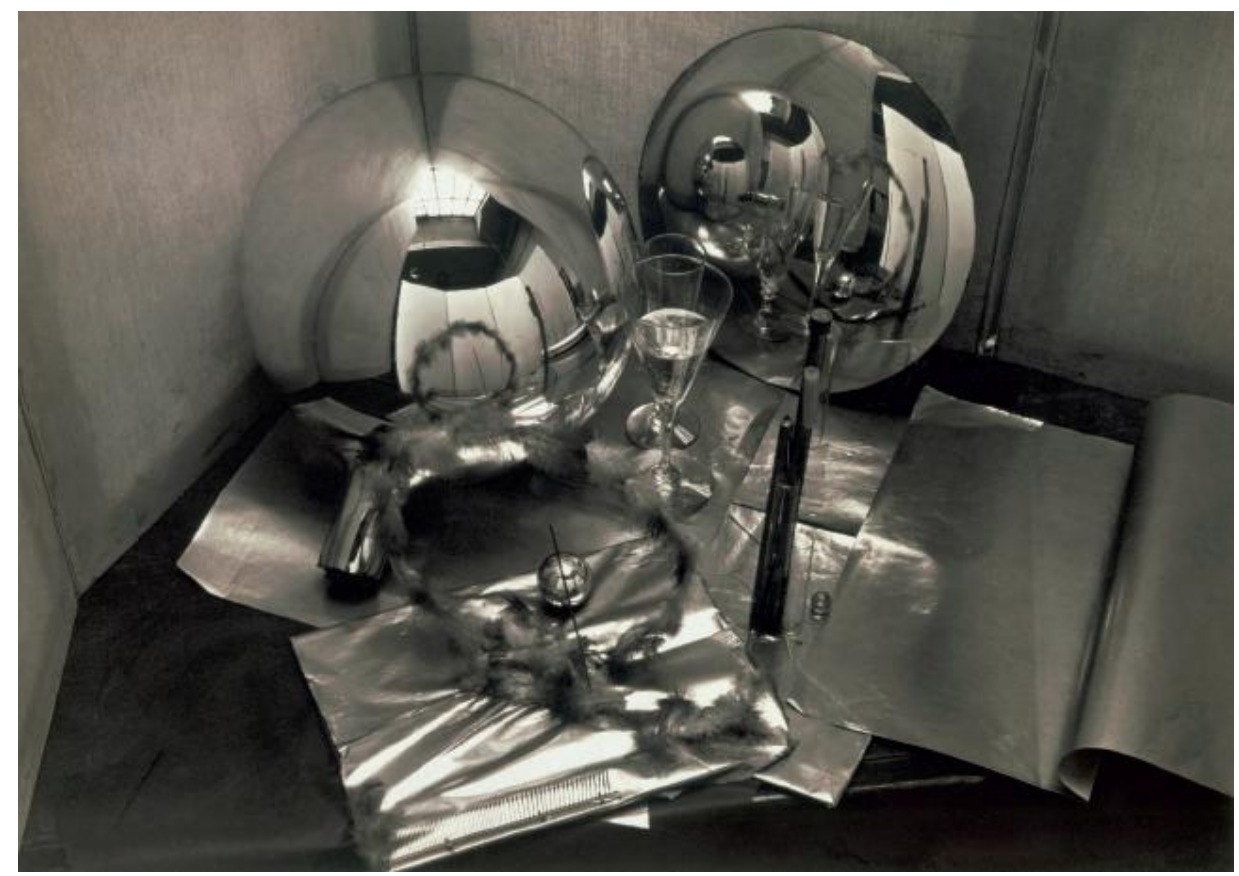

Fonte: Siebenbrodt; Schöbe, (2012, p. 206). 
Figura 3 - à esquerda, Paul Citroen, "Big City (Metropolis), 1923" - montagem de diversas imagens no desenvolvimento de uma composição única.

Figura 4 - à direita, László Moholy-Nagy, "Photoplastic, 1925" - montagem de diversas imagens no desenvolvimento compositivo da imagem.
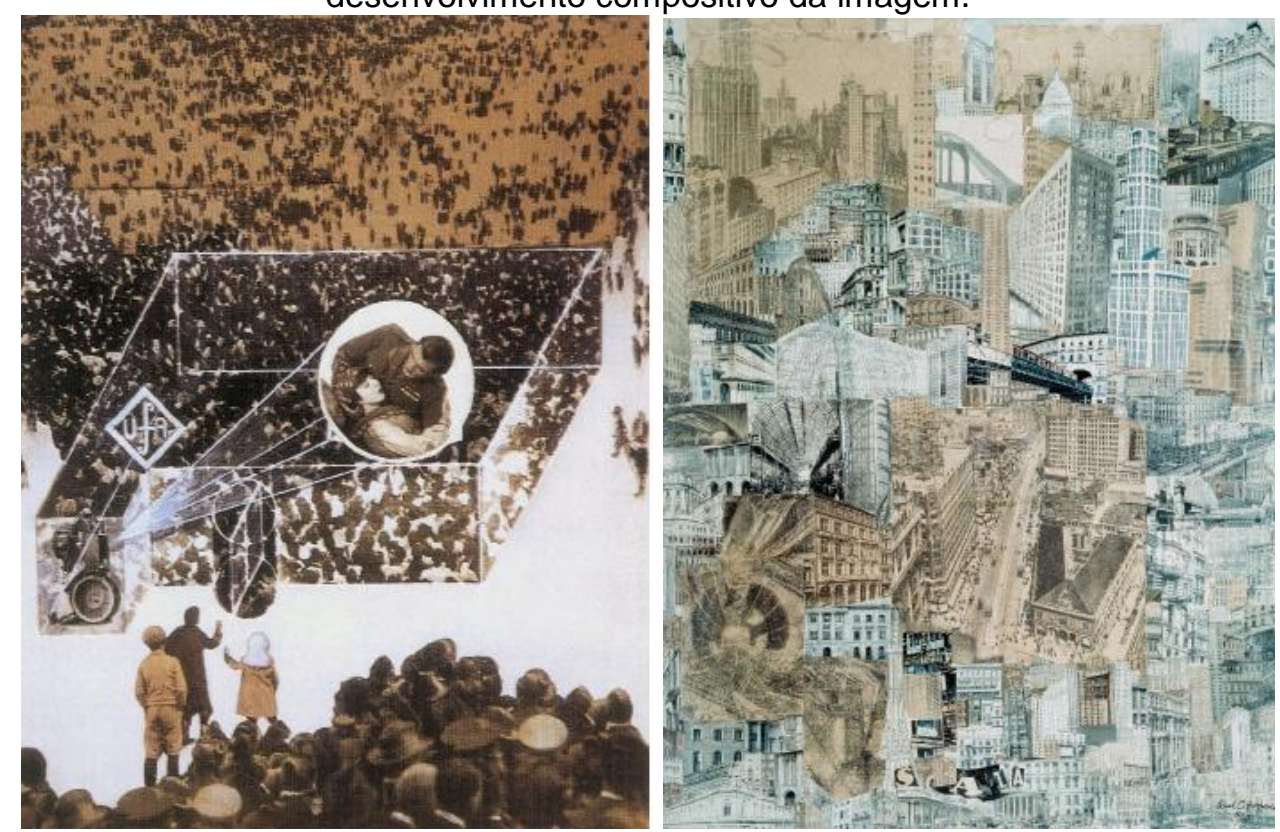

Fonte: Siebenbrodt; Schöbe, (2012, p. 209).

Fonte: Siebenbrodt; Schöbe, (2012, p. 209).

A fotografia atendia ao objetivo da documentação para fins de registro, arquivamento e publicidade, além de sua inserção em livros, conferências e revistas da instituição (SIEBENBRODT; SCHÖBE, 2012), distanciando-se do uso e aplicação como gênero de uma linguagem conceitual, autônoma ou de intenção artística ou criativa no processo de projeto. Nesta fase inicial, o uso da ferramenta aparece subjugado ao valor fotográfico dos objetos (isto é, da produção discente e docente) dando consistência a documentação autoral.

Durante os anos de 1919 a 1923 (SIEBENBRODT; SCHÖBE, 2012) observase que os registros da produção fotográfica foram, predominantemente, o de documentação de produtos ou do resultado de trabalhos dos discentes (incluindo modelos e protótipos), desenvolvidos durante as disciplinas, e incentivado pelos professores.

Enquanto representação, os valores fotográficos aparecem dedicados a aspectos das aplicações práticas da ferramenta, ou seja, a fotografia teve um papel de registro das atribuições configuracionais e funcionais dos objetos (idealizados, projetados) em cada fase do projeto. 
Walter Gropius, fundador e diretor da instituição, propôs essa compreensão do uso da fotografia, quando colocava que esta se destinava a ser um instrumento de reprodução neutra da realidade, gerenciando a ferramenta pela racionalidade funcional de seus recursos para o design a fim de transmitir uma informação objetiva (SIEBENBRODT; SCHÖBE, 2012), amortizando assim outras possibilidades, de caráter experimental e exploratório. Erich Consemüller e Lucia Moholy desenvolveram neste contexto grande parte da documentação de todas as áreas de atuação da Bauhaus, resultando no registro generoso e amplo dos trabalhos desenvolvidos, colaborando para a ampliação dos arquivos históricos da instituição.

Do ponto de vista de Siebenbrodt e Schöbe (2012), esta visão foi preponderante até o ano de 1927, onde os produtos gerados e produzidos eram registrados em conjunto ou classificados por sua lógica de funcionamento, manifestando expressão fiel aos conceitos modernistas, que caracterizaram o pensamento e a proposta da instituição, sem abertura para a construção de outras narrativas.

Considera-se que diferente e além do valor de uso, o caráter da linguagem da fotografia faz dela uma das atividades com alto grau de originalidade, determinandose pela sua aplicação, assim como o uso particular da língua pode determinar o significado ou o valor de um termo ou expressão dentro de um idioma (VIANNA; CAMPOS, 2011).

Outra visão da relação fotografia/design está nas possibilidades criativas, que pode ser apreciada na proposta de László Moholy-Nagy autodidata (entre 1923 a 1925, em Weimar, e de 1925 a 1928, em Dessau) que trouxe outra vivência na impressão de um caráter exploratório à fotografia, proporcionando experiências visuais até então sem precedentes (FONTCUBERTA; COSTA, 1988). Decididamente, essa nova perspectiva influenciou no desenvolvimento experimental desta ferramenta na instituição, contribuindo para que o campo ganhasse importância como um meio independente de expressão e linguagem. Respaldadas por suas colocações conceituais denominadas "Nova Visão ${ }^{12}$ " e "Nova Objetividade $^{13 ",}$ observam-se duas tendências incorporadas a partir da expressão

\footnotetext{
${ }^{12}$ A "Neues Sehen", movimento artístico da fotografia que desenvolveu-se na década de 20 , o movimento é relacionado diretamente com o enfoque da Bauhaus e que considera a fotografia como uma prática artística autônoma com as suas próprias leis de composição e de iluminação e que ter por objetivo tornar a câmera um segundo olho para observar o mundo.

${ }_{13}$ A "Neu Sachlichkeit", movimento artístico surgido na Alemanha no início da década de 20, na fotografia o principal representante foi Albert Renger-Patzsch, cujas propostas encontra-se em fazer um emprego funcional
} 
"Nova Fotografia"14", idealizadas por ele e por Walter Peterhans (SIEBENBRODT; SCHÖBE, 2012), uma com foco no objeto a ser retratado; a outra, como elemento fotográfico criativo em oposição à documentação.

Deste modo, Moholy-Nagy desde 1923, influenciou decisivamente outra visão no desenvolvimento da fotografia na Bauhaus, introduzindo objetivos voltados para a experimentação de imagens no âmbito da percepção, colaborando para a constituição de outros conhecimentos e habilidades ${ }^{15}$. Além disso, o docente apoiou o uso da ferramenta no curso preparatório e nas oficinas de metal.

Grande parte dessas ideias e do desenvolvimento experimental da fotografia, na instituição, entre 1927 e 1928, foi adotado posteriormente em outros campos, como a Arte, Publicidade e o Marketing. Com a saída de Moholy-Nagy, estes ensinamentos e práticas foram reduzidos (SIEBENBRODT; SCHÖBE, 2012), embora já tivessem influenciado os campos do Design e dos mencionados acima. No ano de 1929, Walter Peterhans é nomeado chefe da oficina de fotografia (SIEBENBRODT; SCHÖBE, 2012).

É evidente a preocupação dos precursores, Moholy-Nagy e Peterhans, em reconhecer a importância de desenvolver nos alunos práticas e conhecimentos para usufruir dos recursos experimentais da ferramenta potencializando as funções técnicas.

Alguns trabalhos documentados sobre o processo fotográfico têm a ver com 0 ato de descoberta dos processos de captura e revelação e outras experiências estão nos efeitos gerados pela luz. Nesse aspecto, foram desenvolvidas diversas incursões dentro dos temas das esculturas e objetos tridimensionais direcionadas à relação da luz sobre o movimento. Estes experimentos em práticas simuladas ampliaram o repertório dos alunos sobre os efeitos gerados pela luz (possivelmente trabalhadas em escala reduzida).

Uma dessas criações foi desenvolvida por Moholy-Nagy, que era fascinado pela luz, através do modulador de luz no espaço (Título Original - Licht-Raum Modulator 1922-30 - figura 5).

\footnotetext{
da luz, utilizar enquadramentos diferentes e usar objetivas de diferentes distancias focais. Na Alemanha, os principais representantes foram John Heartfield, Karl Blossfeldt, Walter Peterhans, Helmar Lerski e August Sander. Na República Tcheca, encontrava-se Josef Sudek.

${ }^{14}$ A "Neues fotografie", o movimento foi criado, trazendo, consigo, fotografias com maior nitidez, com caráter documental frente à arte fotográfica, baseada anteriormente na poética autoconsciente.

${ }^{15}$ Considera-se aqui a aproximação entre arte e design.
} 
Figura 5 - Light-Space Modulator, Réplica 1970. Dispositivo para experimentação de efeitos da luz em movimento.

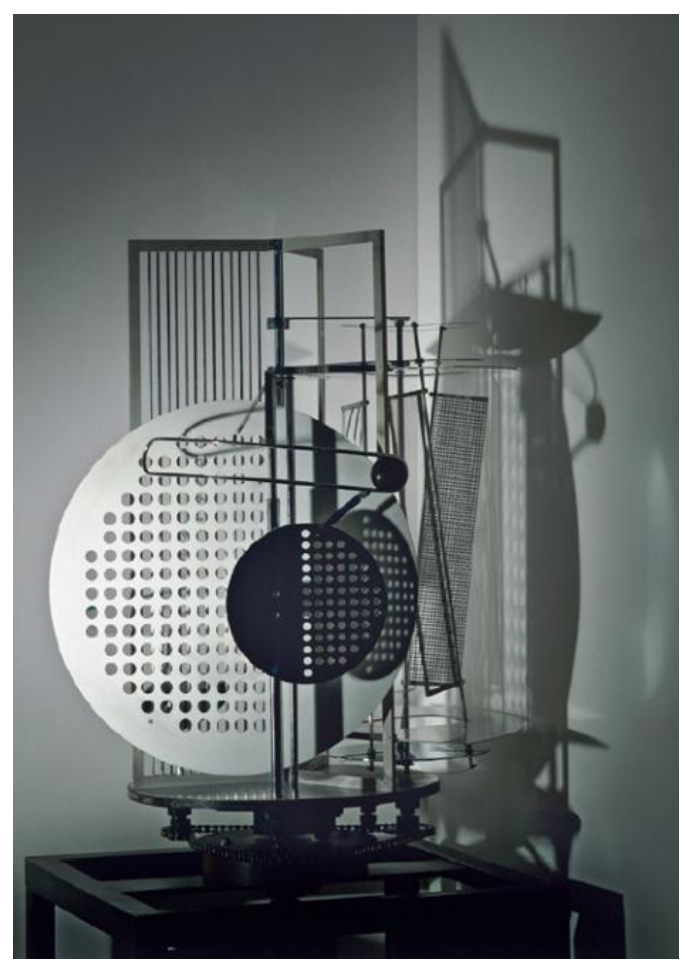

Fonte: Bauhaus-Archiv, (2009, p. 275).

Trata-se de uma escultura cinética desenvolvida a partir de três estruturas metálicas móveis, arranjadas sobre um disco rotatório, que formam o núcleo do modulador, desenvolvido para demonstrar o jogo de luz como manifestação do movimento. Propunha explorar o desenho da luz atrelada ao movimento, através de mudanças na iluminação, gerando múltiplos efeitos óticos.

Outra criação foi idealizada por Edmund Collein, em 1928, na oficina de escultura da Bauhaus de Dessau, disciplina ministrada pelo docente Joost Schmidt (Sculpting Workshop - de 1925 a 1930), uma máquina (figura 06) que permitia uma série de experiências, a partir de figuras, planos, linhas e movimentos articulados entre si, resultando em inúmeras formas que se interpenetravam. Criação desenvolvida a partir de um exercício para investigar o uso de formas planimétricas e estereométricas e a relação entre corpo e espaço positivo e negativo em relação à luz e sombra, visualizada por meio da projeção de luzes e da rotação e torção, em movimento real e virtual (BAUHAUS-ARCHIV, 2009). 
Figura 6 - Série de experimentos: "Von Grader und Kreis zu Hiperbolóide und Kugel”, para a aula de Joost Schmidt na oficina de escultura.
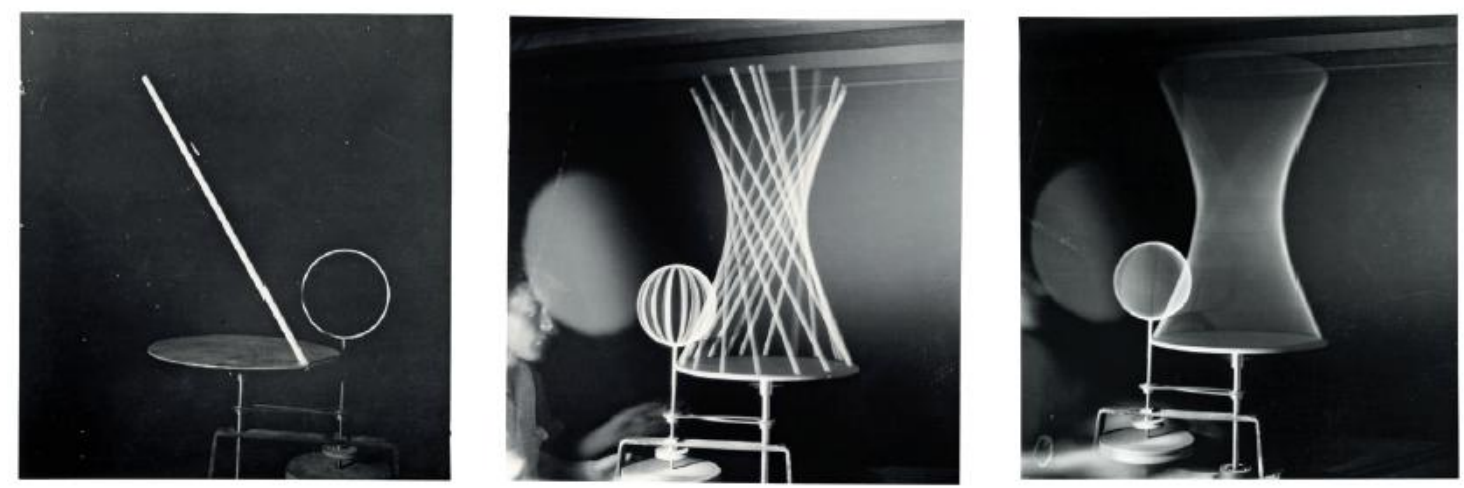

Fonte: Bauhaus-Archiv, (2009, p. 279).

Os estudos direcionados à composição e interpenetração da luz tinham a intenção de ampliar e desenvolver as qualidades da imaginação espacial, a experiência da percepção sensorial do espaço e a consciência visual de planos de interseção de volumes negativos, com vistas à construção e produção complexa da forma.

\subsection{Breve histórico da Escola de ULM}

O desenvolvimento e a racionalização dos processos industriais e de novas técnicas fundamentadas num pensamento lógico, acarretou em processos de planejamento, organização, decisão e otimização incorporados nos projetos, na indústria e no design (BONSIEPE, 2015), e assim a Hochschule für Gestaltung (HfG), mais conhecida como Escola de Ulm ou Escola $\mathrm{HfG}^{16}$, na Alemanha, foi uma das mais importantes iniciativas depois da Segunda Guerra Mundial, ao assumir o protagonismo na formação em Design (pós fechamento da Bauhaus) evidenciando agora no pós-guerra, um pensamento claro e racional na formação.

\footnotetext{
${ }^{16}$ Foi oficialmente inaugurada em 1955 por Max Bill, ex-aluno da Bauhaus (no período de 1927 a 1929), Inge Aicher-Scholl e Otl Aicher. A escola foi fundada em 1953, na cidade de Ulm, na Alemanha, e permaneceu até 1968. Max Bill demitiu-se do cargo de diretor um ano após a fundação e saiu da Escola em 1957 (VILA, 2010). O principal motivo de seu desligamento foi a não concordância com o desenvolvimento dos conteúdos ministrados; outro foi a desconfiança que tinha do rumo que estava sendo dado à instituição, onde o foco estava em uma educação mais técnica (FONTOURA, 1997). Segundo Vila (2010) foi implementado, a partir do seu desligamento, um programa de ensino estritamente tecnológico e científico, eliminando lo caráter intuitivo herdado da Bauhaus.
} 
A escola tinha por objetivo retomar a tradição da Bauhaus, interrompida em 1933 pelo nazismo (MALDONADO, 1991). Desse modo Ulm é considerada a mais expressiva tentativa de se reestabelecer uma ligação com tradição do design alemão e como sucessora dos ideais da Bauhaus, mantendo ligação e influência no seu quadro docente procedente da Bauhaus, personagens como Josef Albers, Walter Peterhans, Helene Nonné-Schmidt e Itten (RINKER, 2006). Bonsiepe (2015) evidencia que a escola diferenciou claramente a arte e o design, atribuindo a este último um domínio independente das artes que passou a ser somente instrumental e utilizado principalmente nos trabalhos desenvolvidos no curso básico (BÜRDEK, 2006).

Nessa perspectiva, um ano após ser inaugurada, em 1956, a escola passa a ter novas disciplinas formativas incorporadas no currículo, como Ergonomia, Técnicas Matemáticas, Economia, Física, Ciências Políticas, Psicologia, Semiótica, Sociologia, Teoria da Ciência, entre outras com maior grau de importância para o curso (BÜRDEK, 2006).

Deste modo o Design foi moldado e se desenvolveu de acordo com a tecnologia de seu tempo e com a filosofia empregada pela escola, formando profissionais com novos saberes, mais abrangentes de acordo com as demandas e exigências impostas pelas mudanças sociais e econômicas deste período. No entanto, fica evidente também que a integração e a concisão das disciplinas científicas em seu currículo, foram sustentadas também pela relação entre Design e a sociedade como relatado por autores como Bonsiepe (2003).

Um dos aspectos dessa necessidade de diferenciação é devido ao fato de que o desenvolvimento de um objeto exige uma investigação incansável e um trabalho metódico para atender as necessidades técnicas, funcionais, estéticas e econômicas (WINGLER, 1975). Bürdek (2006) destaca que sem a Escola de Ulm, a metodologia do design não seria possível. Assim o modo sistêmico sobre a problematização, os métodos de análise e síntese, a justificativa e a seleção das alternativas de projeto que se tornaram repertório da profissão, se devem, em parte, e são legados de procedimentos desenvolvidos na Escola de Ulm.

Neste período, o projeto no ensino do design industrial, se orienta para o aprofundamento da metodologia, devido ao novo modelo educacional, sendo estudados e mencionados por alguns autores como Bonsiepe, 2012; Baxter, 1998; Bürdek, 2006 e Lobach, 2001, que colocam que ele serviu de adaptação para um 
perfil tecnicista e de racionalismo como requisitos essenciais para as soluções projetuais, e que exerceu grande influência sobre grande parte das escolas de design industrial do mundo.

Outro aspecto do fortalecimento da Escola de Ulm está na construção de parceria com a indústria, alimentando e produzindo vários projetos de produtos utilizando o conceito de funcionalismo e racionalismo da "Boa Forma" (que marcaram referencias de objetos que permanecem na memória da produção deste setor de atuação), principalmente no segmento dos eletrodomésticos (DENIS, 2008), elevando assim o status da formação em Design. A Escola de Ulm consolidou uma identidade técnico cientifica do Design, iniciando a reflexão sobre as metodologias para o projeto e a aplicação de linguagens auxiliares e de documentação para a concepção do projeto, influenciando a teoria, a prática e o ensino do Design em diversos outros países.

Sobre a disciplina de fotografia e vídeo (photo; film) o material é escasso e não está claramente documentado na literatura, principalmente nos aspectos de aplicação da linguagem fotográfica dentro do campo do Design de Produto.

Paralelamente, as mudanças e o desenvolvimento da ferramenta foram acompanhados de novas possibilidades na linguagem fotográfica que se deram gradualmente no tempo, exigindo dos profissionais conhecimentos em manipular e transmitir mensagens, representar ideias e conceitos, além de documentar e registrar imagens.

Contudo nas últimas décadas, devido à mudança do formato fotoquímico para o eletrônico/digital, a fotografia passou a ser utilizada incessantemente como instrumento de grande potencial, para e em todas as áreas do conhecimento, sobretudo no design de produtos.

\subsubsection{A oficina de fotografia e vídeo na Escola de UIm}

O plano de ensino abrangia no período de um ano, conteúdos e práticas destinados ao curso básico; dois anos para os cinco departamentos (Design, Construção, Comunicação Visual, Informação e Fotografia / impressão (photo; film); e mais um ano para desenvolver o trabalho final de forma teórica e prática. Durante

o desenvolvimento das atividades, os alunos eram envolvidos em oficinas 
(workshop) de gesso, plástico, madeira, metal e fotografia / impressão, trabalhando com diferentes processos, técnicas e mídias.

O departamento do curso básico passou a ter grande importância por repassar as bases gerais da configuração de produtos (materiais e visuais) incluindo os meios de representação. O departamento de "Visual Design" ${ }^{17}$ que abrangeu competências e habilidades em cinema, fotografia e processos e produção gráfica, fazia parte da base do curso como um dos trabalhos práticos. Assim os alunos deveriam ser treinados em profissões "modernas", ampliando o horizonte do design, com ênfase na prática e não na apenas na teoria (SPITZ, 2002).

De 1956 a 1958 o currículo foi modificado gradualmente, introduzindo novas disciplinas, estreitando ainda mais a relação entre configuração formal e conceptiva, ciência e tecnologia. De 1958 a 1962 a Escola de Ulm estava claramente comprometida com a tradição do racionalismo alemão, relacionada especialmente a adoção de métodos matemáticos. De 1962 a 1966 foi dado peso igual à teoria e à prática nas disciplinas do currículo.

O departamento de Filme ${ }^{18}$ foi organizado em 1961 como seção autônoma, e o conteúdo do curso visava a transmissão de capacitação e desenvolvimentos das novas formas experimentais no fazer filmes com disciplinas voltadas a teoria de câmeras.

Muitos processos não foram devidamente documentados, para resgatar níveis de compreensão do uso da linguagem fotográfica demandados por diferentes meios de representação à época, dificultando estabelecer um fio condutor na perspectiva histórica evolutiva dos processos didáticos desenvolvidos em sala de aula, na qual praticamente em grande parte da documentação não mostra provas concretas na intenção da instituição em reconhecer a importância de desenvolver juntamente com os alunos habilidades e competências dos recursos experimentais da ferramenta fotográfica e de vídeo.

Gomes (2006) ressalta a sua relevância como recurso adequado as várias etapas da projetação: "Potencial usado e exercitado pelos designers como

\footnotetext{
17 No período de 1953 a 1956 Walter Peterhans entre outros professores ministram aulas aos alunos ingressantes, sendo que o ensino caracterizava pela continuidade da tradição da Bauhaus e mesmo que os primeiros professores tivessem uma formação artística, a instituição tinha na arte um interesse instrumental (BÜRDEK, 2006).

${ }_{8}$ Em outubro de 1967, se tornou independente como Instituto de Design de Filmes. E durante o período em que a escola esteve aberta de 1953 a 1968, vinte e sete (27) alunos participaram do departamento de foto e vídeo (foto; film) sendo que apenas seis (6) alunos obterão o diploma final (CURDES, 2001).
} 
ferramenta indispensável para as etapas de estudos experimentais, tendo em vista a concepção, o desenvolvimento do projeto, a documentação e o registro técnico para a fabricação, confecção ou elaboração do objeto" (GOMES, 2006, p. 214).

A imagem sempre foi um dos recursos essenciais para o processo de trabalho do designer, sendo mais e comumente utilizada, por grande parte dos profissionais, como meio de documentação e de comunicação da concepção à fase final do projeto ou do próprio produto, e com menor incidência como uma ferramenta auxiliar para o projeto. Considera-se, também, que por ser um instrumento de comunicação que utiliza mensagens visuais, a fotografia é também um discurso visual, relacionando-se, portanto, a processos criativos e artísticos. Um meio de expressão carregado de informação.

A narrativa deste capítulo, traz a importância e o papel da fotografia nestas duas Instituições de ensino precursoras e de referência para a formação dos designers de produto, ora mais voltado a experimentação visual, ora dedicado a representar e documentar os projetos de objetos e peças visuais ou participando do processo criativo e das fases de metodologia de desenvolvimento de produtos. 
CAPÍTULO 04 


\section{PRINCIPAIS USOS DA FOTOGRAFIA NO PROCESSO DE PROJETO E NA ATUAÇÃO EM DESIGN}

Este item traz uma síntese do levantamento sobre meios, recursos e aplicações da fotografia no projeto de produto, procurando identificar a contribuição e os usos da linguagem fotográfica na construção e no desenvolvimento gradual e sistemático de ideias, considerando a transmissão, a conservação, a documentação e memória, e a prospecção de conceitos e configurações (formais, geométricas, e experimentais em e através de imagens), que trazem ao designer a oportunidade de diferencial para o projeto, colaborando para a ampliação de seu repertório imagético e de capacidades abstrativas na aplicação das ferramentas, considerando o projeto, analise e avaliações de projeto de produto.

É possível identificar também, que dependendo do processo conceitual que o designer tome para selecionar ferramentas fotográficas ou cinematográficas como linguagem visual para a geração de ideias, estas podem auxiliar a trazer à tona elementos e riqueza de informações que possibilitem gerar alternativas para o auxílio do projeto a ser desenvolvido.

Segundo Ferroli e Librelotto (2016), o processo de geração de alternativas ocupa lugar de destaque nos métodos de projeto existentes, permanecendo localizado no período intermediário do processo. Nesse sentido, considera-se importante e deve-se examinar os métodos e ferramentas disponíveis de forma a empregá-los com o máximo de resultado, ao lado do uso simultâneo de outras técnicas e procedimentos, para o gerenciamento de sua aplicação. A bibliografia técnica apresenta várias formas de se proceder com a geração de alternativas, mas, sem a mesma ênfase em relação ao uso das ferramentas fotográficas e de vídeo, talvez devido a dificuldade técnica ou de operação e ao custo de equipamentos mais aprimorados.

As fases iniciais da pesquisa para projeto ou redesign requerem em alguns casos uma abordagem ampliada (e aprofundada) para realizar conexões, para compreender o contexto e para criar novas ideias, facilitados e ampliados por uma gama de métodos e técnicas que contam com a contribuição de capturas fotográficas ou de vídeo, encontradas tradicionalmente na literatura impressa ou em mídia e apresentadas a seguir. 


\subsection{Pesquisa e criação}

Atualmente a ferramenta fotográfica é de fácil acesso e está incorporada na grande maioria dos "smartphones" e "tablets", tornando possível realizar a captura de imagens em qualquer situação ou contexto real, para posteriormente realizar a leitura da cena e dos seus atributos, como as cores, através de um software de imagem. Isto torna possível a simulação de uma paleta de cores para aplicação em materiais e acabamentos do produto, auxiliando o processo de pesquisa e criação (figura 7), dentre as possibilidades de manipulação de imagem.

Figura 7 - Paleta de cores gerada através de software de imagem.
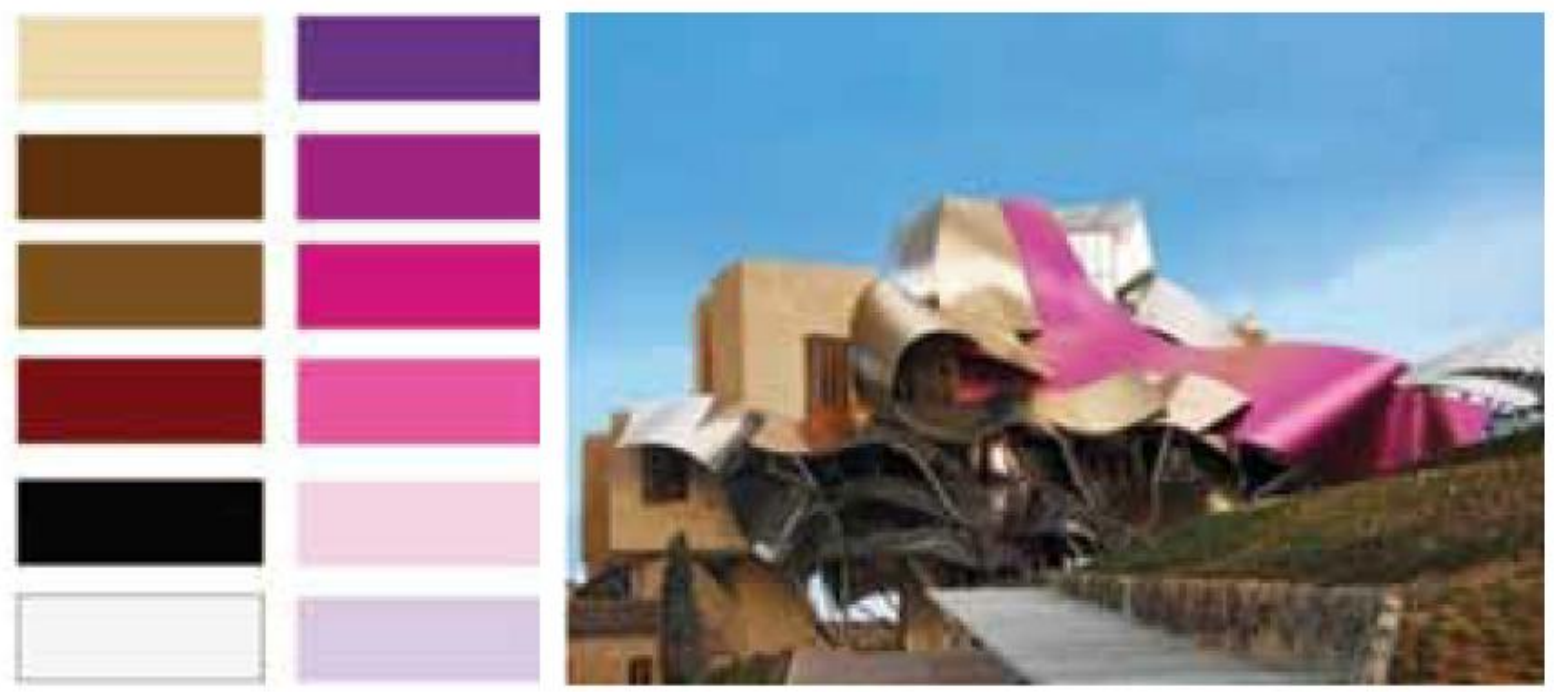

Fonte: Özcan, A. "Agrindustrial Design: 2nd International Product and Service Design Congress and Exhibition on Agricultural IndustriesMediterranean/Food/Design Proceedings" (2016, p. 257).

\subsection{Referência visual}

Grande parte dos designers usa com habilidade e frequência a ferramenta na busca de referências em acervo próprio ou de imagens e/ou padrões já desenvolvidos por fotógrafos (e outros atores que trabalham com representações visuais), sejam eles profissionais ou amadores, em bancos de imagens (figura 8), para a investigação formal, estrutural, conceitual ou outras características inspiradoras, de uso e aplicação funcionais, construtivas ou para a fabricação, pertinentes ao projeto em desenvolvimento, colaborando nos processos iniciais de 
pensamento em Design, que posteriormente podem gerar novos conceitos ou aplicações.

Figura 8 - Exemplo de um dos maiores bancos de imagens que disponibilizam diversas mídias através de planos mensais.

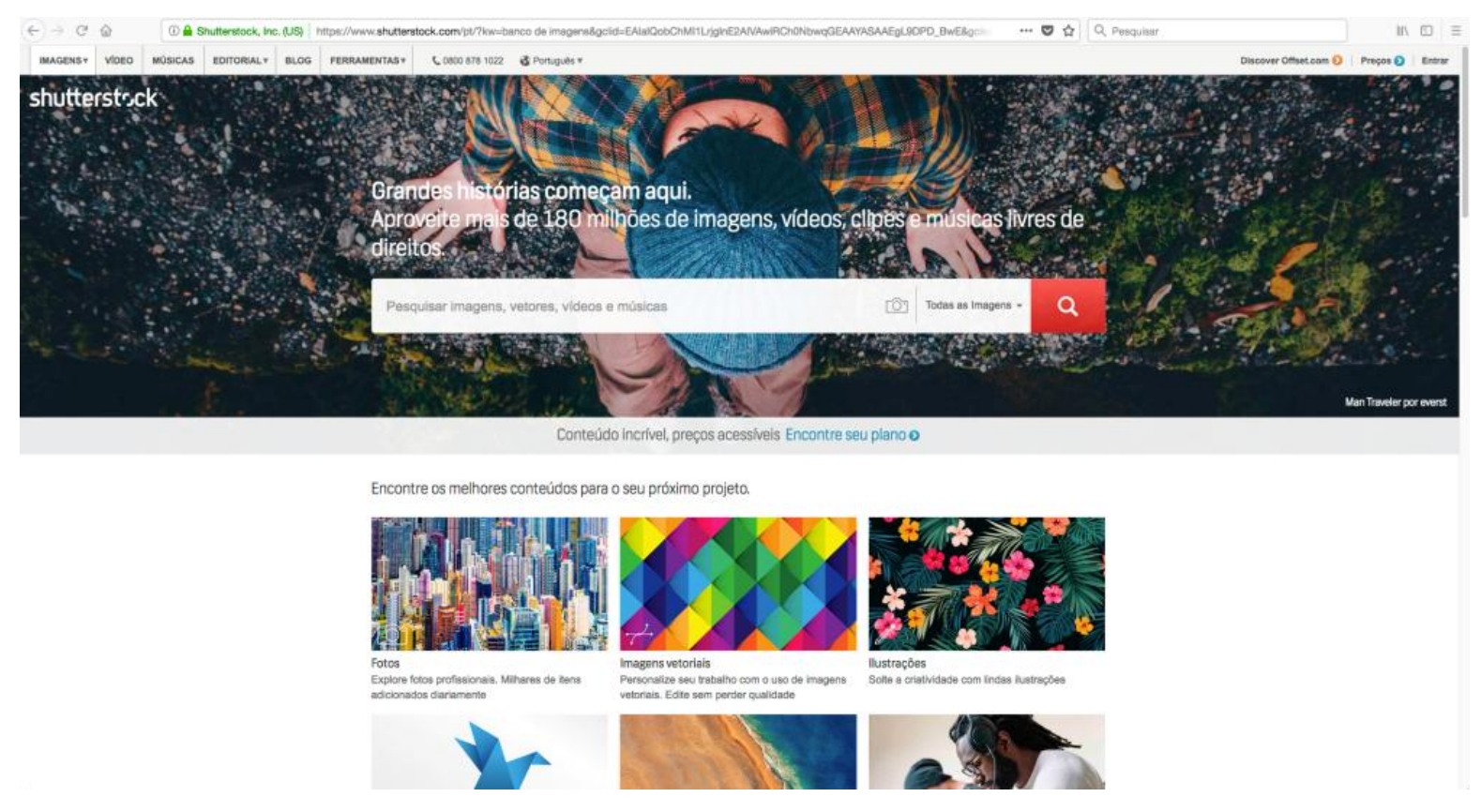

Fonte: https://www.shutterstock.com/. Acesso em 11 de janeiro de 2018

A pesquisa em banco de imagens ${ }^{19}$ fotográficas ou até mesmo de vídeos, auxilia no processo de sua manipulação que junto com outros recursos de representação como o desenho e a computação gráfica, pode gerar novos produtos, auxiliando no processo de busca de alternativas (projetuais/conceituais), assumindo finalidades para o Design além de apenas o registro para documentação que irá auxiliar no processo de geração de ideias; aportes formais, configuracionais, semânticos e sintáticos, podendo constituir característica fundamental do objeto a ser desenvolvido, como ilustrado na figura 9.

\footnotetext{
${ }^{19}$ Há restrições nesta etapa, como o tempo disponível para a criação, que podem eliminar ou minimizar uma busca aprofundada.
} 
Figura 9 - A brincadeira de criança utilizando um carro de brinquedo possibilitou a ideia de desenvolvimento de sketches de um aspirador de pó.
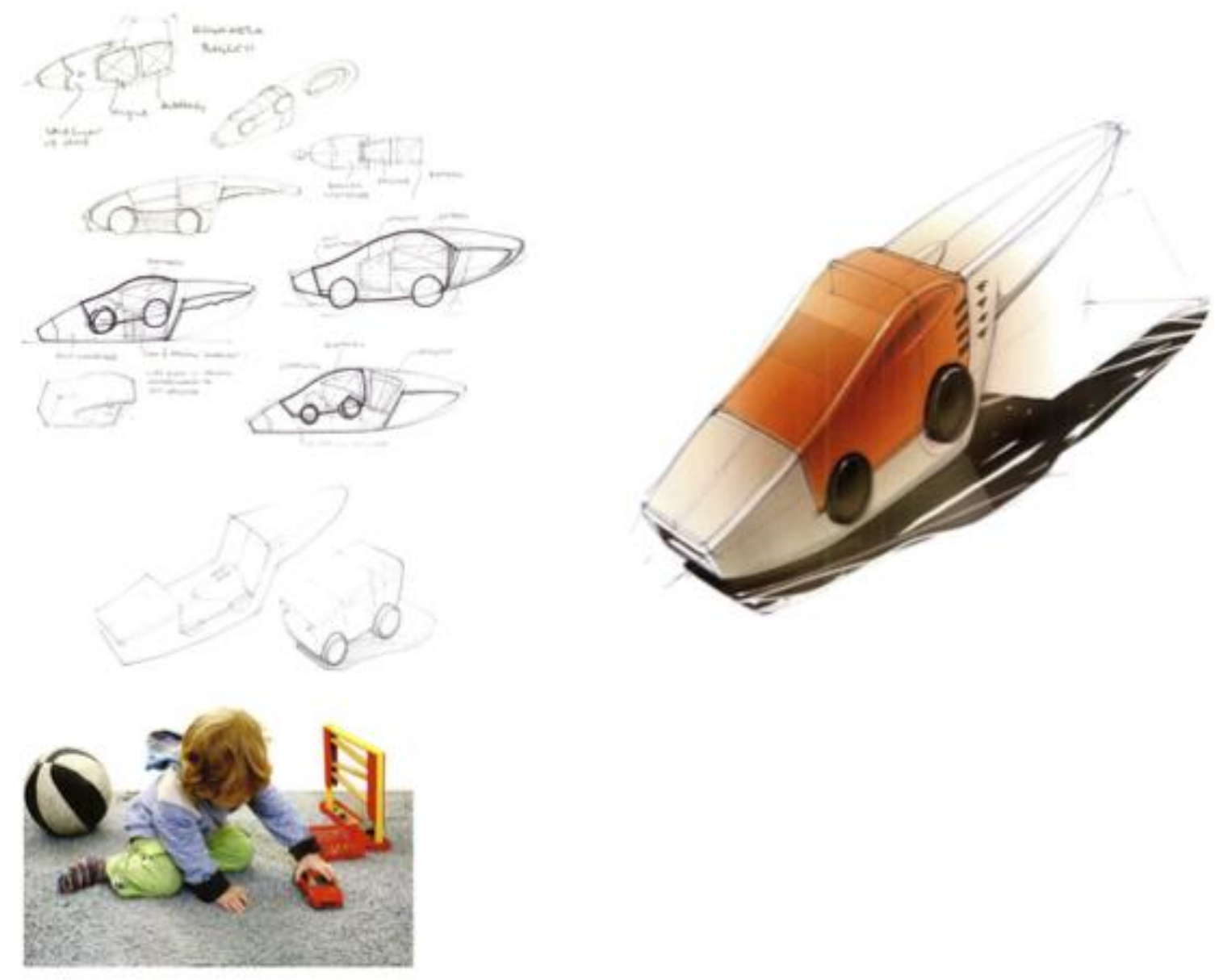

Fonte: Sketches realizados por Robert Bronwasser, SMOOL - Sketching The Basics - Roselien and Koos, Bis Publishers, Amsterdam (2011, p.15).

Outra forma que pode ampliar as possibilidades da abordagem do desenho e encorajar a pensar espacialmente na análise de formas, desta maneira, é com a utilização da captura de movimento ${ }^{20}$ (Motion Capture ou MOCAP) tornando o esboço um objeto, projetando diretamente no espaço. Método desenvolvido por membros do FRONT para materializar o desenho a mão livre no ambiente.

\footnotetext{
${ }^{20}$ Termo usado para descrever o processo de gravação de movimento e transposição em um modelo digital.
} 


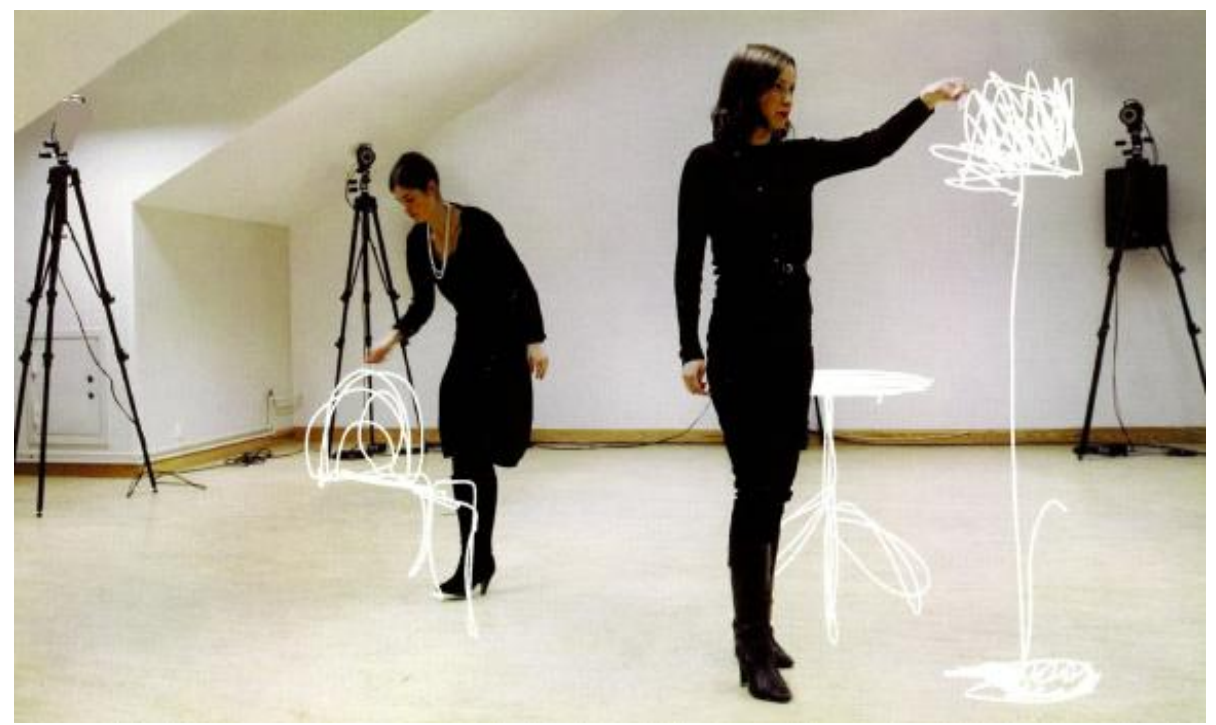

Fonte: Sketch Furniture by FRONT - Sketching The Basics - Roselien and Koos, Bis Publishers, Amsterdam (2011 p. 26).

Outra função da busca por imagem é a identificação de elementos culturais e sociais relacionados ou atribuídos ao produto, considerando sua inserção regional ou de origem, seu processo de produção e também hábitos de consumo. Estes elementos podem ser comunicados em mapas visuais, relacionados a palavras ou termos chaves que permitem caracterizar o foco do projeto, representados através de seleção de imagens em um painel semântico ou mood board (figuras 11 e 12).

Figura 11 - Mapa de imagens relacionadas com o queijo Serrano

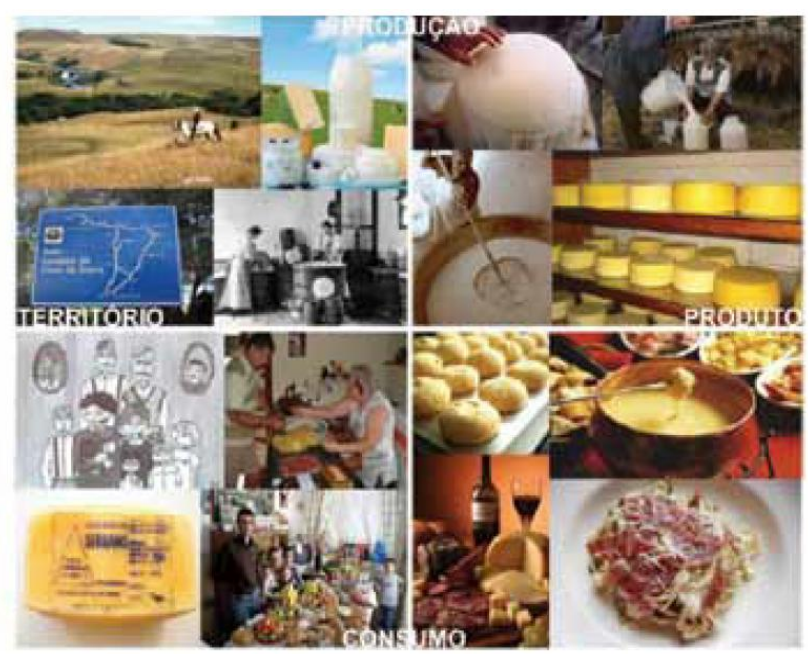

Fonte: Özcan, A. "Agrindustrial Design: 2nd International Product and Service Design Congress and Exhibition on Agricultural Industries-Mediterranean/Food/Design Proceedings." (2016, p. 207) 
Figura 12 - Moodboard de mapeamento de Mercado, a estética e os comentários dos usuários de produtos de limpeza, por Tom Harper

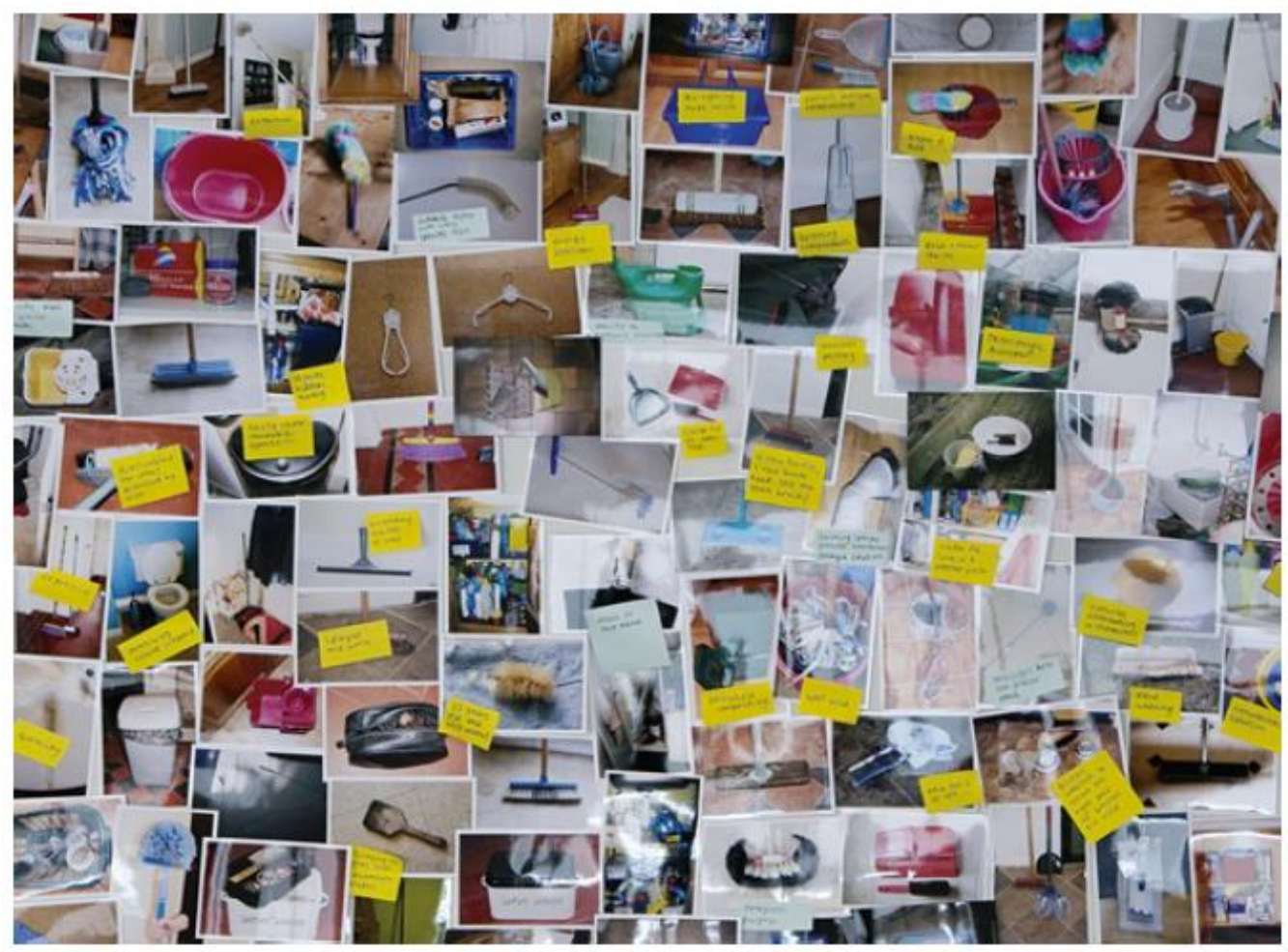

Fonte: Milton, Alex, and Paul Rodgers. Product design. Laurence King (2011, p.223).

O aprendizado da fotografia e do vídeo exige investimentos não apenas financeiros, mas de ferramentas apropriadas e de tempo, que está cada vez mais escasso na formação do designer brasileiro, em favor das análises mercadológicas ou sociais no contexto de projeto (HANNAH, 2015).

Hannah (2015) ressalta ainda que existem hoje e ainda surgirão muitas outras ferramentas e tecnologias que podem ser utilizadas para ampliar as possibilidades de estudo e pesquisa da forma. Deste modo a busca de imagens (fotográficas ou de vídeos) colabora para estabelecer um conjunto de interinfluências criativas, expressivas e técnicas importantes, frisando-se aqui que a busca de soluções do projeto, que se orientam por uma lógica de descoberta que se faz nos momentos iniciais do projeto e que tem por necessidade o acesso à figuração imagética, pode ser baseada na exploração da tecnologia da linguagem fotográfica como forma de retórica da figuração auxiliando no raciocínio projetual e na forma auxiliadora do ver, observar, perceber, pensar, refletir e representar.

É visível que a ferramenta auxilia no processo de análise sistematizado de um grande número de combinações de técnicas possíveis para a representação, 
documentação e análise entre os elementos ou componentes de um produto, identificando possíveis alternativas para se alcançar melhores resultados no projeto.

\subsection{Uso no processo criativo de projeto de produto}

Outra utilização da ferramenta fotográfica no processo criativo se relaciona como auxílio para os estudos dos princípios básicos da natureza (figura 13) e da aplicação dos princípios da biomimética e biônica para gerar alternativas projetuais ou a concepção de novos sistemas para a inovação em projeto.

Figura 13 - A partir de uma referência de uma imagem de borboleta foi gerado o conceito para o desenvolvimento de sketches de uma cadeira.
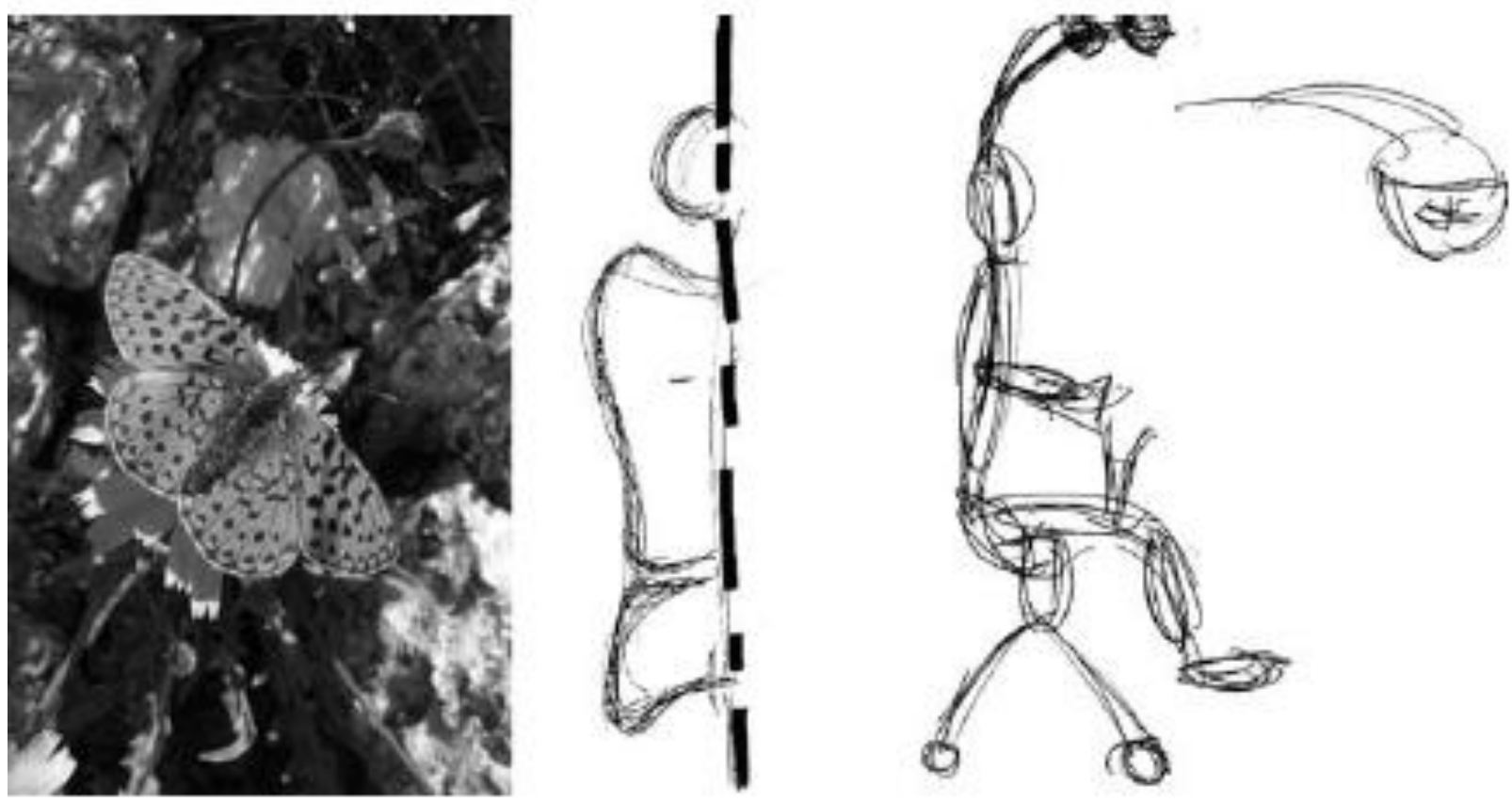

Fonte: Erto, Pasquale, ed. Statistics for innovation. Springer Milan (2009, p. 38).

Outros aspectos sobre aplicação da ferramenta fotográfica é a ideia de mescla de meios (imagem - foto e ilustração - desenho), para proporcionar uma maior estimulação e oportunidade para novas narrativas, como o Chiaroscuro, técnica de ilustração com ênfase na inserção de luz, representada através de desenho claro em regiões escuras de uma imagem. Na figura 14, observa-se que com uma imagem em preto e branco, na qual o sujeito ou objeto estão inseridos na 
sombra, é possível simular e inserir novos elementos através do desenho sobre a imagem.

Figura 14 - Desenvolvimento de fone de ouvido usando mídia mista: fotografia e caneta.
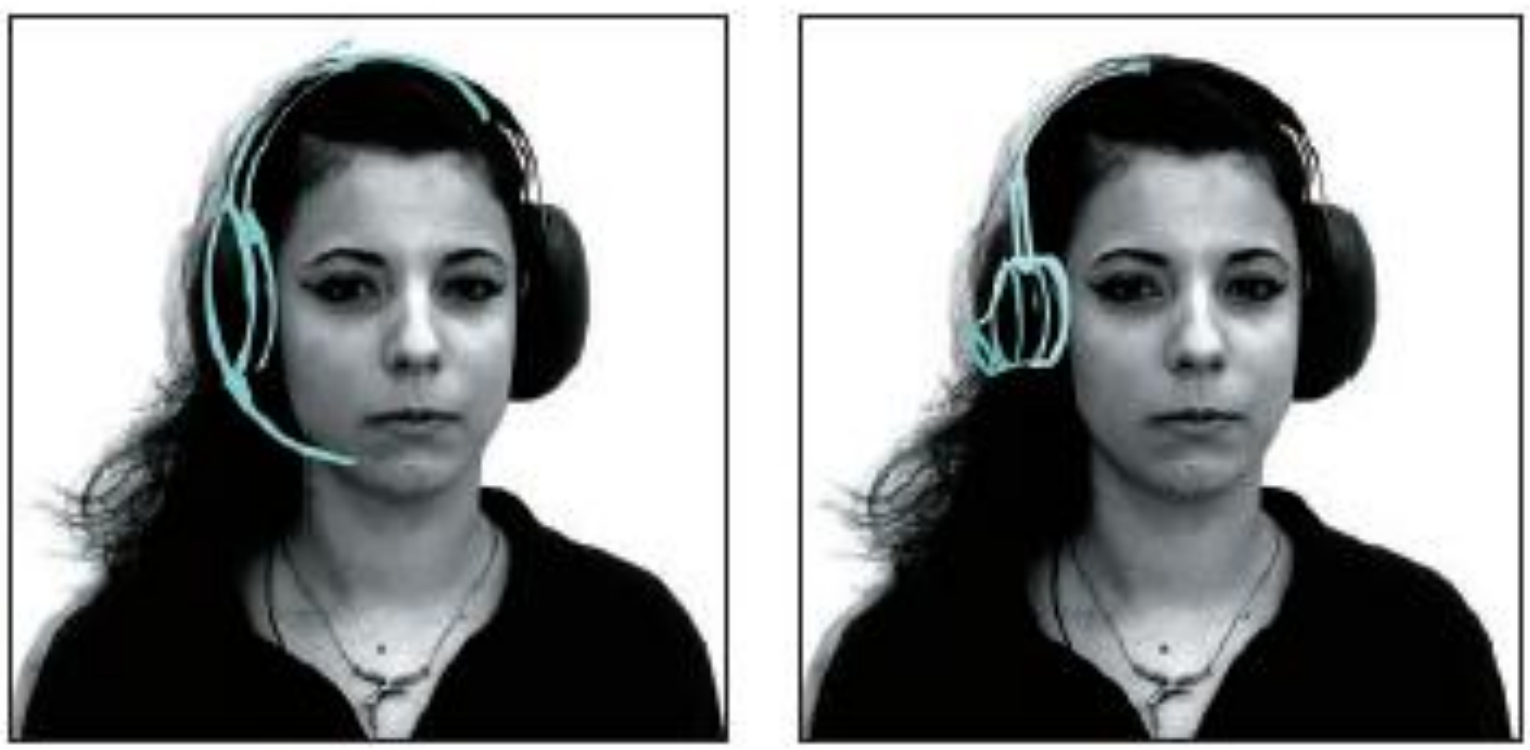

Fonte: BRAMSTON, D. Basics Product Design 01: Idea Searching. Vol. 1. Ava Publishing (2008. p. 17).

A associação da imagem fotográfica com softwares de manipulação, permite novas configurações e estudos com a aplicação do desenho sobre referências selecionadas pelos designers em um sistema interativo.

\subsection{Documentação das fases de processo de projeto}

Outro aspecto de aplicação da ferramenta é a documentação das fases do processo de projeto (figura 15), que é bem difundida para registro dessa etapa de desenvolvimento e/ou futuras modificações, melhorias e técnicas; também é usada também para o registro de patente. 
Figura 15 - A sequência de imagens abaixo apresenta todas as etapas mais importantes no desenvolvimento de uma mesa (Tavalone), com a utilização de resina, grade de ferro, pernas de aglomerado revestidas com resina em várias dimensões.

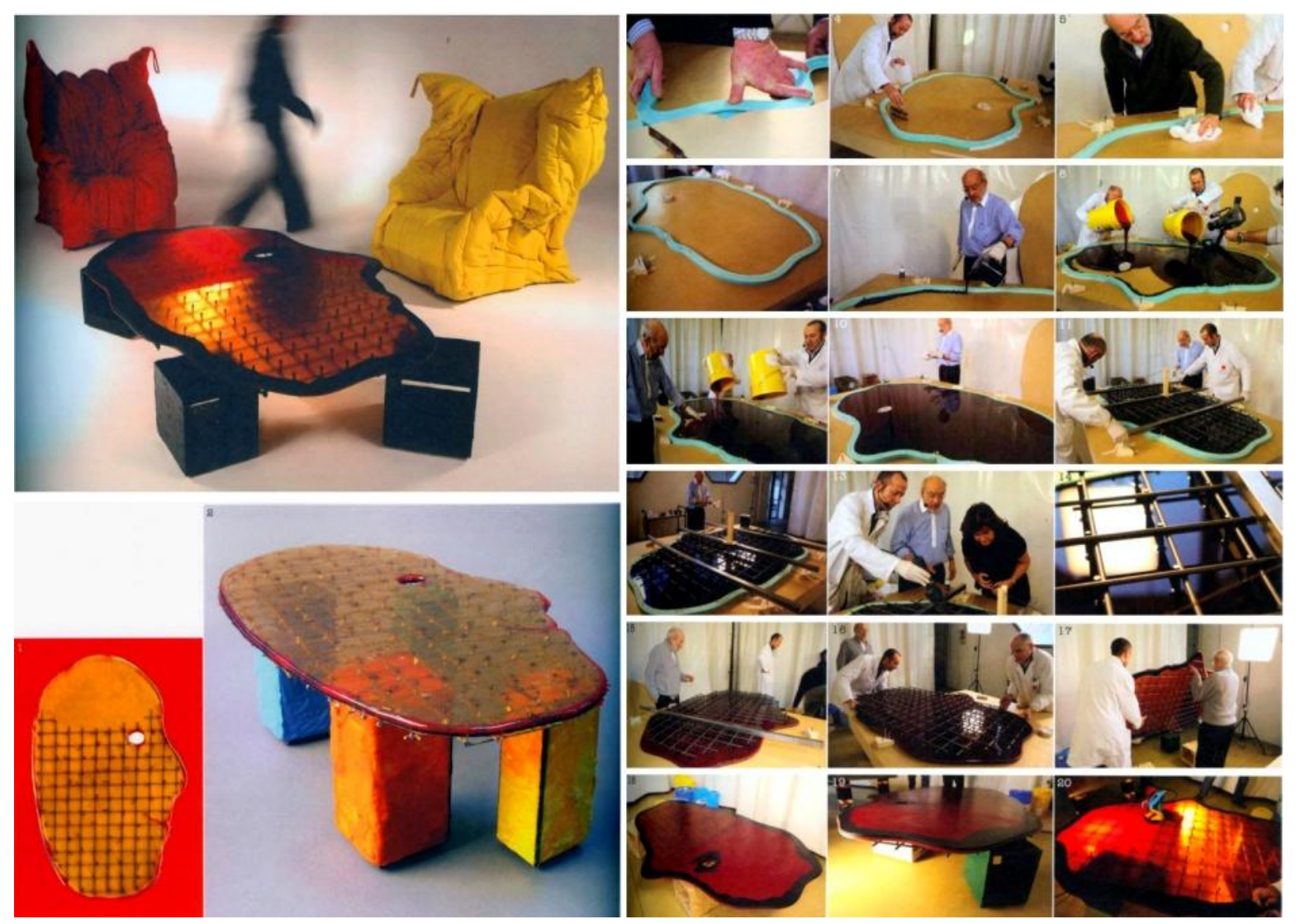

Fonte: Hudson, Jennifer. Process: 50 product designs from concept to manufacture. Laurence King (2008, p.165 a 167).

\subsection{Imagens técnicas}

Além da documentação fiel e expressiva, gerada pela fotografia, a vista (ou visão) explodida do produto é outra possibilidade, mostrando sua composição por peças, componentes mecanismos e sistemas, sendo utilizada para identificar a montagem do produto; estudar as possibilidades de modificações das partes do projeto, e para possibilidades futuras de redesign, que podem ser desenvolvidas por meio da fotografia (figura 16). Também pode ser produzida em softwares tridimensionais ou por meio da ilustração digital. 
Figura 16 - A imagem explodida do fone de ouvido, produto abaixo, apresenta detalhadamente todas as peças que fazem parte do produto.

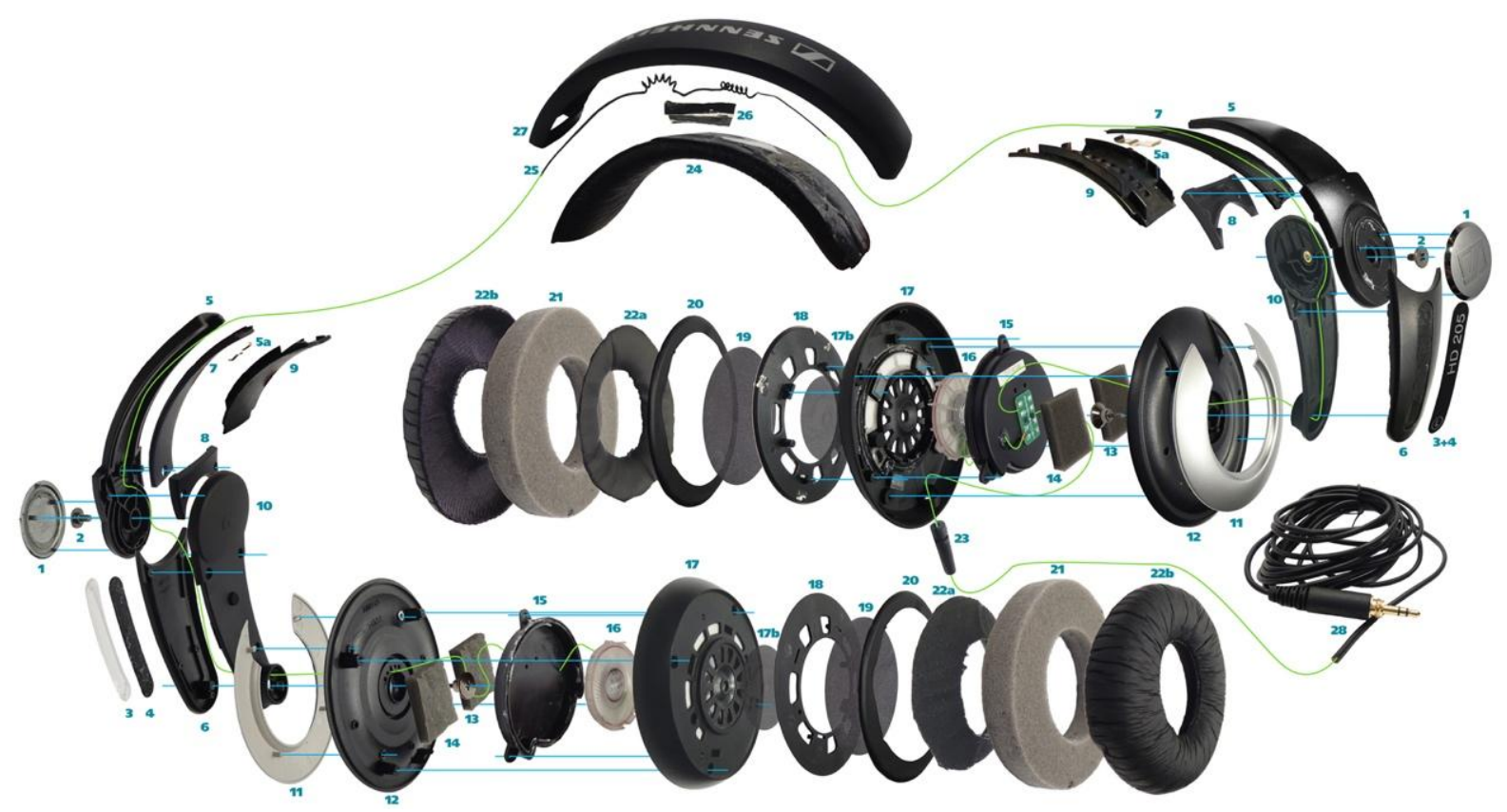

Fonte: goo.gl/mn50kp. Acesso em 07 janeiro de 2018.

\subsection{Análise e pesquisa de uso}

A ferramenta também é utilizada de forma essencial para a formação do designer e para compreensão, análise e pesquisa de situações de como os objetos são utilizados (figura 17), gerando um estudo sobre as relações e hábitos do usuário com o produto em análise, avaliando e prospectando outras maneiras de uso; promovendo adaptações e ajustes formais ou estruturais; resolvendo problemas e gerando soluções; e realçando os potenciais do próprio objeto analisado. Esses registros realizados pelo profissional podem ser gerenciados com o uso de um banco de imagens interno e que seja de fácil acesso para a equipe. 
Figura 17 - Análise sobre suporte de objetos na bicicleta, fotografadas por James Bartlett, apresentando as improvisações/soluções.
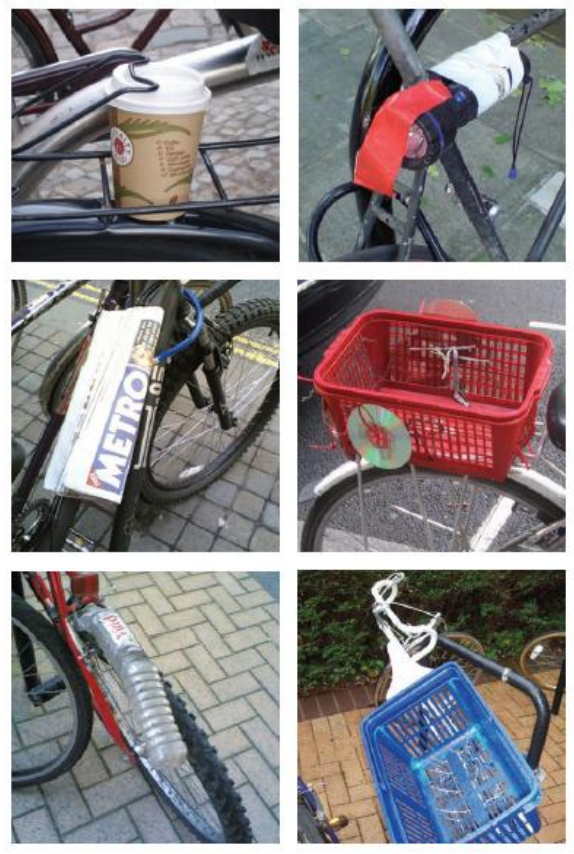

Fonte: PARSONS, Tim. Thinking: Objects: Contemporary approaches to product design. AVA publishing (2009, p. 40 e 41).

A análise de situação de uso do produto também pode ser realizada em estudos ergonômicos, onde o usuário é registrado na interação com o produto ao longo de um período de uso, sendo esse tempo estipulado pelo designer ou equipe, para a investigação de características definidas anteriormente, seguindo metodologias estabelecidas para estudos de casos ergonômicos, que podem se rebater na configuração e na composição do produto (figura 18).

Figura 18 - Três opções posturais da cadeira: (a) ereto (b) reclinado e (c) inclinação para frente.

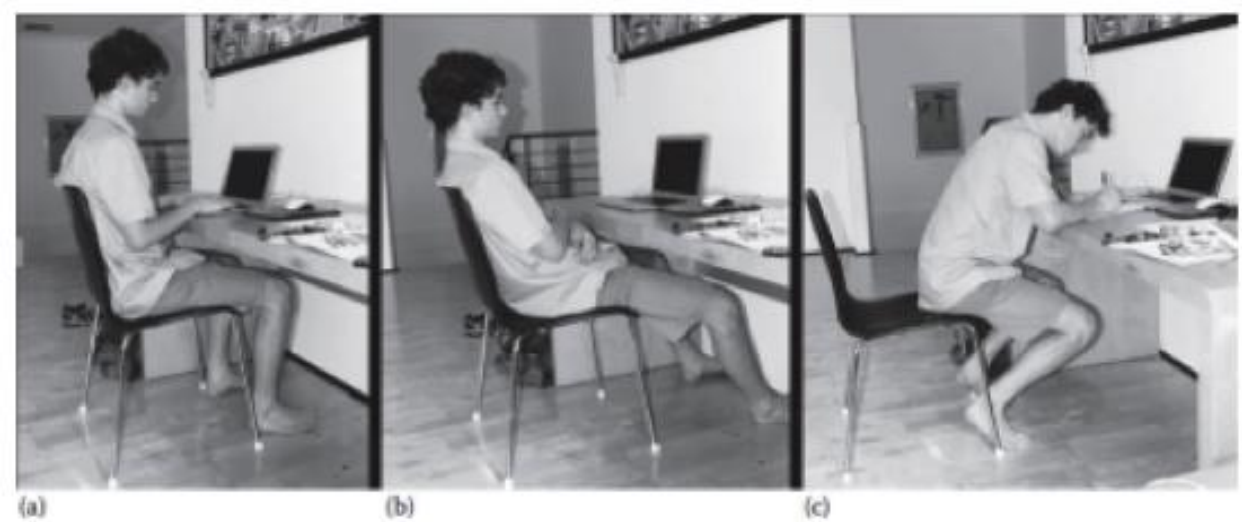

Fonte: HEDGE, Alan (Ed.). Ergonomic Workplace Design for Health, Wellness, and Productivity. CRC Press (2016, p.209). 
Para realizar o registro adequado é necessário ser aplicada a captura dos planos anatômicos (figura 19), que são planos hipotéticos usados para dividir o corpo humano de forma a descrever a localização de estruturas ou a direção dos movimentos. $\mathrm{Na}$ anatomia humana e animal são usados três planos principais:

- plano sagital (lateral direta e esquerda) - plano paralelo à linha sagital, divide o corpo nas porções esquerda e direta;

- plano frontal - ou coronal divide o corpo nas porções anterior frente e posterior costas;

- plano transversal (superior ou inferior) - divide o corpo nas porções cranial superior e caudal inferior.

Figura 19 - Planos anatômicos.

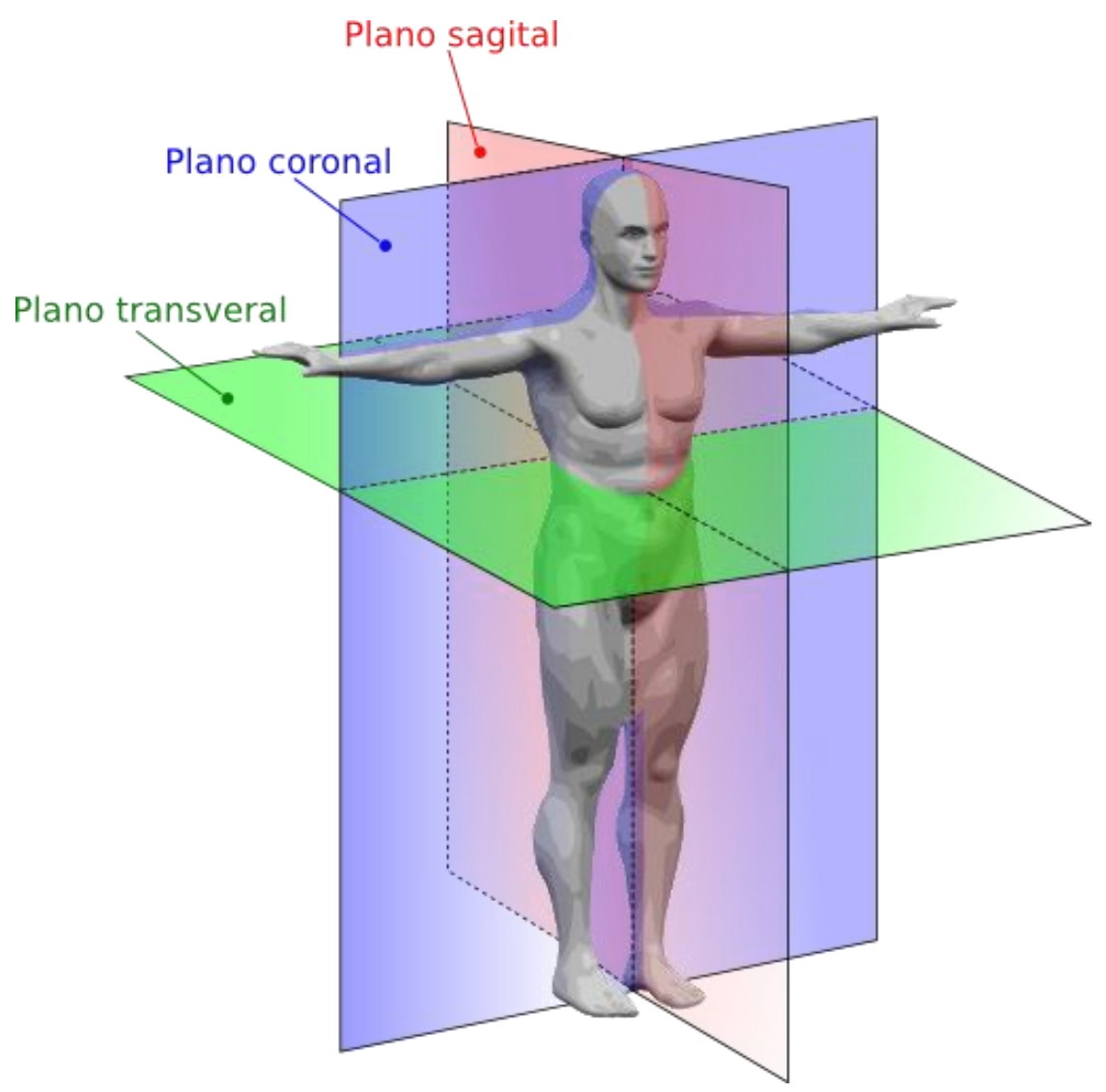

Fonte: https://goo.gl/qsNt3T. Acesso em: 17 de fevereiro de 2018. 
Deste modo, as referências ósseas e articulares, planos, eixos, regiões corporais, tudo pode ser avaliado pelo registro seja ele por imagens ou vídeo.

Um dos aspectos escassos na literatura está nas questões de uso da fotografia e do vídeo para elaboração de laudo técnico, tanto de instalação quanto de manuseio (manual técnico de instalação e operação), de riscos de operação e perícia do produto, além de segurança do trabalhador.

\subsection{Análises através do vídeo}

Com a evolução dos equipamentos de vídeo e softwares, as possibilidades de monitoramento e captura em vídeo tornaram-se uma ferramenta viável para a ergonomia, no registro da interação do usuário com o produto, gerando uma grande gama de probabilidades de análises e registro.

A avaliação de novos produtos requer grande conhecimento da interação humana, incluindo a operação e as vulnerabilidades de todo o sistema. O uso do vídeo aumenta a capacidade de coletar dados mais detalhados sobre as atividades durante a interação do usuário com o sistema do objeto e o ambiente, possibilitando verificar possíveis desempenhos de uma tarefa ou ação.

Com uma ou mais câmeras (figura 20) trabalhando de forma sincronizada, é possível registrar as diversas categorias dessa interação ou o desempenho de uma tarefa e analisá-las em softwares apropriados, identificando o tempo de duração de cada ação, sendo que o registro pode ser acionado automaticamente por detecção de movimento.

Na figura 20 abaixo, pode ser vista uma janela de controle de captura em vídeo, onde é possível realizar investigações de categorias de interação para gravação e armazenamento em formato digital. Na sequência, figura 21, a recomendação de trabalho. 
Figura 20 - Janela de controle para realizar a captura.

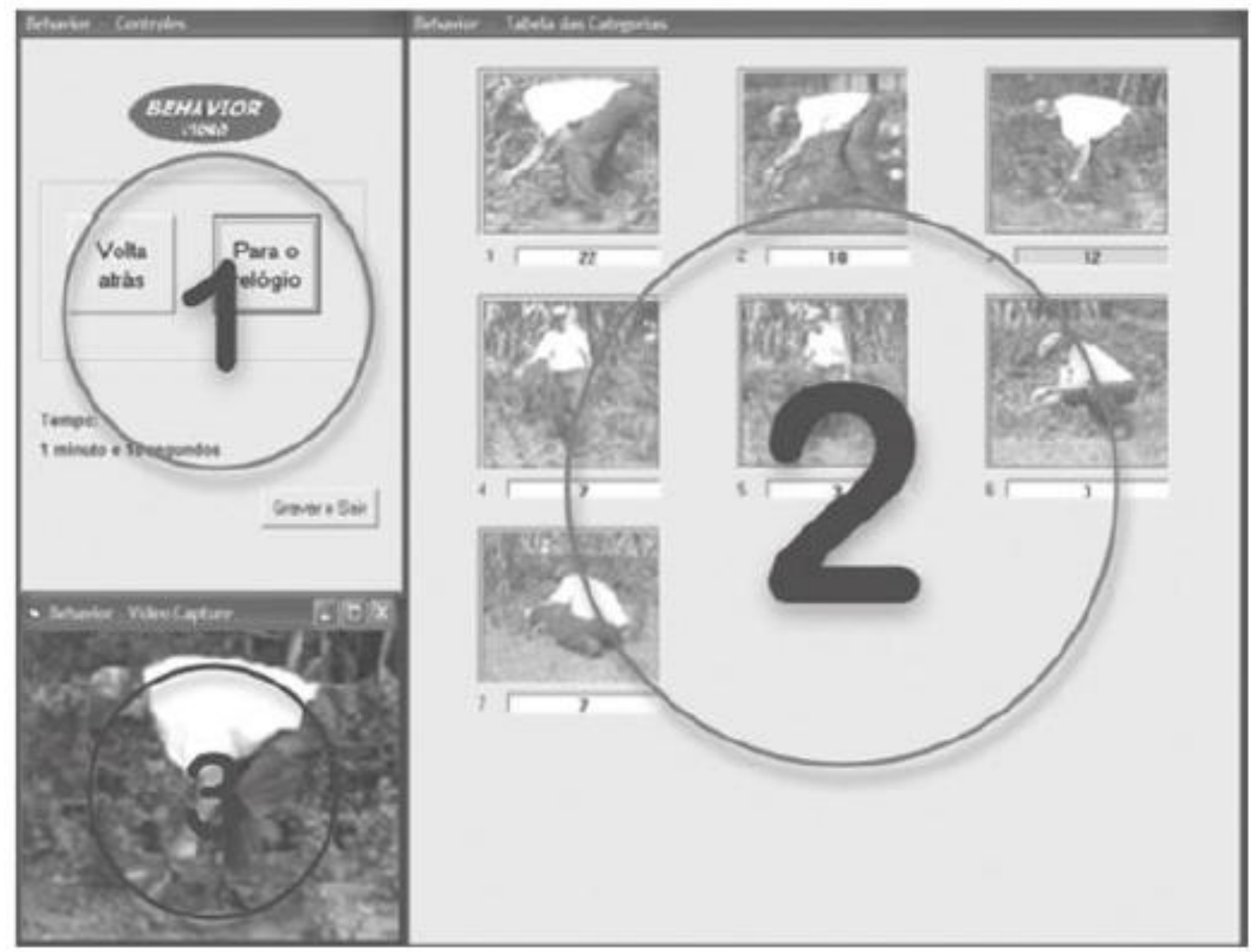

Fonte: Human Factors and Ergonomics in Consumer Product Design: Methods and Techniques (2011, p. 281).

Figura 21 - O uso de dois monitores é recomendado, principalmente para o registro das categorias de interação.
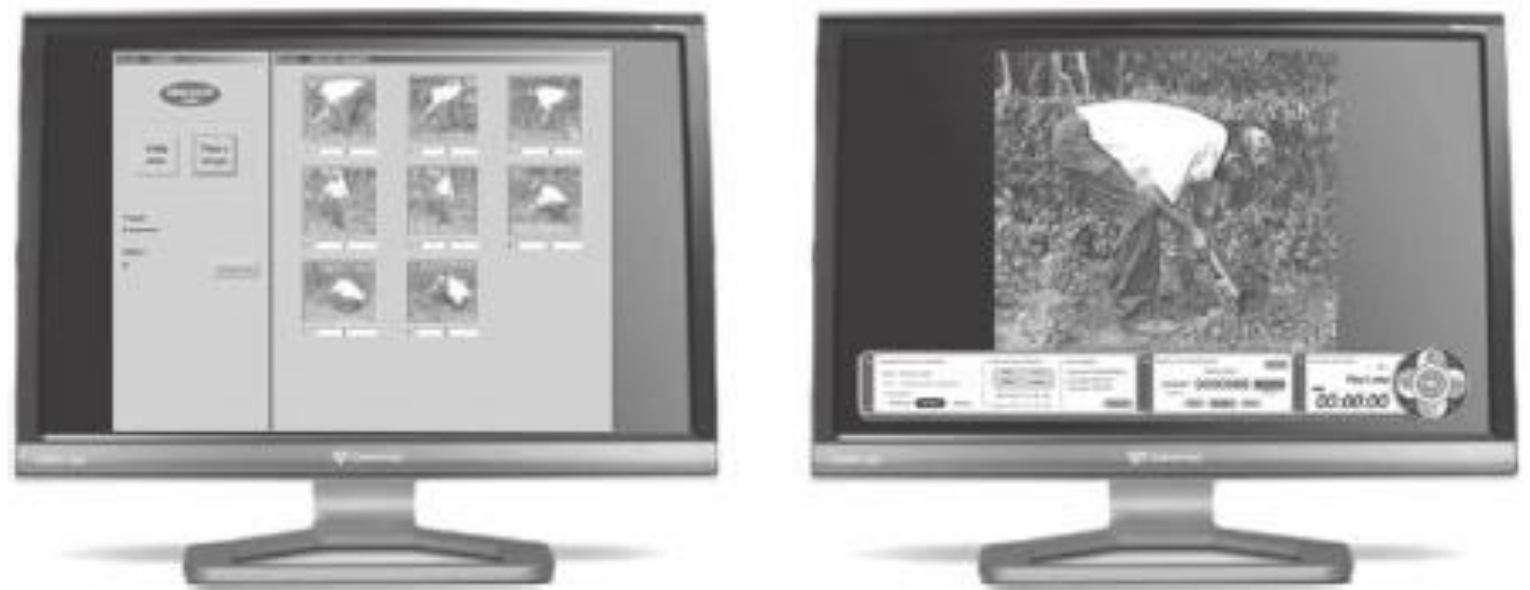

Fonte: Human Factors and Ergonomics in Consumer Product Design: Methods and Techniques (2011, p. 281). 
O uso de softwares digitais associado à captura de imagens em vídeo, traz a possibilidade de registro de ações e intervenções realizadas no próprio software, sendo que é possível gravar e capturar a tela a cada modificação realizada pelo indivíduo, para a avaliação de seu comportamento.

\subsection{Análise e prospecção de uso}

A utilização de técnicas para ilustrar situações simuladas de uso do produto em escala real por associação de imagens fotográficas e softwares específicos, constitui recurso relevante para a prospecção e a comunicação de ideias e interações homem - produtos, utilizando composições através de sobreposição de planos recortados de maneira digital (montagem), com uso de softwares específicos (figura 22 e 23) para compor uma imagem bidimensional ou tridimensional.

Figura 22 - Imagem de totem digital realizada em estúdio fotográfico com inserção de figura humana em software de tratamento digital.

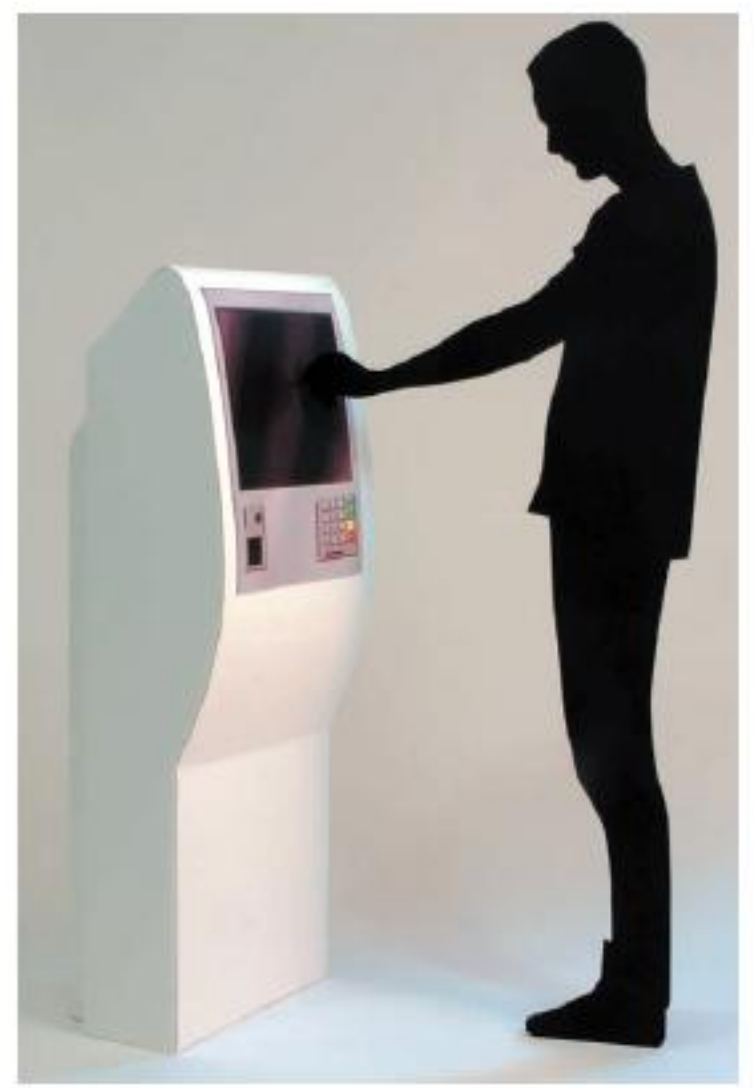

Fonte: Hallgrimsson, Bjarki. Prototyping and modelmaking for product design. Laurence King (2012, p.103). 
Figura 23 - Totem digital e figura humana inserida em ambiente de possível instalação do produto.

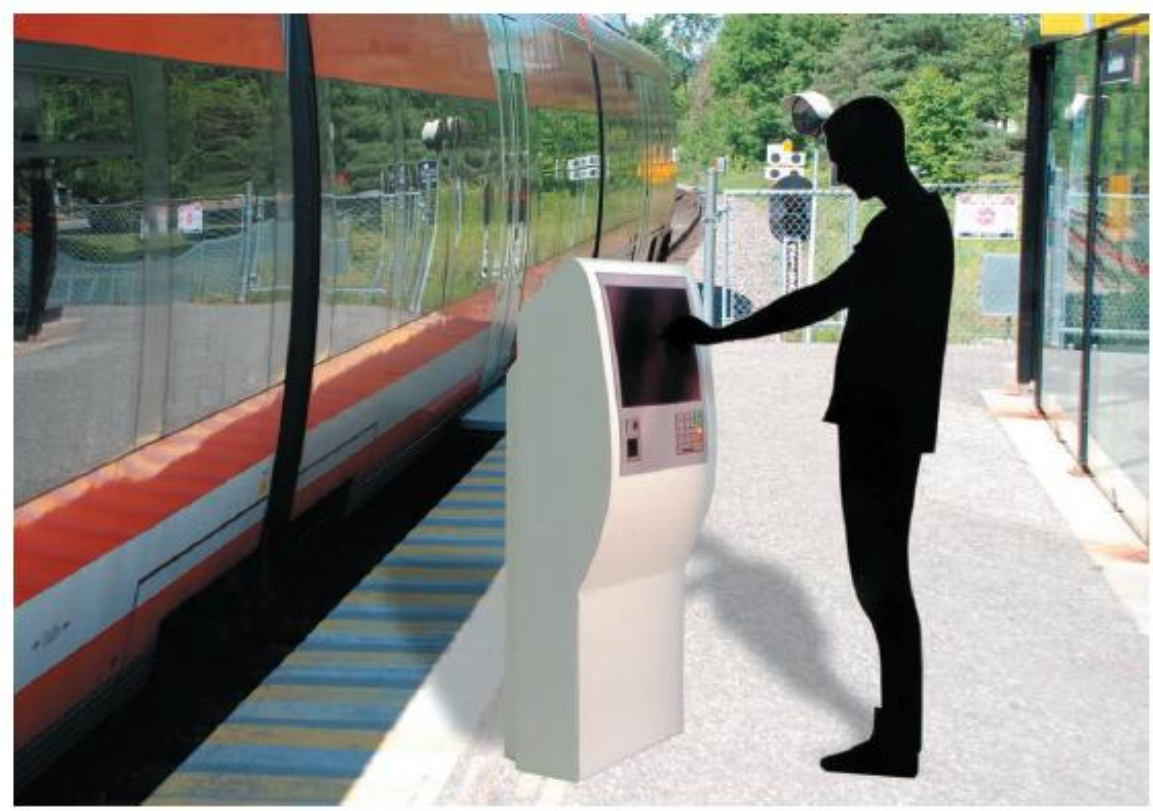

Fonte: Hallgrimsson, Bjarki. Prototyping and modelmaking for product design. Laurence King (2012, p. 103).

\subsection{Recursos recentes - Introdução}

As tecnologias computacionais e os meios visuais de captura recentes oferecem instrumentos que permitem explorar a segunda, terceira e a quarta dimensões, tempo e movimento, proporcionando assim, novas oportunidades não apenas criativas, mas de verificação com maior complexidade. Considera-se que os recursos técnicos fotográficos e de vídeo não devem ser desenvolvidos apenas para destacar as qualidades visuais dos objetos, mas auxiliar o aluno a adquirir uma compreensão da forma, da constituição material dos produtos e da sua inserção no espaço. Algumas das técnicas recentes e menos difundidas, mas igualmente importantes para o conhecimento e a formação em Design são apresentadas abaixo.

\subsubsection{Termográfia infravermelha}

A termografia é um método de medição passivo, realizado por registro fotográfico de padrões de calor emitidos por um determinado corpo, obtido a partir de seu recurso técnico, o termograma. A ferramenta utilizada para realizar a captura é denominada "termo câmera", capaz de detectar o infravermelho em uma escala do espectro eletromagnético (aproximadamente 900-14,000 nanômetros ou 0,9-14 $\mu \mathrm{m}$ ), 
sendo constituídos de sensores de radiação, que amplificam os sinais através de um processador.

A ferramenta amplia a visão perante os objetos e a relação com eles, permitindo uma prospecção aprofundada e interior da matéria em estudo, que é representada por um espectro de cores que exprime variações de temperatura dos materiais, detalhes estes, imperceptíveis visualmente.

O processo funciona em sentido inverso ao da captura de imagem fotográfica tradicional, que necessita de raios de luz visíveis refletidos sobre o objeto. $\mathrm{Na}$ termografia, a imagem registrada constitui parte da radiação térmica infravermelha, emitida do movimento vibratório das moléculas que compõem os materiais.

As imagens térmicas, ou termogramas, representam a quantidade de energia infravermelha emitida, transmitida e refletida por um objeto, uma vez que estas ainda são latentes e não detectadas a olho nu, necessitando desses aparatos e recursos para se transformar em imagens visíveis. As informações obtidas pelo termograma contribuem para uma melhor interpretação de variáveis térmicas dos materiais e corpos, colaborando para verificar outros parâmetros relacionais entre objetos usuários, como a sensibilidade de contato realizado.

O termograma permite ainda, a manipulação da imagem posterior à captura da mesma, que é executada através de softwares que geram diversas informações gráficas e dados (figura 24 e 25).

Figura 24 - Interface do software Flir tools, com diversas capturas realizadas para análise.

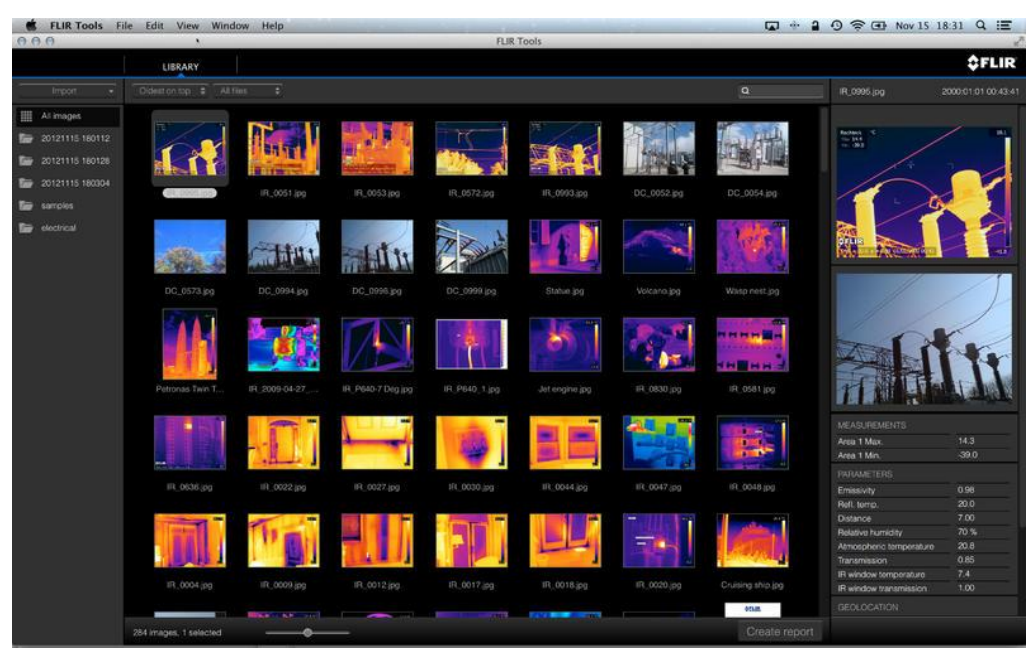

Fonte: http://goo.gl/dpsCbW. Acesso em: 01 de maio 2015. 
Figura 25 - Imagem térmica sofrendo possíveis analises através do software Flir tools.

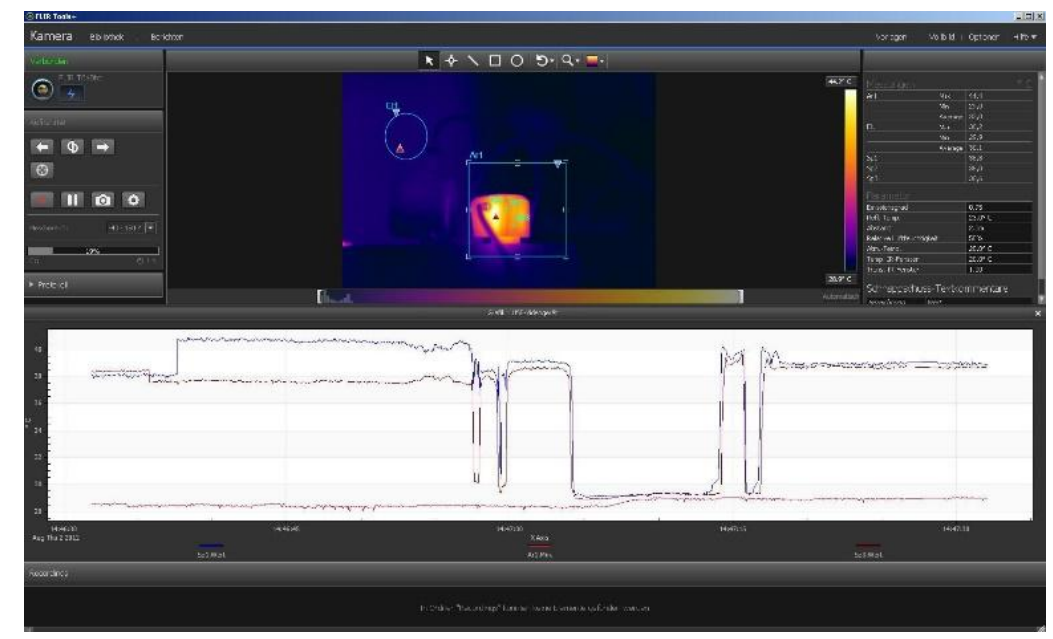

Fonte: http://goo.gl/Krq54j. Acesso em: 01 de maio 2015.

A compreensão e exploração das diversas possibilidades posteriores à captura das imagens geradas por estes dispositivos, também podem auxiliar na compreensão ampliada dos aspectos de significação, antes não observados visualmente.

As aplicações da termografia em projetos têm se mostrado crescentes, devido ao barateamento da tecnologia empregada nas ferramentas existentes no mercado, podendo ser empregada nos estudos em Design de Produtos, bem como aplicadas no âmbito do projeto.

Explorações na área da termografia podem auxiliar na escolha de ferramentas durante a construção de novos produtos, uma vez que através deste processo, é possível obter dados sobre a influência do calor emitido pelo objeto no ambiente e a melhor eficiência no aquecimento ou resfriamento, verificando in loco, o comportamento de materiais de uso contínuo, detecção de defeitos, condutividade térmica e análise de percepção tátil.

Nas diversas aplicações da ferramenta atualmente, verifica-se sua importância em gerar informações sobre corpo humano na interface do contato com os objetos por transferência de calor; na avaliação das propriedades de um material; para identificação de pontos de atrito na geração de calor entre partes dos materiais empregados nos objetos, por exemplo.

Como exemplo de sua aplicação, de acordo com Dischinger (2009), uma das variáveis da pesquisa foi a medição perceptiva através da variação térmica para 
analisar a condutividade térmica dos materiais empregados em produtos, para obtenção de qualidades táteis. Verificando a distribuição de temperatura, a pesquisadora empregou o uso da técnica termográfica para avaliar diversos corposde-prova com diferentes texturas e diferentes matérias, que foram estudadas individualmente.

Realizou-se a transferência de calor corporal (dedo indicador, pressionado por dez segundos sobre o corpo-de-prova) para a peça, obtendo assim o registro termográfico em dois momentos, durante o contato com a peça e logo após a retirada do dedo, verificando variações com relação aos materiais dos corpos-deprova. Segundo a observação das imagens obtidas pela pesquisadora, identifica-se que o corpo-de-prova em metal (figura 26) não concentrou o calor obtido através do toque, mas o corpo-de-prova em silicone (figura 27) apresenta uma região nítida de foco.

Figura 26 - Termografia do corpo-de-prova em metal.

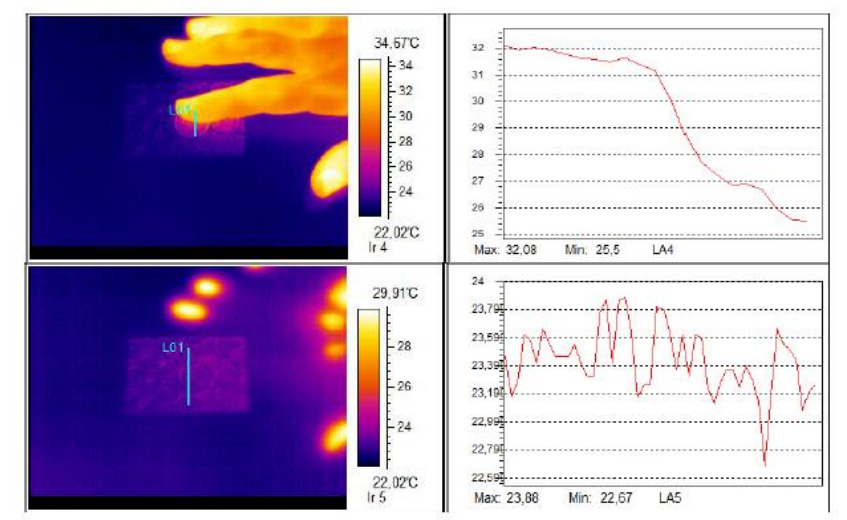

Fonte: DISCHINGER (2009, p. 85).

Figura 27 - Termografia do corpo-de-prova em silicone.

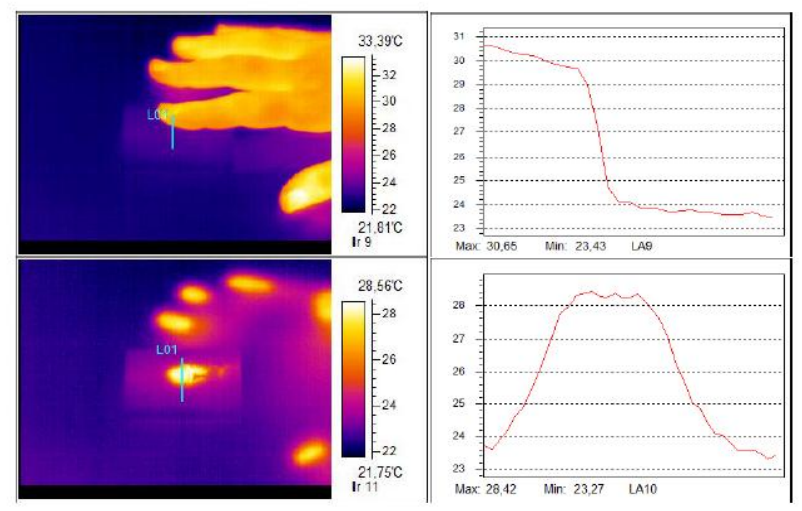

Fonte: DISCHINGER (2009, p. 86). 
As análises identificaram uma variação de retenção de calor resultante do contato, revelando que os corpos-de-prova com maior retenção de calor possuem menor condutividade térmica.

\subsubsection{Fotogrametria digital}

Com a evolução do processamento e da visão computacional, as possibilidades da fotogrametria digital ampliaram-se, aplicando algoritmos mais sofisticados empregados em softwares de extração e processamento de dados, que proporcionaram a expansão de suas possibilidades de captura de dados de objetos e de pessoas, e que se apresenta como aporte técnico para análises no processo de projetos em Design de Produto.

Desde 1990 a fotogrametria digital desenvolveu-se rapidamente e esse conceito evoluiu radicalmente, integrado ás ciências da computação, incluindo o processamento de imagens, reconhecimento de padrões e visão computacional para realizar operações semiautomáticas, automáticas (onde o operador entra com inputs) e completamente automáticas (HEIPKE, 2001).

Deste modo, a fotogrametria é caracterizada presentemente pelo uso de sistema e interface digital em suas diversas fases de processamento, sendo que permite inúmeras possibilidades de geração de produtos fotogramétricos, desde a captura até o tratamento das imagens. Para a aplicação desta técnica é necessário o domínio da ferramenta fotográfica e da fundamentação teórica da fotogrametria, consequentemente os recursos do software utilizado, tendo por base a possibilidade de aplicação, bem como de todo o processo das etapas a serem desenvolvidas para a geração do resultado desejado.

Silva (2015) observa que apesar da fotogrametria se basear em princípios geométricos simples (interseção de retas) e pela fisiologia da visão (estereoscopia ${ }^{21}$ ), as medições com precisão nas fotografias envolvem na fase atual, métodos digitais avançados. Deste modo, qualquer objeto tridimensional que seja visível em ambas as vistas de um par estereoscópico, pode ser reconstituído tridimensionalmente (KASSER; EGELS, 2002). A reconstituição é realizada pela determinação das coordenadas obtidas no espaço tridimensional e são obtidas por triangulação (figura

\footnotetext{
${ }^{21}$ Consiste no registro de duas vistas de uma cena, que dá a imagem plana a impressão de relevo, devido a captura de perspectivas diferentes. A estereoscopia gera a percepção de profundidade que é facilmente realizada devida a utilização simultânea dos dois olhos ou duas objetivas ou ainda a junção de duas imagens capturadas com vistas diferentes.
} 
28), adotando como base a projeção de pontos no espaço sobre planos da imagem bidimensional capturada (CUYPERS et al., 2009).

Figura 28 - Princípio de triangulação fotométrica.

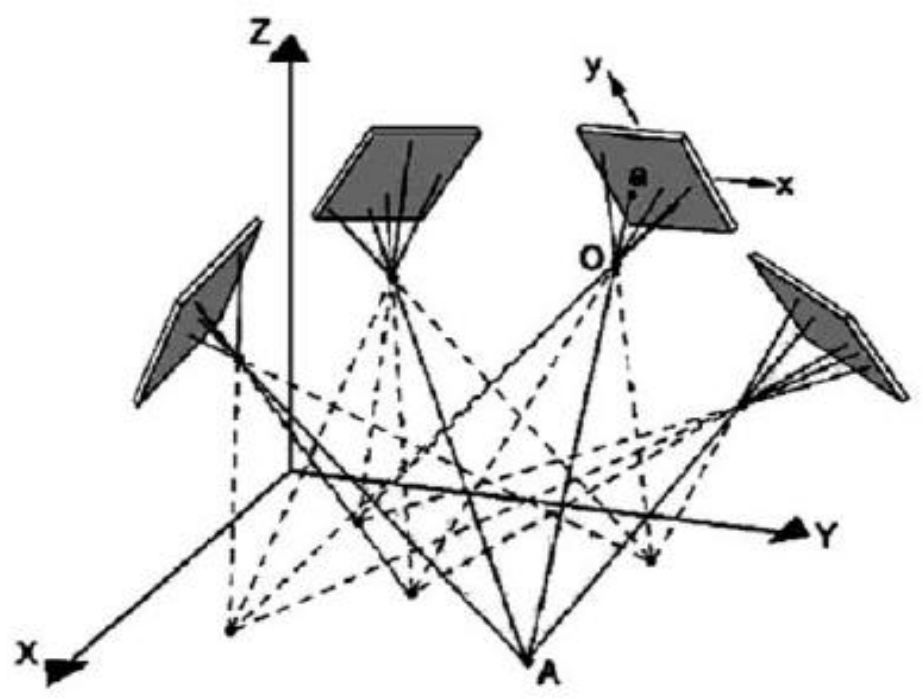

Fonte: CUYPERS et al. (2009).

Porém, é necessário mais de dois pontos de vistas para reconstrução completa de um objeto (KASSER; EGELS, 2002). O mesmo autor expõe duas possíveis estratégias para a aquisição de imagens de um objeto, em configurações convergentes e paralelas (figura 29), mas que podem ser modificadas conforme 0 local e objeto a ser capturado.

Figura 29 - Estratégias para aquisição de conjuntos de imagens
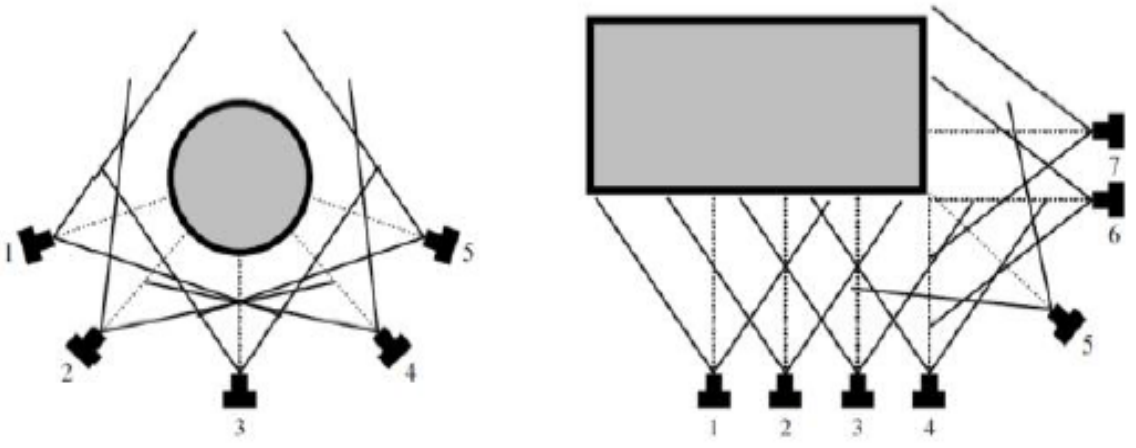

Fonte: KASSER; EGELS (2002). 
Dantas et al. (2016) enfatiza que a obtenção de melhores resultados com esta ferramenta depende da qualidade das imagens adquiridas com a necessidade da aplicação de alguns pré-requisitos gerais da fotografia como iluminação, estabilização, tamanho e especificações do sensor, requisitos que auxiliam no tratamento para o produto fotogramétrico.

A técnica pode ser realizada através da captura de imagens por câmeras digitais de alta ou baixa definição (influência na qualidade e possibilidades de tratamento), mas consideradas com baixo custo frente à aquisição de produtos fotogramétricos, onde softwares, a partir de processamentos de calibração e ajustes, dispensam o emprego de câmeras métricas ou semimétricas, simplificando o processo e o tratamento dos dados obtidos.

Para realizar a captura para o tratamento tridimensional deve-se obter duas ou mais imagens (figura 30), a partir de ângulos diferentes e que, posteriormente, serão unificadas através de processamento digital, relacionando pontos comuns identificados nos pixels de cada imagem, através de cálculos desenvolvidos por cada software (figura 31). Deste modo, cada software tem a sua característica e função específica, de modo que o estudo ideal para determinado tipo de projeto deve ser realizado através de uma combinação de técnicas e softwares por terem especificidades e peculiaridades que atendam necessidades distintas.

Figura 30 -: Imagens carregadas no sistema VisualSFM.

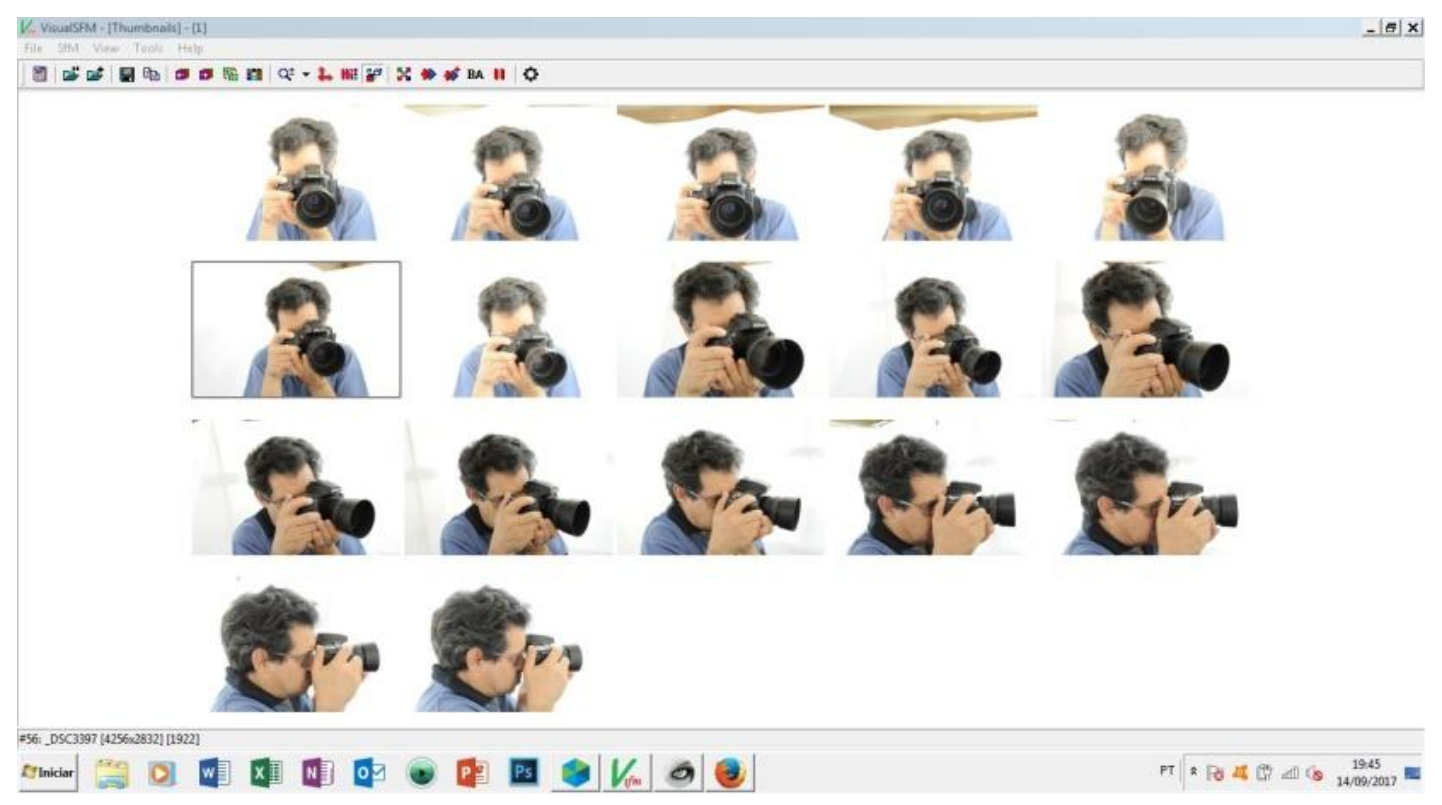

Fonte: Captura de tela gerado pelo autor, 2017. 
Figura 31 - Restituição fotogramétrica - nuvem de pontos.

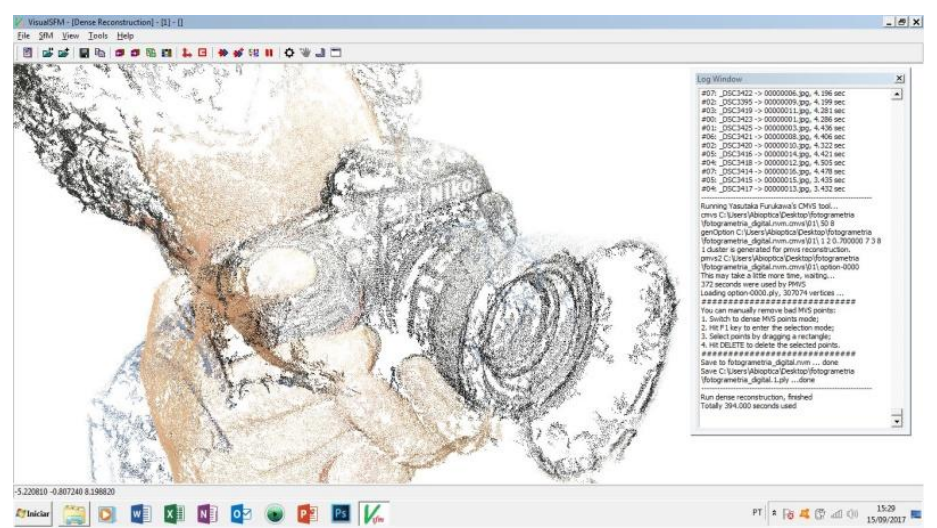

Fonte: Captura de tela gerada pelo autor, 2017.

Assim, deve-se levar em consideração para o registro, regras específicas na aquisição de imagens para obtenção de resultados mais precisos. Notadamente as que proporcionam a redução de tempo e mão de obra para um melhor processamento através de software de tratamento. O processo de captura da imagem requer uma qualificação do usuário na utilização da ferramenta fotográfica, uma vez que a primeira etapa de captura é feita de maneira manual.

Desta forma, pode-se considerar que estudos de produtos e componentes físicos existentes através de tecnologias de fotogrametria digital tridimensionais são imprescindíveis (figura 32) no estudo de situações de uso extremas e de projetos ou desempenho de objetos de alta complexidade tecnológica, por exemplo.

Figura 32 - Edição e correção da nuvem de pontos - MeshLab.

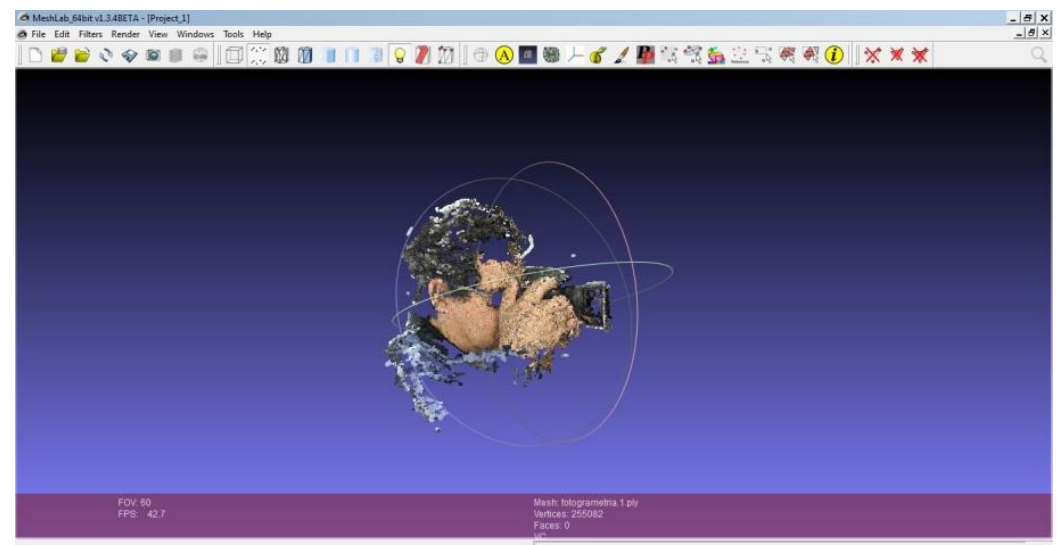

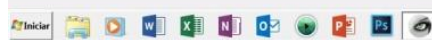

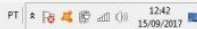

Fonte: Captura de tela gerado pelo autor, 2017. 
Trata-se, portanto, de uma possibilidade de baixo custo a serviço do projeto de produtos, servindo para realizar medições, analisar superfícies, fabricar moldes, ou ainda ser aplicada com fidelidade ao desenvolvimento de produtos inovadores (SILVA, 2011). Pode-se ainda, destacar e ampliar estas possibilidades, incluindo o redesenho e analise de situações de uso, bem como o uso da ferramenta e de procedimentos atualizados dentro do ensino de Design.

\subsubsection{Biofotogrametria}

Inúmeras possibilidades de exploração e experimentação em estudos, propostas, projetos de produtos e também analises sobre objetos, emergem da relação do movimento entre o controle e o gesto (RICIERI, 2008). Assim, a biomecânica deve ser considerada como um instrumento significativo e importante nestes projetos, pois estabelece interações (ou verifica a falta delas) entre o trabalho, as ações e atividades com o homem, no tocante aos movimentos de músculos e ossos envolvidos, e suas consequências no uso.

A Biofotogrametria surgiu no contexto da instrumentação para análise biomecânica, como uma variação da fotogrametria bidimensional (2D) (RICIERI, 2008), priorizando as dificuldades da análise de movimento, e a aplicação em medições de diferentes tipos de movimentos (WHITERS, 2002; LODOVICO et al., 2003; PANTANALI, 2004; RICIERI, 2004a), constituindo instrumento para quantificar medidas, desempenhando papel útil em conceitos e elaboração de teorias sobre o movimento corporal humano (AMADIO et al., 1999).

No entanto, é uma ferramenta utilizada em documentação médica e de saúde (técnicas avançadas de ressonância magnética e tomografia) e que vem ampliando as possibilidades de formas de análises ergonômicas, com possibilidades de análises em situações de uso ou atividades, razão que faz com que a Biofotogrametria seja um instrumento de alto potencial voltado para estudos de biomecânica e avaliação postural (figura 33 e 34). 
Figura. 33 e 34 - Captura e análise digital, com agachamento (inicial e final) - Plano Sagital.
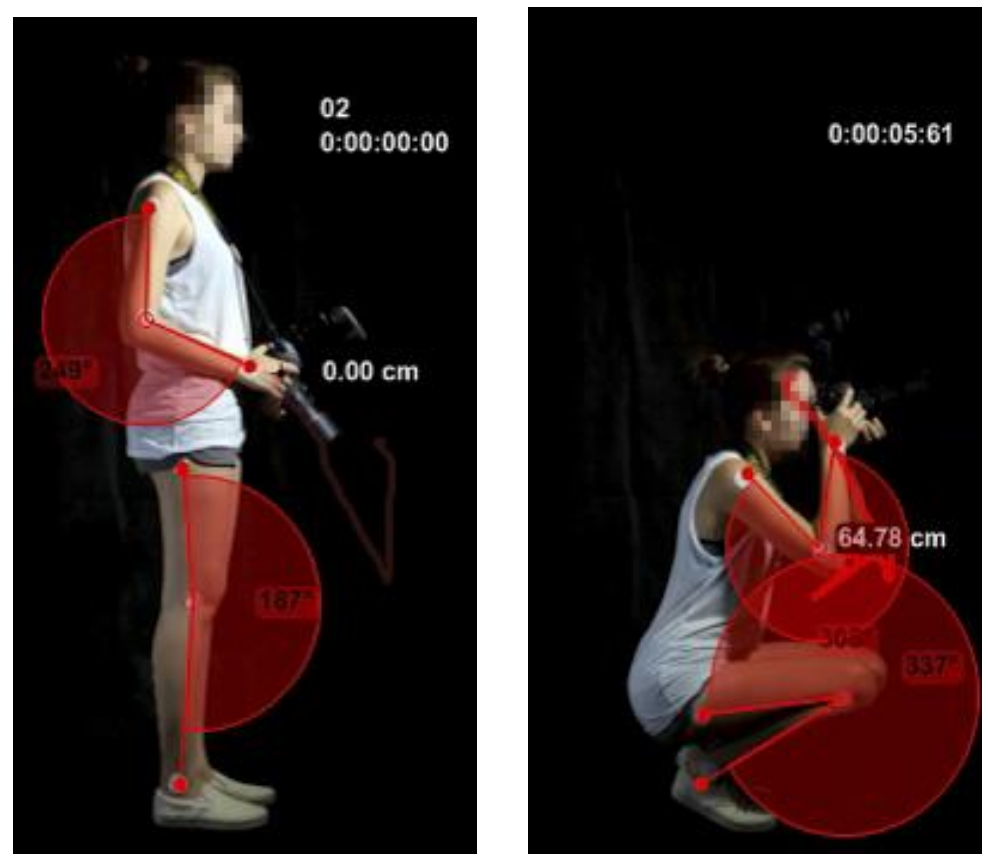

Fonte: Elaborado pelo autor, 2017.

É um processo reprodutível, de alta qualidade, baixo custo, aplicável a ciência, a educação e a prática profissional com confiabilidade (RICIERI, 2008). Ribeiro et al. (2005) define a técnica como relativamente simples, fácil e objetiva, com baixo custo, facilidade de fotointerpretação ${ }^{22} \mathrm{com}$ alta precisão e a reprodutibilidade dos resultados, possibilitando 0 arquivamento e acesso aos registros de imagens, compondo vantagens que justificam sua ampla utilização.

Tendo à disposição recursos computacionais (figura 35), notadamente o processamento de informações complexas e a economia de tempo no trabalho com interfaces mais ágeis e que aceitam registros em movimento (vídeo/filme) para se proceder a análises, o desenvolvimento da Biofotogrametria foi incentivado, contando com um meio propicio ao processamento sistematizado de análise 2D, cujas etapas e condutas são operadas de modo manual ou automatizadas, representando aspectos quantitativos de um movimento.

\footnotetext{
${ }^{22}$ É a extração de informação qualitativa dos objetos fotografados por análise visual humana.
} 
Figura 35 - interface do software Kinovea para análise de situações capturadas em vídeo.

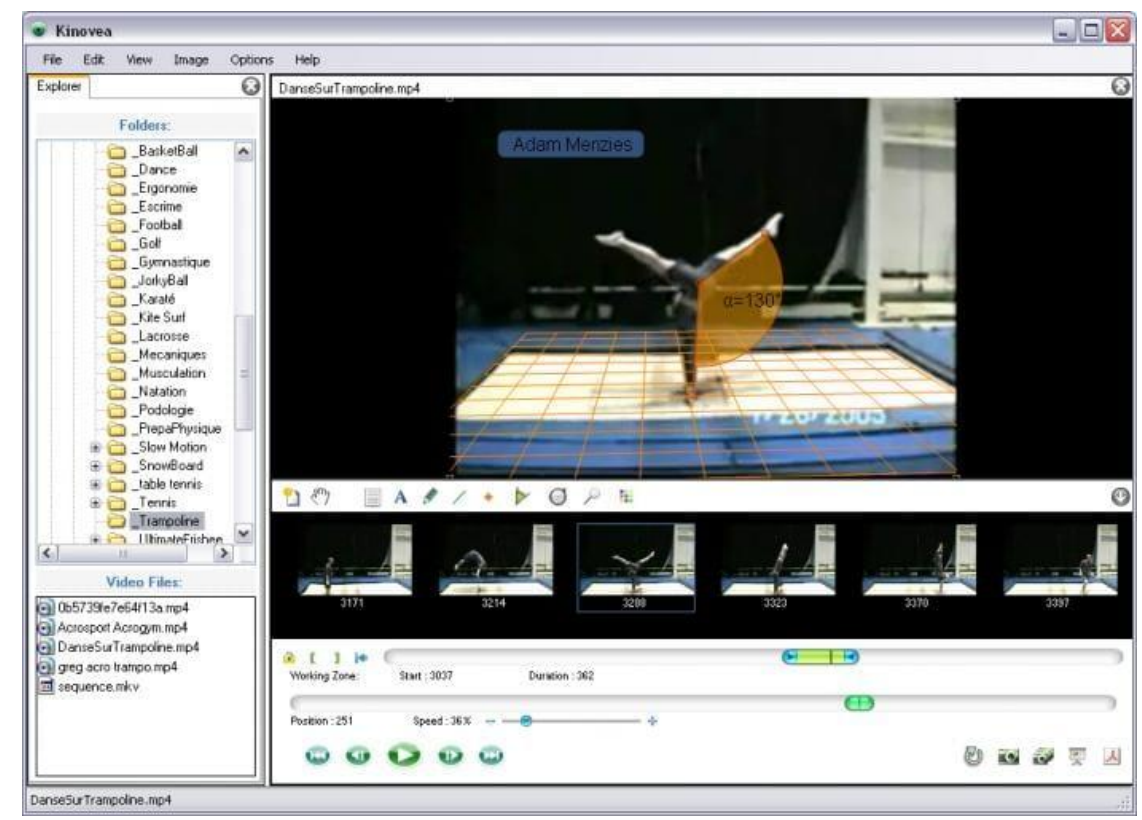

Fonte: https://goo.gl/Gm69r9. Acesso em 12 de janeiro de 2018

A técnica incorporou e adaptou para seu uso, os conceitos de restituição de imagem $^{23}$ e fotointerpretação da fotogrametria cartográfica ${ }^{24}$, definições que se tornaram premissas fundamentais no desenvolvimento e validação da técnica de avaliação sistemática dos movimentos corporais em seres humanos (RICIERI, 2008).

Segundo Ricieri (2008), a restituição abrange os estudos preliminares acerca das condições em que se deve realizar o registro da imagem do movimento desejado para uma fotointerpretação precisa. Para realizar a restituição é necessário envolver conhecimentos anatômicos gerais e de superfície (RICIERI 2008), conhecimento da linguagem fotográfica (fotografia e vídeo), fotogramétricos e princípios instrumentais do software de análise.

As referências ósseas e articulares, planos, eixos, regiões corporais, tudo pode ser avaliado pela Biofotogrametria (RICIERI 2008), desde que a imagem adquirida seja previamente planejada antes da aquisição e que sejam realizadas possíveis manifestações motoras, gestos.

\footnotetext{
${ }^{23}$ Consiste na transformação de imagens em arquivos vetoriais representativos.

${ }^{24}$ Ferramenta útil à agrimensura e que levou à sua adaptação para utilização em outras áreas do conhecimento.
} 
Todo o processo é pautado principalmente pela aquisição e de condições de registro da imagem, com domínio do uso das ferramentas tanto de captura como do software para o tratamento dos dados obtidos. Outro aspecto que deve ser aplicado é a distribuição de marcadores de superfície, denominado modelagem, que orienta as referências anatômicas que se deseja controlar durante o processo de medidas (RICIERI 2008).

Assim, a aquisição dos dados por vídeo é determinada pelo tipo de movimento a ser analisado. Com essa obtenção dos dados, são submetidas a técnicas de reconhecimento das coordenadas de referência anatômica, que podem variar segundo a natureza do sistema de análise utilizado, desde a automatização computacional, até a semiautomatização e o processamento manual (BARROS et al., 1999).

A avaliação biomecânica de um movimento permite a quantificação dos graus de habilidade ou destreza, na execução de determinada tarefa ou fenômeno denominado desempenho (AMADIO et al., 1999).

A disponibilidade de captura de imagens digitais está disseminada em largas proporções com o aprimoramento de captura através da utilização do telefone celular e consequentemente, a utilização em atividades métricas tem crescido devido à agilidade na coleta de dados e pela disponibilidade da ferramenta. Deste modo, as possibilidades de uso ampliaram-se com algoritmos mais sofisticados empregados em softwares de extração e processamento de dados, sejam fotográficos ou em vídeo.

As pesquisas sobre aspectos do movimento corporal por meio de imagens representaram uma nova possibilidade metodológica ${ }^{25}$ e deram origem a uma nova seção da biomecânica, conhecido como Cinemetria ${ }^{26}$ (CAPOZZO; CAVANAGH, 1994). Sendo que esta é composta por um conjunto de métodos que visam medir parâmetros cinemáticos do movimento a partir da aquisição de imagens durante a sua realização (AMADIO; DUARTE, 1996). Deste modo, a análise biomecânica avalia o movimento de um organismo vivo e o efeito de determinadas forças sobre esse organismo (HAMIL; KNUTZEN, 2008).

\footnotetext{
${ }^{25} \mathrm{Na}$ atividade científico-acadêmica, independente da especialidade, a documentação fotográfica viabiliza a transmissão de conhecimento e experiências entre um profissional e sua comunidade científica, e vice-versa (OLIVEIRA, 1980, HOCHMAN; NAHAS; FERREIRA, 2005).

${ }^{26}$ Metodologia biomecânica que se destina à obtenção de variáveis cinemáticas para a descrição de posições ou movimentos no espaço (Barros, 2001).
} 
Os avanços tecnológicos, em progressivo desenvolvimento, têm permitido o tratamento de novos paradigmas para o diagnóstico rápido no processo de acompanhamento sistematizado, na análise biomecânica de movimentos de uso de produtos resultando em aportes para modificações técnicas ou até mesmo redesenho do mesmo.

Desta forma, se coloca justificativa crescente para inclusão desses novos procedimentos rápidos para a avaliação da biomecânica dos movimentos, oferecendo ao designer informações detalhadas de diversas situações de uso e aplicação do produto real ou modelo a ser desenvolvido. A biofotogrametria mostra ser um instrumento capaz de oferecer evidências consistentes na avaliação biomecânica dos movimentos, abrindo caminhos para novas formulações e estudos no campo.

\subsubsection{Escaneamento Tridimensional}

A digitalização consiste essencialmente na obtenção de informações de diversos pontos de uma superfície tridimensional de forma que estes possam ser reconstruídos em uma linguagem computacional, permitindo a construção de uma amostra digital análoga. Ou seja, ao contrair elementos sobre a posição espacial dos pontos em uma superfície, transforma os mesmos em uma malha.

O processo de digitalização tridimensional tem um papel importante não apenas no processo de reconstrução e recuperação tridimensional de objetos, mas, sobretudo na área do Design de Produto sendo possível realizar ensaios, testes, verificação, manipulação, construção de moldes, tratamento, estudos, análises volumétricas, parte do processo de engenharia reversa, armazenamento digital, inspeção como controle de qualidade, enriquecimentos visuais (sombras, reflexos, brilho, cores, textura, iluminação), simulação de animação, correção de modelos, cópia de modelos existentes e documentação de produtos, etc., que não impliquem na perda dos pontos da estrutura tridimensional, uma vez que o modelo digital pode ser inúmeras vezes recuperado, ampliando assim, as possibilidades de criação no processo de projeto.

Alencar (2010) esclarece que três etapas são inerentes ao processo de reconstrução tridimensional a partir da digitalização tridimensional e são resumidas 
em: a) aquisição dos dados de elevação de superfície; b) o processamento dos dados; e c) a própria reconstrução com precisão absoluta.

Assim, o procedimento da captura consiste, inicialmente, na definição da área a ser apreendida, possibilitando a aquisição da nuvem de pontos, sendo que a nuvem é o conjunto de coordenadas de três dimensões ( $X, Y$ e $Z$ ), representando assim a superfície digitalizada (figura 36), desencadeando informações para a recuperação e reconstrução das estruturas em um sistema computacional a partir da utilização de algum software de processamento da captura.

Figura 36: Experiência de Sutherland (1972) com malhas poligonais complexas no processo de modelagem da carroceria.
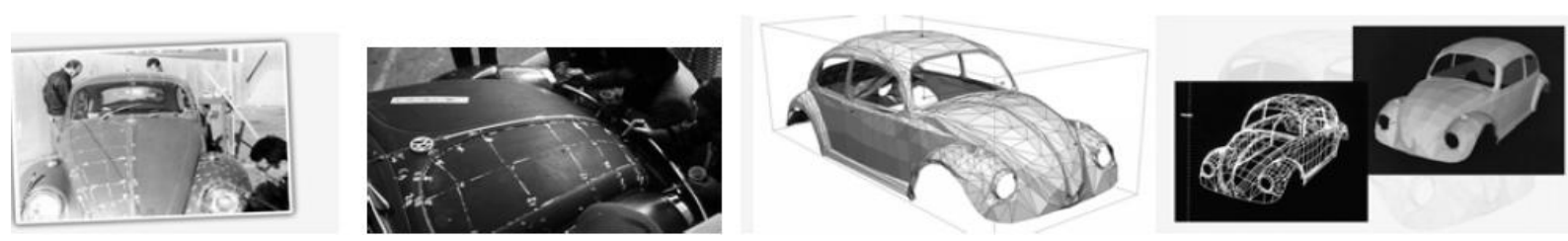

Fonte: goo.gl/bmJxTW - acesso em 7 de janeiro de 2018

Nesse sentido, a digitalização consiste basicamente, na possibilidade de aquisição de todos os pontos de uma estrutura tridimensional, distribuídas no espaço de modo organizado, desencadeando subsídios para a recuperação e reconstrução das estruturas digitalmente em três dimensões (SILVA, 2010).

As imagens capturadas pelo escaneamento tridimensional expandem a percepção e compreensão do projeto e servem para realizar estudos, análises e investigações que não impliquem na perda das estruturas, uma vez que o modelo virtual pode ser facilmente resgatado (SILVA, 2010).

No mercado existem diversos modelos de escâner tridimensionais com diversas características, recursos, modelos e opções para atender as mais diferentes necessidades do mercado. No entanto, para enriquecer essa discussão, Araújo (2010) apresenta dois quadros comparativos entre as principais técnicas de reconstrução tridimensional extraídas e adaptadas de Sansoni et al (2009). 
Quadro 1 - Classificação de técnicas de reconstrução tridimensional.

\begin{tabular}{|c|c|c|c|c|c|c|c|c|c|}
\hline & Triangulation & $\begin{array}{l}\text { Time } \\
\text { delay }\end{array}$ & $\begin{array}{l}\text { Monocular } \\
\text { Images }\end{array}$ & Pássive & Active & Direct & Indirect & Range & $\begin{array}{l}\text { Surface } \\
\text { Orientation }\end{array}$ \\
\hline $\begin{array}{l}\text { Laser } \\
\text { triangulators }\end{array}$ & $\mathrm{x}$ & & & & $\mathrm{x}$ & $\mathrm{x}$ & & $\mathrm{x}$ & \\
\hline Structured light & $\mathrm{x}$ & & & & $\mathrm{x}$ & $\mathrm{x}$ & & $\mathrm{x}$ & \\
\hline Stereo vision & $\mathrm{x}$ & & & $\mathrm{x}$ & & $\mathrm{x}$ & & $\mathrm{x}$ & \\
\hline Photogrammetry & $\mathrm{x}$ & & & $\mathrm{x}$ & & $\mathrm{x}$ & & $\mathrm{x}$ & \\
\hline Time of Flight & & $\mathrm{x}$ & & & $\mathrm{x}$ & $\mathrm{x}$ & & $\mathrm{x}$ & \\
\hline Interferometry & & $\mathrm{x}$ & & & $\mathrm{x}$ & $\mathrm{x}$ & & $\mathrm{x}$ & \\
\hline $\begin{array}{l}\text { Moiré fringe } \\
\text { range } \\
\text { contours }\end{array}$ & & & $x$ & & $\mathrm{x}$ & & $\mathrm{x}$ & $x$ & \\
\hline $\begin{array}{l}\text { Shape from } \\
\text { focusing }\end{array}$ & & & $\mathrm{x}$ & $\mathrm{x}$ & $\mathrm{x}$ & & $\mathrm{x}$ & $\mathrm{x}$ & \\
\hline $\begin{array}{l}\text { Shape from } \\
\text { shadows }\end{array}$ & & & $x$ & & $\mathrm{x}$ & & $x$ & $x$ & \\
\hline Texture gradients & & & $\mathrm{x}$ & $\mathrm{x}$ & & & $\mathrm{x}$ & & $\mathrm{x}$ \\
\hline $\begin{array}{l}\text { Shape from } \\
\text { shading }\end{array}$ & & & $\mathrm{x}$ & & $\mathrm{x}$ & & $x$ & & $x$ \\
\hline $\begin{array}{l}\text { Shape from } \\
\text { photometry }\end{array}$ & & & $\mathrm{x}$ & & $\mathrm{x}$ & & $\mathrm{x}$ & & $\mathrm{x}$ \\
\hline $\begin{array}{l}\text { Shape-from- } \\
\text { silhouette }\end{array}$ & $x$ & & & $\mathrm{x}$ & & $x$ & & $x$ & \\
\hline $\begin{array}{l}\text { Computer } \\
\text { tomography }\end{array}$ & $\mathrm{x}$ & & & & $\mathrm{x}$ & $\mathrm{x}$ & & & \\
\hline
\end{tabular}

Fonte: Araújo (2010) adaptação de Sansoni et al. (2009).

Quadro 2 - Comparação entre as técnicas de reconstrução tridimensional.

\begin{tabular}{|c|c|c|}
\hline Tecnologia & Pontos fortes & Pontos fracos \\
\hline $\begin{array}{l}\text { Trianguladores à } \\
\text { laser }\end{array}$ & $\begin{array}{l}\text { - Relativamente simples; } \\
\text { - Performance geralmente independente da luz } \\
\text { ambiente; } \\
\text { - Alto nível de aquisiçāo de dados. }\end{array}$ & $\begin{array}{l}\text { - Problemas de segurança associados ao uso de fonte } \\
\text { laser; } \\
\text { - Volume de alcance e mediçāo limitados; } \\
\text { - Perda de dados por oclusōes e sombras; } \\
\text { - Custo. }\end{array}$ \\
\hline Luz estruturada & $\begin{array}{l}\text { - Alto nível de aquisiçāo de dados; } \\
\text { - Volume de mediçāo intermediário; } \\
\text { - Performance geralmente dependente da luz } \\
\text { ambiente. }\end{array}$ & $\begin{array}{l}\text { - Problemas de segurança quando baseados em laser; } \\
\text { - Relativamente complexo computacionalmente; } \\
\text { - Perda de dados por oclusōes e sombras; } \\
\text { - Custo. }\end{array}$ \\
\hline Visão estéreo & $\begin{array}{l}\text { - Simples e barato; } \\
\text { - Precisāo alta para objetos bem definidos. }\end{array}$ & $\begin{array}{l}\text { - Computacionalmente custoso; } \\
\text { - Cobertura de dados esparsa; } \\
\text { - Limitado para cenários bem definidos; } \\
\text { - Baixo nivel de aquisiçāo de dados. }\end{array}$ \\
\hline Fotogrametria & $\begin{array}{l}\text { - Simples e barato; } \\
\text { - Precisāo alta para objetos bem definidos. }\end{array}$ & $\begin{array}{l}\text { - Computacionalmente custoso; } \\
\text { - Cobertura de dados esparsa; } \\
\text { - Limitado para cenários bem definidos; } \\
\text { - Baixo nível de aquisiçāo de dados. }\end{array}$ \\
\hline Tempo de vôo & $\begin{array}{l}\text { - Distância de medida de médio para grande; } \\
\text { - Bom nível de aquisição de dados; } \\
\text { - Performance geralmente independente da luz } \\
\text { ambiente. }\end{array}$ & $\begin{array}{l}\text { - Custo; } \\
\text { - Precisāo inferior ao da triangulaçāo em pequenas } \\
\text { distâncias. }\end{array}$ \\
\hline Interferometria & - Precisāo de Sub-micron para micro-distâncias. & $\begin{array}{l}\text { - Capacidade de medida limitada a superfícies quase } \\
\text { lisas; } \\
\text { - Custo; } \\
\text { - Aplicabilidade limitada em ambiente industrial. }\end{array}$ \\
\hline $\begin{array}{l}\text { Gama de } \\
\text { contornos moiré }\end{array}$ & $\begin{array}{l}\text { - Simples e barato; } \\
\text { - Pequenas distâncias. }\end{array}$ & - Limitado para medidas de superfícies suavizadas. \\
\hline Forma pelo foco & $\begin{array}{l}\text { - Simples e barato; } \\
\text { - Sensores disponiveis para inspeçāo de superfícies e } \\
\text { microprofilometria. }\end{array}$ & $\begin{array}{l}\text { - Campos de visāo limitados; } \\
\text { - Resoluçāo especial nāo uniforme; } \\
\text { - Performance afetada pela luz ambiente (quando } \\
\text { passiva). }\end{array}$ \\
\hline Forma por sombras & $\begin{array}{l}\text { - Barato; } \\
\text { - Demanda pouca capacidade computacional. }\end{array}$ & - Baixa precisāo. \\
\hline $\begin{array}{l}\text { Gradação } \\
\text { textura }\end{array}$ & - Simples e barato. & - Baixa precisāo. \\
\hline $\begin{array}{l}\text { Forma por } \\
\text { sombreamento }\end{array}$ & - Simples e barato. & - Baixa precisāo. \\
\hline Forma pela silhueta & $\begin{array}{l}\text { - Simples e barato; } \\
\text { - Precisāo relativamente alta para objetos bem } \\
\text { definidos; } \\
\text { - Pode ser usado para objetos de diferentes tamanhos. }\end{array}$ & $\begin{array}{l}\text { - Performance alterada pela luz ambiente; } \\
\text { - Baixa precisāo geométrica para objetos com formas } \\
\text { côncavas. }\end{array}$ \\
\hline $\begin{array}{l}\text { Tomografia } \\
\text { computadorizada }\end{array}$ & $\begin{array}{l}\text { - Performance independente da luz ambiente; } \\
\text { - Alto nível de aquisiçāo de dados; } \\
\text { - Permite aquisiçāo da geometria interna dos objetos. }\end{array}$ & $\begin{array}{l}\text { - Custo; } \\
\text { - Computacionalmente custoso; } \\
\text { - Necessita de instalaçōes especificas; } \\
\text { - Problemas de segurança devido à radiaçāo; } \\
\text { - Necessita de operador especializado. }\end{array}$ \\
\hline
\end{tabular}

Fonte: Araújo (2010) adaptação de Sansoni et al. (2009). 
Neste contexto de desenvolvimento especializado das ferramentas e seus recursos, coloca-se a questão sobre como este conhecimento é transmitido na formação de designers, especialmente aqueles que irão atuar no segmento de produtos. Onde a integração de conhecimentos é extremamente necessária, sendo que as tecnologias não são isoladas e demandam conhecimentos distintos para os processos de utilização e aplicação.

Ao utilizar a linguagem fotográfica, são realizadas escolhas, conscientes ou não, omitindo ou selecionando determinados aspectos pelo enquadramento compositivo e gerador, propondo e alimentando novos dados para o uso de ferramentas. Assim, para adotar determinada técnica, é necessário que o aluno identifique e conheça todo um conjunto de funções inseridas em cada modelo de equipamento e, deste modo, o desenvolvimento e aprimoramento das ferramentas devem ser orientados em três estágios - organização conceitual, configuração da ferramenta e testes de validação.

Ao mesmo tempo, a linguagem fotográfica adquire também outros papéis, como representação formal de estudos analíticos, avaliativos e estruturais, a investigação entre forma e conteúdo, além de explorações de acabamento, aparência, entre outros aspectos. Esta linguagem evolui e modifica seus significados tão rápido como qualquer outra (SUDJIC, 2010) linguagem.

Discussões pertinentes aos campos de pesquisas e reflexões a respeito de métodos e estratégias, aprendizagem, habilidades, procedimentos e soluções em práticas de ensino estão sempre em pauta e/ou em mudança face a atualização constante decorrente de alterações sociais, econômicas e tecnológicas.

Tendo como cenário, o respaldo de teorias e práticas educacionais como lócus em que se insere esta pesquisa, considera-se que alguns métodos educacionais necessitam ser (re)discutidos e ampliados, principalmente no que diz respeito à instrumentação e aos conteúdos da área tecnológica, incluindo os estudos pertinentes à fotografia, vídeo, termografia, fotogrametria, holografia, realidade aumentada, biofotogrametria, metrologia e a digitalização tridimensional.

Constata-se como promissor no processo de formação em Design, instigar o aluno a criar adaptações ou modificações no aparelho (dispositivos) para atender a sua necessidade; para selecionar recursos e equipamentos de baixo custo em estrita consonância com nível de captura a ser realizado e com os objetivos da proposta ou intervenção a favor do projeto, ou dos objetos (produtos); além de 
situações de apreensão de tempos e movimentos na interação do homem com o produto e do homem com o homem.

Como um produtor de cultura visual, o designer de produto carece de compreensão de porquê um sistema prevalece sobre o outro e sob que circunstâncias são adequadas e inovadoras alterações nos sistemas de representação (onde se incluem processos e procedimentos fotográficos), para uma melhor ampliação no raciocínio (ideação - desenvolvimento - execução - avaliação) do projeto e de etapas de execução referentes à produção e uso de objetos, expandindo suas reflexões em suas aplicações.

A apresentação dos recursos, processos e procedimentos fotográficos aqui apresentados podem complementar e/ou substituir outros processos tradicionais relativos a imagens manuais ou digitais (como representações por desenhos manuais ou por softwares), contribuindo para o processo de ensino do designer e sua aplicabilidade em casos reais ou simulados, de forma a proporcionar a capacidade de análise, observação, argumentação e raciocínio, favorecendo o aprendizado (ALENCAR, 2010) e devendo ser testado dentro da academia.

As pesquisas atuais têm comprovado que, para a aprendizagem na área tecnológica, atividades que privilegiam o manuseio e a utilização de objetos concretos podem ser muito satisfatórias para a aprendizagem do aluno, ajudando-o a superar as restrições metodológicas e melhorando o raciocínio no processo de ensino da área tecnológica (BAZZO, 1998).

\subsubsection{Holografia}

A holografia surgiu como forma de registro de imagem e é utilizada pela Física como uma sofisticada técnica para análise de materiais e armazenamento de dados. Vem sendo aplicada em outras áreas que usam a imagem como estudo e representação de ideias, projetos e cenários (cenas) futuros ou idealizados, visto que essa técnica permite constituir imagens em três dimensões (laser) (figura 37), que resultam em uma forma de representação ótica ou uma fotografia em três dimensões. Desta forma, este recurso converge para um novo conceito de pensar, e amplia as possibilidades de visualização espacial - holograma tridimensional - ao invés da forma linear, até então aplicada em diversos sistemas. 
Figura 37 - Representação esquemática da geração de holograma.
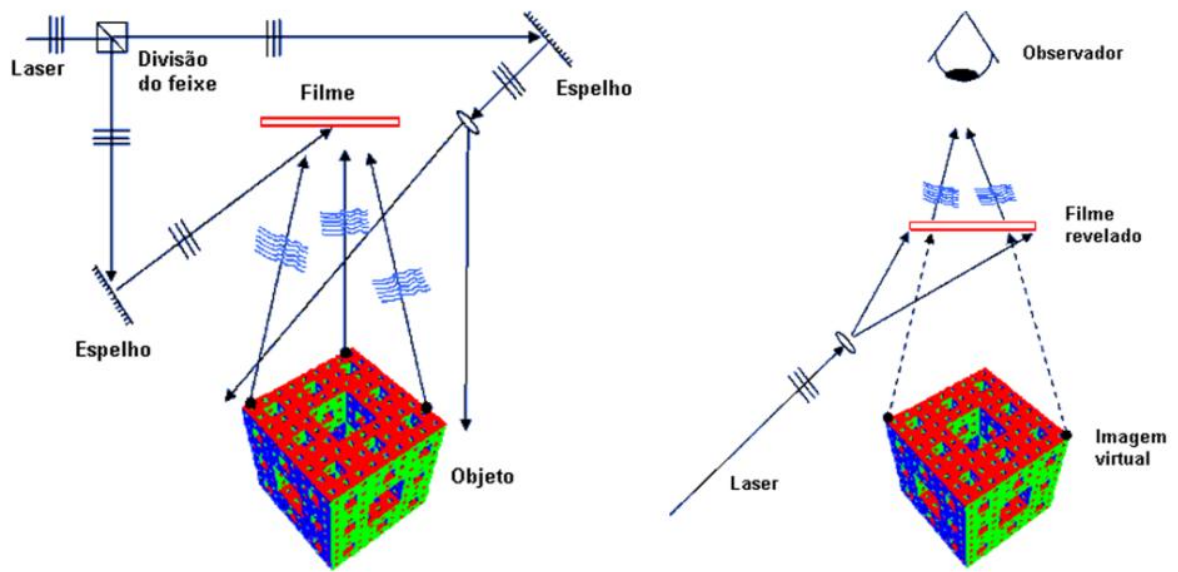

Fonte: https://goo.gl/qf4zci. Acesso em 16 de fevereiro de 2018

Para os autores Aguilar e López (2004), a linguagem holográfica aparenta grande semelhança com a linguagem fotográfica, embora conte com outras características especificas (tecnológicas) e proporcionem a possibilidade do registro de imagens, além do emprego de meios similares. As principais diferenças podem ser:

- a fotografia é lida de modo bidimensional, enquanto a holografia é o registro, a percepção e a visualização tridimensional da forma; e

- a possibilidade de a holografia armazenar a fase da onda que chega até o meio do registro, algo que a fotografia não possibilita.

Desta forma, SILVA (2014) esclarece esse ponto colocando que:

[...] a fotografia lida com imagens estáticas cuja profundidade se encerra na superfície de impressão a holografia faz a captura das três dimensões de algo e reconstrói opticamente com a profundidade percebida, com cenas ou, sem, movimento (SILVA, 2014, p. 222).

O holograma trabalha em cinco principais formatos: em relevo, transmissão, reflexão, integrais e de luz pulsada ${ }^{27}$. Desta forma, não devem ser apenas consideradas como mais uma forma de visualização de imagens em três dimensões, mas sim como um processo para codificar uma informação visual e depois decodifica-la, recriando integralmente esta mesma informação.

${ }^{27}$ Que não serão detalhadas na pesquisa devido sua complexidade. 
Os hologramas têm diferentes propriedades que relevam sua importância para o campo do Design:

- Perspectiva - trata-se da possibilidade de observar o objeto representado pelo holograma de diferentes posições (diferentes ângulos), com profundidade (relevo);

- Associatividade - é criada pela associação de duas ondas, sendo uma a que ilumina o holograma, podendo ser perpendicular ou paralela ao mesmo; e

- Distributividade - a informação está distribuída ao longo de toda sua superfície.

Nesse sentido, torna-se promissor o desenvolvimento de novo escopo de aplicação para o Design, principalmente para obter imagens tridimensionais de pessoas e outros elementos espaciais; com inserção de produtos, componentes, características variadas nos e dos ambientes, interagindo ou recebendo interações, em escala de reprodução real, mantendo as proporções e métricas, possibilitando gerar aspectos antropométricos e ergonômicos determinantes e que são prioritários para o designer (BARCELLOS, et. al., 2015).

Como exemplo, a figura 38 apresenta uma imagem que trabalha com projetores que possuem a tecnologia holográfica (modelos dreamoc - HD3; POP3; XXL3; Diamond), da empresa RealFiction, que combina um objeto real introduzido em seu interior com uma câmera com animação tridimensional, que podem ser visualizadas em um raio de $200^{\circ}$. Assim, o observador consegue ver uma animação em três dimensões desenvolvidas para interagir com o objeto físico presente em seu interior.

Figura 38 - O Dreamoc da RealFiction - projetor holográfico.

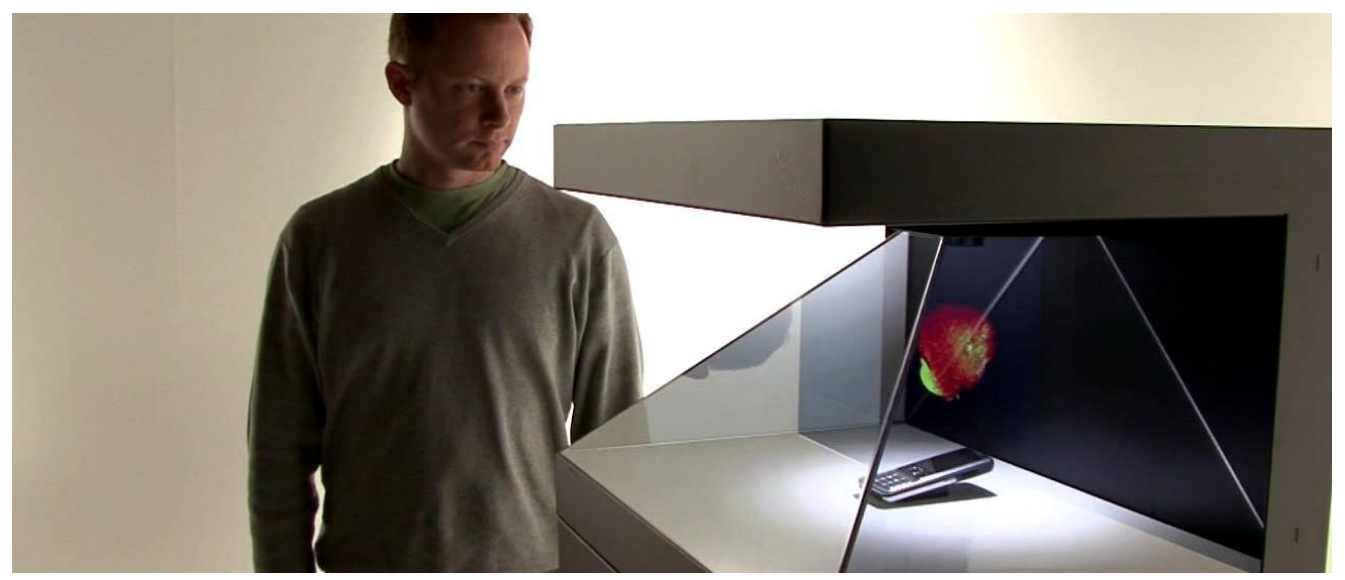

Fonte: https://www.realfiction.com/. Acesso em 16 fevereiro de 2018. 
No Design de Produto é importante e necessária a visualização espacial nos processos de formação do profissional, pois existe uma carência no desenvolvimento desta habilidade por parte do discente, visto as dificuldades verificadas na capacidade cognitiva espacial do aluno em alguns exercícios e desenvolvimento de projetos de produtos, como fator preponderante de desestímulo à aprendizagem nas disciplinas básicas de representação e de projeto de produto.

Silva (2014) esclarece que:

[...] área projetual de desenvolvimento de produtos e de artefatos industriais, carece repensar e se preparar para as inovações no intuito de extração do leque de aspectos e das potencialidades e ganhos em termos de qualidade, eficiência, recursos, praticidade dentre outros aspectos, dos quais as novas tecnologias estarão oferecendo (SILVA, 2014, p. 226).

Entretanto, a realidade é outra, pois é um sistema de difícil acesso e que necessita de aprimoramentos para ser inserido ao campo, mas será de grande importância quando for difundido e quando estiver hibridizado em aparelhos menores, como as outras ferramentas apresentadas neste capítulo.

Cabe, portanto, um acompanhamento mais próximo e atento ao desenvolvimento de equipamentos e programas mais acessíveis, e viáveis para a sua incorporação nas instituições de ensino de graduação.

\footnotetext{
Atualmente, a holografia vem sendo aplicada em outros níveis utilizando o código de padrões, que cria uma unidade digital distinta, e tornou-se uma tecnologia viável, podendo ser integrada a processos de reprodução de imagem, no dia a dia em novas áreas de exploração, abrangendo aplicações em Design (BARCELLOS, et. al., 2015 p.572).
}

Como visto em outras ferramentas, a dificuldade no campo é a visualização de objetos em três dimensões, que é muito comum, mas é desejável aprimorar essa habilidade necessária para o designer de produto, através de práticas e exercícios. Assim, considera-se que o uso da holografia pode contribuir para constituir essa habilidade, considerando a sua propriedade para exibir objetos tridimensionalmente, para observação, estudo e exploração.

\subsubsection{Realidade aumentada}


Realidade Aumentada (RA) se refere a um sistema no qual o meio físico onde o sujeito se encontra é combinado ${ }^{28}$ em tempo real com informações interativas geradas por um sistema computacional, criando uma percepção ampliada do ambiente ao seu redor.

Segundo Cardoso et. al. (2007) o RA é uma amplificação da percepção sensorial por meio de recursos computacionais, sendo assim uma tecnologia para exibir elementos digitais em um ambiente real em tempo real. O Design pode utilizála como uma ferramenta de alto potencial, auxiliando no processo de projeto e reduzindo custos no processo de projeto.

A tecnologia embarcada na realidade aumentada é composta por um sistema que requer um hardware de captura (câmera de vídeo) da informação; software para geração, em tempo real, de elementos virtuais e hardware para mapear tais elementos no mundo real (CARDOSO, et. al., 2007). Desta forma recurso contemporâneo é usual e compatível com as novas gerações de interface do usuário, potencializando as interações com as aplicações computacionais e que inicialmente foram inseridas como forma de propaganda, advergame ${ }^{29}$ e em jogos digitais, sendo que ela é uma variante da Realidade Virtual (RV), assim a RA faz uso da combinação RV e do mundo real, ampliando a percepção e interação do usuário.

As técnicas de RA devem possibilitar condições ao designer de desenvolver aplicações relacionadas com o projeto, visando ampliar suas ferramentas de criação; estudos; seleção de alternativas projetuais; visualização e divulgação de resultados; e de análise. Ela permite que o usuário veja o mundo real, com objetos e sons sobrepostos ou combinados através de um display com câmera integrada, possibilitando a inserção de objetos virtuais no mundo real. No design, podem-se experimentar soluções de projeto, inserindo-os no ambiente, simulando cenários futuros; permitindo assim antecipar, experimentar e estudar as possibilidades e propostas de soluções de produtos nos ambientes.

Nesse sentido a resolução e o uso desse sistema, em um cenário ideal, permitem ao usuário ter a impressão de que os objetos virtuais e reais coexistem no mesmo espaço, sendo muito difícil distinguir o real do virtual (FERNANDES;

\footnotetext{
${ }^{28}$ Essa combinação é realizada através da câmera fotográfica do dispositivo, principalmente um smartphone ou um tablet.

${ }_{29}$ É o nome dado a estratégia de comunicação mercadológica (ferramenta do marketing) que usa jogos, em particular os eletrônicos, como ferramentas para divulgar e promover marcas, produtos, organizações e/ou pontos de vista.
} 
SÁNCHES, 2008). A figura 39 mostra um exemplo de uma cena de RA, onde podemos perceber a inserção de objetos virtuais em um ambiente real, através de dispositivos moveis.

Figura 39 - Artoolkit.

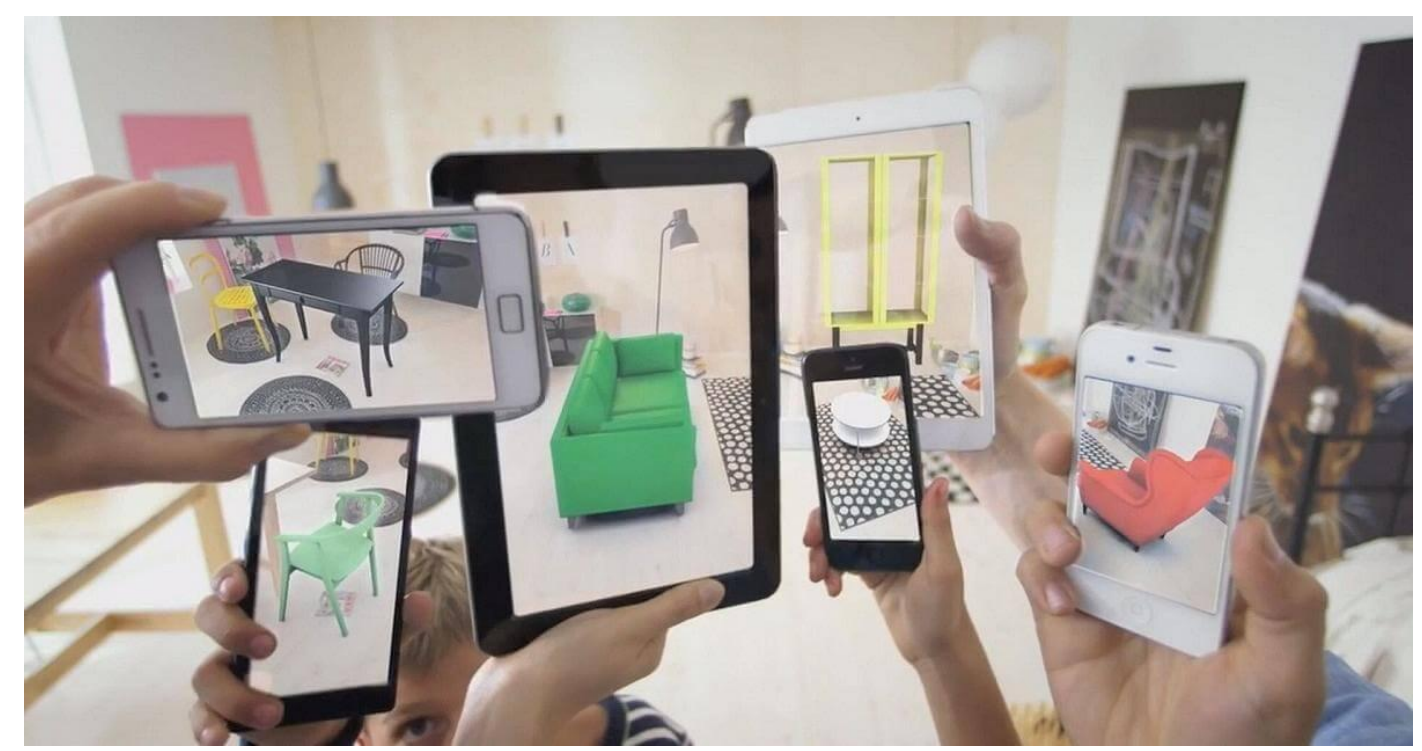

Fonte: https://goo.gl/G5AR7c. Acesso em 16 de fevereiro de 2018.

Outra possibilidade que a ferramenta permite é a de remover ou esconder objetos desse ambiente, com sobreposições gráficas, criando a ilusão com inserção de novos produtos, embora atualmente ainda persistam dificuldades nesta aplicação, pois os sistemas não são tão avançados na remoção de objetos, pois é uma tarefa muito mais complexa que a adição

A possibilidade de inserir elementos virtuais no ambiente real tem gerado muitas aplicações e apresentado forte crescimento no uso, auxiliando gradativamente o usuário a se beneficiar desse avanço.

\footnotetext{
Uma das características mais importantes da RA é a modificação no foco da interação homem computador. Com o uso de RA, a interação não se dá com um único componente e/ou elemento localizado, mas, com o ambiente que circunda aquele que interage (CARDOSO et. al., 2007 pg. 8 e 9).
}

Azuma (2001) esclarece que a RA pode ser classificada em quatro sistemas, conforme o tipo de display utilizado: 
- Sistema de visão ótica direta - utiliza óculos ou capacetes com lentes para receberem a imagem real ao mesmo tempo que possibilitam a projeção de imagens virtuais;

- Sistema de visão direta por vídeo - utiliza capacetes com micro câmeras de vídeo acopladas;

- Sistema de visão por vídeo baseado em monitor - utiliza uma webcam para capturar a cena real; e

- Sistema de visão ótica por projeção - utiliza superfícies do ambiente real, onde são projetadas imagens dos objetos virtuais, cujo conjunto é apresentado ao usuário que visualiza a necessidade de nenhum equipamento auxiliar.

No campo do Design de produto ela pode ser utilizada ou aplicada nas:

- Análise de inserção de projetos virtuais em ambiente real;

- Visualização de elementos construtivos do produto;

- Simulação de modelos virtuais em ambiente real;

- Simulações de uso de produtos;

- Demonstrações do desenvolvimento de projeto;

- Aplicação de qualquer elemento virtual concebido tridimensionalmente

Por não necessitar de um equipamento de alto investimento, essa ferramenta pode ser inserida como ferramenta auxiliar para o projeto em Instituições de Ensino de Design de Produto, principalmente o sistema de visão por vídeo, pois é mais fácil de ser ajustado e manipulado, ampliando a gama de recursos que o aluno tem disponível em sala de aula.

Uma das áreas de aplicação mais promissoras da RV no Design de Produto é a concepção de automóveis, possibilitando atenuar alguns problemas de execução (e (re) execução) dos modelos físicos existentes. Embora não seja possível eliminar completamente o uso de modelos, no processo de design de um carro (figura 40), alguns desenvolvedores adotam sistema permitindo aos designers realizar mais interações, com experimentações em detalhes e acabamentos externos, em um 
prazo mais curto, deixando para usar modelos de clay ${ }^{30}$ apenas para a apresentação final do projeto (CARDOSO et. al., 2001).

Figura 40 - Carro virtual (esquerda) ao lado de uma maquete real.

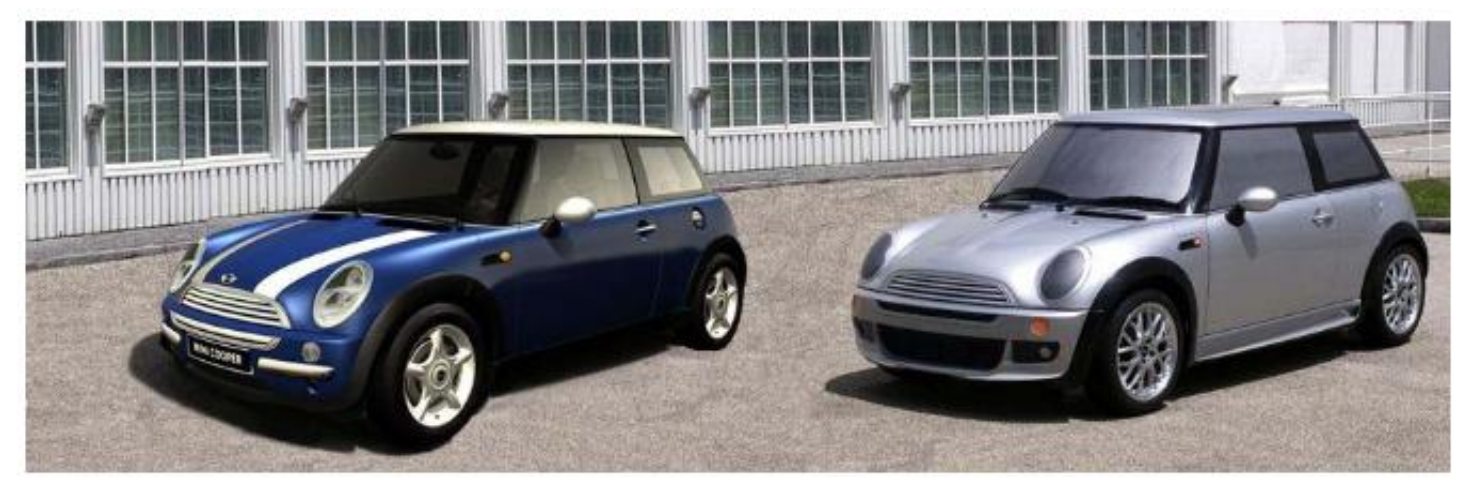

Fonte: KLINKER, G., DUTOIT, A. H., BAUER, M., BAYER, J., NOVAK, V., MATZKE, D. Fata Morgana - A Presentation System for Product Design. Proceedings of the International Symposium on Mixed and Augmented Reality (ISMAR'02) (2002, p.31).

Desta forma, o designer pode interagir com os objetos de maneira natural, usando a percepção; a visualização antecipada das soluções de projetos e as possibilidades de uso inseridas em ambientes e locais existentes, e compreender mais facilmente as características de desenvolvimento do produto, avaliando também seu impacto visual em um ambiente real. Assim, o RA pode ajudar os designers a ampliar sua capacidade de visualização dos objetos e destes no espaço de forma mais eficaz.

\footnotetext{
${ }^{30}$ Massa de modelar profissional.
} 
CAPÍTULO 05 


\section{PROCEDIMENTOS ADOTADOS - PESQUISA DE CAMPO}

Os levantamentos de campo realizados com a comunidade acadêmica selecionada tiveram como objetivo conhecer e analisar de que maneira a linguagem fotográfica vem sendo instrumentada e utilizada na formação em Design, notadamente em processos e procedimentos de projeto em instituições de ensino selecionadas no Estado de São Paulo, incluindo observações sobre práticas pedagógicas na região considerada, visando à coleta de dados instrumentais e de base que confirmem ou confrontem a hipótese e promovam possíveis indicações, projeções e perspectivas.

Através de estudos e pesquisas qualitativos, e quantitativos, executados por meio de entrevistas com docentes e alunos de instituições, previamente localizadas e posteriormente selecionadas, os procedimentos e instrumentais adotados e desenvolvidos focaram questões relevantes para a obtenção de dados que respondessem aos aspectos e às particularidades envolvidas no ensino de Projeto de Produto relacionado à linguagem fotográfica, que permeiam a hipótese desta tese.

Neste sentido, as pesquisas qualitativa e quantitativa foram definidas na medida em que se enfrentaram os novos aspectos e situações sociais observadas no campo, impondo ao pesquisador o uso de métodos indutivos, para analisar os aspectos da amostragem considerada, verificando as diversas manifestações da habilidade do uso da linguagem fotográfica e sua aplicação no processo de projeto de produto (referencial teórico), no ensino de Design em instituições do Estado de São Paulo.

Posteriormente aos levantamentos de campo, as análises foram realizadas através da combinação entre o estudo retrospectivo (dos eventos ocorridos no desenvolvimento desta tese, dos referenciais bibliográficos) e o foco comparativo, onde os critérios centrais da pesquisa consistiam em determinar se as descobertas estão embasadas no material empírico e se os métodos foram adequadamente selecionados e aplicados, assim como na relevância das descobertas e na reflexividade dos procedimentos. 


\subsection{A escolha do método adequado a pesquisa}

Para a definição do método, enfatiza-se que se trata de processo de pesquisa altamente dinâmico (e se renova a cada projeto), necessitando, todavia, ser revestido de cientificidade, qualquer que seja sua acepção, bem como apoiado e validado pela comunidade de pesquisadores, teóricos e estudiosos como afirmado por Coelho (2010).

O interesse nas abordagens qualitativa e quantitativa de pesquisa veio ao encontro da necessidade de se pesquisar e trabalhar em consonância e de forma colaborativa com as organizações (instituições de ensino - docentes e alunos), verificando e testando as ideias (do projeto de pesquisa) aplicadas às situações reais (docentes e alunos de instituições de ensino em Design), como esquematizados na figura 41 .

Figura 41 - Fluxograma da elaboração da tese com rebatimento ao quadro sinótico.

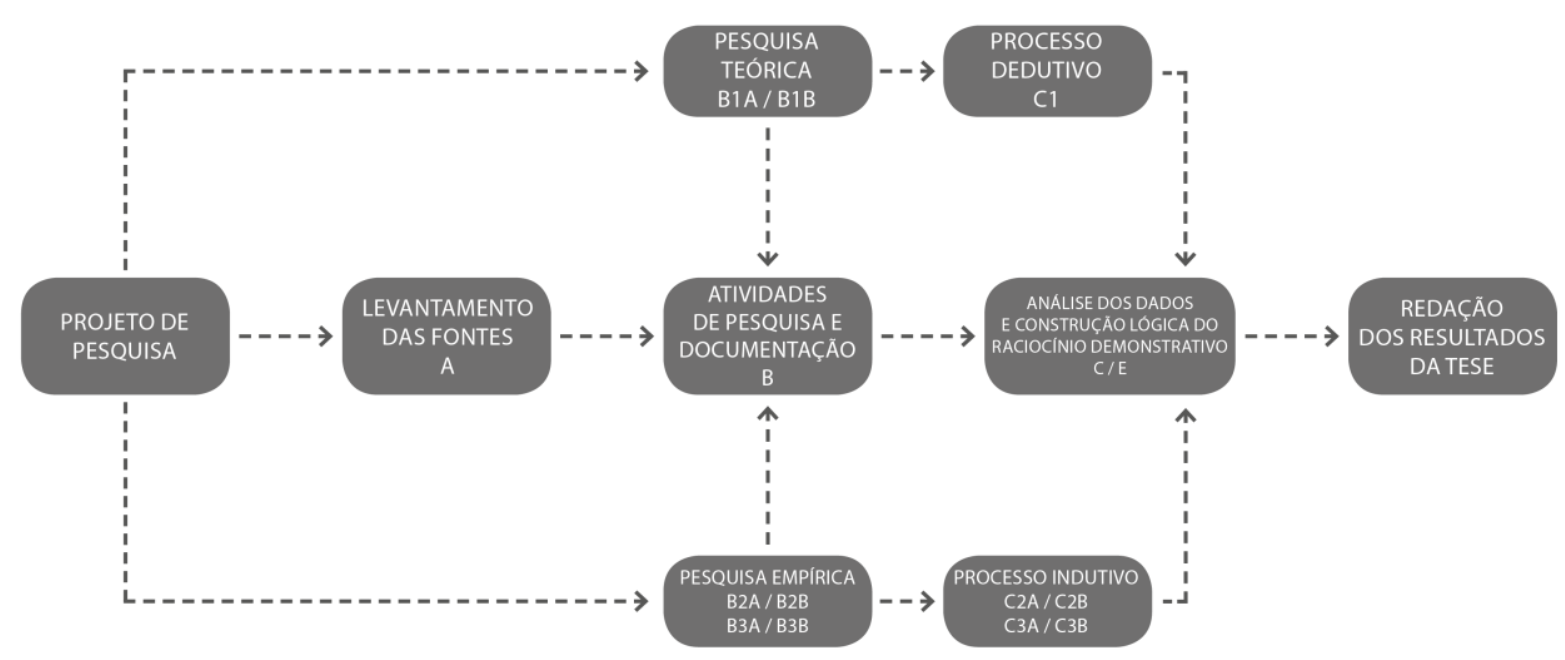

Fonte: adaptada pelo autor com base em Severino (2007, p.128).

Adotaram-se métodos qualitativos e quantitativos de pesquisa por consideralos uma abordagem adequada de procedimentos para captar, reconhecer e analisar as diferentes perspectivas e reflexões encontradas no processo e durante 0 percurso de investigação; atingir os objetivos propostos; e coletar informações atualizadas dos protagonistas pesquisados, sobre as mudanças no ensino e na 
profissão referentes à adequação às novas tecnologias concernentes a linguagem fotográfica.

Como a pesquisa aborda diversas perspectivas, a perda friccional nas decisões foi reduzida pela abordagem da triangulação sistemática das perspectivas conforme comenta Flick (1992), revelando a maior diversidade de aspectos possíveis dentro dos dois subproblemas de pesquisa fixados (docentes e alunos), aumentando o grau de proximidade com o objeto na forma pela qual os casos e os campos são explorados. Esta estratégia tem como objetivo ampliar a abrangência de respostas referentes à manifestação de conhecimentos relacionados à linguagem fotográfica, e ao uso de ferramentas e de softwares.

Figura 42 - Esquema sobre a coleta de dados quali e quanti.

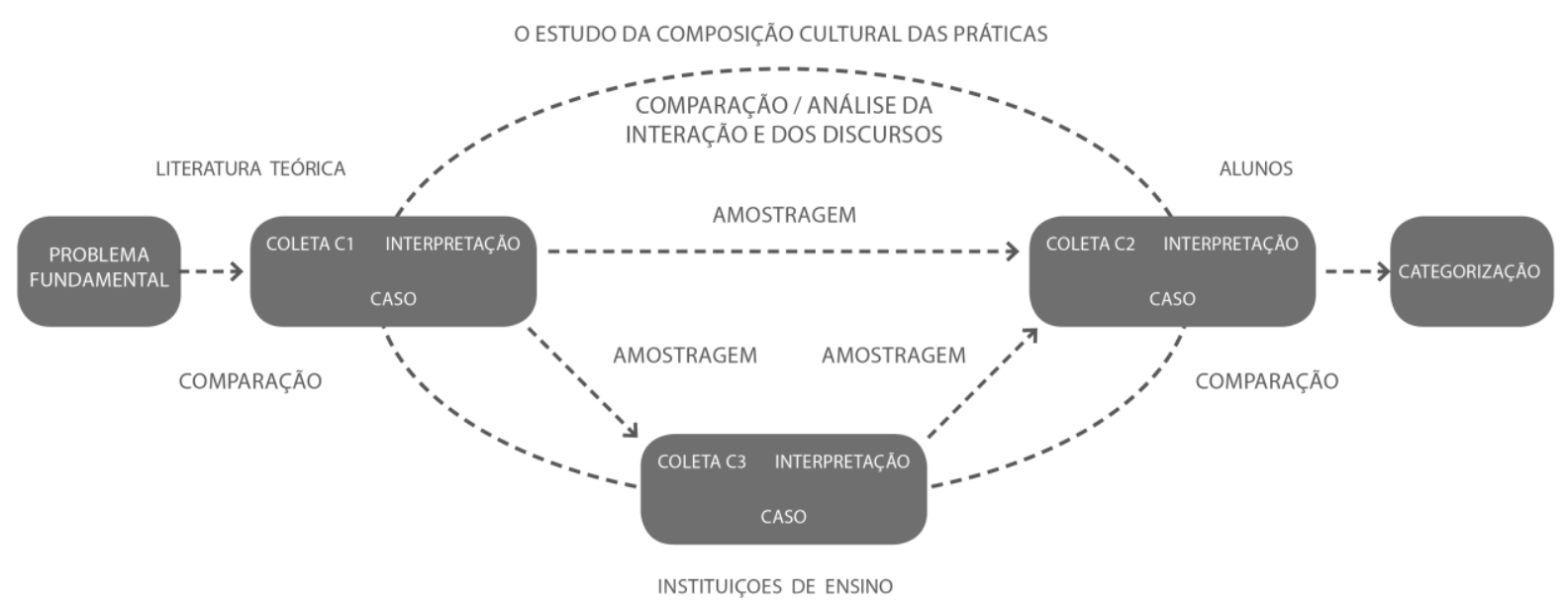

Fonte: adaptada pelo autor com base em Flick (2004, p. 61).

\subsection{Dados necessários para o levantamento}

Nesse contexto segue apresentado como foi realizada a obtenção dos dados necessários para atender aos subproblemas 02 e 03, (ver quadro sinótico no apêndice e).

\subsection{Acesso às instituições de ensino}

$\mathrm{Na}$ etapa inicial de coleta de dados em campo, foi realizada a busca de conteúdos informacionais que tratam do uso da linguagem fotográfica nas práticas 
de projetos, observadas nos métodos pedagógicos das instituições ${ }^{31}$ de ensino de Design de Produto estaduais, municipais e particulares do Estado de São Paulo, ativas anos de 2016 e 2017. Primeiro foram identificados e confirmados os dados sobre a atividade das escolas, que constituem a base de instituições e docentes selecionados para as entrevistas, sobre questões acerca da linguagem fotográfica empregadas nos processos e procedimentos metodológicos observados nas práticas pedagógicas.

Optou-se por iniciar a coleta de dados com a aplicação de entrevista piloto nas instituições, tendo em vista detectar a validade, e as variáveis norteadoras para concepção do questionário final, aplicado aos docentes através de entrevistas individuais.

\subsection{Técnica de coleta de dados}

A aplicação de técnicas de obtenção de dados para o subproblema dois foi mediante entrevistas em profundidade, semiestruturadas com observações, participante e não participante do pesquisador, usando o procedimento de gravação em vídeo e áudio.

\subsection{Entrevista episódica com docentes}

A entrevista com os professores se revelou acertada e gerou informações consistentes sobre conhecimentos recorrentes nos processos de ensino da linguagem fotográfica, verificando acontecimentos relevantes a partir do conjunto de experiências de cada indivíduo. Assim, foi possível contribuir para identificar uma progressão coerente de como a linguagem fotográfica se desenvolve no campo do Design, além de construir a narrativa a partir da experiência do entrevistado, resultando em formas de conhecimento contextualizadas.

O tipo de entrevista selecionada foi a episódica, que se revelou profícua quando aplicada no contexto de ensino, permitindo interação, ao mesmo que condução e correção de rota no desenvolvimento das narrativas dos entrevistados (captadas em imagens e áudio), dirigindo o teor para as visões e as opiniões sobre a linguagem fotográfica no ensino; no projeto em Design de Produto; nas mudanças

\footnotetext{
${ }^{31}$ Devido à importância do acesso às instituições de ensino, foi elaborado um pedido de autorização de pesquisa, destinado ao Gestor Educacional, com esclarecimento sobre o uso dos dados obtidos (gravações em vídeo e áudio) para fins exclusivamente acadêmicos e científicos.
} 
tecnológicas com foco nos avanços e variações das ferramentas de captura fotográfica em seus diversos níveis. Em particular, o aspecto das mudanças foi mencionado como elemento gerador de grande impacto em praticamente todas as variáveis de emprego no campo do ensino do Design, sendo abordado tanto em contextos situacionais concretos de uso, como nos laboratórios das instituições e salas de aula mediadas pelos assistentes e professores.

A fim de tornar acessíveis tanto o conhecimento episódico que coloca narrativas dissertativas e reflexivas do ponto de vista do entrevistado, como os semânticos (significantes), o processo seguiu orientações e critérios específicos delineados por Flick (2002), abaixo descritos:

- Deve combinar convites para narrar acontecimentos concretos (que sejam relevantes ao tema em estudo), por meio de perguntas mais gerais que busquem respostas mais amplas (tais como definição, argumentação e assim por diante) de relevância pontual.

- Deve mencionar situações concretas em que se pode pressupor que os entrevistados possuem determinadas experiências.

- Deve ser suficientemente aberta para permitir que o entrevistado selecione os episódios ou situações que ele quer expor, e também para decidir que forma de apresentação ele quer dar (por exemplo, uma narrativa ou uma descrição). O ponto de referência, para o entrevistado, deve ser a relevância subjetiva da situação.

Foram entrevistados pelo pesquisador, 33 docentes de 17 instituições. As entrevistas foram gravadas em vídeo (imagem e áudio) que foram transcritas (anexo em DVD deste documento) e que foram aplicadas, entre agosto de 2016 a agosto de 2017, abrangendo grande parte das instituições de Design de Produto do Estado de São Paulo, onde os participantes foram selecionados previamente através de agendamento por telefone.

Os docentes participantes da pesquisa estão contemplando as seguintes instituições de ensino: 
- Instituição - Municipal: Faculdade de Tecnologia de Birigui (FATEB) / Birigui 1; Faculdades Adamantinenses Integradas (FAI) / Adamantina - 1;

- Instituição - Estadual: Faculdade de Arquitetura e Urbanismo (FAU/USP) / São Paulo - 2; Universidade Estadual Paulista (UNESP) / Bauru - 12; Centro Universitário Senac (SENAC) / São Paulo - 2;

- Instituição - Privada: Universidade Anhembi Morumbi (AM) / São Paulo - 1; Estácio de Sá Carapicuíba (FNC) / São Paulo - 1; Fundação Armando Alvares Penteado (FAAP) / São Paulo - 1; Instituto Europeo di Design (IED) / São Paulo - 1; Universidade Presbiteriana Mackenzie (MACKENZIE) / São Paulo - 1; Instituto Mauá de Tecnologia (MAUÁ) / São Paulo - 2; Universidade São Judas (USJT) / São Paulo - 1; Escola Superior de Propaganda e Marketing (ESPM) / São Paulo - 1; Centro Universitário Monte Serrat (UNIMONTE) / Santos - 1; Faculdades Integrada de Bauru (FIB) / Bauru - 2; Universidade do Sagrado Coração (USC) / Bauru - 2; Universidade de Sorocaba (UNISO) / Sorocaba - 1.

Foi necessário suprimir três respondentes que não pertenciam ao ensino de graduação de Design de Produto e sim do Design Gráfico.

As perguntas constantes de um roteiro previamente estabelecido foram desenvolvidas com o propósito de identificar as situações do emprego da linguagem fotográfica, dando espaço para a narrativa que foi delineada em nove fases (FLICK, 2002), objetivando analisar o conhecimento e a visão do docente sobre o campo específico do uso da linguagem fotográfica em processo de projeto, bem como verificar eventuais limitações ou restrições no contexto do ensino e atuação, obtendo assim, material que permite comparar o conhecimento dos entrevistados de diferentes instituições de ensino. O questionário continha também algumas questões abertas a novas ou imprevisíveis direções ou caminhos tomados durante a entrevista, que pudessem colaborar para constituir os resultados.

Outro aspecto mencionado por Flick (2004) diz respeito à necessidade do entrevistador deixar claro no processo da entrevista que ele também conhece os tópicos, que se mostrou condição de sucesso na condução da entrevista.

No quadro 3 abaixo, é possível identificar a força e a fragilidade do uso da ferramenta. 
Quadro 3 - Forças e fragilidades da entrevista episódica.

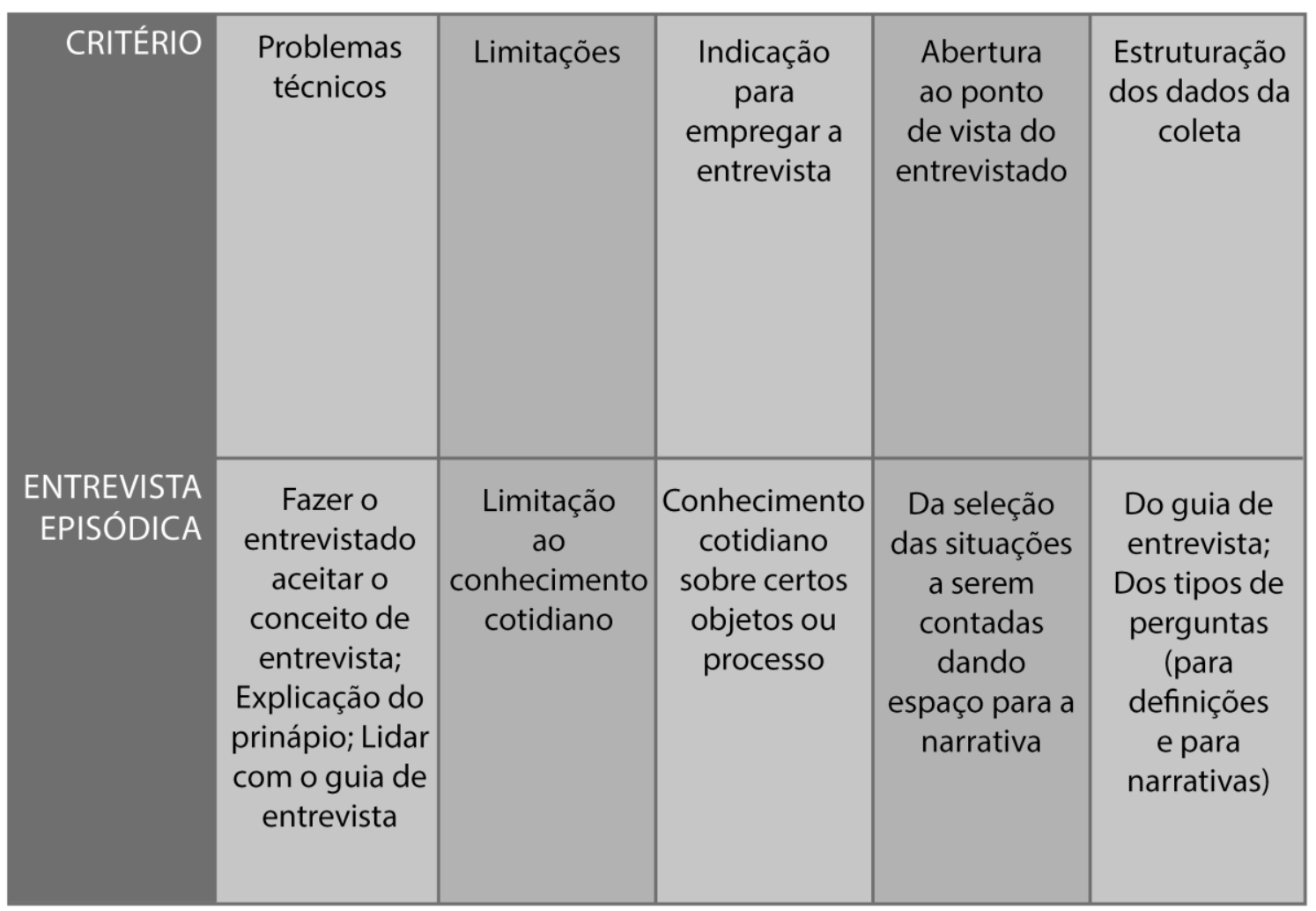

Fonte: Tabela adaptada com base em Flick (2002, p. 125-126).

\subsection{Entrevista Piloto com Docentes}

A aplicação previa de entrevista piloto com um docente, identificou problemas técnicos concernentes ao próprio método da entrevista episódica. Dessa forma, no início do processo, o entrevistado teve de ser orientado pelo entrevistador, demonstrando como o guia da entrevista seria aplicado.

Também com a utilização da técnica, foi possível identificar que a entrevista episódica gera não apenas lembranças sobre as diferentes situações do uso da ferramenta fotográfica e conceitos aplicados em sala de aula, mas também a descrição dos seguintes tipos de dados (figura 43), que ampliam a forma investigativa no uso da ferramenta, que destacamos entre as citadas por FLICK, (2002):

- Narrativas de situações em diferentes níveis de concretude.

- Episódios repetidos como situações que ocorrem regularmente, porém não baseadas em uma referência local ou temporal clara. 
- Exemplos, que são abstraídos de situações concretas e metafóricas, que vão desde clichês até estereótipos.

- Definições subjetivas (de tecnologia), quando explicitamente perguntadas.

- Ligadas a essas definições, proposições argumentativo-teóricas, como explicações a cerca de conceitos e suas relações.

Figura 43 - Tipos de dados da entrevista episódica.

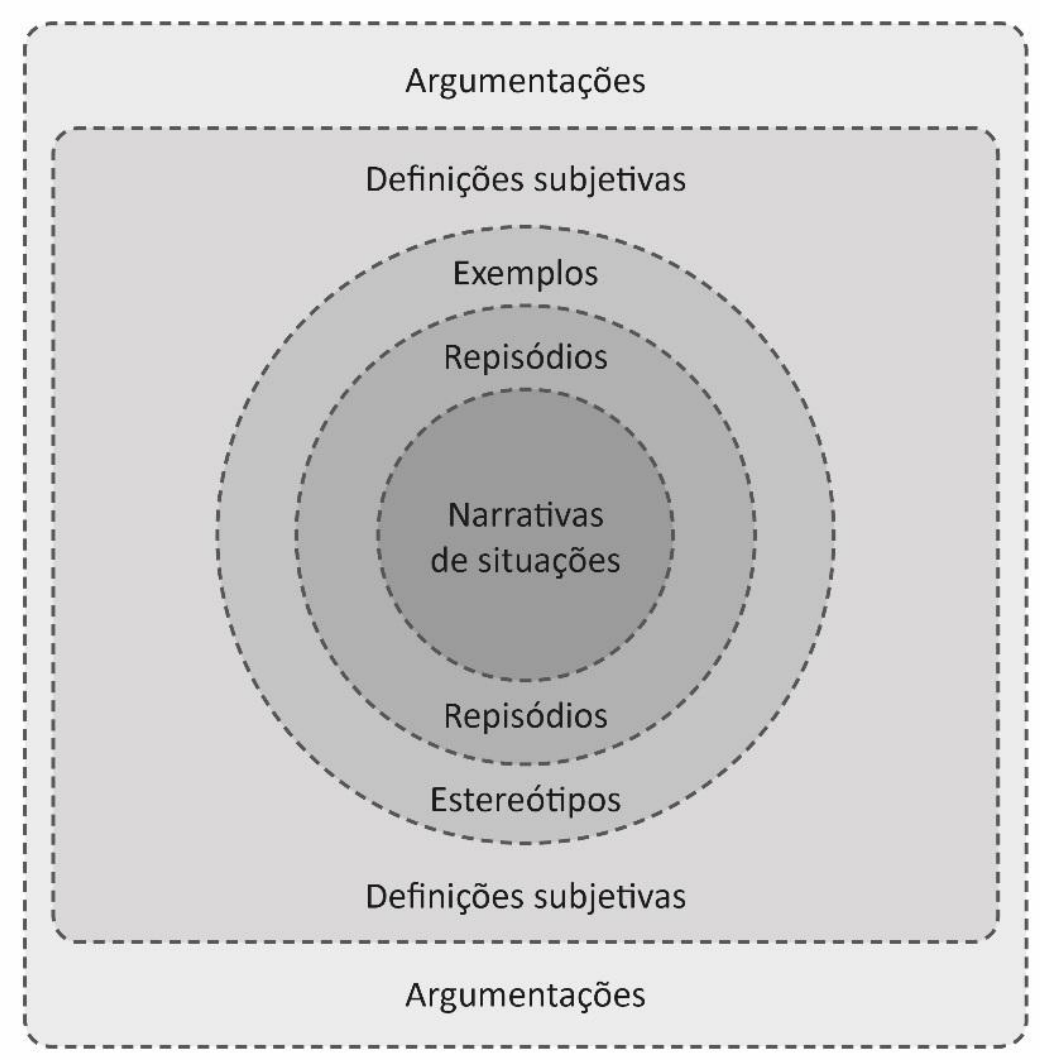

Fonte: Figura adaptada com base em Flick (2004, p. 132).

Destarte, para ampliar a fidedignidade das entrevistas, em razão de sua importância, analisaram-se os resultados da entrevista piloto direcionada a um determinado docente, o que possibilitou realizar as devidas modificações para os eventos subsequentes. Compreendeu-se, que para cada entrevista foi necessário realizar um conhecimento prévio a respeito da atuação e o percurso acadêmico, ou de pesquisa, e treinamento técnico do entrevistado, consultando o currículo LATTES (CNPQ), bem como os dados individuais, informados ou disponíveis na instituição a que está vinculado, identificando também quais são as disciplinas ministradas. 
Outros dois aspectos importantes devem ser destacados. O primeiro diz respeito à documentação, que foi realizada através de áudio e vídeo para o detalhamento minucioso do que foi dito ou narrado pelo entrevistado. $O$ segundo aspecto refere-se à transcrição cuidadosa de toda a entrevista, realizada manualmente, por meio do áudio capturado separadamente do vídeo.

\subsection{Questionário on-line com alunos}

Este procedimento visou a busca de conteúdos informacionais necessários que tratem do uso da linguagem fotográfica em práticas de projetos, observadas em alunos (quadro sinótico - apêndice e). Essa estratificação teve como objetivo gerar um alto grau de comparabilidade na técnica de tratamento de dados, compreendendo a aplicação de um questionário adequado para atender critérios da pesquisa quantitativa $\left(\right.$ Survey $\left.^{32}\right)$.

Deste modo, pretendeu-se estudar como os alunos estão adquirindo conhecimentos e realizando práticas relacionadas à linguagem fotográfica em instituições de ensino do Estado de São Paulo, presumindo diversas hipóteses (ou cenários) que foram consideradas, incorporadas e desenvolvidas através de um questionário (apêndice d), visando obter dados possíveis para confirmar, ou não, e inferir comparações de visões particulares deste grupo com as respostas realizadas pelos docentes.

A elaboração do questionário é essencial, pois é possível identificar informações relevantes para a pesquisa, extraí-las e analisá-las, e nesse sentido buscou-se o meio digital de comunicação, que proporcionaria redução de tempo no acesso ao aluno e uma melhor obtenção dos dados de forma viável e econômica. Desta forma, foi utilizado o recurso digital de questionário do Google Forms ${ }^{33}$ para o levantamento de dados, ferramenta que garante que esse instrumental só poderia ser finalizado se todas as questões obrigatórias estivessem respondidas pelos participantes.

\footnotetext{
${ }^{32}$ A pesquisa Survey é a aquisição de dados ou informações sobre características, ações ou opiniões de um grupo de pessoas selecionadas, por meio de um instrumento de pesquisa, normalmente o questionário (TANUR, 1982 apud PINSONNEAULT; KRAEMER, 1993).

${ }^{33} \mathrm{O}$ Google Forms tem por objetivo facilitar a criação de formulários e questionários diversos e que esta disponível gratuitamente para todos que possuírem uma conta Google, o serviço pode ser acessado em diversas plataformas, como web, desktop e celular, desta forma é um sistema útil para todos aqueles que queiram fazer um formulário de pesquisa ou de coleta de opiniões.
} 
Optamos por essa ferramenta por ser atual e de fácil acesso para os observados, que através de seu serviço de formulário, possibilita ao pesquisador formas diversificadas de elaboração, disponibilização, coleta, tabulação e avaliação dos dados e respostas. Após sua formulação o pesquisador construiu um texto explicativo para a orientação do público alvo, esclarecendo como responder aos questionamentos. Para a execução foi realizado um planejamento e uso de estratégia para sua divulgação. Assim, o formulário foi disponibilizado em grupos fechados do Facebook de cada instituição participante das entrevistas com os docentes. Também foram enviados por mensagem eletrônica, comunicado e esclarecimento para cada um dos docentes envolvidos na pesquisa, solicitando a divulgação do questionário para seus alunos.

Ao disponibilizar o formulário através de um endereço eletrônico (URL ${ }^{34}$ ), imediatamente os alunos tiveram acesso, sendo que as respostas realizadas pelos participantes vão aparecendo ineditamente na página do sistema para visualização imediata dos dados coletados pelo pesquisador, onde a cada momento pode ser observado o andamento da pesquisa, ou seja, a análise pode ser realizada em tempo real.

Não foi necessário o deslocamento do pesquisador até o local onde está presente o grupo visado, em contrapartida, foi imprescindível para os grupos ou alunos, terem acesso ao endereço e a computadores ou dispositivos móveis conectados à internet. Outro ponto importante que colaborou para a adoção deste método de pesquisa foi a segurança dos dados inseridos no formulário, que são armazenados em servidores virtuais e não em dispositivos físicos, já que a autenticidade e o sigilo dos dados coletados têm grande valor para o pesquisador.

Este método de entrevista não tem interesse no entrevistado enquanto pessoa, mas sim em sua opinião, apreendendo a sua capacidade dentro da instituição em identificar a presença de disciplinas ligadas à linguagem fotográfica e a transferência do conhecimento e a prática proposta e instrumentada através dos docentes. Cada entrevista on-line ${ }^{35}$ é integrada ao estudo não como um caso único,

\footnotetext{
${ }^{34}$ Para visualizar o questionário acessar: <https://goo.gl/forms/OcKh3oDtqaflaMfw1> - Acesso em 27 de dezembro de 2017.

${ }^{35} \mathrm{O}$ guia da entrevista possui uma função diretiva, ao excluir tópicos improdutivos, tendo em vista que o entrevistado não consegue apenas restringir suas respostas ao interesse da pesquisa.
} 
mas como a representação de um grupo ligado diretamente a instituição e ao campo do Design de Produto.

A sistematização, a análise e interpretação das informações obtidas nos questionários respondidos pelos alunos visam principalmente analisar e comparar as respostas sobre os conteúdos de conhecimentos adquiridos e transmitidos dentro da instituição sobre linguagem fotográfica.

\subsection{Questionário piloto on-line}

$\mathrm{Na}$ elaboração do texto do questionário foi observado que a estrutura do questionário assegurasse que as questões constituíssem tópicos de relevância e assim foram adotadas questões fechadas, não permitindo ao aluno a possibilidade de improvisar as respostas.

As entrevistas foram direcionadas especificamente aos alunos de cada instituição já investigadas na primeira fase de coleta dos dados.

O guia foi desenvolvido em seis seções:

- Seção 1 - é realizado o esclarecimento sobre o questionário e a necessidade de aceitação ou não do "Termo de Consentimento Livre e Esclarecido". Para dar sequência nas questões é necessário aceitar o termo, sendo que o aluno precisa inserir seu correio eletrônico pessoal.

- Seção 2 - informações sobre o aluno, como nome completo, a instituição de ensino, cidade, curso e ano/semestre, para identificar possíveis respondentes que não se enquadrem no Estado de São Paulo.

- Seção 3 - questão um, fechada para identificar se é oferecida a disciplina de Fotografia e de Vídeo na instituição; e uma questão aberta a respeito das variações de nomenclaturas utilizados na disciplina e sua duração.

- Seção 4 - a questão dois foi dividida em três fases, sendo a primeira fechada - se ele utiliza a linguagem fotográfica nos projetos do curso; a segunda constituída de uma questão aberta - se ele pode indicar como é utilizada - e outra fechada - se a linguagem pode desenvolver um papel preponderante no processo de projeto; e a terceira, fechada - se o aluno utiliza a linguagem 
fotográfica e o vídeo em outras aplicações dentro do curso, seguida de complemento com uma questão aberta para que ele possa indicar em quais momentos é aplicada.

- Seção 5 - questão três, fechada para identificar se o aluno acredita que o sistema digital viabiliza e agiliza o/no desenvolvimento do projeto.

- Seção 6 - questão quatro, fechada para identificar se aluno já realizou algum curso ou workshop em outra instituição; e uma questão aberta para que ele possa indicar qual curso ou workshop realizou.

O questionário foi aplicado como teste para um aluno da graduação e as questões foram reajustadas em seções para que 0 aluno pudesse refletir $e$ responder em uma sequência, sem o conflito em relação a questões internas relacionadas à instituição, referindo-se apenas aos aspectos do uso da linguagem fotográfica em processos de projeto e as possibilidades de captura, e de como recebem essas informações dentro e fora da instituição de ensino.

\subsection{Sobre os métodos para coleta de dados:}

A opção do pesquisador em adotar dois métodos de coleta de dados e campo, entrevistas presenciais com docentes (abordagem qualitativa) e questionário a distância, on-line com alunos (abordagem quantitativa), aqui já apresentados, indica que esta decisão está em conformidade com o propósito do estudo e estes dois modos são eficazes para garantia de excelência na obtenção dos dados.

\subsection{Transcrição das entrevistas e sistematização dos questionários}

Após coletar os dados por meio da entrevista com docentes, se aplicou tecnicamente, a transcrição literal do áudio para a interpretação dos dados. Os questionários direcionados aos alunos, por serem de natureza quantitativa com questões fechadas e abertas, aplicadas virtualmente, foram tabuladas automaticamente.

As entrevistas foram transcritas, juntamente com as observações em notas adicionais realizadas pelo entrevistador, conferidas e comparadas com as gravações realizadas por meio de vídeo e áudio. 
Desta forma, conseguiu-se documentar cada entrevista em sua especificidade e estrutura, permitindo ao pesquisador, futuramente, reconstruir, analisar e fragmentar as narrativas em busca de trechos relevantes à sua pesquisa, sendo que os textos produzidos constroem uma realidade estudada no momento da sua realização, tornando acessível o material empírico em procedimentos interpretativos.

\subsection{Técnicas de tratamento dos dados}

A interpretação de dados é o núcleo das pesquisas qualitativa e quantitativa, e demanda o uso de métodos de pesquisa que consistem na aplicação de técnicas para a interpretação dos textos coletados e transcritos, decidindo assim, posteriormente, sobre quais dados devem ser selecionados.

Pretende-se com isso codificar, organizar e categorizar o material, procedendo à leitura e análise estritamente sequencial do texto, identificando os elementos representativos e fundamentais para a interpretação, o cruzamento, e confronto de informações.

O procedimento utilizado para a análise dos dados obtidos pela amostragem foi a codificação temática identificada como a mais adequada a estudos comparativos, como mencionado por Flick (2009).

Devido às diversas perspectivas provenientes da questão central da pesquisa, a análise dos dados busca identificar se há visões distintas acerca da linguagem fotográfica especificamente utilizada por esses grupos no processo de projeto, em suas diversas variáveis, tanto por parte das instituições de ensino de design, como dos alunos (incluindo na fase de análise, a bibliografia especializada).

Assim, as análises sobre o material, obtidas nas coletas de dados primários, de campo, visam garantir a comparabilidade (assertiva ou em confronto, distinta ou coincidente, prevista e imprevista, entre outras evidências) através de uma triangulação de dados coletados.

Destarte, é possível adquirir a comparabilidade entre dados de entrevistas episódicas e entrevistas on-line semiestruturadas com alunos, mencionados anteriormente.

A codificação temática foi aplicada, nas narrativas resultantes das transcrições das entrevistas com docentes, mediante um procedimento realizado de leitura, seguida de destaque sobre itens relacionados ao tema da linguagem fotográfica no ensino, (incluindo o contexto pedagógico e de práticas na formação 
em Design de produto), desenvolvida em várias etapas. O procedimento da análise qualitativa do conteúdo dos docentes está sintetizado nas etapas:

- A primeira etapa consistiu em definir o material, selecionar as entrevistas ou aquelas partes que sejam relevantes na solução de cada subproblema da pesquisa.

- A segunda etapa compreendeu a análise da coleta de dados (Como foram realizadas as entrevistas? Quem participou? Qual o local da entrevista? De onde vêm os documentos que serão analisados? etc.).

- Na terceira etapa há uma caracterização formal do material (Como foi documentado o material - Gravações em áudio e vídeo. Como foi editado influência da transcrição sobre os textos? etc.).

- Na quarta etapa foi necessário direcionar a análise para os textos selecionados a fim de identificar, de fato, o que se espera interpretar com eles.

- Na sexta etapa a questão da pesquisa foi diferenciada ainda mais, com base em teorias, sendo especificadas em subquestões.

- Na sétima etapa foi definida a menor unidade de codificação, enquadrando-a em uma categoria.

- Na oitava etapa, análises efetivas foram realizadas com referência à questão da pesquisa, elaborando e respondendo questões de validade.

Como se trata de análise qualitativa, fundamentada na narrativa docente, foi selecionada uma ferramenta de análise compatível com a natureza da pesquisa (o software Atlas.ti), a qual está detalhada a seguir.

\subsection{Percurso metodológico da pesquisa com o software Atlas.TI}

Tendo em vista o avanço das tecnologias existentes de análise e cruzamento de dados por meio de documentos digitais ${ }^{36}$, optou-se por utilizar o software Atlas.TI

\footnotetext{
${ }^{36}$ Foi realizada a transcrição completa de todas as entrevistas aplicadas nas instituições de ensino selecionadas.
} 
(Qualitative Research and Solutions), em sua versão 8.0. O software é um exemplo de tecnologia digital (CAQDAS ${ }^{37}$ - Computer Assisted Qualitative Data Analysis Software) que permite diversas possibilidades de emprego estratégico, sistemático e complexo para a análise, portanto para atender ao rigor do método científico e, consequentemente, na escolha e uso corretos dos recursos tecnológicos adequados para a averiguação precisa referente à coleta de dados realizada.

Porém, sua principal função está em garantir uma maior sistematicidade para o trabalho de análise, através da organização do material e do fornecimento de suportes para as ideias do pesquisador, principalmente pelo fato da pesquisa tratar de um grande volume de informações.

Conforme as informações (entrevistas semiestruturadas episódicas - trinta e três entrevistas em profundidade semiestruturadas episódicas), os objetivos e as estratégias da tese, o software permite maior flexibilidade para o cruzamento dos dados necessários em uma análise longitudinal ${ }^{38}$. O software ${ }^{39}$ permite a descoberta de fenômenos complexos que, possivelmente, não seriam identificáveis na simples leitura do texto e no modo tradicional de tratamento dos dados.

O estudo privilegiou o contexto dos processos e a subjetividade envolvidos na transferência de conhecimento de professores de instituições de ensino (estadual, privada e municipal), ligados à graduação de Design de Produto do Estado de São Paulo.

Nesse sentido o uso do software não garante a automaticidade e qualidade à pesquisa, é necessário que o pesquisador tenha conhecimentos para a investigação com o uso da ferramenta, permitindo tornar os resultados mais coerentes, confiáveis e tornando-os mais inteligíveis. Desta forma, o pesquisador deve ter o conhecimento prévio para dar significado aos dados.

$\mathrm{Na}$ literatura específica a respeito da aplicação do software, não foram encontrados estudos que discutam como as articulações dos recursos são aplicadas, por isso, nos tópicos seguintes, será realizado o detalhamento das informações

\footnotetext{
${ }^{37}$ As análises de dados qualitativos assistidos por computador / auxiliados por computador (CAQDAS) oferecem ferramentas que auxiliam na pesquisa qualitativa, como análise de transcrição, codificação e interpretação de texto, abstração recursiva, análise de conteúdo, análise do discurso, metodologia da teoria fundamentada, etc.

${ }^{38}$ Possibilidade de utilização de diversos instrumentos complementares com o objetivo de auxiliar o pesquisador a registrar e possibilitar o acompanhamento dos registros efetuados em cada etapa para confiabilidade do estudo.

${ }^{39}$ É importante destacar que foi necessário que o pesquisador realizasse a aquisição do software e o treinamento completo, pois o mesmo não realiza todas as suas potencialidades sem que se conheçam suas bases para a análise. Assim, foi necessário adequar a teoria desenvolvida para a tese.
} 
desta natureza, para contribuir para o campo e para que novos pesquisadores possam utilizar essa estratégia de pesquisa e interferir, se for o caso. Serão destacadas as potencialidades e recursos indispensáveis durante o processo que realizamos para o cruzamento dos dados.

\subsection{Componentes do software}

O software se apresenta como uma ferramenta de incontestável valor para a análise de dados qualitativos, possibilitando que o pesquisador tenha maior disponibilidade para desempenhar o seu papel principal como analista crítico e reflexivo, pois seus componentes propiciam todas as possibilidades de investigação.

O projeto desenvolvido no software é denominado unidade hermenêutica (Hermeneutic Unit - HU), que permite desenvolver uma análise interligando os principais elementos inseridos ao projeto que são (FRIESE, 2014):

- os documentos primários, dados brutos (Primary Documents - PD, entrevistas em profundidade semiestruturadas episódicas transcritas em forma de texto com a extensão do arquivo DOC, representando as informações que foram coletadas em campo;

- as citações (Quotations) que são fragmentos selecionados dos documentos primários, constituindo os trechos selecionados pelo fato de expressarem alguma ideia que o pesquisador identifica pela relevância para a pesquisa, reduzindo os dados brutos em uma primeira instancia, selecionando aspectos mais relevantes do material;

- os códigos (Codes) são a unidade básica da análise, realizada em um segundo nível de redução dos dados;

- as notas ou anotações (Memos) são as observações e até mesmo conclusões como parte do processo de análise dos dados; 
- as famílias (Families) ou os códigos, que são os conjuntos que agrupam e classificam as citações; agrupamentos que podem ser entendidos como formas de relacionar os dados, fazendo parte do processo interpretativo;

- as redes (Networks) são formas de associar os componentes de uma maneira gráfica, de modo a facilitar a visualização de relações de códigos e entre partes do texto e permitir ao pesquisador, estabelecer conclusões; e

- as saídas (Outputs) são relatórios gerados pelo software, a partir das necessidades da pesquisa, sendo, portanto, possível agregar as diferentes ferramentas e associá-las.

Os elementos aqui apresentados têm como meta descomplicar as diversas possibilidades de visualizar os processos de análise dos dados qualitativos em um menor tempo e com maior confiabilidade. Os elementos dão origem às conexões a serem realizadas para ilustrar as relações que foram identificadas pelo pesquisador, permitindo assim, uma visão mais clara e mais completa dos dados ampliando a confiabilidade.

\subsection{Organização dos dados das entrevistas e questionários}

Os casos estudados foram interpretados a partir de uma breve descrição de cada um, incluindo dados do entrevistado e questões referentes à pesquisa. Esta análise individual permitiu estabelecer a categorização que será utilizada para a comparação entre eles.

Já o cruzamento dos dados obtidos nas observações, com os dados obtidos nas entrevistas tanto dos docentes como dos alunos, foi capaz de estabelecer padrões recorrentes que permitem a interpretação dos resultados obtidos no trabalho de campo.

Estes elementos compõem um processo de codificação e categorização temática, obtidas pelas narrativas que podem ser encontradas nos pontos de vista de cada sujeito participante das entrevistas, que permeiam diferentes domínios de conhecimento do uso da ferramenta e sua aplicação no campo.

Quadro 4 - Codificação e categorização. 


\begin{tabular}{|c|c|}
\hline \multicolumn{2}{|c|}{ Codificação e categorização } \\
\hline Critérios & Codificação temática \\
\hline Abertura para cada texto através de: & $\begin{array}{l}\text { - Princípio da análise de casos } \\
\text { - Breve caracterização do caso }\end{array}$ \\
\hline $\begin{array}{l}\text { Estruturação (por exemplo aprofundamento) } \\
\text { do assunto: }\end{array}$ & $\begin{array}{l}\text { - Elaboração de uma estrutura temática para } \\
\text { a análise de casos } \\
\text { - Distribuição essencial e social de perspectivas }\end{array}$ \\
\hline $\begin{array}{l}\text { Contribuição ao desenvolvimento geral da in- } \\
\text { terpretação como método: }\end{array}$ & $\begin{array}{l}\text { - Comparação de grupos em relação ao assun- } \\
\text { to após a análise de casos }\end{array}$ \\
\hline Domínio da aplicação & - Comparações de grupo \\
\hline Problemas na aplicação & $\begin{array}{l}\text { - Consome tempo devido à posição intermedi- } \\
\text { ária da etapa da análise de casos }\end{array}$ \\
\hline Limitações do método & $\begin{array}{l}\text { - Limitada a estudos com grupos comparati- } \\
\text { vos pré-definidos }\end{array}$ \\
\hline Referências & - Flick $(1994 ; 1995 a)$ \\
\hline
\end{tabular}

Fonte: Tabela adaptada com base em Flick (2004, p. 224-225).

Assim, as análises de textos consistem em reduzir enunciados e narrativas a categorias, voltando-se à elaboração de semelhanças e diferenças detectadas em ambos os grupos.

\subsection{Organização e categorização através do software Atlas.ti}

A análise do conteúdo das trinta e seis entrevistas ${ }^{40}$ (semiestruturadas episódicas, transcritas no formado DOC), foi realizada após receberem um código alfanumérico, possibilitando a identificação do docente participante e o número de ordem da coleta de dados realizada, procedendo-se então uma leitura flutuante ${ }^{41}$ (pré-análise) e seleção manual (processo em papel) de passagens relevantes. Após nova leitura exaustiva de todo o material (no software), para analisar as informações que contemplem os objetivos da pesquisa, foram identificadas as unidades de análise, que são os fragmentos de texto selecionados e que serão interpretados (free quotation) por se tratarem de dados significativos e relevantes (unidade de

\footnotetext{
${ }^{40}$ Três entrevistas foram descartadas por enquadrarem em instituições fora do foco da pesquisa e por não se adequarem ao escopo necessário.

${ }^{41} \mathrm{Na}$ hermenêutica, a primeira etapa constitui-se na leitura inicial do texto (RICOEUR, 2016).
} 
análise), identificando-os com a definição de nomenclaturas extraídas da nuvem de palavras obtidas de todas as entrevistas (Figura 44).

Figura 44 - Nuvem de palavras.

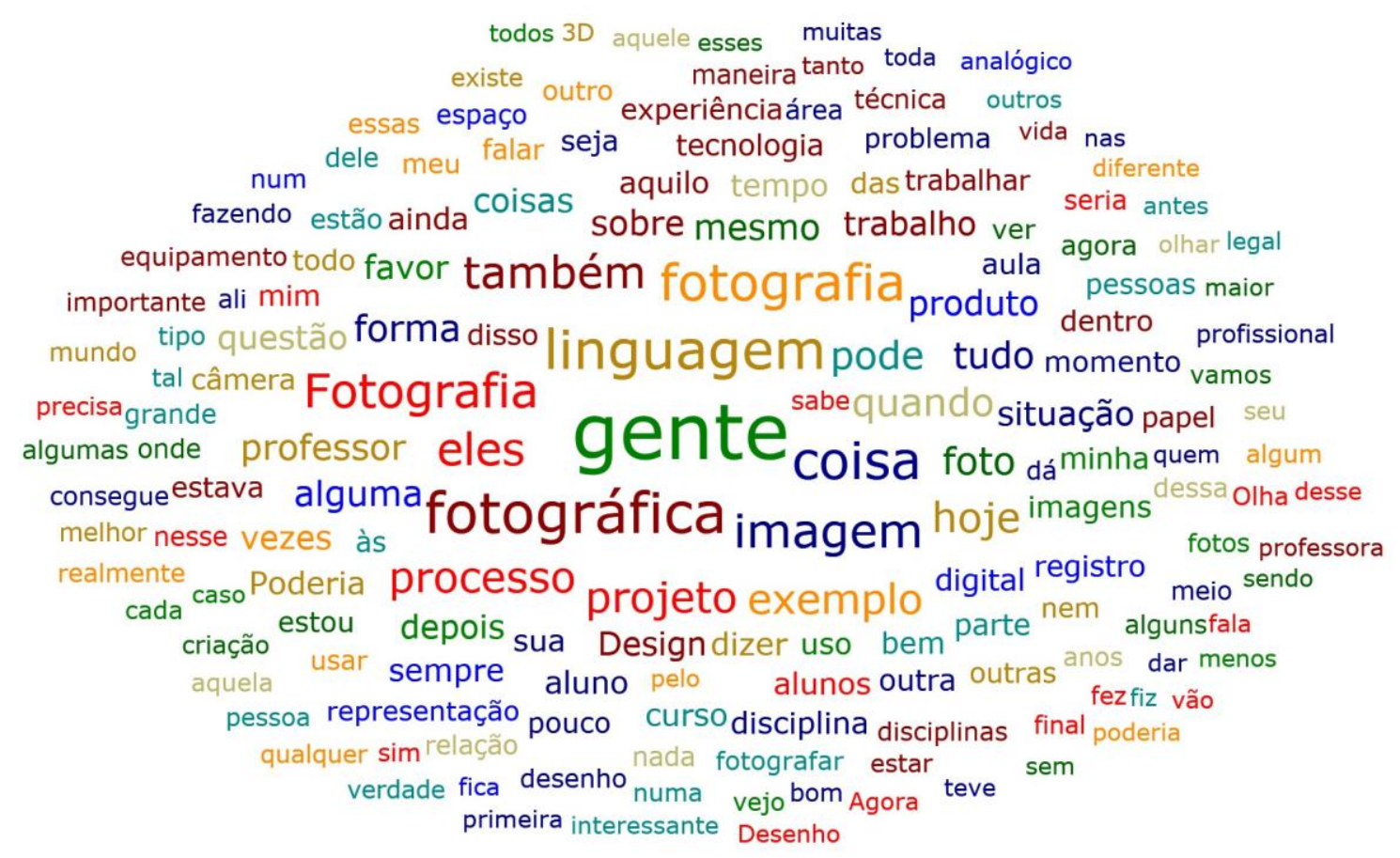

Fonte: elaborado pelo autor (2017).

O recurso da nuvem de palavras foi relevante para a contagem de palavras, e auxiliou no desenvolvimento de uma análise textual, gerada a partir de todos os vocábulos contidos nos documentos, em ordem alfabética e número de frequência, depois transpostas em uma planilha (Excel), expondo as recorrências mais utilizadas durante as entrevistas (após exclusão de artigos, pronomes, adjetivos e alguns verbos que mascaravam os resultados fundamentais).

Após esse procedimento, utilizou-se desta base para a inserção das palavras relacionadas aos códigos, para o procedimento de autocodificação (recurso do software), onde os vocábulos foram selecionados automaticamente nas entrevistas, após etapa de conferencia e filtragem, pois nem tudo que foi automaticamente codificado na nuvem trata-se efetivamente do contexto a ser analisado para a construção das categorias. 
Ao realizar essa busca, tanto manual como automática, novos significados surgiram e outras unidades de análise foram localizadas de acordo com o referencial teórico adotado na pesquisa e os objetivos propostos na tese, resultando numa base para a construção dos códigos por categoria; codificação seleção de fragmentos e associações para conduzir inferências e interpretação das redes, conexões e contradições identificadas no software. Essa redução de possibilidade de análise permitiu observar, compreender e interpretar o que há por trás dos discursos dos diferentes docentes relevantes para o problema de investigação.

A seleção de palavras sobre as experiências dos docentes entrevistados elegeu algumas categorias de análise que são: design análise, design investigação, design de produto, ensino, ferramentas, linguagem fotográfica, representação e tecnologia. Na figura 45 podemos observar o esquema produzido, que apresenta as relações estabelecidas entre os elementos estruturantes dos grupos de códigos gerado.

Figura 45 - Relações entre os elementos estruturantes.

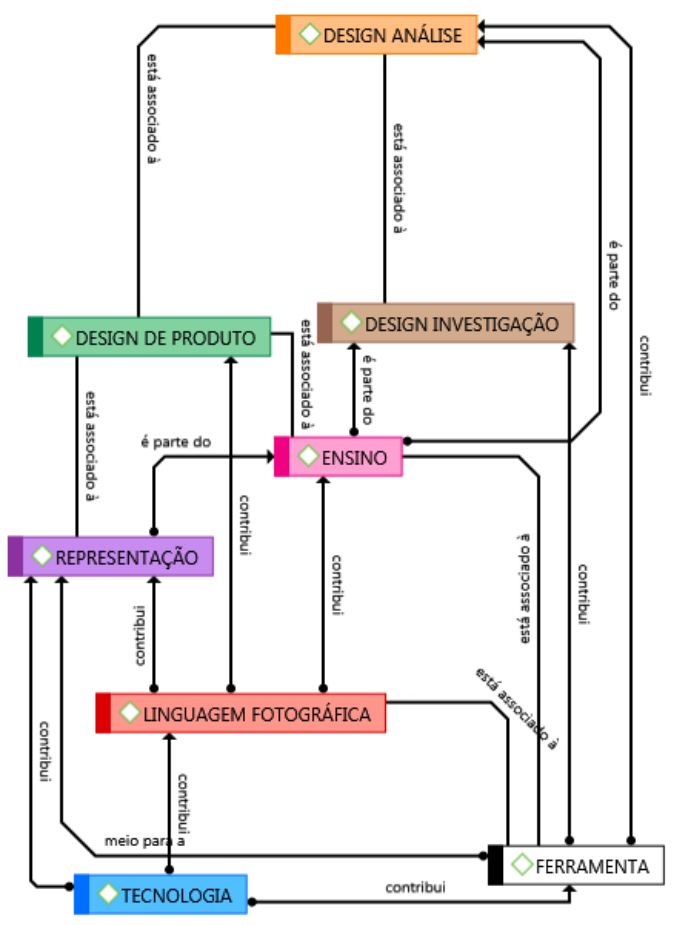

Fonte: elaborado pelo autor (2017). 
Dentre essas categorias, foram geradas 93 palavras (figura 46), que correspondem aos elementos estruturantes para a etapa de análise de dados, representando toda citação que indique os motivos que originam conhecimentos e ações realizadas pelos professores em relação à linguagem fotográfica e a formação em Design de Produto.

Figura 46 - Elementos estruturantes da análise.

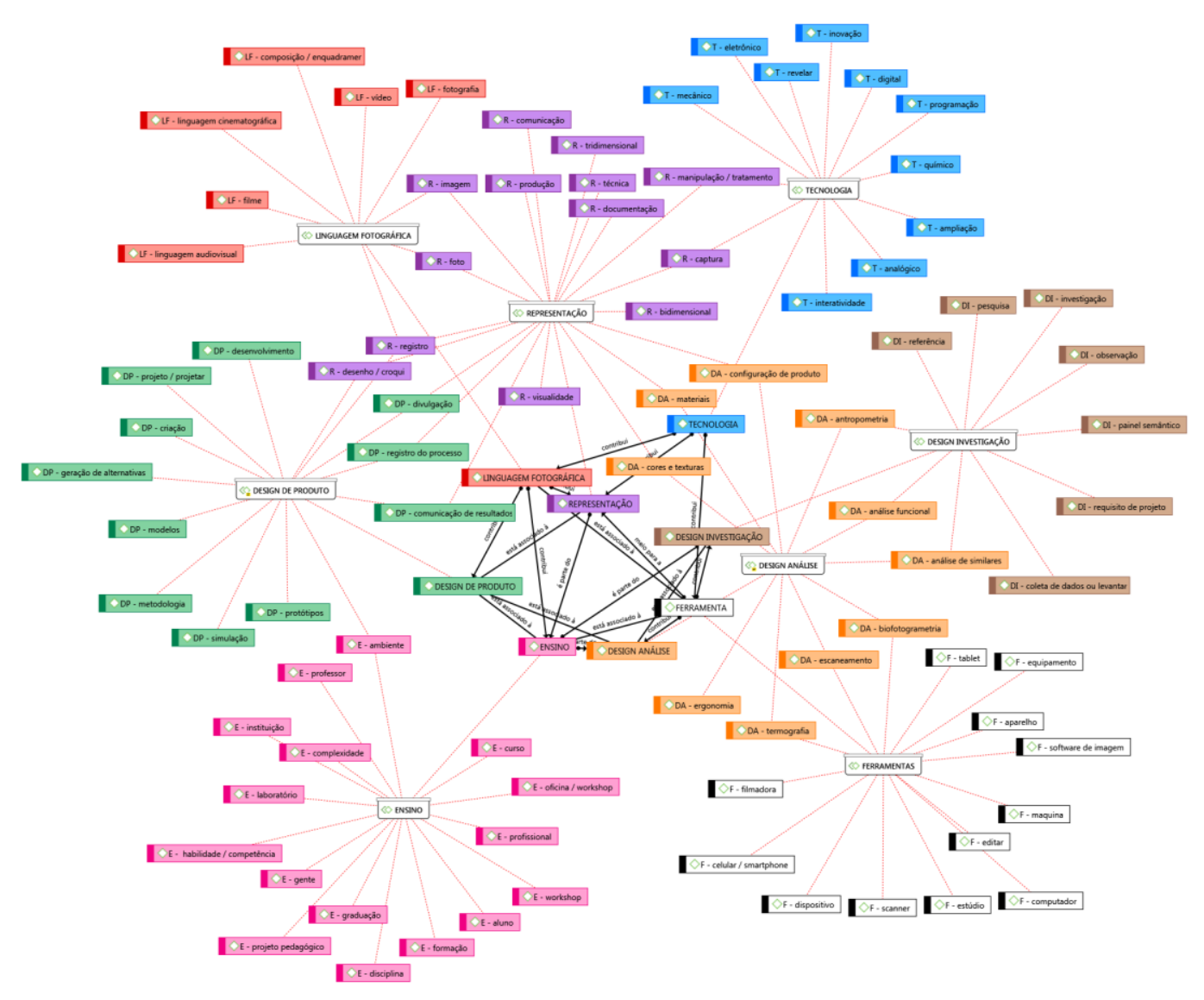

Fonte: Elaborado pelo autor (2017).

Outra fase importante foi a geração de 23 grupos de documentos para a tabulação de informações, como a década de nascimento de cada docente (apêndice d); gênero (apêndice d); qual foi sua graduação (apêndice d); titulação máxima (graduação; especialização; mestrado e doutorado - apêndice d) e qual o modelo da instituição (estadual; privada ou municipal - apêndice d).

O processo de organização e sistematização passou por oito fases:

- Organização do material para responder aos objetivos da tese quando foi necessária a preparação dos materiais (exploração do material); 
- Identificação e codificação dos documentos (interferência individual);

- Criação das unidades hermenêuticas;

- Associação dos documentos primários;

- Descoberta das passagens relevantes;

- Construção dos códigos a partir da nuvem de palavras;

- Seleção de segmentos do texto; e

- Criação dos memos (reflexão sobre os dados obtidos através do software).

\subsection{Inferências e interpretação dos resultados}

Nesta etapa reunimos as entrevistas, que já estavam preparadas para a análise, para identificar as diferentes informações no sentido de dar continuidade ao processo de categorização e classificação das unidades, assim, agrupamos os dados de acordo com as semelhanças e analogias, com base no problema e objetivos da tese.

Cada código recebeu um nome correspondente à categoria estipulada, e foram identificadas por meio da nuvem de palavras geral. Na medida em que a leitura foi realizada pelo pesquisador, inseriu-se a codificação no documento em um processo semiautomático e a auto codificação do software (figura 47), sendo que as citações ficam salvas e podem ser utilizadas para a construção de uma hierarquia demonstrando todas as ocorrências dos códigos relacionados às citações.

Figura 47 - Exemplo de codificação do documento.

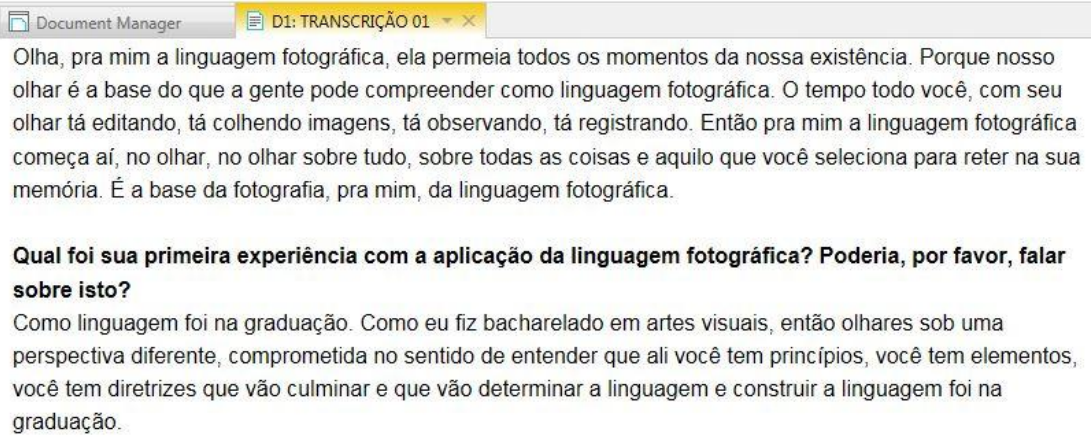
olhar é a base do que a gente pode compreender como linguagem fotográfica. O tempo todo você, com seu olhar tá editando, tá colhendo imagens, tá observando, tá registrando. Então pra mim a linguagem fotográfica começa aí, no olhar, no olhar sobre tudo, sobre todas as coisas e aquilo que você seleciona para reter na sua memória. É a base da fotografia, pra mim, da linguagem fotográfica.

Qual foi sua primeira experiência com a aplicação da linguagem fotográfica? Poderia, por favor, falar sobre isto?

Como linguagem foi na graduação. Como eu fiz bacharelado em artes visuais, então olhares sob uma perspectiva diferente, comprometida no sentido de entender que ali você tem princípios, você tem elementos, você tem diretrizes que vão culminar e que vão determinar a linguagem e construir a linguagem foi na graduação.

Fonte: elaborado pelo autor (2017).

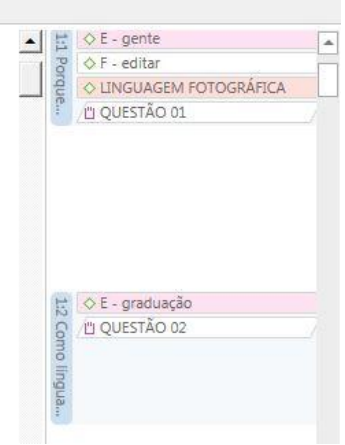


Portanto, a partir dos códigos primários obtidos na primeira leitura, uma segunda codificação foi realizada, com olhar atento para as informações do texto; a forma de escrita e os destaques utilizados. Cada família de significação foi formulada, tendo em vista as codificações previamente realizadas, com a finalidade de compor a análise de forma reflexiva, apreendendo os dados que emergem e estão submersos nas entrevistas.

Os elementos estruturantes da categorização Design Análise, estão representados na figura 48, onde são mostrados os códigos referentes aos processos para transformar os requisitos de projeto em um design do sistema a ser desenvolvido.

\section{Figura 48 - Categorização Design Análise}

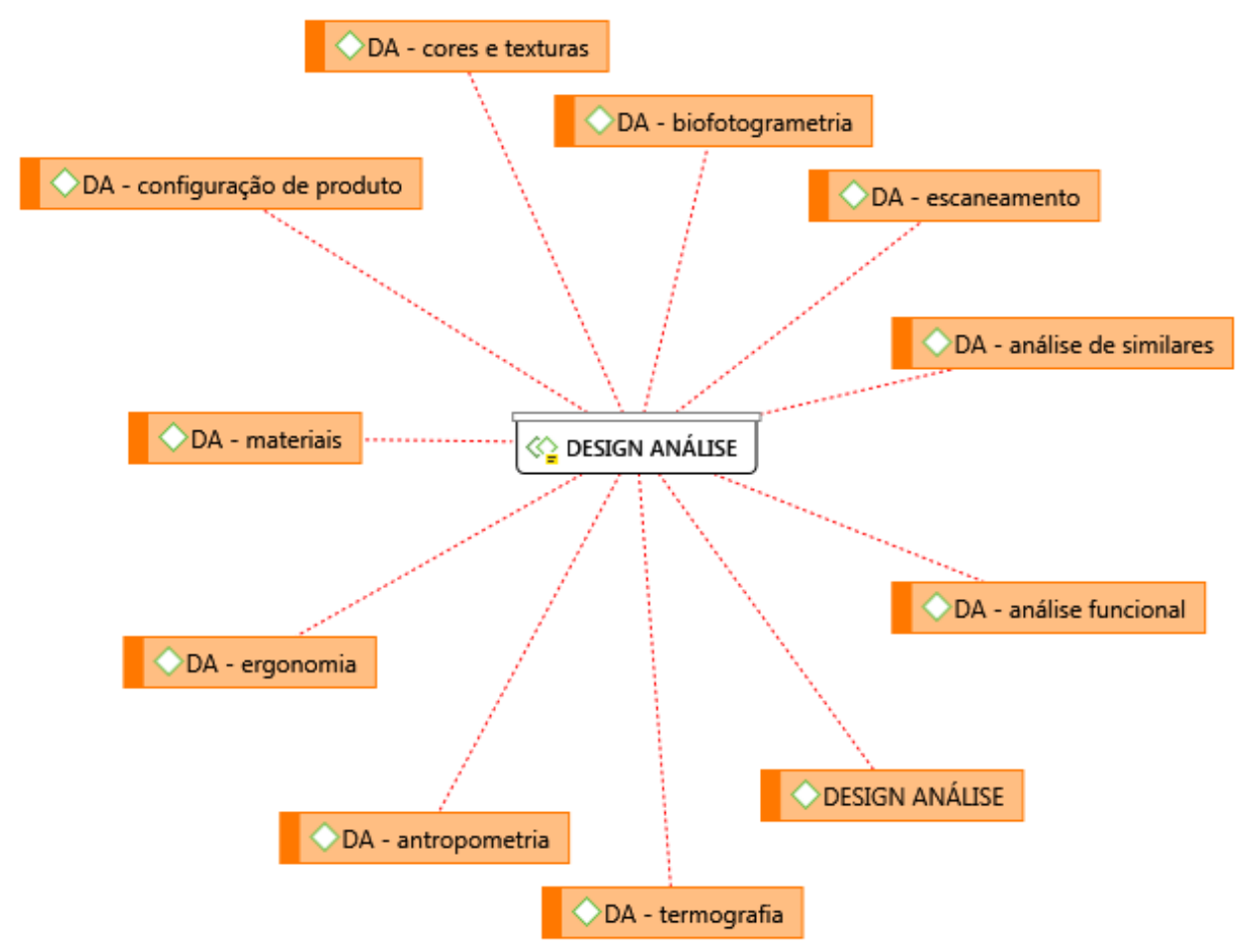

Fonte: elaborado pelo autor (2017).

Os elementos estruturantes da categorização Design de Produto estão representados na figura 49 , onde estão apresentados os códigos e relações referentes aos processos e possibilidades de criação e produção de objetos e produtos. 
Figura 49 - Categorização Design de Produto.

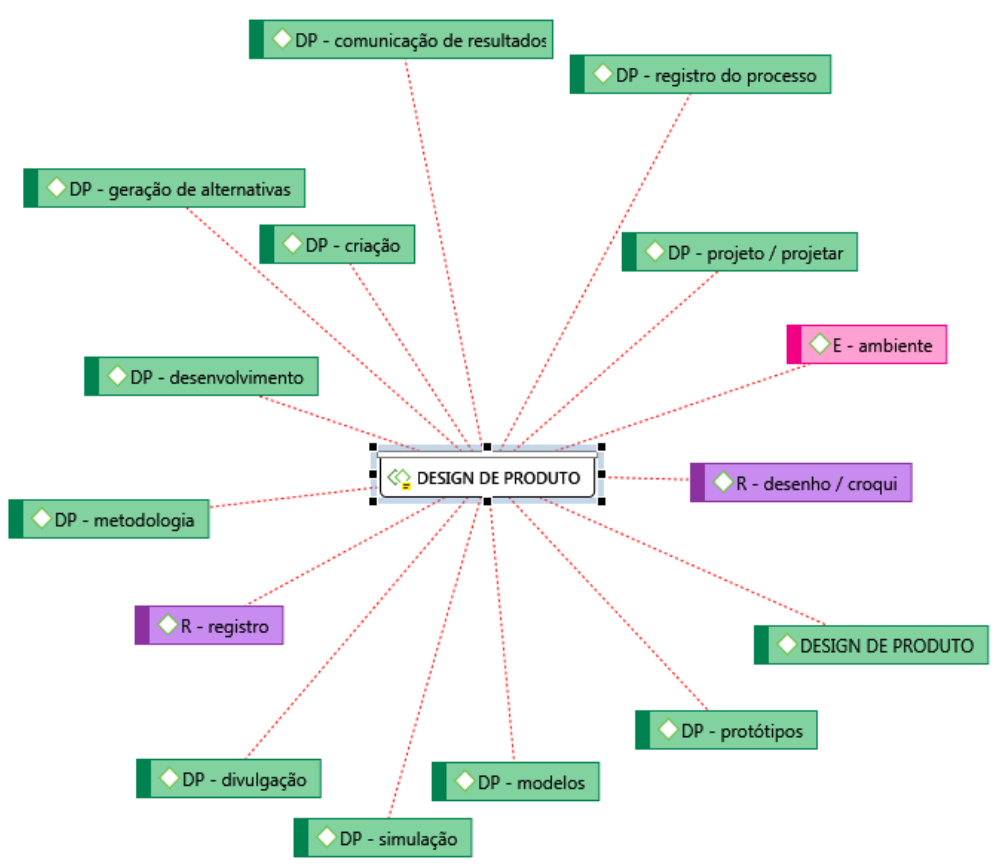

Fonte: elaborado pelo autor (2017).

Os elementos estruturantes da categorização Design Investigação estão representados na figura 50 , onde se apresentam os códigos e relações referentes as aplicações metodológicas de investigação em projetos de forma prática e teórica.

Figura 50 - Categorização Design Investigação.

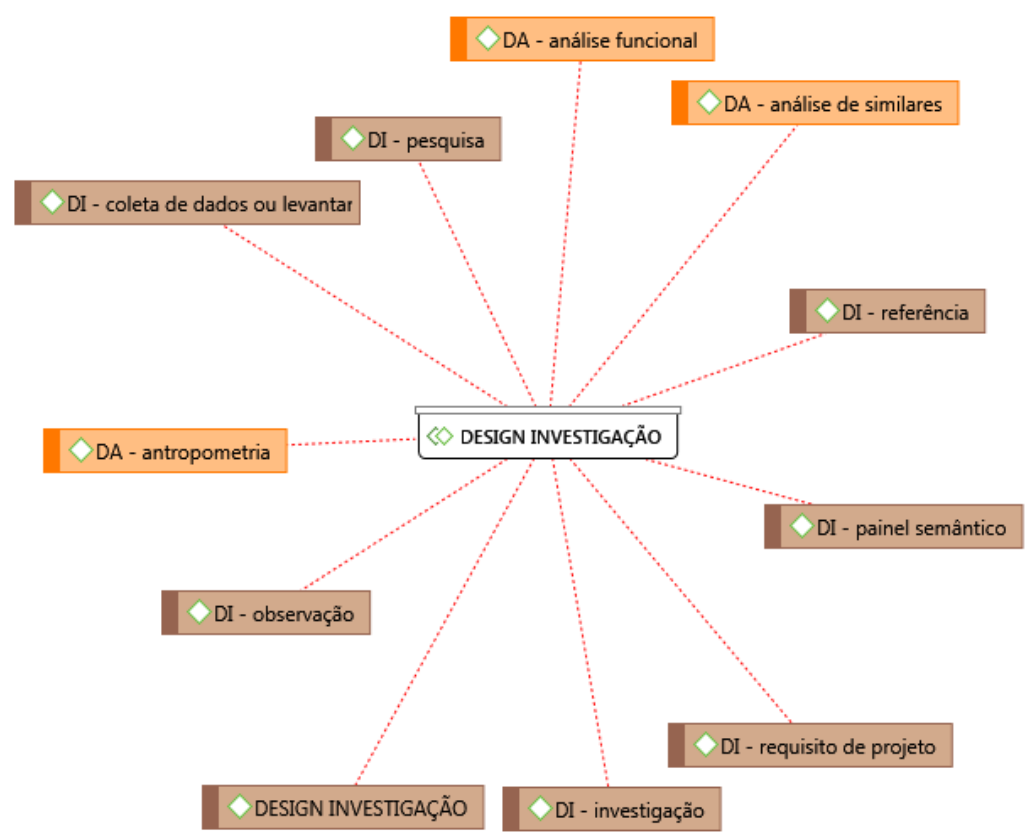

Fonte: elaborado pelo autor (2017). 
$\mathrm{Na}$ figura 51 estão representados os elementos estruturantes da categorização ensino, onde estão sediados os códigos, para identificar como uma unidade de organização institucional proporciona o ensino da linguagem fotográfica ao aluno de Design de Produto.

Figura 51 - Categorização ensino.

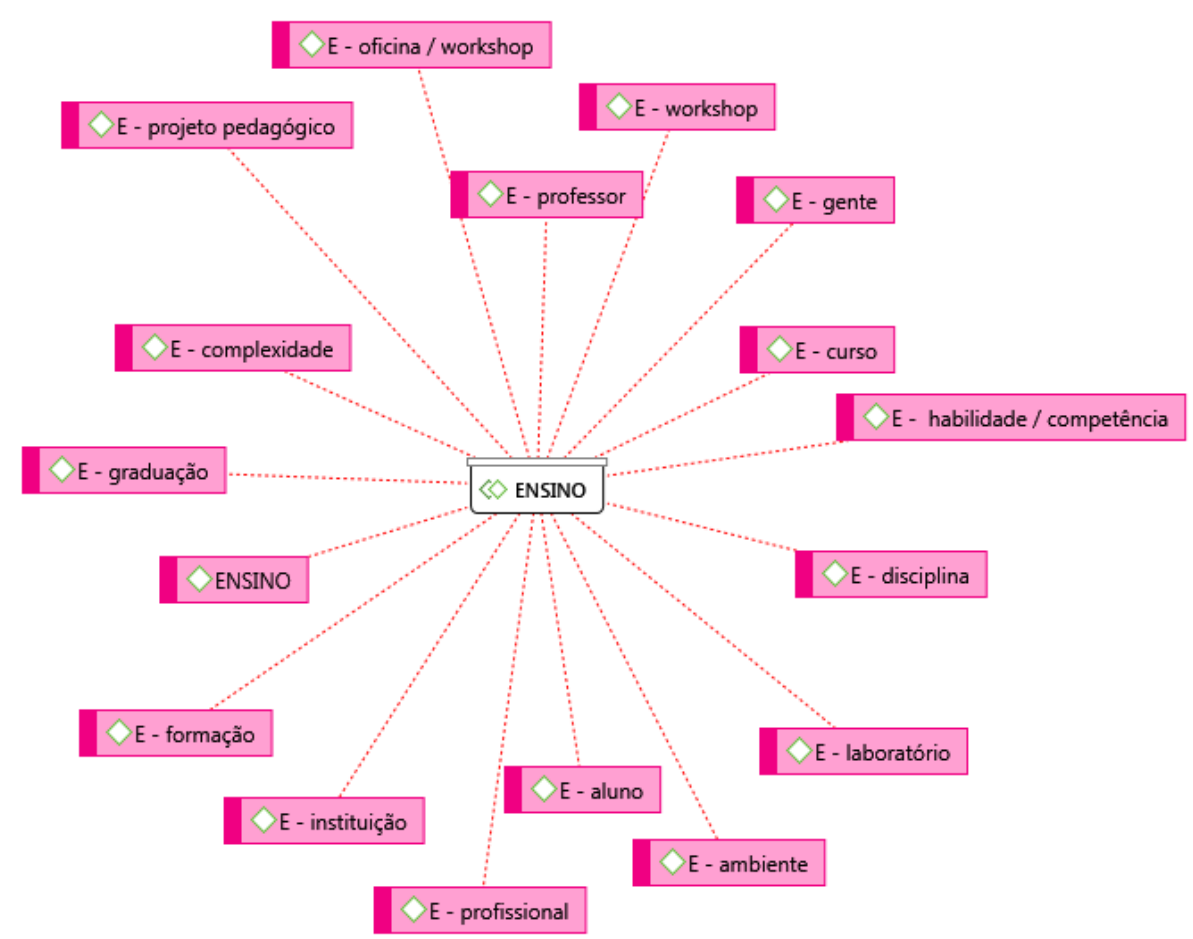

Fonte: elaborado pelo autor (2017).

Nas figuras 52, 53, 54, 55 seguem os elementos para as categorizações sobre os temas: Ferramentas; Linguagem fotográfica; Representação; e Tecnologia.

$\mathrm{Na}$ figura 52 estão representados os elementos estruturantes da categorização Ferramentas, onde apresentamos os códigos, para identificar como as técnicas e as ferramentas fazem parte do ensino do Design, buscando maior eficiência nos processos de projetos. 
Figura 52 - Categorização Ferramentas.

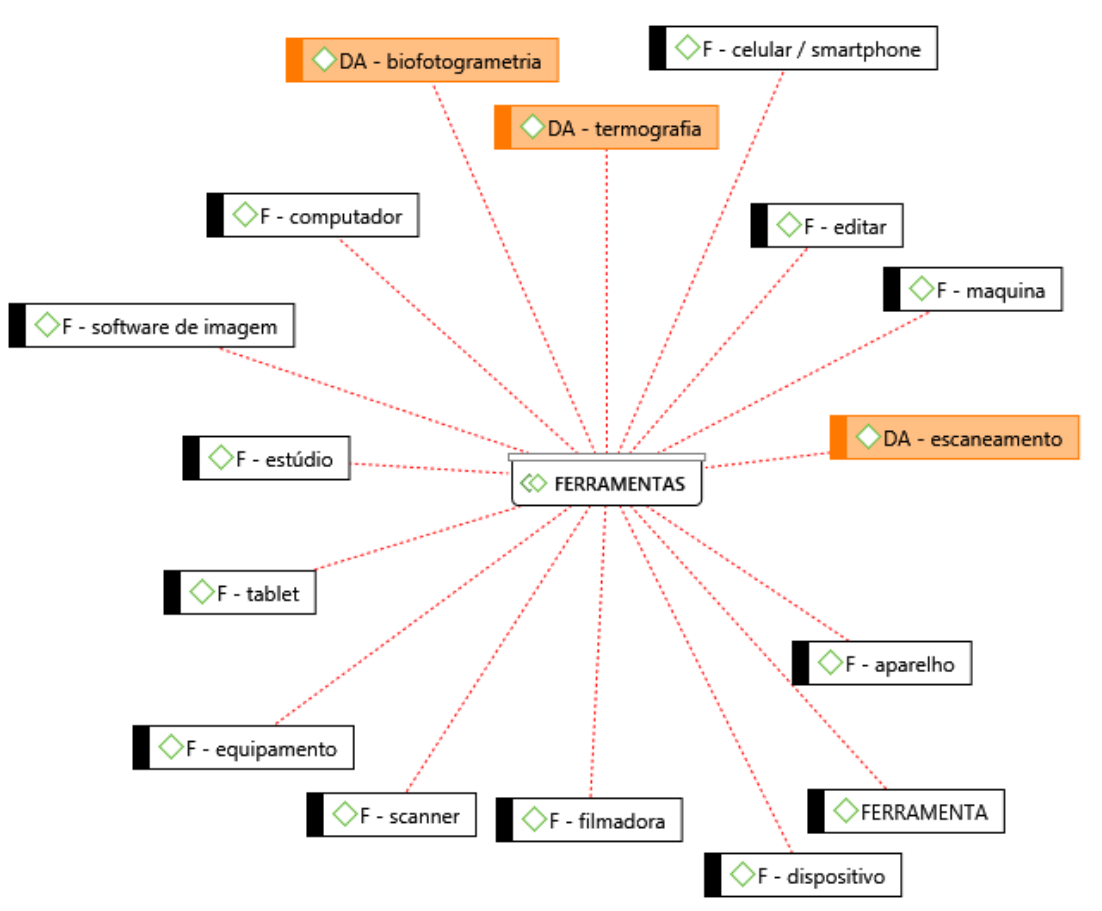

Fonte: elaborado pelo autor (2017).

$\mathrm{Na}$ figura 53 estão representados os elementos estruturantes da categorização Linguagem Fotográfica (LF), onde apresentamos os códigos ligados às linguagens de captura fixa ou em movimento e que interferem na formação do designer como uma importante ferramenta auxiliar para o processo de projeto.

Figura 53 - Categorização Linguagem Fotográfica.

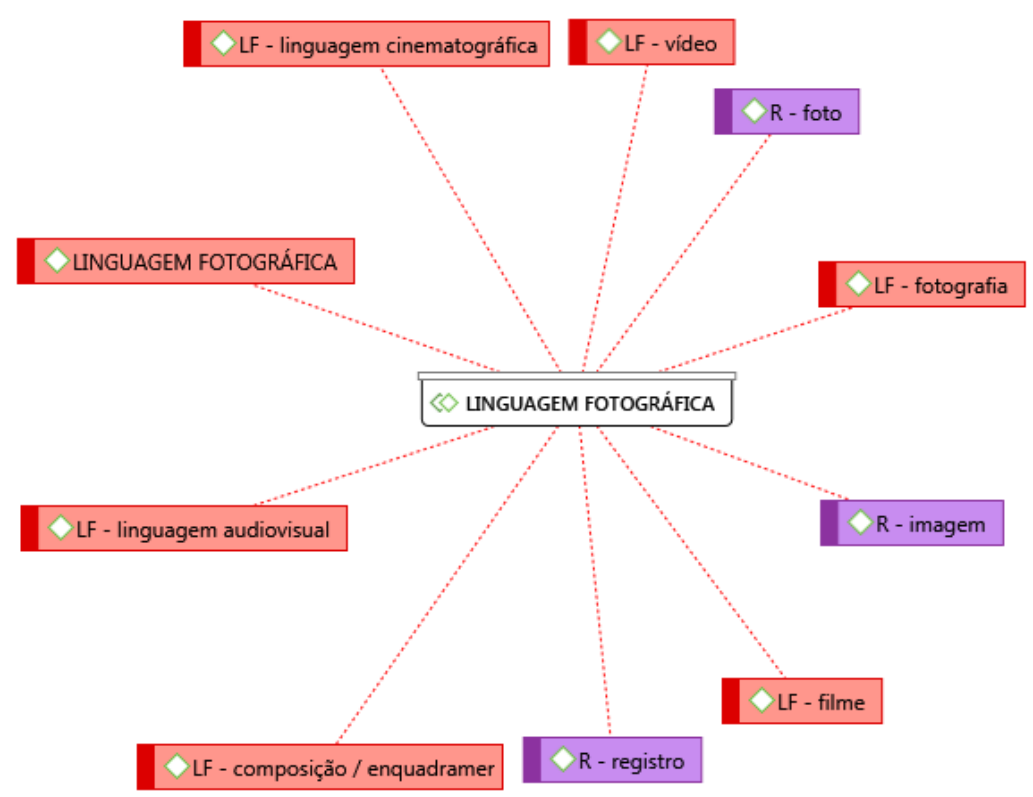


Fonte: elaborado pelo autor (2017).

$\mathrm{Na}$ figura 54 estão representados os elementos estruturantes da categorização Representação, onde apresentamos os códigos relacionados às possibilidades de representações realizadas pelo designer. Dessa forma, muitos recursos podem ser empregados, variando dos mais precisos aos mais abstratos.

Figura 54 - Categorização Representação.

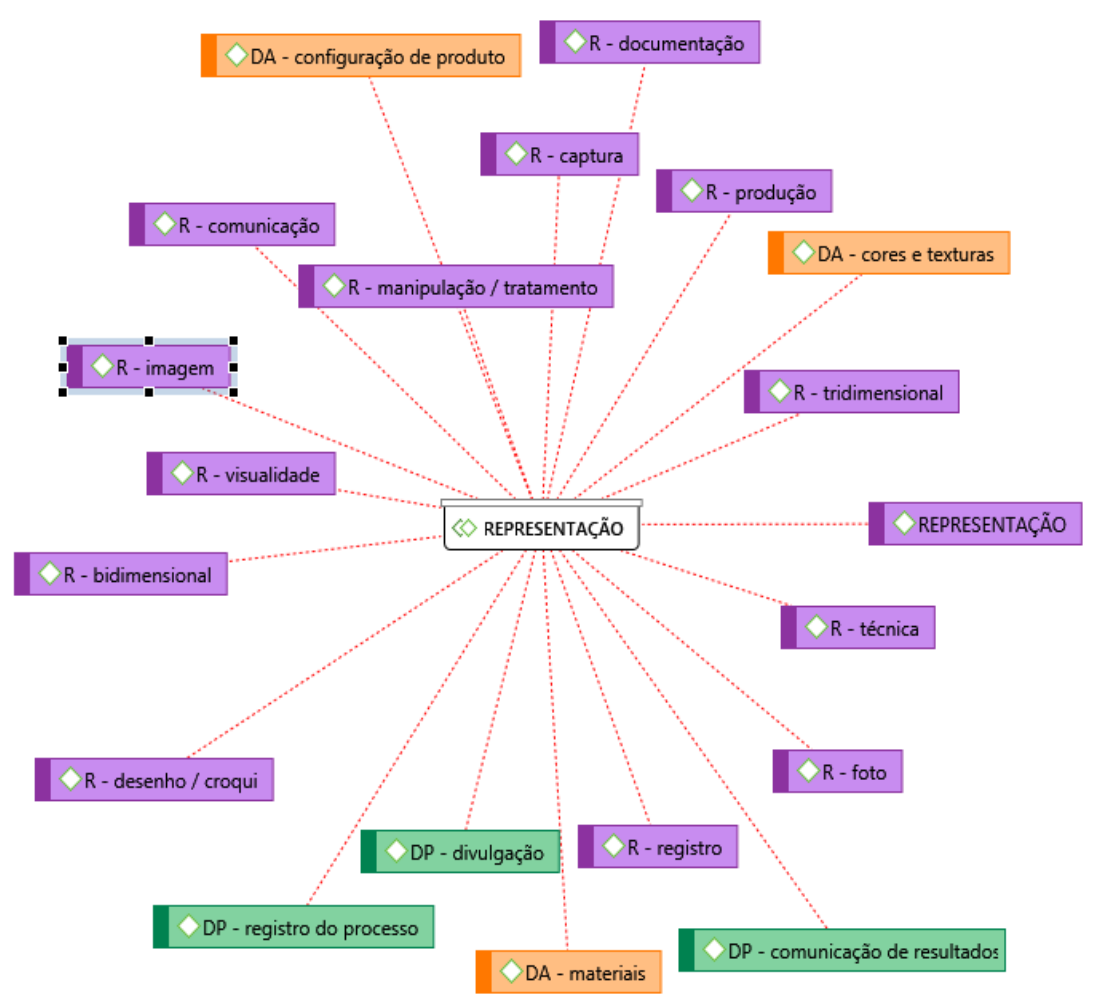

Fonte: elaborado pelo autor (2017).

$\mathrm{Na}$ figura 55 estão representados os elementos estruturantes da categorização Tecnologia, onde apresentamos os códigos ligados às mudanças dos sistemas analógico/mecânico e digital/eletrônico, ocasiões em que suas concepções modificam as necessidades de aplicação das ferramentas. 


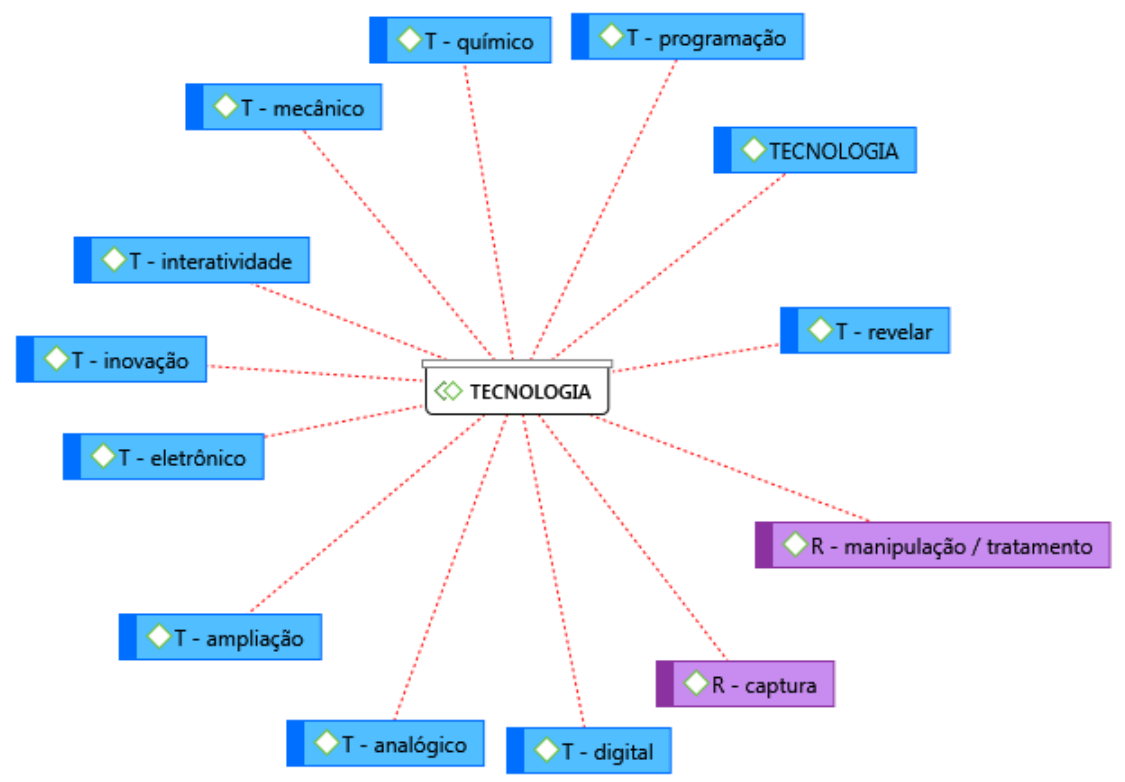

Fonte: elaborado pelo autor (2017).

Também foi necessário localizar o sinônimo de cada codificação, para identificar possíveis variações na fala do entrevistado, o que levou um tempo maior na aplicação desse processo de localização do trecho da narrativa dos entrevistados em as entrevistas, referentes as temáticas fixadas. Nesta etapa, as transcrições das falas dos participantes (docentes) foram filtradas, interpretadas e analisadas para obtenção de resultados necessários para a descrição de um texto final interpretativo. 
CAPÍTULO 06 


\section{ANÁLISES E RESULTADOS}

\subsection{Mudanças fundamentais do papel da fotografia no processo projetual, contextualizada na evolução da tecnologia}

No processo evolutivo, a fotografia e o vídeo vêm sendo expandidos e aprofundados em diversas incursões teóricas, práticas e tecnológicas, que se intensificaram nas últimas décadas devido à sua mudança de formato (analógico/mecânico x digital/eletrônico) e que passa a ser utilizada constantemente por ter um grande potencial, pois carrega uma carga muito grande como uma linguagem, onde a imagem é memorizada de forma numérica e não mais por processos fotoquímicos.

Essa ruptura repercutiu definitivamente na sociedade, que descobriu a inevitável manipulação que opera o processo de toda imagem. Tal ruptura, que atingiu seu auge assumindo todas as antigas aplicações da fotografia fotoquímica. Essa constante discussão se realiza à luz do fato da fotografia ser base tecnológica, conceitual e ideológica das diversas mídias contemporâneas. Machado (2000) acrescenta que o desenvolvimento tecnológico e a criação de novas técnicas de produção e reprodução de imagens, viabilizadas por meio da tecnologia, propiciaram a proliferação das mesmas em grande escala, contribuindo decisivamente e constantemente para o esquecimento da fotografia, anteriormente vista como uma atividade de extrema perícia técnica, devido a conceitos científicos acumulados por um período de cinco séculos de pesquisa na Ótica, na Mecânica e na Química.

A perícia técnica e conhecimentos científicos aplicados à linguagem fotográfica chamam a atenção devido às suas potencialidades para a compreensão da linguagem. Alguns respondentes esclarecem essa potencialidade e sua necessidade:

[...] o contato do analógico, ele força o estudante a compreensão da técnica com a linguagem. Então força o estudante a sair do automático do disparo, então a própria manutenção aqui do sistema analógico é uma manutenção didática (fragmento D15/15:16).

[...] então no revelador, quando ele vê a imagem surgindo assim, na folha de papel branco, isso é uma coisa assim, que é inesquecível para quem gosta de Fotografia, quem gosta de imagem. Então essa experiência, não existe nada que substitua essa experiência de ver a foto surgindo (fragmento D35/35:23). 
[...] a fotografia branca e preta, a linguagem dela, você trabalhando com a câmera manual, você tem experiência nisso, você faz a tua luz, você faz a tua sombra, você consegue, dependendo da sensibilidade do filme, você consegue efeitos incríveis na fotografia branca e preta (fragmento D4/4:4).

Entretanto, "[...] as faculdades, as escolas, por questões de custo, de espaço físico, de tempo do processo de aprendizagem, claro que falando no analógico é muito mais complicado, demanda muito mais tempo e muito mais recurso" (fragmento D22/22:29), porém, "[...] a Fotografia analógica, ela não vai acabar. Obviamente, ela não vai acabar porque ela traz consigo todos esses detalhes, essas características importantíssimas, já dentro de um processo" (fragmento D22/22:30).

[...] o aluno, ele dá pouca, pelo menos eu percebo isso nos alunos de Design, ele dá pouco valor, dá pouca importância, ao espaço que nós temos de laboratório, quer dizer, tem um laboratório ainda analógico, de fotografia em preto e branco e um laboratório de o estúdio [...] (fragmento D23/23:12).

No entanto, dentro das instituições não será viável devido aos altos custos dos materiais e manutenção dos equipamentos cada vez mais escassos, como relata um dos entrevistados:

[...] com o passar do tempo, isso acabou se tornando obsoleto, então com o advento das câmeras digitais, nós não temos mais essa necessidade. Alguns alunos apresentam ainda algum interesse em relação a: "Eu gostaria de ver revelação, como que é?" Mas acaba sendo um processo que se torna improdutivo (fragmento D5/5:17).

Desta forma um dos respondentes apresenta um ponto importante e que deve ser analisado no processo de ensino da linguagem fotográfica:

"[...] hoje, as escolas ou o processo do ensino da Fotografia, se ele tão tiver realmente um momento em que possa participar como foi feito dentro da fotografia analógica, é difícil. Eu vejo que os alunos, eles passam por ela como passam por outras experiências, mas fica a desejar, quer dizer, fica só a imagem pela imagem, o conteúdo de megabits carregando, enchendo cartões, carregando HD, enchendo redes sociais, enchendo Flickers, Instagram, de um monte... é um monte das mesmas coisas de imagens (fragmento D22/22:28).

Conforme a análise de campo, esse processo de mudança não está sendo realizado nas instituições devido à dificuldade de encontrar possibilidades didáticas como as que foram criadas ao longo do tempo com processo fotoquímico, mas que requer um alto investimento por parte da instituição. 
Mesmo com essa defasagem no ensino, devido à falta de conhecimento por consequência da transposição da tecnologia, a opinião de vários participantes da pesquisa é a seguinte:

[...] o sistema digital facilitou muito o uso da Fotografia. Então, no início da profissão era muito complicado utilizar, porque exatamente você tinha que ter um aparato técnico e você tinha que tem um conhecimento técnico muito grande. Diferente de hoje, o meio digital facilitou demais, então você consegue tirar fotografia, ao mesmo tempo já consegue ver como ficou, ao mesmo tempo já tratar, então o processo ficou muito rápido (fragmento D25/25:25).

[...] com a tecnologia digital e com o acesso que a tecnologia digital, facilidade de acesso que a própria tecnologia digital traz, eu acredito que o emprego da linguagem, na verdade o emprego do dispositivo e consequentemente 0 emprego da linguagem, ele foi amplificado [...] (fragmento D1/1:22).

"[...] com o advento da fotografia digital, você busca outras formas também, aí você busca outra dinâmica, porque ela te favorece a rapidez de você ver 0 resultado imediato" (fragmento D4/4:5). "[...] é importante a gente conhecer sim o processo analógico, mas hoje não dá mais, de forma nenhuma, para você ficar sem se envolver cada vez mais na questão do digital, da Fotografia Digital" (fragmento D28/28:16)

Mesmo sendo a imagem digital mais vantajosa que a analógica, ela também tem suas desvantagens, como relatam os entrevistados:

[...] é uma vantagem, mas também, uma desvantagem que a Fotografia tem é que ela é digital, ela pode ter vários tamanhos e ela vai ocupando um espaço enorme, então, a gente está acumulando uma quantidade de fotografia enorme. E depois que virou digital a gente nunca mais imprimiu nada, nunca mais ampliou nada, não tem mais álbum quase nenhum de foto, tudo no Flicker, no celular, no computador, um porta retrato digital, ninguém mais faz álbum (fragmento D7/7:41).

[...] o acesso, ela facilita a exploração da linguagem e o emprego da linguagem no fazer projetual, que antes você dependia, você ficava muito restrito a ter um excelente equipamento, a ter recursos para poder revelar aquele filme, para poder ampliar aquela fotografia (fragmento D1/1:23).

[...] com as câmeras digitais você vai vendo, tem câmera que você consegue analisar tudo. E toda vez que a gente fica muito digital, a gente fica muito rápido, muito eficiente, mas perde um pouco, eu acho, de expressividade e um pouco de entendimento do que você realmente está fazendo, o que você está conseguindo. Muita coisa acaba sendo mais automática, do que você sabe realmente o que está fazendo (fragmento D11/11:5). 
[...] aproveitando esse momento, é um distanciamento, daquilo que se foi feito antes. Então, só o fato de você chegar hoje dentro da fotografia digital, dentro do ambiente digital, e querer trabalhar tudo isso, eu não sei se só isso resolve, se só isso vai criar no aluno uma relação mais íntima com a Fotografia. Então assim, instituições que ainda podem oferecer ou até praticar um pouco da Fotografia Analógica, eu vejo que aí está a essência de trazer o aluno para dentro da Fotografia, para que ele possa criar uma empatia maior, uma relação mais íntima com ela e isso você faz no ambiente analógico, porque ali você tem tempo, tempo de reflexão (fragmento D22/22:23).

Em contrapartida, há quem relate que surgiram diversas mudanças como mencionado nos depoimentos a seguir: "[...] na nossa universidade, no momento em que surgiu a fotografia Digital, ávida de uma certa forma, por parte dos professores que eram responsáveis da área, uma descrença, imaginando que não fosse, de forma nenhuma, vingar" (fragmento D28/28:15). Uma das principais mudanças destacadas é a da velocidade tanto no processo de produção quanto na aquisição de imagem, "[...] então você aprendia as técnicas de expressão, para você conseguir representar a fotografia, hoje você não tem mais essa necessidade, esse tempo. Então, nesses casos, a fotografia avançou o tempo de produção [...]" (fragmento D25/25:38).

[...] o processo analógico era demorado, você tinha que revelar o filme, esperar que ele secasse, depois fazer sua cópia, fazer o copião, depois fazer a ampliação, ver se as fotos estavam realmente boas. Aí vai, você perdia muitas fotos que eram tremidas, ou desfocadas, ou mal iluminadas, então a perda era muito grande (fragmento D4/4:26).

[...] a parte ruim de você não ser mais analógico, de você perder todas aquelas questões de entendimento realmente do que você está fazendo. Em contra partida, a velocidade é muito maior. O resultado é muito mais rápido, a produtividade é muito maior (fragmento D11/11:13).

[...] é uma questão de proposição e você ir tentando romper essa resistência que a facilidade que os meios eletrônicos trouxeram, de você apertar o botão e a foto estar pronta, de ele perceber que: "Olha!, Se eu demorar um pouquinho mais, não é questão de que a imagem vai estar diferente, sou eu que vou ter uma relação mais duradoura, mais longa e consequentemente, eu posso abrir os meus horizontes em função de que eu estou tendo um tempo de maior qualidade com aquilo que eu estou investigando" (fragmento D20/20:26).

Destaca-se, também, outro depoimento muito similar aos anteriores, no qual se verifica que:

[...] hoje, ao mesmo tempo que você tira, você transfere, você já tá no seu computador, você faz upload daquilo, faz download daquilo, tá ali, você trata no software de edição e a rapidez e a facilidade de manipulação dessa imagem, que antes a manipulação também tinha uma limitação, no âmbito 
de quando você estava ali revelando, e logo depois da revelação e com a tecnologia digital isso ganha assim, você tanto manipula durante, você tanto pode manipular durante a aquisição como registro, quanto depois, na pós produção (fragmento D1/1:91).

Um dos respondentes apresenta uma das possibilidades para que os alunos tenham acesso ao mundo digital: "[...] a ideia foi exatamente fazer uma parceria, mesmo porque a gente nem sempre vai conseguir reciclar o nosso equipamento tão rápido, então teve essa ideia e teve também a ideia por conta de professores qualificados [...]" (fragmento D8/8:24).

[...] todas essas tecnologias vão mudar radicalmente no que a gente vê hoje de projeto. Então, quando você conseguir trabalhar com uma holografia, uma realidade aumentada e manipular isso, você vai ter uma nova forma de projetar totalmente diferente e isso deriva exatamente da linguagem fotográfica (fragmento D25/25:41).

Com essas mudanças, durante anos a fotografia e o vídeo têm assumido um papel significativo frente aos meios de representação da realidade, porém, as implementações e transformações que influenciaram diretamente no sistema da ferramenta, possibilitaram sua transposição do meio fotoquímico para o eletrônico. A fotografia, hoje, permite não só registrar uma imagem fiel à realidade, mas também manipulá-la e transformá-la digitalmente.

Um dos respondentes esclarece que:

[...] atualmente a gente não pode mais nem falar numa tecnologia fotográfica, a gente começa a falar numa tecnologia de aquisição de imagem. Não é mais, simplesmente a coisa ótica, mas ela passa a ter esses outros processos de escaneamento e que já tem sido usado, os escaneamento de objetos tridimensionais, coisas do tipo, não é uma fotografia, stricto sensu, no sentido do registro de uma imagem, mas é um registro de posição de pontos e coisas do tipo, que no final das contas compõe uma imagem sintética (fragmento D27/27:15).

Desta forma, o risco entre a perda referente à tecnologia e o mundo acadêmico pode ser reduzido com a aproximação temática, didática e institucional entre o currículo do ensino do Design de Produto e a realidade tecnológica e social.

No entanto, a imagem eletrônica é mais flexível e suscetível às transformações proporcionadas por sua plataforma e demonstram que a interferência do sistema computacional de manipulação se apresenta como importante ferramenta para a criatividade, permitindo a ele, possibilidades de modificações infinitas na estrutura da imagem, experimentações inesgotáveis e 
possibilidades expressivas diversas, além da criação de um novo produto, acelerando todo o processo.

\subsection{O emprego da fotografia e do vídeo como meios tecnológicos para recurso projetual no Design de Produto}

$\mathrm{Na}$ opinião dos participantes, em relação ao emprego da fotografia e do vídeo como recurso projetual, as ferramentas atendem principalmente ao aspecto de documentação conforme relatado por um dos docentes:

[...] normalmente nós direcionamos para que os alunos fotografem ou registrem, ou fotografia ou vídeo dos processos produtivos e como se construiu o modelo, como se construiu um produto em si e isso eles levam depois para apresentação (fragmento D5/5:27).

O mesmo entrevistado enfatiza que o aluno "[...] tem dificuldades em relação a representações, sejam desenhos, ou qualquer outro tipo de representação, até mesmo computação gráfica, então se utiliza da fotografia para poder representar ou direcionar algum modelo ou algum produto em si [...]" (fragmento D5/5:26).

[...] utiliza dos recursos que tem disponível para realizar a captura. Entretanto sem a fotografia e como se tirar uma ferramenta dele, mas não é, faz parte do processo criativo já dos designers, a fotografia. Então o que eu trabalho com o aluno é fazer entender isto, que eles têm um aliado que a fotografia acelera o processo, que a fotografia facilita o processo [...] (fragmento D2/2:13).

Desta forma, "[...] o aluno, ele tem que conhecer as ferramentas para ele entender a maneira como ele pode usá-las. Isso é o mais importante [...]" (fragmento D8/8:15), pois "[...] eleva a categoria e a qualidade do produto [...]" (fragmento D2/2:15).

A fotografia e o vídeo são recursos essenciais para o processo de produção da imagem, não apenas para a documentação, pois as suas implicações auxiliam também no processo antecipativos de criação, bem como as possibilidades de diferentes linguagens geradas pelos recursos técnicos da ferramenta, que devem dar suporte para o desenvolvimento do projeto.

Nesse sentido, os entrevistados, além da documentação, relatam como se utilizam das ferramentas e suas variáveis no campo do Design de Produto: 
[...] a gente trabalha com Design de Produto e Ergonomia, nós temos focado à disciplina, muito às questões de uso e habilidades. E nas questões de uso e habilidade, eu tenho usado a fotografia, a linguagem fotográfica como instrumento de uso em sala de aula direto. Então o aluno desenvolve um protótipo, um modelo, um mock-up e eu, é através da fotografia que eu faço o registro, porque nós não temos condições de trazer todos os modelos para cá [...] (fragmento D30/30:11).

[...] em meios de expressão e transporte, a fotografia é utilizada desde a análise de similares, que é o começo do método de desenvolvimento, depois no painel semântico, que é o que dá as formas do produto e depois no final do produto, para ele ser passado posteriormente para um Photoshop ou tratamento de imagem ou para uma ilustração e depois, se tem o modelo, a fotografia do modelo final. " (fragmento D25/25:10).

\section{"[...] também para o registro de projeto e o registro dos procedimentos"} (fragmento D30/30:7).

[...] análise da Tarefa, tem que ser um registro fotográfico de uso de passo a passo e de toda a interação entre o produto e o usuário, então a foto é também uma ferramenta importantíssima. Depois, no final, para a representação da ideia, para registro dos mock-ups, dos modelos, a foto é usada como uma forma de registro (fragmento D10/10:11).

[...] ela pode entrar como recurso técnico de levantamento de dados como recurso técnico para exposição do produto, como recurso de linguagem para a demonstração desse produto alocado ao seu ambiente, então em todos os momentos a fotografia é vislumbrada porque você faz um reforço textual quando você entra com a imagem (fragmento D2/2:21).

Mesmo com as diversas variáveis de utilização da ferramenta é possível notar que: "[...] ela é um elemento que coopera, que colabora, que divide essa autoria com outros meios, com outras linguagens" (fragmento D1/1:25).

[...] faz parte do processo criativo já dos designers, a fotografia. Então o que eu trabalho com o aluno é fazer entender isto, que eles têm um aliado que a fotografia acelera o processo, que a fotografia facilita o processo, mas que por outro lado ela precisa também a forma adequada de interpretar como usar a imagem (fragmento D2/2:13).

As imagens geradas pelas ferramentas mexem com o próprio designer, por ele já conhecer as possibilidades de captura, mas as imagens devem também ser um gatilho para o desenvolvimento, auxiliando como uma ferramenta para 0 processo criativo.

As referências imagéticas são muito importantes para o processo de criação e para a geração de novas ideias. Assim, a imagem serve como uma forma de preencher um vazio onde as ideias estão desprovidas de iluminação e que é necessário encontra-la para auxiliar nos processos projetuais com um recurso a 
mais.

Porém, outras possibilidades de experimentação devem ser investigadas, pois o equipamento fotográfico e de vídeo oferecem padrões para a criação e os processos são inesgotáveis para o surgimento de novas possibilidades de investigação, permitindo contribuições para o processo. Identifica-se, portanto, a necessidade da apropriação das técnicas e da interferência no sistema, forçando a exploração de novas possiblidades e criando a necessidade de interferir no dispositivo, combinando facilidades de uso, aplicação e manipulação das ferramentas.

\subsection{Como o conhecimento técnico sobre linguagem fotográfica é aplicada por docentes no campo do Design de Produto}

Existem dois grandes obstáculos no ensino e orientação didática nas universidades voltadas ao campo do Design de Produto, que estão excessivamente preocupadas com a transmissão do conhecimento através de um corpo docente. Um dos obstáculos é o ensino orientado para a aquisição de conhecimentos, outro, o ensino orientado para aquisição do saber como projetar. No entanto, o ensino universitário tem por objetivo principal acumular conhecimentos, orientados segundo determinadas disciplinas científicas, diferente do ensino voltado ao desenvolvimento de capacidades para resolver problemas concretos de projetos.

Desta forma, os entrevistados direcionam os conhecimentos técnicos sobre a linguagem fotográfica de modo disseminado em diversas disciplinas da grade curricular, para atender apenas a transmissão do conhecimento conforme relatado por um dos docentes:

[...] então você pode ter matrizes onde você tem especificamente a disciplina de linguagem fotográfica, como você pode ter matrizes onde a linguagem fotográfica é discutida no âmbito de uma disciplina chamada linguagem audiovisual. De toda maneira, a linguagem é tratada, talvez não necessariamente com uma disciplina específica direcionada a ela, mas dentro de um escopo de disciplina, ou seja, uma disciplina que compõe um projeto ou mesmo na disciplina de projeto, então [...] (fragmento D1/1:14).

[...] todas as disciplinas que compõem aquele semestre, elas convergem para elas dão suporte, elas dão subsídio para o desenvolvimento do projeto, então no período $X$ existe a disciplina, seja de linguagem fotográfica, seja de linguagem dos meios audiovisuais, ela diretamente contribuirá e será requisitada para compor com o projeto do semestre (fragmento D1/1:16). 
Entretanto, outro respondente menciona sobre a importância da disciplina para dar:

[...] aporte para esses projetos e exatamente na linguagem, nos cursos de Fotografia é que dá toda essa indicação. Em nenhum momento em sala de aula, na disciplina Projeto, foi falado sobre a Fotografia, sobre o ensino, a história, a aplicação, simplesmente é cobrado num determinado momento e principalmente no relatório, o registro dessas imagens (fragmento D28/28:13).

Para Bonsiepe (2015), o programa de ensino do Design deveria ser organizado de acordo com áreas de problemas e não de acordo com disciplinas ou áreas de conhecimentos.

Nesse sentido um dos entrevistados, relata os motivos da diluição nas disciplinas da linguagem fotográfica nos projetos a serem desenvolvidos pelos alunos:

[...] hoje a gente já percebe que a área de Design se expandiu tanto e nesse caso específico, o curso aí tem 3 anos e meio e a gente tem que encaixar tanta exigência do MEC, que para, de forma específica da área de Design, que a gente não tem como trabalhar a fotografia em 1 ano, 1 ano e meio, 2 anos. E a gente sabe exatamente que 1 semestre de Fotografia é pouco e esse conteúdo tem que ser e é diluído em outros projetos e em outras disciplinas também. A gente tem uma disciplina chamada Linguagem Audiovisual, que é uma disciplina que apresenta para os alunos algumas técnicas que a gente apresentava lá atrás na disciplina de Fotografia (fragmento D19/19:28).

[...] disciplinas básicas, que dizem, de observação, por exemplo, usar o meio de expressão, se utiliza muito a Fotografia como base de referência para o início de entendimento de representação manual, para depois, posterior criação dessa forma (fragmento D25/25:8).

Dessa maneira e interessante notar a linguagem fotográfica é vista como um recurso, "[...] mais uma linguagem de representação e que deve ser utilizada dentro de toda a sua potencialidade nas disciplinas de Projeto. Tanto do ponto de vista sintático, quanto semântico [...]" (fragmento D14/14:1) e "[...] a fotografia não é nada além de uma linguagem equivalente ao desenho[...]" (fragmento D3/3:2), ou "[...] didaticamente ele ainda guarda um registro, uma importância muito grande, por conta de forçar o estudante a compreensão desses elementos na linguagem" (fragmento D15/15:18). 
[...] essa linguagem fotográfica vai ter uma quebra de vários paradigmas que antigamente existiam, que vão precisar ser modificados e isso ser direcionado da melhor maneira para o profissional utilizar isso como uma forma ainda de auxílio, de ajuda para o seu projeto e para o seu método de desenvolvimento, do que como um aparato que atrapalhe esse desenvolvimento (fragmento D25/25:42).

O conhecimento técnico sobre a linguagem fotográfica e a aplicação das ferramentas permitem a realização de estudos investigativos com a utilização de objetos reais e a plataforma utilizada facilita a averiguação de problemas, enquanto permite corroborar soluções de forma concreta com aplicações reais, auxiliando um raciocínio expandido pelo processo de virtualização de objetos (escaneamento tridimensional, fotogrametria e biofotogrametria).

O conhecimento técnico das ferramentas é disseminado como registro, coleta de dados e como referência conforme as declarações dos entrevistados, para o registro do processo ou memória do processo: "[...] é importante que o aluno, ele tenha essa percepção da fotografia como entretenimento, como registro, como o uso mais corriqueiro até esse uso mais profissional de registro e que vai até mais longe" (fragmento D35/35:12).

[...] aquelas fotos mais espontâneas, do grupo lixando na oficina, mas é mais um pouco memória do processo de projeto, do processo de produção dos modelos, do processo de discussão de questões conceituais, metodológicas do projeto. Mas eles não são, vamos dizer, instrumentados na disciplina de Projeto, para desenvolver essa técnica (fragmento D6/6:15).

[...] no desenvolvimento de produtos, no processo de desenvolvimento de produtos na disciplina, a efetivação dos registros dos protótipos, dos mock-ups e tudo, é exatamente utilizada a linguagem fotográfica para o registro desses modelos ou os mock-ups nos relatórios do projeto (fragmento D28/28:10).

[...] registrar o processo eu acho que é uma coisa que é importante e facilita e eu acho que é extremamente eficiente, mas eu acho que essa questão do registro do processo, dentro da disciplina de Projeto, não é uma questão que está ligada só a questão da Fotografia, eu poderia colocar, no caso da disciplina de Projeto, a questão do Desenho também (fragmento D34/34:6).

Para a coleta de dados ou pesquisa de campo é reportado por alguns participantes:

[...] existe uma etapa de projeto que tem que ser fotográfica. Isso também acontece em outras disciplinas, em que cada vez mais os professores, alguns professores estão colocando a etapa de registro fotográfico como parte, como etapa de projeto mesmo, então isso também tem acontecido no departamento. Principalmente o que? O momento de coleta de dados [...] (fragmento D23/23:14). 
Para as referências visuais é comentado:

Se eu vou buscar referências e essas referências não são suficientes e isso acaba podando o meu processo criativo. Então eu tenho que quebrar um pouco os paradigmas e ir além, quer dizer, a linguagem fotográfica aliada a outros meios referenciais para que eu possa buscar uma solução para determinado problema (fragmento D36/36:09).

As técnicas tornam-se mais adequadas quando o problema do projeto é decomposto em subproblemas. Assim, a eficácia em estimular o uso da ferramenta para gerar ideias vai depender da capacidade de definir os parâmetros de sua aplicação, antes de realizar a captura. Porém, ocorrem grandes dificuldades na aplicação sistemática das ferramentas e suas técnicas no momento de gerar e ampliar as alternativas para o projeto, devido aos processos do perceber, identificar e articular a linguagem por meio das técnicas já existentes de cada ferramenta, divulgadas em literatura especializada de maneira fragmentada.

\subsection{A ferramenta fotográfica e de vídeo é utilizada no campo do Design de Produto}

É importante destacar como é indispensável que o docente tenha o conhecimento das tecnologias disponíveis baseadas na linguagem fotográfica e como elas vêm sendo utilizadas no campo do Design de Produto, para que possam auxiliar os alunos durante as fases de projeto, permitindo assim um maior desempenho das ferramentas da fotografia e do vídeo.

$\mathrm{Na}$ fala dos respondentes não foi possível identificar todas as variáveis de utilização das ferramentas ou até possibilidades de intervenção de uso das já existentes. Os recursos recentes como a fotogrametria e termografia infravermelha não foram mencionadas e consequentemente não são utilizadas nas instituições de ensino como aporte necessário para o projeto. Outros processos como a pesquisa para criação e prospecção de uso são pouco argumentados por grande parte dos entrevistados. Isso causa uma grande defasagem no ensino com relação a aplicação de outras possibilidades que contribuam para o processo de projeto.

É necessário que os docentes estejam atualizados para melhorar a aplicação e uso de ferramentas disponíveis na instituição (mesmo que estejam defasadas), de modo que contribua na ampliação de possíveis habilidades durante as diversas fases do projeto. Nesse sentido, dois respondentes mencionam que uma das 
grandes defasagens de instrumentação dentro da instituição está relacionada ao equipamento de captura tridimensional. Eles comentam a seguir como essa tecnologia vem sendo utilizada e sua importância para o campo:

[...] o escaneamento 3D, quando se popularizar, eu acho que aí sim isso abre um universo de possibilidades muito interessantes. Fazer modelos depois fazer reversamente, usar arquivos, fazer uma documentação bastante precisa dos projetos, acho que aí tem coisa bastante interessante, até do ponto de vista de Ergonomia também, análise Ergonômica com os Scanners Tridimensionais, sejam os de mão, sejam os de cabine (fragmento D6/6:13).

[...] a evolução desses conceitos, esses parâmetros fotográficos e tridimensionais que vão auxiliar inúmeras formas de projetar que está, eu acredito que vai ser bem interessante nas simulações, nas verificações, nos estúdios de verificação, eu acho que vai ter um papel fundamental [...] (fragmento D18/18:17).

No entanto, o que importa é que a mensagem e as ferramentas devem apenas organizar o processo mental e servirem como base para simulações e verificações. O pensador Flusser $^{42}$ (2002) trata com minúcia sobre aspectos da mensagem e a ferramenta onde elabora uma simbólica teoria do fenômeno fotográfico onde a onipresença das imagens mediadas por tecnologias veio substituir o predomínio da linguagem verbal.

Um detalhe importante no caso do uso de ferramentas é a preocupação no planejamento onde você tem outro tipo de controle para cada processo.

O único contratempo da utilização da linguagem fotográfica é não fazer as perguntas realmente importantes para o desenvolvimento do projeto, sendo que cada projeto exige uma quantidade especifica de informação e que deve ser planejada antes do processo de aquisição das imagens e seleção do tipo de ferramenta de captura será utilizada. Sem o planejamento adequado, as imagens geradas ou abrem possibilidades ou impedem o encontro de conexões viáveis.

Os docentes participantes da pesquisa explicaram a importância das ferramentas, principalmente da fotografia e do vídeo nas práticas pedagógicas e, de forma geral, apresentam como as dificuldades advindas do ensino básico e secundário dos alunos ingressantes no curso prejudicam as práticas de ensino e o progresso das etapas estipuladas pedagogicamente por cada instituição.

Desta forma, os programas de ensino básico e secundário não aprovisionam

\footnotetext{
42 Filosofia da caixa preta reúne conferências pronunciadas na França e na Alemanha que, a pedido da European Photography, foram reunidos no livro publicado primeiramente em alemão no ano de 1983.
} 
especificamente treinamento de sensibilização para elementos tecnológico-estéticos em geral, e prática da competência projetual (BONSIEPE, 2012). "[...] às vezes eles não percebem que a fotografia e o vídeo não só pode ser uma coisa de uso para registro, mas também ela pode ser uma forma de expressão, também ela pode ser uma possibilidade de ferramenta para a construção de um discurso." (fragmento D23/23:12) .

[...] a gente pega um aluno com 18 anos que não é um nativo digital, mas é quase um nativo digital, já é uma pessoa que tem facebook, tem as habilidades de celular, mas ele muitas vezes não tem o olhar. Então você vê fotos assim, muito ruins em grande quantidade (fragmento D7/7:34).

[...] muita gente, com relação a fotografia, acha que é simplesmente apertar o botão e pronto, está feita a imagem. A partir do momento que se começa a conhecer mais profundamente as técnicas fotográficas, equipamentos e tudo mais, a pessoa começa a perceber, o aluno em si começa a perceber que não é tão simples assim (fragmento D5/5:36).

[...] a mentalidade dos alunos que estão chegando, eles vêm com uma formação um pouco diferenciada, então ele te obriga a estar caminhando junto com ele e a forma visual ainda, você consegue colocar uma ideia, chamar a atenção dele, até mesmo para pensar diferente com relação ao projeto (fragmento D26/26:9).

Por isso, uma das decorrências restritivas no ensino pré-universitário manifesta-se na deficiência da percepção estética. Sendo que a universidade recebe alunos com uma baixa sensibilidade aos fenômenos estéticos, e praticamente nenhuma experiência projetual. É necessário, no entanto, rever, formular e discutir constantemente sobre as diretrizes do processo de seleção desse aluno ingressante, obtendo assim um maior grau de aproveitamento das disciplinas oferecidas ligadas aos processos de representação.

Mesmo com essa deficiência, outro aspecto mencionado nas entrevistas é a importância do uso das ferramentas, deixando um pouco de lado o embasamento e fundamentos da linguagem fotográfica em si, apresentando desta forma uma fragilidade nas habilidades que devem ser adquiridas durante a evolução das disciplinas no curso. Nesse sentido os docentes explicaram que:

[...] você tem uma disciplina, por exemplo, de fotografia no curso de Design Industrial, que está no primeiro semestre. $O$ que o aluno vai aprender ao ter contato com essa disciplina? Aliás, o que ele pode extrair dali, para dentro do curso? Eu diria assim, informações básicas e muito poucas (fragmento D14/14:24). 
"[...] a fotografia é como uma ferramenta, mas uma ferramenta que tem que ser explorada pelo aluno de maneiras muitas vezes não convencionais, de forma não convencional" (fragmento D14/14:16).

Outro aspecto mencionado por um entrevistado é a preocupação sobre a importância da fotografia para os alunos:

[...] quando você não tem essa disciplina, disciplinas como essas, que são muito ferramentais e muito usadas, o aluno, às vezes ele vai fazer um curso fora, de Fotografia e aí ele volta e quem não tem, quem não fez, o aluno que não fez, fica uma situação muito díspar, é evidente no trabalho, que aquilo fez uma diferença [...] (fragmento D8/8:22).

Nesse ponto o aluno que busca obter esse conhecimento fora da instituição, acaba aperfeiçoando as possibilidades de aplicação durante as atividades a serem realizadas, principalmente nas disciplinas de Projeto. Segundo Bonsiepe (2015), fica evidente que os estudantes buscarão, por motivos óbvios, sua relação com a prática, já que a teoria facilmente pode dar a impressão de ser nada além de um exercício especulativo.

Conforme esses relatos, as ferramentas não formam e nem capacitam os alunos para serem designers, são apenas ferramentas que devem ser utilizadas com conhecimento e técnicas adequadas para sua aplicação em processos de projeto. No entanto, estão em constante evolução e é necessária a atualização constante, porém, o legado histórico dela é essencial para uma boa aplicação e possíveis interferências necessárias para a evolução de seus processos.

Outra percepção de um dos docentes perante a importância da ferramenta e a exacerbação de informações e a de que:

[...] hoje você tem uma geração de alunos que nasceu com essa quantidade de ferramentas e quantidade de informações vastas, só que eles não sabem onde buscar esses referenciais, por isso que eu acredito ser mais importante 0 aluno saber 0 que ele precisa antes da pesquisa e não pesquisar a respeito do problema (fragmento D25/25:19).

Em compensação outros participantes esclarecem a necessidade de se trabalhar determinadas competências e habilidades:

[...] a pedagogia, você tem que ter muito claro qual é o objetivo do exercício, se você sabe que habilidade você está querendo trabalhar com o aluno, qual é a competência que você quer desenvolver no aluno, aí você consegue dizer se ele precisa "perder tempo" [...] (fragmento D7/7:42).

"[...] na atividade acadêmica, isso, esse acesso deveria ser uma ferramenta 
de facilitação, de aperfeiçoamento do aluno" (fragmento D30/30:24), para que ele possa ampliar um repertório do aluno.

Alguns docentes expressaram como lidam com os processos pedagógicos de ensino dentro de sala de aula:

[...] então o que eu trabalho com o aluno é fazer entender isto, que eles têm um aliado que a fotografia acelera o processo, que a fotografia facilita 0 processo, mas que por outro lado ela precisa também a forma adequada de interpretar como usar a imagem, não é vulgarmente, que você coloca qualquer imagem (fragmento D2/2:13).

[...] fica muito mais fácil você ensinar a observar através de uma imagem já fixada, ou seja, uma imagem fotográfica e, pela observação dessa imagem fotográfica, fazer o desenho. Então lá está fixado a forma, luz, sombra, textura e assim por diante (fragmento D32/32:11).

[...] então você pode, de novo, colocar alguns pontos, algumas questões para o aluno, para que ele entenda a importância daquilo e de novo, ele comece por conta própria, a prestar atenção em algumas coisas que possam ajudá-lo a tratar isso da melhor forma possível (fragmento D33/33:14).

[...] o que me chamou mais a atenção é que, a partir do momento que, nas aulas iniciais principalmente, na fotografia básica, a descoberta dos alunos em relação aos recursos das câmeras, que é isso que ultimamente tem me chamado muita a atenção. E a falta desses conhecimentos que acaba dificultando a representação das imagens e aquilo com que eles esperavam conseguir, mas experiências assim, alunos que se projetaram em relação a fotografia também (fragmento D5/5:4).

Desta forma um dos docentes afirma que:

[...] ela é tudo. Ela explica desde iluminação, ela fala sobre como funciona uma câmera, ela auxilia os alunos a montar o ambiente ideal para fotografia, ela fala a questão teórica da fotografia, a questão técnica e a produção dessa fotografia, ela também trabalha com a fotografia para diversas áreas de Design, então fotografia de moda, de produto, de ambiente, fotografia formato artístico, então é uma disciplina que ela engloba desde a parte simples, lá o que era a fotografia, quando começou, até a fotografia digital e então a produção de matérias (fragmento D19/19:17).

Fica evidente que o aluno com esse tipo de formação em fotografia não prioriza aspectos voltados para os processos dentro do campo do Design de Produto, entretanto um dos docentes entrevistados enfatiza:

[...] se outros professores estiverem atentos a esses detalhes, o aluno, 0 estudante, tem um ganho, às vezes, o estudante é deparado com essa questão só no final do curso, quando ele vai trabalhar com imagem e ele precisa fazer a leitura daquelas imagens (fragmento D15/15:28). 
Alguns comentários são mais contundentes ao afirmarem que existem problemas relacionados ao tempo e à informação transmitida.

[...] a gente não conseguiu avançar muito ainda, viu Júlio, porque é aquela loucura de qualquer curso, o professor, ele tem um programa de trabalho, ele tem tanta $x$ horas aqui dentro e tal e esse tipo de exploração, ele esta acontecendo ou nas Iniciações Científicas ou quando a gente faz alguma oficina e ai o professor tem que dispor ou um aluno que queira ficar (fragmento D14/14:37).

"[...] essa disciplina que aconteceu lá, o aluno carrega, óbvio, algum conhecimento, alguma informação, mas ela não está, necessariamente, sendo aplicada nas disciplinas de Projeto posteriormente" (fragmento D14/14:25). "[...] em seis meses você não ensina alguém a fotografar. Você ensina a usar, de alguma forma o equipamento. No produto, a ênfase que a gente dava era a valorização do produto através das imagens" (fragmento D2/02:14).

Um dos respondentes ainda esclarece a diferença entre as instituições privadas e as instituições públicas:

[...] com quem coordena o curso e com entendimento daquele coordenador sobre os elementos que são prioritários para a formação desse aluno, que é sempre uma equação muito difícil de ser resolvida, porque você tem um número de horas que as nossas diretrizes nacionais curriculares colocam, que o MEC coloca como sendo mínimo para a formação daquele aluno, e você tem um rol de conteúdos que precisam ser distribuídos naquelas matrizes, então como isso vai ser combinado, distribuído, isso vai depender muito de quem tá na coordenação desse curso (fragmento D1/1:19).

Por fim, identifica-se que a linguagem é por outros docentes como uma das possibilidades de "[...] induzir o aluno a ter uma visão diferente do mundo que cerca ele e possibilitar outras coisas" (fragmento D25/25:1).

[...] então eu penso que tem havido no nosso curso, um movimento dos alunos nesse sentido, dos alunos estarem querendo investigar mais as linguagens e assim, eu tenho proposto isso, tenho batido um pouco o pé nisso, tipo, os alunos, vamos investigar, vamos trabalhar, porque a ideia aqui não é formar ninguém fotografo (fragmento D23/23:13).

"[...] em termos didáticos, o grande problema nosso é que os nossos alunos não têm uma fundamentação em fotografia" (fragmento D27/27:5).

É interessante notar que o avanço tecnológico tem proporcionado ao designer uma enorme facilidade com o uso e aplicação de ferramentas que auxiliem o processo de projeto e a utilização de um vasto conteúdo referencial através da 
internet, embora não seja vasto o conhecimento tanto de softwares como de ferramentas que fazem com que sejam bem aplicadas ao projeto. Entretanto, a dependência das ferramentas é gradativa e ampliadas com o surgimento de novas possibilidades. Desta forma, é necessário que o docente explore no aluno, a essência da curiosidade, da experimentabilidade, da criatividade e por fim, da funcionalidade para uma completa aplicação e para que os conceitos e o desenvolvimento do intelecto do aluno sejam ampliados no processo de aplicação das ferramentas, que não podem ser substituídas por um sistema, contribuindo para que possa atender as demandas do mercado de trabalho.

\subsection{A fotografia e o vídeo geram interferências nas ações dos processos de projeto e nos processos de representação}

Com a expansão do uso de ferramentas e, sobretudo, da mudança das tecnologias, já não é mais possível fechar os olhos para suas aplicações técnicas no campo, cuja presença se faz notar cada vez mais nas interferências em ações dos processos de projeto e que influem de maneira crescente tanto na atividade projetual quanto na metodologia. Logo o designer deve conhecer e necessita ser treinado para obter conhecimentos e para saber em que momento as ferramentas devem ser aplicadas para gerar mediações positivas no projeto.

Conforme relatado pelos entrevistados, sua importância para o campo e interferências geradas nas ações dos processos de projeto é evidente, demonstrando sua importância, como informado por um participante: "[...] hoje ela é fundamental, pelo acesso, em muitas outras etapas do projeto, vamos supor, nas etapas preliminares que eu tenho de analisar a problemática" (fragmento D30/30:33). O mesmo respondente menciona que:

[...] não desconsidero em hipótese alguma, a não utilização da Fotografia, eu acho que é fundamental como linguagem de informação. Projeto é muita informação, eu tenho uma ideia, eu tenho que representar, está certo? O primeiro momento é representar no papel, talvez o segundo momento é representar na forma e talvez o terceiro momento já é representar na Fotografia, porque tudo leva a isso (fragmento D30/30:32).

[...] para o aluno a importância que a ferramenta tem tanto na construção daquilo que ele está produzindo e a importância final na representação daquilo que foi construído, assim, nas duas fases, ela pode servir como uma ferramenta de pesquisa, e, no final também, ela entra como uma ferramenta de representação (fragmento D20/20:20). 
É interessante notar que na fala deste docente, a fotografia e o vídeo influenciam diretamente as etapas preliminares, mas que por outro lado "Registrar o desenvolvimento de um processo, não de um produto, mas de um processo, também um processo às vezes de colaboração de vários grupos diferentes, pode ser registrado através de Fotografia, é interessante" (fragmento D35/35:17).

Outros depoimentos também chamam a atenção para outros níveis mais técnicos que ampliam a força das ferramentas:

[...] esses níveis de expressão interessantes que a fotografia te permite, elas vão desde a tomada da imagem, onde você pode fazer distorções com lentes, com coisas deste tipo ou, ao contrário, você fechar, travar de tal maneira que você tenha o desenho preciso (fragmento D3/3:8).

O mesmo docente enfatiza que:

[...] a linguagem da fotografia é interessante, porque ela reúne a prática com a teoria e ela te dá uma imagem precisa, formal, caracterizada. Então eu acho que o que eu entendo a partir da ideia da linguagem fotográfica é que ela me permite um registro muito interessante. Um registro preciso e um registro que me dá outras referências que não só aquelas do produto (fragmento D3/3:5).

[...] hoje nós temos softwares que permitem a análise e as imagens fotográficas que você, por exemplo, você faz uma imagem, vamos supor, um indivíduo encostado numa cadeira, dependendo da posição que ele está, mesmo que você utilize um software de análise, essa imagem vai permitir que você verifique se de fato, as suas observações estão coerentes com a sua análise que você está fazendo naquele local de trabalho (fragmento D26/26:11).

"[...] você trabalha com formas e a forma em si, ela te induz a uma necessidade de precisão, de definição extremamente grande e aí a linguagem visual mais precisa é a fotografia" (fragmento D3/3:4). Nota-se que o respondente apresenta a importância da linguagem para realizar a captura e obter um registro preciso que atenda às necessidades do designer, gerando possibilidades de obter um melhor referencial.

As ferramentas não têm um papel preponderante sobre o projeto, porém, elas são auxiliares poderosos para todo o processo. Desta forma, dividem-se as opiniões quando mencionam: "[...] eu acho que o uso da fotografia, ele é universal. Ele é universal, então ele pode servir como um elemento, não necessariamente deva ser" (fragmento D3/3:28) e o mesmo entrevistado menciona que: 
[...] ele pode ser um auxiliar poderoso, mas não um papel preponderante. Papel preponderante no projeto realmente é aquele processo de projetação. Esse é o papel preponderante. Fotografia converge como um elemento a mais. Como um dado importante, sim, mas sim, complementar (fragmento D3/3:32).

"[...] a fotografia é processo, então ela não é auxiliar, ela é parte da concepção. Então, não colocaria ela nessa hierarquia de auxiliar ao projeto, ela é parte do projeto, ela é projeto, ela é uma etapa do projeto" (fragmento D21/21:12).

Para que a fotografia e o vídeo gerem interferências positivas no processo de projeto é necessário administrar a utilização de sua linguagem, dessa forma 0 mesmo docente menciona que:

[...] você pode administrar, como você pode gerir um sistema em que fotografia, o desenho, a linguagem do produto em si, da moldagem final do produto e dos acabamentos, eles todos são simplesmente a mesma coisa, eles são todos meras partes de um mesmo processo (fragmento D3/3:11).

Percebe-se, ainda, que durante 0 cruzamento dos dados não surgiu nenhuma informação relevante a respeito de uso, aplicação ou transferência de conhecimentos com a utilização de softwares de gerenciamento de projetos onde a fotografia e o vídeo são muito utilizados por equipes, sendo que a grande aplicação é a documentação de todo o projeto, inferindo assim, diretamente nas ações realizadas pelo designer com a capacidade auxiliar na tomada de decisões e de comunicação.

Nesse sentido, devem ser levantadas quais as tecnologias de fácil acesso no momento, para a realização do projeto. Entretanto, frente à crescente complexidade que envolve os problemas projetuais, o designer depende cada vez mais de conhecimentos científicos de uso e aplicação de ferramentas tecnológicas.

As novas ferramentas e técnicas digitais apresentam grandes vantagens no processo de ampliar o potencial e qualidade das representações e influem sistematicamente nos processos projetuais, transformando assim, a captura e manipulação de imagem, onde a apreensão do espaço tridimensional é uma constante em projetos.

Desta forma, as representações devem gerar interferências positivas nas ações dos processos de projeto, para que o designer tenha em mãos, grandes possibilidades dentro das possíveis referências (banco de imagens, coleta de dados, documentação das fases do processo de projeto e situações de uso do produto). 
Nesse sentido, um dos respondentes destaca a importância da linguagem fotográfica: "[...] porque ela reúne a prática com a teoria e ela te dá uma imagem precisa, formal, caracterizada. Então eu acho que o que eu entendo a partir da ideia da linguagem fotográfica é que ela me permite um registro muito interessante" (fragmento D3/3:5). O mesmo respondente menciona que: "[...] a imagem que você está registrando, ela te dá um conjunto de referências, de formas, de elementos compositivos, componentes desse processo, então é aí que a linguagem do desenho e a da fotografia convergem, na minha percepção" (fragmento D3/3:6). As referências auxiliarão o designer a prestar atenção aos detalhes minuciosos que passariam despercebidas no projeto, aumentando sua bagagem visual, substituindo referências já estabelecidas.

Outros depoimentos confirmam que a linguagem fotográfica amplia as possibilidades de representação:

[...] a partir do momento que a imagem fotográfica virou também imagem digital, eu acho que amplificou essa gama de representação e aí, com a possibilidade também da manipulação dessa imagem digital, também eu acho que aumentou a gama do que a gente poderia definir como imagem fotográfica (fragmento D32/32:1).

[...] com o tempo a gente vai percebendo que o ato de fotografar é muito mais do que simplesmente um clique, é compor imagem, enfim, é você representar exatamente, você ter o controle daquilo que você quer representar através da câmera, no caso (fragmento D32/32:5).

[...] então, quando fala em fotografia está falando em registrar a imagem de alguma coisa, então, quando fala em linguagem fotográfica, para mim tem vários significados. Então a base é essa aí, é uma representação da imagem de alguma coisa, mas como tem a participação humana na coisa, então essa imagem pode variar muito, então geralmente ela vai dar a personalidade do perfil do fotógrafo junto (fragmento D35/35:1).

Ainda existem algumas limitações dessa forma de representação com relação ao desenho, como comenta o entrevistado 5: "Enquanto só representação, ela fica só no primeiro plano, pesquisa, algumas representações, mas ainda o desenho o aluno consegue tirar da cabeça e colocar. Para produzir uma fotografia que você já tem na cabeça, aí já é outro caminho." (fragmento D5/5:37).

Para o entrevistado 29:

[...] linguagem fotográfica e a máquina fotográfica, como produtor de um objeto, uma captação de imagem, para mim está no mesmo patamar dos croquis, do desenho, dessa fase, quando você está, até não procurando, não sabendo direito o que você está procurando, que você está em fase de começo de criação e acho que você pode também, se você tiver domínio 
dessa linguagem e tiver equipamento, você pode usar a Fotografia também como esse elemento de busca, de algo, de um começo da criação, porque a criação para mim é o seguinte, a criação, eu já disse, não é um acidente de percurso, ela não acontece por uma pedrada na cabeça, então, você tem que construir caminhos, exatamente, o trabalho da criação e a dificuldade da criação, exatamente são esses caminhos, porque ninguém tem esses caminhos, então, como isso não existe e você fica andando num lugar que não tem pegada, que não tem norte, não tem sul, não tem em cima, embaixo, você tem que ser um cara muito esforçado, do lado cognitivo, de você realizar um esforço muito grande para tentar enxergar um caminho onde não existe, isso que é criar (fragmento D29/29:32).

“[...] eu estou com dificuldade em desenhar tal coisa, eu vou lá e fotografo, e eu tenho uma referência imediata e, às vezes, dá até para trabalhar em cima da própria fotografia, ilustrando" (fragmento D32/32:6).

É possível notar a valorização da dimensão visual para o desenvolvimento de algumas técnicas e critérios de representação do espaço tridimensional ou bidimensional, abrindo enormes possibilidades para o design ligado ao domínio da percepção para revelar o potencial da visualidade. Os procedimentos ligados à imagem estática e em movimento também apresentam suas limitações, de modo que parece oportuno buscar outras formas de representação.

\subsection{As diversas técnicas de representação contribuem para que o designer otimize a atividade projetual.}

Uma das técnicas para otimização da atividade projetual é a documentação do processo de projeto que se inicia na pesquisa. Alguns comentários dos respondentes definem que:

[...] quando você idealiza o seu projeto, que você cria, você aplica a metodologia e que nós desenvolvemos o protótipo, esse protótipo vai necessitar de correções futuras, então, estando isso registrado em fotografias, ele vai te ajudar amanhã ou depois, mesmo você tendo o desenho técnico dele, que permitiu o desenvolvimento do protótipo, nós podemos, através dessas fotos, fazer uma análise e através dela fazer algumas correções que talvez o produto final não tenha ficado com uma eficiência, como a gente desejaria (fragmento D26/26:16).

[...] a Fotografia, ela é assim, essencial, ela é primordial dentro deste processo. Então, não tem como não ser realmente porque toda vez que você vai iniciar um projeto, começar, você tem que começar lá na pesquisa, quer dizer, na pesquisa você já tem a fotografia (fragmento D22/22:18).

Entretanto, a documentação necessita de alguns parâmetros para que ela seja efetiva na busca de dados necessários para atender o designer, de maneira 
que complemente sua bagagem com novas referências para a pesquisa. Nesse sentido, um dos respondentes questiona: "Será que essas pessoas que estão usando a fotografia, elas estão pesquisando de verdade? Ou elas estão simplesmente fazendo um único registro e satisfazendo com ele?" (fragmento D20/20:36).

Essa outra possibilidade como referência visual, não necessariamente precisa ser desenvolvida pelo designer. Desta forma, alguns depoimentos chamaram a atenção para a possibilidade que é colocada para o designer como uma forma de investigação que pode ser utilizada juntamente com de diversas técnicas (painel semântico, biomimética, colagem e chiaroscuro):

[...] em cada etapa de pesquisa e depois da criação e depois da execução do projeto, sempre eles têm que apresentar um painel visual. Eles têm que traduzir um conceito, eles têm que traduzir uma ideia em forma de imagem, então, o painel semântico, ou um painel de tema visual, ou um painel de imagens, até uma colagem é muito requisitada (fragmento D10/10:10).

"[...] ela é simplesmente uma referência que vai servir de suporte para que ele possa executar a proposta que está sendo colocada na referida técnica que está sendo desenvolvida" (fragmento D28/28:8).

Outra técnica muito utilizada é o registro na pesquisa de campo para a documentação e investigação de produtos para a análise de mercado em situações e simulações de uso. Desta forma o respondente 25 narra a respeito da produção e novos produtos com a pesquisa dos produtos já existentes:

[...] a análise de similares, ela se baseia em fotografia, basicamente porque você nunca tem sempre todos os produtos de análise, então você às vezes, pega um produto que é só vendido na China, então não tem outra forma de você conseguir visualizar esse produto, a não ser a fotografia, você não tem como tempo hábil de comprar o produto, pegar essa imagem e visualizar esse produto, a não ser a Fotografia (fragmento D25/25:11).

Já o respondente 7 descreve a necessidade da captura de situações de uso e análise de mercado: "[...] então esse é um primeiro uso que a gente faz, sempre a gente pede foto de análise de situação de uso em todos os Projetos de Produto que eu dou a gente pede análise de mercado, análise de situação de uso, sempre" (fragmento D7/7:48).

Um dos docentes esclarece que outras ferramentas de pesquisas podem mascarar as possibilidades de aproximação ao produto: 
[...] esse levantamento visual pode fazer com que esse olhar dele, possa descobrir nuances, texturas, volumes, formas, que a princípio, o conhecimento prévio que a gente tem que as outras ferramentas de pesquisa podem oferecer, podem mascarar essa possibilidade dele fazer uma aproximação do produto, um distanciamento e perceber que esse material, toda essa possibilidade que ele tem, tanto no espaço urbano, quanto numa pesquisa de produto, ele possa traduzir isso de uma forma de como isso acontece (fragmento D20/20:12).

Outra questão técnica voltada à análise de situações de uso do produto refere-se a estudos ergonômicos para correções ou avaliações de possíveis problemas na sua produção, como reportado por grande parte dos respondentes: "[...] é um aspecto funcional de documentar, de entender de ver como é que está o braço, como é que está curvada a pessoa, posturas, coisas inapropriadas ou excelências no projeto" (fragmento D6/6:11). O mesmo docente detalha que a fotografia:

[...] é para documentar o usuário abrindo a embalagem, a fotografia é para documentar o usuário sentado na cadeira, não tem... Aspecto ergonômico, para fazer uma análise das qualidades de algum produto que estejam testando, usando, simulando uso, mas não como um instrumento de criatividade nem como um instrumento, como uma veleidade artística, não (fragmento D6/6:10).

"[...] fazemos o vídeo do uso do produto porque nós temos que fazer a avaliação, quem faz a avaliação não são os autores, os designers daquele produto, são os seus colegas. Então, nós utilizamos a imagem padronizada para que também, não posso estimular a abertura de uma embalagem para um e para outro, pode haver diferença, então utilizo imagem (fragmento D30/30:13).

O docente 7 menciona os problemas técnicos para realizar a captura e obter uma melhor documentação do que é necessário para o projeto:

[...] o problema é você entender quando você precisa fotografar pessoa, porque no nosso caso a gente usa muito para fazer análise de produto ou de situações cotidianas e os ângulos são sempre um grande problema, os enquadramentos, porque às vezes a pessoa: "Ah! Porque eu quero mostrar a postura, que fica com o braço inclinado". Aí você faz uma foto frontal da pessoa usando o produto e cadê o ângulo [...] (fragmento D7/7:15)

[...] sempre nessa questão da pesquisa, mesmo. Da pesquisa, de fotografar o local, de fotografar o produto, ou o produto em uso também, acho que isso é legal, a questão da dinâmica, por exemplo, no caso do carro, entrando no carro, abrindo a maçaneta, dirigindo o volante, foto de perfil, foto de frente (fragmento D18/18:10). 
No caso de situações onde é necessário outro tipo de processamento a imagem é aplicada em softwares gráficos para o tratamento e análise, como mencionado por apenas um dos participantes:

[...] a fotografia, ela tem contribuído muito, no sentido não só de a gente ter a captura e o registro dessa imagem, como também como análise e principalmente como uma maneira de você, hoje, utilizar essa imagem como algo que você pode transformar, traduzir dentro de um programa gráfico, em algo que possa ser ensaiado, analisado e assim por diante [...] (fragmento D14/14:30).

Com a prática e uso das ferramentas, acredita-se na fala de um dos docentes que o olhar começa a ampliar suas possibilidades e a bagagem crítica, desenvolvendo conhecimentos detalhados para a resolução de problemas: "Então o olhar começa a ficar mais crítico, você entendeu? Então uma foto, contra a luz, em baixa velocidade, de pessoas caminhando, você consegue imagens fantásticas" (fragmento D4/4:9). Nesse sentido, outros autores comentam:

[...] eles estudam os elementos de imagem cinematográfica e os elementos de linguagem, de uma maneira mais ampla, para a partir disso, extraírem referências que possam servir como base para eles estruturarem, para eles criarem e estruturarem a transcriação e o próprio projeto (fragmento D1/1:12).

[...] ela é muito utilizada como referencial, e não só como referencial, mas como estudo tridimensional. Às vezes quando você termina um produto, você faz um modelo em escala e exatamente usa a iluminação e a fotografia para entender como é que aquele material vai ser utilizado (fragmento D25/25:32).

Com o avanço tecnológico e as possibilidades automáticas das ferramentas o aluno acaba esquecendo da necessidade de realizar capturas com um cuidado técnico para atender as necessidades do projeto. "Então talvez aqueles que se esmerem por fazer fotos com uma preocupação de cuidado, de rigor, uma busca estética, acho que, talvez, esses se beneficiem da facilidade do recurso" (fragmento D6/6:6). Porém, as contribuições das técnicas de representação acabam sendo deixadas de lado. "[...] atentos a esses detalhes, o aluno, o estudante, tem um ganho, às vezes, o estudante é deparado com essa questão só no final do curso, quando ele vai trabalhar com imagem e ele precisa fazer a leitura daquelas imagens." (fragmento D15/15:28).

Entretanto, para otimizar o processo com o uso das ferramentas e técnicas especificas é necessário, como menciona o docente 20: 
[...] então essa característica tem uma resistência muito grande, porque assim, você vai fazer uma foto em algum lugar, aí eu uso a sombra como referência para produzir, tentando investigar o que está acontecendo ali, se você falar para ele: "você vai ter que, pelo menos, observar isso durante algumas horas do dia. O percurso do sol", ele acha um absurdo, porque assim, é um tempo que, de repente, ele não vai estar conectado, é um tempo que ele vai estar só em função de uma ferramenta (fragmento D20/20:23).

Desta forma, em algumas necessidades a fotografia e o vídeo sobressaem em relação ao desenho, pois:

[...] quando você tem que demonstrar algo real, então, ou seja, se você vai fazer uma coleta de dados sobre vários modelos de amortecedor, por exemplo, não adianta você desenhar aqueles modelos de amortecedor, você tem que fotografar os modelos de amortecedor para você mostrar, no caso de uma análise de semelhantes ou uma questão que você precise referenciar de alguma forma (fragmento D23/23:28).

"[...] eu acho que ela pode ser uma linguagem mais rápida porque se você tiver uma boa quantidade principalmente de referências, de buscas, de procuras, de etc., ela é muito mais rápida do que o desenho a mão (fragmento D29/29:33). É importante notar que a prática auxilia a ampliar as possibilidades de melhorar cada vez mais as técnicas de devem ser transmitidas aos alunos.

\subsection{As diversas técnicas de captura e manipulação de imagem oferecidas e a disposição no ensino de Design de Produto, no Design de Análise e no Design de Investigação}

Ao longo dos depoimentos, foram observados alguns apontamentos que indicam quais são as diversas técnicas de captura e manipulação de imagem oferecidas no ensino no Design de Produto. Entretanto, é possível identificar na fala de dois respondentes que a disciplina de Fotografia, onde deveriam ser apresentadas técnicas de captura e manipulação para o Design de Produto, ela é totalmente direcionada para o Design Gráfico.

Desta forma o entrevistado 20 comenta:

[...] para a construção de uma marca ou de uma sinalização, essa coisa do reconhecimento do espaço com possibilidades de olhar formas. Então, muitas vezes ele olha as coisas de uma maneira muito orgânica, então qual que é a ideia? De produzir essa imagem e dessas imagens, buscar fazer uma vetorização de círculos, quadrados, repetições visuais. Quais as possibilidades de construção gráfica, ou de elementos geométricos presente nessas imagens? Então assim, aquilo que, na verdade, é uma 
imagem orgânica, ele vai buscar por quadrados, círculos, cores, paleta de cor, tudo aquilo que possa ser referência, para que, posteriormente, isso seja aplicado ou utilizado em Design, ou seja, dessa forma a gente pretende assim, de maneira conjunta, trabalhar em outras disciplinas como a disciplina de Fotografia servindo para pesquisa e levantamento visual daquilo que pode ser o ponto de partida para a criação de uma marca, de uma sinalização, de uma proposta gráfica, mas sem a ideia de você definir o ponto de partida, o ponto de partida é a imagem, então a gente vai tentar extrair todas essas formas, todas essas cores, daquela imagem, naquele espaço, que a princípio o aluno elegeu para ser estudado (fragmento D20/20:10).

O entrevistado 19 também menciona:

[...] é extremamente importante o pensar imagem e esse pensar imagem de qualquer forma, utilizando uma imagem fotográfica, como utilizando um desenho artístico, como utilizando objetos, enfim, toda a questão da parte visual da Produção Gráfica, assim, que a gente pode colocar no papel, eu acabo utilizando nas minhas disciplinas (fragmento D19/19:13).

Desta forma, é evidente que esse aluno não terá um aproveitamento com o uso das ferramentas nas disciplinas subsequentes. Assim, um dos aspetos apresentados por um dos respondentes entra na questão da falta de preparo do aluno em disciplinas introdutórias a respeito da técnica e manipulação das ferramentas da linguagem fotográfica, para que possam auxiliar em sua produção. "[...] no desenvolvimento, na produção de imagens, quando o aluno tem alguma proposta, algum tipo de imagem que ele queira produzir e ele não consegue. Então, acaba sendo aquela pesquisa ou uma produção que fica a meio do caminho" (fragmento D5/5:31).

$\mathrm{Na}$ utilização das técnicas de captura e manipulação da imagem são identificados apenas aspectos para a apresentação e registro do processo ou projeto, conforme mencionado pelo respondente 5:

[...] a fotografia está como registro, ela está cada vez mais disseminada, então hoje em dia os alunos interagem muito mais, através das redes sociais, com as instituições, com os professores e vice-versa, então, a grande maioria é tudo por imagens, então, aquilo que eu tinha falado anteriormente, então, a maioria imagens e pouco texto, então as imagens estão tomando cada vez mais um grau de importância maior em relação a essas conversas, vamos falar assim (fragmento D5/5:29).

[...] no caso da apresentação do projeto, quando o aluno fotografa, ou quando o profissional, porque pode acontecer também com o profissional, fotografa o projeto e não tem um nível de qualidade aquela foto, tem aquele fundo cinza, aquele back ground cinza sem tratamento, isso interfere realmente na imagem e interfere na qualidade da apresentação (fragmento D18/18:14). 
[...] essa disciplina é focada em registro de processo e em apresentação de projetos e pesquisa, então, assim, como faz uma pesquisa? Como eu apresento essa pesquisa? Como eu recolho essas referências? Então algumas, são metodologias que para o Designer são muito usadas e são muito cotidianas, por isso que eu acho que elas são importantes de chegarem a esse aluno no primeiro semestre (fragmento D8/8:11).

Estas passagens insinuam que não é dada a devida importância para outras possibilidades técnicas das ferramentas dentro das atividades no ensino. Nesse sentido, as ferramentas acabam sendo subutilizadas para o campo, não contribuindo para as disciplinas subsequentes e impossibilitando o aluno avançar em questões que são relevantes para o Design de Produto, como a criação, a geração de alternativas, captura do protótipo/modelo, simulações digitais, possibilidade de geração de alternativas e na comunicação dos resultados.

Desta forma, encontramos algumas passagens que corroboram com essas questões, como respondente 6 , que explica como o aluno é orientado a respeito da comunicação dos resultados:

\begin{abstract}
E ao final do projeto eles tem que apresentar uma série de itens, na subfase de comunicação dos resultados dos projetos, uma série de itens modelo de aparência. $E$ tudo isso tem que ser muito bem fotografado, eu dou uma série de instruções técnicas de como enquadrar, de como iluminar, de como focar, de como limpar o fundo, de como valorizar o modelo para que o modelo tenha uma qualidade de fotografia industrial, dos modelos que eles fazer para que seja utilizada essa imagem nas pranchas de visualização que eles têm que submeter ao final do projeto. Então tem ainda essa última forma de utilização da fotografia como reprodução, como registro do modelo de aparências (fragmento D6/6:9).
\end{abstract}

Outro respondente posiciona-se sobre os processos de registro do modelo: "[...] o projeto, a atividade projetual, ela prescinde do uso sistemático intenso de modelos. E aí o registro fotográfico é fundamental para que você possa, de uma forma razoavelmente rápida viabilizar uma abordagem diagramática [...]" (fragmento D13/13:9).

A imagem também é apresentada ao aluno como possibilidade de análise de semelhança do mundo virtual para o mundo real, conforme mencionado pelo docente 26:

[...] por isso que eu estou te falando desta correlação com a disciplina de Projeto e de Fotografia, porque lá no $C A D$, você vai gerar através do CAD, isso aí vai estar em $3 \mathrm{D}$, você registrando uma imagem e depois tentando chegar na semelhança dela lá no 3D, para você imprimir isso aí depois e gerar, que eu chamo isso de materialização da pesquisa (fragmento D26/26:20). 
Grande parte dos respondentes menciona a importância da imagem no processo de ensino, como uma ferramenta que gera referências para outras disciplinas como as de Desenho e Projeto.

[...] ela ajuda muito nas disciplinas de Desenho porque, como eu disse, quando você tira fotografia, obviamente você não precisa desenhar, mas as questões de composição e enquadramento que a Fotografia consegue trabalhar, o Desenho tem muita dificuldade de conseguir ensinar. Se você for ficar no Desenho. E a Fotografia, pela efemeridade do momento, faz você criar uma capacidade muito grande de entendimento, de composição, que principalmente para os designer de produto, não os designers gráfico, que pouco trabalha a composição em 2D, eu acredito que uma disciplina de Fotografia possa suprir essa carência, desde que não seja uma disciplina satélite, porque a maioria das vezes que tem uma disciplina de Fotografia, ela está por estar, não tem um foco (fragmento D11/11:11).

"Na disciplina Desenho de Observação, nós utilizamos muito de referências em que, muitas das vezes, é tirado exatamente dessa linguagem da Fotografia" (fragmento D28/28:7).

[...] teria que aprender a fazer uma composição, saber resgatar a iluminação correta naquele momento e tudo mais, e isso vale muito como um treino de Desenho, enquanto você está desenhando tem que levar em consideração todos esses aspectos (fragmento D32/32:4).

As técnicas de captura devem ser direcionadas também para a manipulação das ferramentas de análise, tratando de técnicas de análise de similares, análise funcional, ergonomia, antropometria, cores e texturas, materiais, fotogrametria, biofotogrametria, escaneamento, entre outras possibilidades.

Nenhum dos entrevistados mencionou o uso da fotogrametria digital e da termografia como um dos aportes técnicos para análise no processo de projeto. No entanto, identifica-se que alguns entrevistados direcionam suas atividades com foco no Design para a análise, ampliando as possibilidades das técnicas de captura, mas não foram identificadas outras variáveis dentro das já mencionadas.

Os participantes comentam a respeito da análise funcional: "[...] eu traria a possibilidade para o aluno dele enxergar uma cadeira, mas não só uma cadeira, mas que fosse integrada ao homem, que talvez tivesse formas, esteticamente seriam abastecidas pelas informações de outros fotógrafos" (fragmento D2/2:34).

Sobre a análise de similares é explicado que "[...] o professor tem que trabalhar com a imagem já quando o aluno vai fazer pesquisas dos produtos existentes, para ele elaborar um outro produto, ele tem que buscar imagens. Então 
ele trabalha com essas imagens.." (fragmento D4/4:20).

Sobre a biofotogrametria, um dos docentes explica: "[...] então eu faço o registro da imagem, pego a imagem, jogo no AutoCAD, faço a análise, por exemplo, de postura. Isso chama Biofotogrametria. É através da imagem fotográfica, eu faço a mensuração de uma situação biométrica" (fragmento D30/30:16).

A antropometria e ergonomia foram comentadas por outro respondente:

[...] a gente tem a informação dessas técnicas, mas basicamente para a área da graduação e mesmo aqui no campus, a gente não tem esses equipamentos, mas algumas realizações, por exemplo, dimensionamento da mão, a gente não usa a fotografia, mas a Xerox, por exemplo, é uma técnica que dá para usar e no fim, a impressão que você tem de poder gerar uma série de imagens que vai servir como uma dimensão antropométrica, é interessante. Por outro lado, na Ergonomia, os vários registros das etapas de levantamento de dados antropométricos, ela é também bastante significativa, a gente também tem usado (fragmento D28/28:11).

A respeito dos materiais foi explicado:

Pinhole, imagens diretas, fotogramas feitos diretamente com objetos na luz. Então, são coisas assim, que conseguem transmitir para o aluno, uma propriedade dos materiais que depois ele pode aproveitar essa propriedade assim, de ser sensível à imagem e depois, isso aí poder se transformar numa imagem positiva (fragmento D35/35:24).

O Design de Investigação é um outro aspecto muito importante, em que a captura e a manipulação das ferramentas de investigação possibilitam um grande aporte dentro do campo, e que tratam de técnicas de coleta de dados (levantamento), investigação, observação, painel semântico, referência, requisito de projetos, entre outras possibilidades direcionadas ao campo.

Por fim, faz-se necessária uma reorientação do ensino universitário, e não somente do ensino do Design, contra-atacando o perigo de uma paulatina atrofia na capacidade de projetar, que é a coluna vertebral do ensino do Design (BONSIEPE, 2015), considerando as necessidades de aplicação e uso das diversas técnicas de captura e manipulação de imagem necessárias para a formação acadêmica.

\subsection{Há necessidade do aluno estar familiarizado com as diversas ferramentas para a produção de imagem}

Com o aparente distanciamento da prática das diversas ferramentas existentes para a produção de imagens, o aluno não está a frente dos desafios 
projetuais, principalmente onde a linguagem fotográfica está inserida como um recurso auxiliar. A mudança para os meios digitais (analógico/mecânico $x$ digital/eletrônico) mudou o panorama dos fenômenos da linguagem fotográfica e que foram enriquecidas principalmente pelo poder computacional.

Essa evolução manifesta-se nas possibilidades que se devem levar em consideração no processo de projeto e que influem na atividade do designer em novas ações para o campo.

Desta forma, os alunos necessitam desses conhecimentos sobre as diversas possibilidades de aplicação das ferramentas existentes para avançar em outras disciplinas de projeto como mencionam os respondentes 14 e 2 :

[...] hoje um aluno que vai simplesmente registrar com a câmera que ele tem no celular, sem a mínima preocupação em preparar o lugar, em colocar um fundo, em limpar área, tirar os ruídos todos dali da imagem, é um registro que não ajuda, ele não vai contribuir em nada, eu acho (fragmento D14/14:34).

[...] sem a fotografia e como se tirar uma ferramenta dele, mas não é, faz parte do processo criativo já dos designers, a fotografia. Então o que eu trabalho com o aluno é fazer entender isto, que eles têm um aliado que a fotografia acelera o processo, que a fotografia facilita o processo, mas que por outro lado ela precisa também a forma adequada de interpretar como usar a imagem, não é vulgarmente, que você coloca qualquer imagem (fragmento D2/2:13).

O respondente 14 relata a importância da ferramenta:

[...] a gente tem apresentado para os alunos, a questão do registro principalmente fotográfico como um instrumento de trabalho, como uma ferramenta importante e que ela tem que acontecer desde o primeiro momento. $O$ que a gente tem observado e a gente, nesse sentido, tem insistido que 0 aluno adote outros caminhos, que não, simplesmente extraído do computador ou de um site qualquer, uma imagem, é que ele, primeiro vá buscar imagens de boa qualidade e ele também trabalha a questão da própria imagem, fotografando alguns outros objetos que estão por aí (fragmento D14/14:12).

Um dos docentes esclarece a falta da disciplina na instituição e relata sobre a importância técnica e de sua linguagem:

[...] eu volto a insistir, se existisse a disciplina que mostrasse tecnicamente as questões técnicas e de linguagem, qual o objetivo da imagem que você quer produzir? Para que você está produzindo essa imagem? A sensibilidade da pessoa entender qual é o uso da imagem que ela está fazendo e aí sim eu acho que poderia ser digital. Não teria tanta diferença (fragmento D7/7:34). 
Outro aspecto mencionado pelos docentes está relacionado às fragilidades ao acesso dessa instrumentação. Nesse sentido o docente 25 comenta:

[...] que seria mais interessante era 0 aluno trazer essas fotografias que ele tivesse tirado, mas às vezes você não tem tempo hábil para trabalhar isso com o aluno, ou seja, o aluno às vezes não tem esse equipamento, ou a universidade não pode possibilitar esse equipamento para o aluno sair do campo da universidade para tirar uma foto lá fora, para usar como referencial, mas isso está sempre interligado com todas as partes e sempre trata de uma maneira que o aluno possa controlar essa iluminação para facilitar o trabalho dele ou o processo criativo da parte do método (fragmento D25/25:18).

[...] nas universidades públicas, há uma distância muito grande entre você atualizar tecnologicamente a universidade em função do que tem no mercado. O que a gente observa é que muitos dos nossos alunos tinha aceso a essa informação fora e dentro você não correspondia na mesma intensidade que era cobrado (fragmento D28/28:17).

Um dos respondentes mostra uma opinião contrária:

[...] por estarmos, assim, num mundo rodeado de imagem, e este mundo ainda ter a possiblidade da gente ter hoje equipamentos que cada pessoa porta sua própria câmera fotografia, então é fundamental ter uma disciplina de fotografia que evidencie para o estudante as interferências daquele equipamento, mesmo sendo mobile, na linguagem fotográfica (fragmento D15/15:20).

Para o respondente 14: "[...] o aluno hoje, ele dispõe de uma profusão enorme de informações, mas ele não sabe, ele não sabe selecionar" (fragmento D14/14:22).

Nesse sentido, é necessário que o aluno consiga adquirir competências e habilidades técnicas das diversas ferramentas. Um dos depoimentos chama a atenção para a forma que o docente ocupa a linguagem fotográfica em suas práticas didáticas em sala de aula e como é transferido esse conhecimento para os alunos.

É interessante notar que: "[...] é muito importante para os alunos, para eles perceberem, sentirem a força da Fotografia, o que ela pode, para depois, primeiro como entretenimento, como estética, para depois usar isso aí como uma ferramenta" (fragmento D35/35:12).

[...] a trajetória dentro de uma sala de aula, é que, você tem que dar para o aluno, as informações básicas para ele poder operar primeiramente, a ferramenta, que é a câmera. Então, todas as informações são direcionadas para que ele possa dominar as características técnicas e, ao fazer, enquanto ele vai praticando, vai se adequando a esta nova ferramenta, ele 
começa a perceber esses elementos dentro desta comunicação como linguagem, que também já foi passado. Só que é muita informação, vamos dizer assim, quando você passa toda essa questão da linguagem, passa tudo isso daí, passa as questões técnicas de câmera, lente, abertura, ISO, todas essas relações, ele fica, você percebe que ele fica muito perdido, então o que eu tento colocar isso, são doses menores e ir dosando isso conforme ele for evoluindo (fragmento D22/22:13).

Por outro lado, um dos docentes questiona os aspectos voltados à tecnologia computacional em conjunto com as ferramentas:

[...] é impossível dissociar as questões das linguagens de alguns aspectos técnicos. Mas o que eu, como é que eu penso, trabalhando isso academicamente? Primeira coisa eu penso que é preciso olhar, é preciso olhar muito e o que eu vejo nessa juventude, por isso eu digo que não acredito muito no computador como suporte para exercitar esse olhar, porque eu acho que a primeira coisa é o exercício do olhar e hoje em dia, o tipo de estudante que eu pego, que são do segundo ano, o costume é esse, o olhar ali, o olhar na tela do computador (fragmento D23/23:9).

Um dos aspectos que gerou essa defasagem no campo é a acelerada criação de novos cursos de Design, que se ampliaram durante os anos 90, não possibilitando o tempo suficiente para a preparação adequada dos docentes, sendo a maioria deles com formação em áreas correlatas e sem atuação e aprendizado prático. Mesmo com a consolidação do design, não significa que todas as questões relacionadas ao ensino estejam resolvidas, sendo que uma delas está diretamente ligada as disciplinas de linguagem fotográfica.

\subsection{De que forma a fotografia e o vídeo tem sido aplicados como suporte nos processos e procedimentos em Design de Produto; no Design de Análise e no Design de Investigação}

A fotografia e o vídeo oferecem hoje, uma grande possibilidade para a visualização rápida de conceitos projetuais, seja bidimensional ou tridimensional, ampliando assim, cognitivamente a transmissão de conhecimento através do uso de ferramentas como suporte para análise.

No relato dos docentes é possível identificar uma variedade de aplicações das ferramentas para os processos e procedimentos em Design de Produto, uma delas e que chama atenção é sua aplicação para a ergonomia, uma das variáveis mais evoluídas dentro do campo, devido à importância que a ferramenta tem para 
obtenção dos dados necessários, principalmente na fase de coleta, como esclarece um dos participantes: "[...] então essa área de imagem fotográfica, vídeo, ela tem uma correlação muito significativa com ergonomia." (fragmento D26/26:14). Continuando, o mesmo docente, informa:

[...] como eu trabalho com um pouco de pesquisa de campo, porque eu trabalho com Ergonomia Aplicada, então, quando eu faço pesquisa de campo, eu acompanho sempre os alunos, eu não os deixo sozinhos, não, porque tem alguns entraves metodológicos que às vezes você pode ter problemas para justificar depois, no relatório final (fragmento D26/26:5).

Também na coleta de grupos sociais e na estação de trabalho, como o relato:

[...]e depois, também, quando você trabalha com grupos sociais reais, com pessoas porque daí não é uma questão de exposição da pessoa, mas é uma questão de você ter um registro de gente, de situações reais que envolvam pessoas, você não pode, por exemplo, quando você vai mostrar uma situação de trabalho, por exemplo, tá, você pode desenhar a sua estação de trabalho, mas quando você está, por exemplo, trabalhando um aspecto ergonômico da estação de trabalho, uma fotografia diz muito mais daquilo, ou uma sequência de fotografias diz muito mais daquilo do que um desenho (fragmento D23/23:29).

[..] quando eles forem aplicar a metodologia, que eles registrem todas as ocorrências e a montagem de um determinado equipamento, se for um projeto, ou quando eu faço uma análise ergonômica de um posto de trabalho, ou até mesmo uma filmagem (fragmento D26/26:10).

É interessante ressaltar a importância do espaço físico para obter os registros, como relata o participante 23: "[...] as pesquisas que são desenvolvidas pelo LEI (Laboratório de Ergonomia e Interfaces), em ergonomia, a maioria delas tem base em registros fotográficos. Quando eu mostro desvios de coluna, coisas com idosos, é tudo feito com fotografia" (fragmento D23/23:30). A ergonomia é uma pequena fração das aplicações da ferramenta. "[...] ele tem que obter uma coisa chapada e que disso daí ele pode trabalhar e, aí sim, trabalhar a análise daquele objeto e a compreensão daquele objeto enquanto Geometria, enquanto um projeto que foi feito por alguém e que tem um sentido por trás" (fragmento D14/14:20).

Outras variáveis de uso e aplicação das ferramentas ainda são reduzidas, mas vem sendo ampliadas conforme surgem as necessidades de soluções dos problemas envolvidos no projeto. Nesse sentido, a busca para a aceleração na formação de inteligência visual é necessária para que o aluno amplie sua 
capacidade e competências ao avaliar situações para antecipação e correção de falhas no projeto.

Por outro lado, o sistema digital vem contribuindo para a formação da inteligência visual em algumas perspectivas técnicas do campo como na percepção da forma e cores: "Dentro da percepção da forma, eu trabalho com o conhecimento das cores e é óbvio que eu trabalho a fotografia na percepção da forma, porque não existe ferramenta melhor, além do olho humano, do que a fotografia (fragmento D2/2:22). Um dos respondentes explica que a fotografia também é importante na análise de similares. "[...] pesquisa de mercado, pesquisa de produtos, análise e avaliação de similares e durante o processo projetual também." (fragmento D18/18:5).

O mesmo respondente relata:

[...] sempre eu solicito uma revisão iconográfica, uma revisão bibliográfica dos produtos existentes no Mercado, por exemplo, como uma análise de similares, então ele já, de alguma forma, utiliza o uso da imagem para representar, à partir de critérios estabelecidos, de requisitos de projeto (fragmento D18/18:7).

Outro docente comenta ainda:

[...] muito importante na análise de situações reais e no segundo momento, eu acho que quando o aluno faz determinados modelos físicos, a gente trabalha muito com modelo volumétrico, aí eu acho que a fotografia faz muita diferença, porque o render em 3D é uma distorção do projeto (fragmento D7/7:37).

A pesquisa de mercado e análise de similares contribui para a construção do painel semântico. Por fim, sobre redesign do produto:

[...] então, nas de Projeto da graduação de Produto, a gente normalmente, quando a gente faz redesign ou uma situação real, porque às vezes alguns projetos são prospectivos, então aí não tem uma análise, mas quando tem análise de produto a gente sempre faz uso da fotografia numa primeira fase (fragmento D7/7:47).

O design de investigação figura com um aspecto muito importante para o campo e foi detectado entre os depoimentos coletados. Os participantes comentam a respeito das referências como suporte para o projeto: "[...] você precisa de referências visuais e, obviamente que, muitas vezes a referência visual está na sua cabeça com tudo aquilo que você vivenciou, mas registro fotográfico é 
extremamente importante como referência" (fragmento D19/19:8). O participante 4 menciona sobre a observação: "Aí a gente tenta buscar com esses alunos reforçar a ideia da necessidade de ele enxergar antes o que ele vai fotografar, ele tem que ver antes e depois buscar, dentro do retângulo fotográfico, da tela, buscar aquela imagem que ele queria" (fragmento D4/4:7).

Em relação a coleta: o respondente 6 diz:

[...] eles têm que fotografar usuários, tem que observar usuários, fotografar situações de uso. Eles capturam imagens no levantamento de dados da internet, então isso também é uma fotografia que está sendo usada como um dado secundário, isso não é um dado primário, produzido pelos próprios alunos, mas é um dado secundário que eles importam da internet (fragmento D6/6:8).

O participante 19 comenta a respeito da investigação: "O processo de investigação de determinado ambiente, para que você possa depois investigar cor formas e tudo isso que muitas vezes só indo no local você não consegue perceber." (fragmento D19/19:9). O participante 10, sobre os painéis semânticos: "O próprio professor que dá aula de projeto, ele vai orientar a fazer os painéis. Aí é uma orientação de cada série, cada ano vai ter uma orientação diferente (fragmento D10/10:13).

Entretanto, a fotografia e o vídeo são suportes para a investigação e auxiliam como ponto de partida, como relatam alguns dos entrevistados:

[...] no projeto dos alunos, a fotografia, sendo solicitada aos alunos na fase de pesquisa, em diferentes momentos, eles têm que fotografar usuários, tem que observar usuários, fotografar situações de uso. Eles capturam imagens no levantamento de dados da internet, então isso também é uma fotografia que está sendo usada como um dado secundário, isso não é um dado primário, produzido pelos próprios alunos, mas é um dado secundário que eles importam da internet (fragmento D6/6:8).

[...] na fase de levantamento de dados, algumas bases de informação, elas são mediadas pela fotografia, seja como dado primário produzido pela equipe de projeto, seja como dado secundário importado de algum livro, algum arquivo, algum banco de dados, algum mecanismo de busca na internet, como dado secundário, como dado primário, no levantamento de dados. Depois o acompanhamento quase como still fotográfico, de cinema - acompanhamento do processo de projeto da equipe, fazendo essa memória do projeto. Então fotografia como cristalização da memória e também, depois a fotografia como forma de comunicação dos resultados (fragmento D6/6:12).

Em suas aplicações como uma ferramenta para gerar referências: 
[...] que interfere no projeto do design porque você tem mais referências à mão, então isso, é mais informação, com certeza interferiria no meu projeto, eu ter acesso à mais informação, então eu tenho mais, é isso, eu tenho mais referências para eu poder usar naquilo, canalizar para um fim. Então eu tendo mais referências eu acho que muda o projeto, ele tende a ficar mais complexo, tende a ficar mais embasado (fragmento D8/8:27).

[...] utilização de imagens na pesquisa é primordial, então eles vão estar trabalhando com imagens ou próprias ou pesquisadas, direto já na fase inicial do projeto, que é a pesquisa. Então normalmente eles não produzem fotografia nessa fase, às vezes alguma coisa, mas o normal é que seja oriundo de pesquisa (fragmento D5/5:24).

\subsection{A linguagem fotográfica no design perdeu o seu papel fundamental de fomentar e socializar a comunicação e informação nos processos de projeto}

Considerando as ferramentas de captura como facilitadoras no processo de documentação e registro seja bidimensional ou tridimensional, nunca perdeu seu papel fundamental de fomentar e socializar a comunicação e informação no processo de projeto.

Um dos depoimentos apresenta a importância do papel da linguagem como o "[...] melhor meio de comunicação, ela transmite imediatamente a realidade" (fragmento D4/4:36). O docente 3 menciona que a linguagem fotográfica não perdeu sua função: "[...] se você achar que a documentação não auxilia no projeto, a gente está negando a ideia do próprio projeto em si" (fragmento D3/3:27). Ainda para o respondente 3: "[...]cristalização da memória [...]" (fragmento D3/3:27).

Na opinião do docente 14:

[...] eu vejo a linguagem fotográfica como mais um recurso, mais uma linguagem de representação e que deve ser utilizada dentro de toda a sua potencialidade nas disciplinas de Projeto. Tanto do ponto de vista sintático, quanto semântico, como é que essa linguagem ou essa maneira de representar [...] (fragmento D14/14:1).

Diversas outras disciplinas dependem do conhecimento da linguagem fotográfica, como afirma o entrevistado:

[...] hoje, por exemplo em disciplinas que eu leciono, elas dependem de ferramentas digitais, elas dependem de imagem, de fotografia, então eu acho que a linguagem fotográfica, ela está muito ampliada, ela está muito, e ela permeia aí muitos campos do conhecimento criativo, da criatividade, você acaba tendo que conhecer e se apropriar da fotografia de alguma maneira, seja só para mostrar o resultado final do seu projeto, para registrar o processo ou para usar como uma ferramenta criativa e de composição, 
como a gente estava falando, como um canvas aí para você criar em cima [...] (fragmento D3/3:27).

Para o respondente 20: "[...] a fotografia, ela facilitou muito essa questão de você pensar um projeto e você ter uma referência muito rápido demais [...]" (fragmento D20/20:35).

No entanto, para que exista, na atual conjuntura das tecnologias vigentes, uma valorização do papel da linguagem fotográfica, é necessário obter noções: "[...] de manipulação da fotografia como meio de representação, ou de expressão, não só de comunicação como de expressão [...]" (fragmento D9/9:1).

E ainda na tradução da ideia em forma de imagem:

[...] em cada etapa de pesquisa e depois da criação e depois da execução do projeto, sempre eles têm que apresentar um painel visual. Eles têm que traduzir um conceito, eles têm que traduzir uma ideia em forma de imagem, então, o painel semântico, ou um painel de tema visual, ou um painel de imagens, até uma colagem é muito requisitada (fragmento D10/10:10).

Quando a linguagem é utilizada apenas em uma perspectiva de documentação, ela perde as possibilidades de ampliar e fomentar uma comunicação e informação no processo de projeto, principalmente pela multiplicidade de possibilidades com o sistema digital. Nesse sentido, o respondente 13 menciona sobre: "[...] o risco aí é a tentação de viajar na imagem, quer dizer, virar um discurso bidimensional, então, cabe às disciplinas de Projeto, manter o fio terra da materialização, mas é um laboratório de investigação muito interessante, muito rápido" (fragmento D13/13:26). Entretanto, de acordo com o respondente 21:

[...] a imagem digital, ela está dentro do processo dessa multiplicação das possibilidades de comunicação, das possibilidades de informação. Comunicação tem, mas informação é outra coisa, é quando você consegue codificar essa profusão de comunicações para que ela vire informação [...] (fragmento D21/21:24).

[...] ela transita numa outra raia. Na raia do pensamento e da comunicação não verbal. Feliz, ou infelizmente, a ferramenta, o parâmetro, a aposta, o discurso do poder da academia, é essencialmente verbal, de forma que existe um atrito interessante aí nessa história (fragmento D13/13:1).

Para ela não perder sua função foi necessário ampliar o poder das ferramentas então elas estão: "[...] cada vez mais acessíveis e à mão, com uma resolução, em alguns casos, inimagináveis, em alguns casos você tem no seu 
próprio telefone, uma resolução ali, de máquina profissional [...]" (fragmento D33/33:20).

Um dos docentes esclarece que na graduação de Design Gráfico o uso da linguagem fotográfica tem uma riqueza muito maior que no de Produto:

[...] na verdade, o que também limita um pouco dessa ação, na falta de palavra melhor, é justamente a questão de ser o Design de Produto, eu acho que, evidentemente, o pessoal de Gráfico tira proveito, muito mais da riqueza do que pode ser feito enquanto linguagem e as coisas que hoje, dá para fazer, eu imagino que isso deva ser muito mais aproveitado, eu acho que essa questão do Design de Produto acaba também ficando que realmente isso era também uma questão documental [...] (fragmento D34/34:9).

Mesmo com esse avanço no outro campo, é importante notar que as mudanças e hibridizações das ferramentas permitem novas possibilidades dentro das já programadas, principalmente em virtude do grande acesso dos alunos aos smartphones, que permitem alta qualidade de aquisição de imagem (captura bidimensional, captura termográfica e escaneamento tridimensional nativo). Alguns docentes relatam: "[...] muitos também acabam utilizando o próprio celular para registro de todos os projetos. Poucos são aqueles que utilizam uma câmera profissional para poder registrar o momento" (fragmento D19/19:24). "[...] o grande problema da elaboração fotográfica é que ele se limita a fotografar com o celular, ele não vem, não pede a câmera fotográfica [...]" (fragmento D4/4:17). "[...] a gente percebe que os alunos fazem muito uso disso em projeto, muitas vezes, não com a câmera, o que é uma pena, por ter preguiça, porque enfim, mas usam bastante o registro no aparelho celular [...]" (fragmento D23/23:27). Com uso dos smartphones, os docentes não estão dando a devida atenção para essa nova ferramenta ou até mesmo não acreditando nas novas possibilidades adivinhas desta tecnologia.

Entretanto, outra parte dos docentes acredita no potencial:

[...] facilitar o acesso a esse tipo de registro. Então se tornou o que antes você precisava de um determinado equipamento que não era acessível, pelo custo ou pelas dimensões, agora ele tá no seu bolso, então a qualquer momento você pode dispor dele para registrar o que você quiser [...] (fragmento D1/1:6).

[...] todo mundo tem um Smartphone da vida para fotografar qualquer momento e assim por diante. Você acha que o uso do Smartphone facilita para o designer tanto na utilização de referências como para fazer, registrar o processo de projeto [...] (fragmento D30/30:29).

[...] exatamente hoje você consegue utilizar todo esse tipo de aparato, hoje 
você não precisa mais nem do notebook, você tem um celular em mão e internet, você consegue ter o acesso a qualquer tipo de informação que você precisa para auxiliar o seu projeto [...] (fragmento D25/25:28)

De acordo com o respondente 33: "[...] eles estão fotografando como nunca fotografaram antes, porque as ferramentas estão cada vez mais acessíveis e à mão, com uma resolução, em alguns casos, inimagináveis, em alguns casos você tem no seu próprio telefone [...]" (fragmento D33/33:20).

Para outro docente: "[...] um equipamento de celular, o registro que ele tem difere muito do registro de um equipamento reflex, um equipamento maior. Então a facilidade que o equipamento de celular tem no registro é muito maior do que boa parte dos equipamentos reflex" (fragmento D15/15:21).

No entanto, um dos respondentes esclarece:

[...] por incrível que pareça, a gente percebe o seguinte, apesar de hoje todo mundo ter a máquina fotográfica no celular e todo mundo estar fazendo a selfie o tempo todo, estar usando isso o tempo todo, profissionalmente fazse muito pouco, então se nós não pedirmos, se nós não falarmos, dificilmente, por exemplo, um aluno de laboratório vai fazer um registro, por exemplo, do passo a passo do desenvolvimento da ideia dele, isso é absolutamente comum (fragmento D33/33:19).

Deve-se considerar que existem muitos modelos de smartphones no mercado e também diversas configurações e possibilidades de captura. Assim, alguns docentes incentivam o uso e a necessidade do aparelho, mas esclarecem: "[...] o aluno, ele tem que conhecer as ferramentas para ele entender a maneira como ele pode usá-las. Isso é o mais importante [...]' (fragmento D8/8:15). e para que ele:

[..] consiga fazer uma representação de seus trabalhos e de si, até, como designer. Então como ele usa essa ferramenta e, é claro assim, que a gente fomenta que ele explore essa linguagem, então fotomontagens, enfim, explorações diversas são bem-vindas" (fragmento D8/8:18).

Desta forma, o respondente 10 comenta que "[...] é o melhor meio de representação e de registro, então eu consigo ver como registro, como memória, como forma de você guardar e relembrar depois, de um momento que a gente viu, mas pode esquecer" (fragmento D10/10:6).

As modificações das ferramentas dificultaram fomentar a competência cognitiva, devido aos resultados automáticos por elas produzidos e não dando sequência nas capacidades e habilidades existentes no pensar em imagens, 
capacidades e habilidades que devem ser trabalhadas em disciplinas voltadas ao ensino da linguagem fotográfica, mas que são valorizadas pelos docentes apenas nas apresentações finais dos projetos.

\subsection{Pesquisa e resultados da coleta de dados digital de alunos dos cursos de Design de Produto}

O questionário online aplicado aos alunos de Design de Produto tem por intuito obter dados relevantes e consistentes sobre o estado atual do uso da fotografia no projeto de produto, na opinião dos alunos, traçando um breve retrato de como este tema vem sendo inserido e praticado na visão de múltiplos respondentes de diferentes localidades do Estado de São Paulo.

A necessidade de trabalhar com a plataforma digital do Google Forms para essa coleta, revelou-se a mais eficiente, tendo sido adotada e aplicada, entre agosto e novembro de 2017, atingindo um total de 69 alunos respondentes, o que abrange grande parte das instituições de Design de Produto do Estado de São Paulo, adotando artifício de participação aleatória dos sujeitos, portanto, sem seleção prévia. Decorrente desta plataforma, os resultados são tabulados quantitativamente em forma de gráficos, embora a análise do teor do conjunto das respostas leva a tecer algumas considerações e aspectos qualitativos sobre a fotografia e o ensino de Design.

Uma das estratégias adotadas para obter melhor a disponibilidade dos alunos, quanto a cooperarem respondendo a entrevista e disponibilizarem de seu tempo, o questionário foi estruturado em seis seções, constituindo um roteiro de maneira que em cada sessão fossem coletadas informações necessárias para o levantamento quantitativo. Para cada seção, o respondente preencheu os dados para dar continuidade à pesquisa, favorecendo assim, a rapidez necessária para realização da coleta de dados digital.

Na seção 1 todos os respondentes (69 - 100\%) concordaram em participar da pesquisa, dando permissão para que as informações por eles oferecidas, fossem utilizadas na publicação acadêmica resultante deste trabalho (Gráfico 1). Desta forma, aceitaram o "Termo de Consentimento Livre e Esclarecido" caso contrário não teriam acesso às próximas seções, sendo suprimidos automaticamente da coleta (ver apêndice d). 


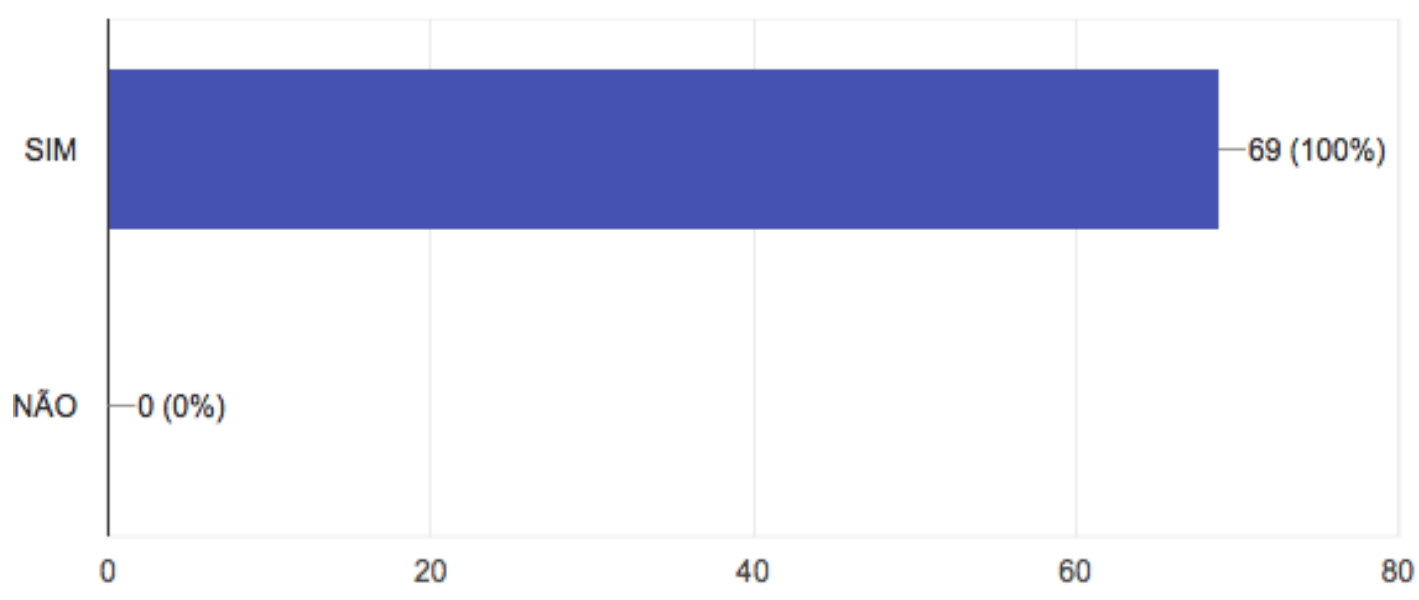

Fonte: elaborada pelo autor (2017).

Cabe observar que a quantidade de respondentes poderia ser ampliada, atingindo uma totalidade das instituições de ensino do Estado de São Paulo, em cursos de Design de Produto, mas devido a dificuldade de divulgação pelos meios digitais (facebook e e-mail), não atenderam as expectativas do pesquisador em abranger instituições onde os docentes vinculados às disciplinas de Linguagem Fotográfica não retornaram o contato ou não aceitaram participar da pesquisa.

Todos os docentes participantes da pesquisa também encaminharam para seus alunos o formulário, sendo facultativa a participação, não obtendo grande visibilidade dos alunos em contribuir devido à especificidade do estudo e por lidar com disciplinas que, em muitas instituições, não é dada a devida importância na grade curricular e em sua alocação no semestre.

Para obter um alto grau de veracidade dos respondentes, foi necessário, na seção 2 (ver apêndice d) obter nome completo dos respondentes, a identificação da instituição de ensino, a cidade, o curso e o semestre. Nessa seção foi possível suprimir três respondentes que não estavam localizados no Estado de São Paulo e um respondente do curso de Design Gráfico, totalizando quatro respondentes suprimidos. 
Gráfico 2 - Contagem de instituições de Ensino Superior e Cidade com alunos participantes.

Contagem de Instituição de Ensino / Cidade:

20

16

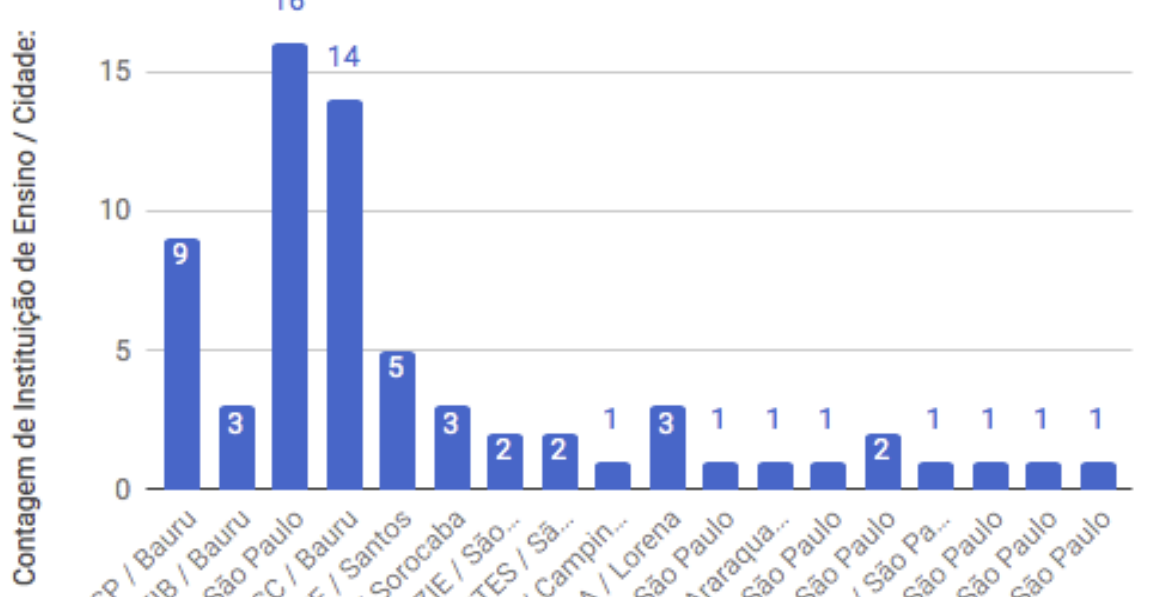

Instituição de Ensino / Cidade:

Fonte: elaborada pelo autor (2017).

Gráfico 3 - Semestre letivo de cada participante.

\section{Contagem de Semestre}

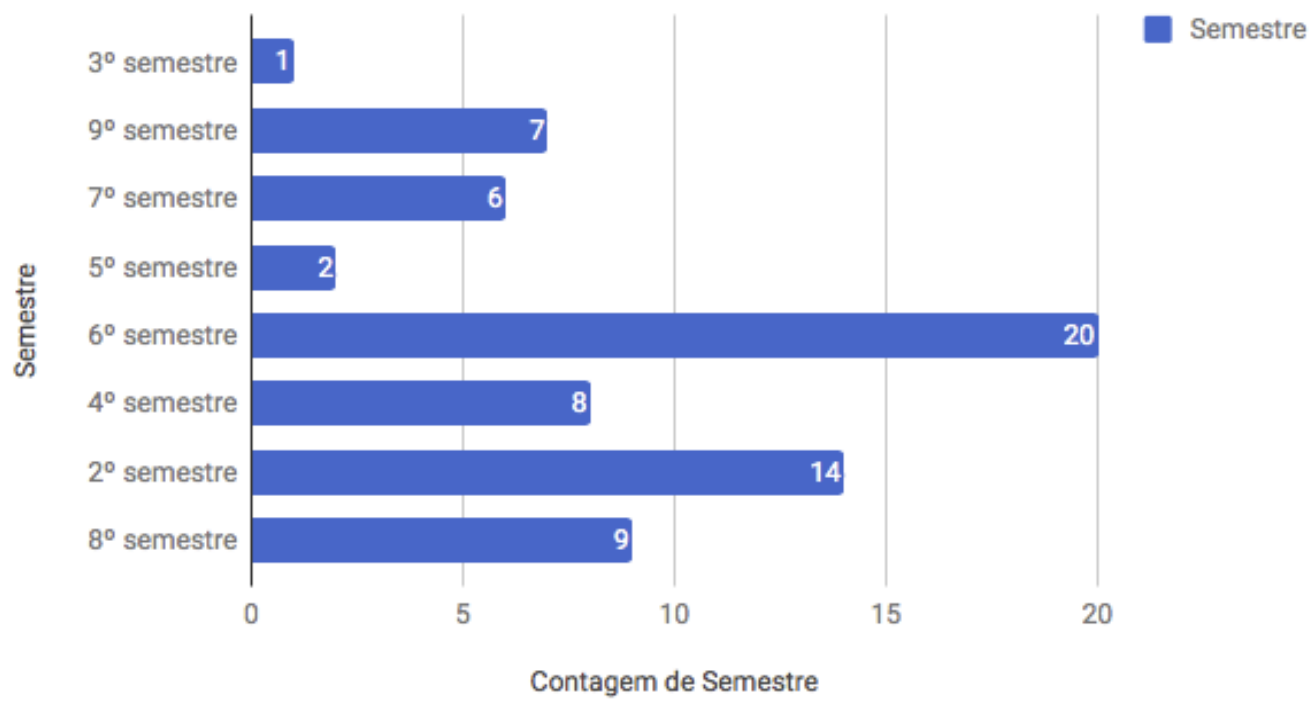

Fonte: elaborada pelo autor (2017).

Os alunos participantes da pesquisa estão contemplando as seguintes instituições de ensino: Universidade Estadual Paulista (UNESP) / Bauru - 9; 
Faculdades Integradas de Bauru (FIB) / Bauru - 3; Faculdade de Arquitetura e Urbanismo (FAU/USP) / São Paulo - 16; Universidade do Sagrado Coração (USC) / Bauru - 14; Centro Universitário Monte Serrat (UNIMONTE) / Santos - 5; Universidade de Sorocaba (UNISO) / Sorocaba - 3; Universidade Presbiteriana Mackenzie (MACKENZIE) / São Paulo - 2; Centro Universitário Belas Artes (BA) / São Paulo - 2; Faculdade de Campinas (FACAMP) / Campinas - 1; Centro Universitário Teresa D’Ávila (UNIFATEA) / Lorena - 3; Faculdade Paulista de Artes (FPA) / São Paulo - 1; Universidade de Araraquara (UNIARA) / Araraquara - 1; Fundação Armando Alvares Penteado (FAAP) / São Paulo - 1; Centro Universitário Senac (SENAC) / São Paulo - 2; Universidade Nove de Julho (UNINOVE) / São Paulo - 1; Instituto Mauá de Tecnologia (MAUÁ) / São Paulo - 1; Escola superior de Propaganda e Marketing (ESPM) / São Paulo - 1; Faculdades Metropolitanas Unidas (FMU) / São Paulo - 1; acolhendo também instituições onde os docentes não foram entrevistados, ampliando a abrangência da pesquisa, sua importância e atualidade para o campo de conhecimento do Design de Produto.

Com a contagem foi possível identificar que a maioria dos participantes é da própria instituição onde o pesquisador tem vínculo (Faculdade de Arquitetura e Urbanismo (FAU/USP) / São Paulo), onde grande parte dos docentes por conhecerem a pesquisa, divulgou o questionário por meio digital, obtendo desta forma, maior adesão por parte dos alunos. Outras instituições como: Universidade Estadual Paulista (UNESP) / Bauru; Faculdades Integradas de Bauru (FIB) / Bauru; Universidade do Sagrado Coração (USC) / Bauru, fazem parte da cidade de origem do pesquisador e contribuíram de forma significativa.

A contagem de participantes em relação ao semestre letivo apresenta uma grande quantidade de respondentes do $6^{\circ}$ semestre (20\%), que passaram pelas disciplinas básicas; e do $2^{\circ}$ semestre (14\%) que ainda estão iniciando as disciplinas do curso básico, sendo os outros percentuais distribuídos pelos demais semestres do curso, atendendo desta forma, a um espectro completo da formação do aluno.

Nesta seção poderia ser alocada uma questão para identificar em que semestre as disciplinas de Linguagem Fotográfica são oferecidas no curso. Desta forma, seria possível identificar em que momento o aluno obtém o conhecimento das ferramentas. Porém, por meio das grades curriculares de cada curso, é possível identificar como cada instituição está dando a devida importante para os meios de representação. 
$\mathrm{Na}$ seção três (ver apêndice d) estão colocadas as questões diretamente relacionadas à inserção da Fotografia nos cursos, sendo que na primeira (Gráfico 4) é possível identificar que grande parte das instituições oferecem disciplinas de Fotografia ou de Vídeo em sua grade curricular; e apenas 4,3\% responderam que as disciplinas não são oferecidas nas instituições.

Gráfico 4 - Respostas sobre a oferta da disciplina de Fotografia ou Vídeo - (questão fechada).

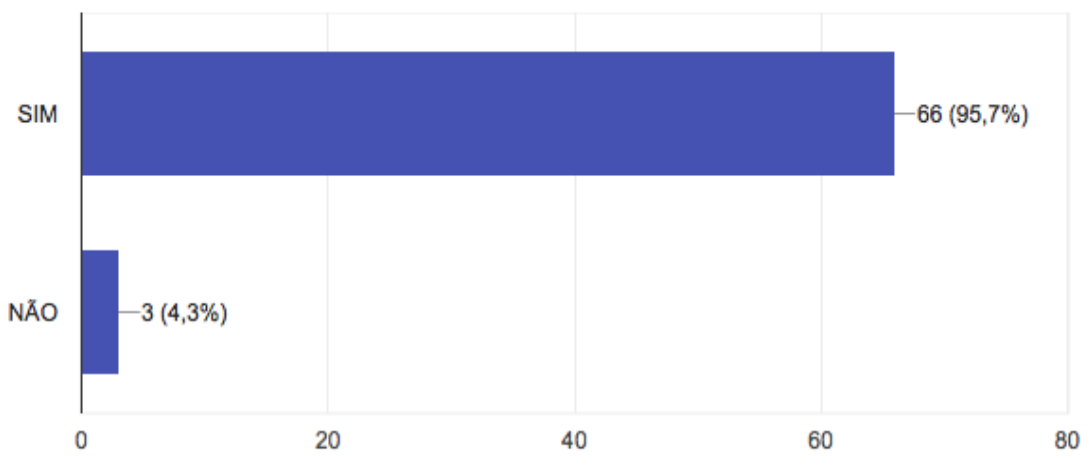

Fonte: elaborada pelo autor (2017).

Essa questão apresenta que poucas são as instituições que não oferecem as disciplinas de Linguagem Fotográfica na grade curricular.

$\mathrm{Na}$ sequência em questão aberta, quando o participante ficava livre para responder ou não, se destaca a diversidade de nomenclaturas utilizadas (Gráfico 5) para as disciplinas de Linguagem Fotográfica. 
Gráfico 5 - Nome das disciplinas oferecidas nas instituições de ensino.

Contagem de Caso sim qual o nome da disciplina e duração?

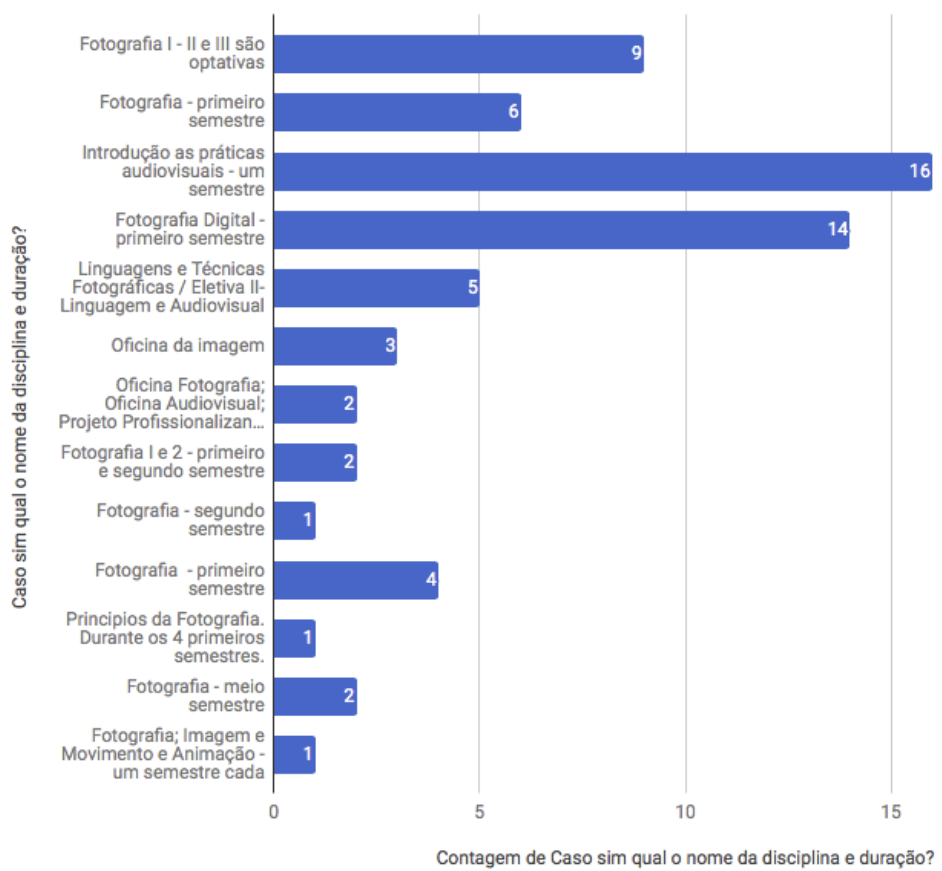

Fonte: elaborada pelo autor (2017).

Mesmo que a disciplina esteja presente na grade curricular, ela não está necessariamente direcionada aos alunos de Design de Produto. Existem grandes possibilidades de desvio de interpretação sobre o enfoque e conteúdo das disciplinas, pois fica evidente nessa questão, que a fotografia e o vídeo estão mais relacionados à imagem do que ao projeto. Nesse sentido, abrangeria outras competências em Design e uma maior aproximação à arte, comunicação visual, imagem em movimento, animação, etc.

Tais mudanças de terminologia sugerem uma revisão curricular, atendendo a inserção de conteúdo, que abordem conceitos e possibilidades práticas de aplicação destes recursos, e reorganização das grades curriculares, principalmente no que diz respeito a sua alocação no semestre de maneira que o aluno possa dominar a linguagens da fotografia e do vídeo de forma mais apropriada e aplicá-las no seu desenvolvimento ao longo dos anos de sua graduação, onde as diversas técnicas digitais possibilitariam novas formas de produção de imagens, sejam elas bidimensionais ou tridimensionais, juntamente com os recursos computacionais.

A seção quatro, foi subdividida em três fases referentes a utilização da linguagem fotográfica durante os projetos envolvidos nas diversas disciplinas do 
curso (ver apêndice d). Na primeira fase (a) a primeira questão (Gráfico 6) é fechada, onde apenas $14,5 \%$ dos alunos mencionam que não utilizam a fotografia e o vídeo nos projetos, sendo que a maioria, $85,5 \%$, a utilizam.

Gráfico 6 - Você utiliza da linguagem da fotografia e do vídeo nos projetos do curso?

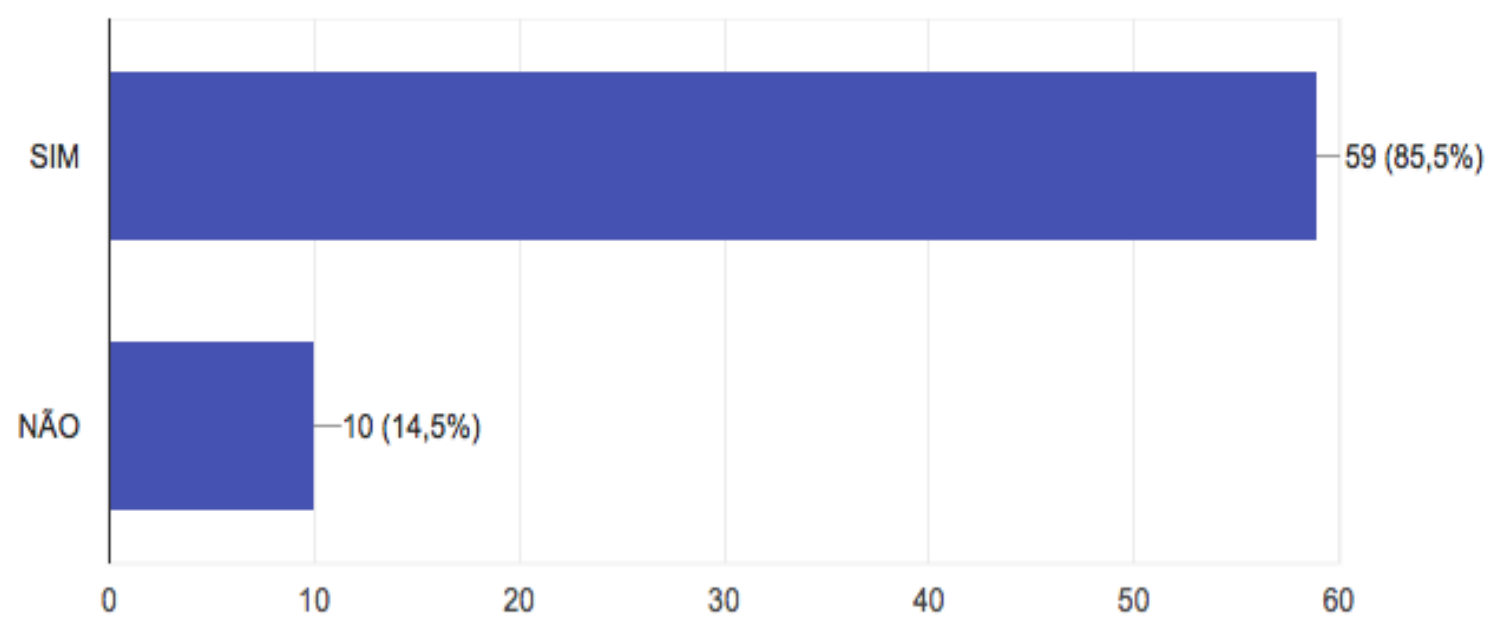

Fonte: elaborada pelo autor (2017).

Já em relação a questão aberta, na qual os alunos tinham a liberdade de responder ou não, aparece a opinião dos respondentes, refletindo aspectos subjetivos, mas qualitativos e indica uma diversidade de possibilidades de como a linguagem fotográfica vem sendo utilizada pelos alunos, onde seguem arrolados os resultados obtidos:

- Fotografia de protótipos, mock-ups e produtos;

- Imagens para apresentação, documentação, divulgação e comunicação do produto desenvolvido;

- Relatórios de produção de protótipos;

- Composição de grid para montar projetos;

- Registro do processo de criação;

- Simulações de uso do produto para testes;

- Documentação do processo de desenvolvimento do projeto;

- Na fase de pesquisa e problematização;

- Stopmotion de funcionamento;

- Representação utilizada em produções gráficas e painéis expositivos; 
- Compreender os planos de configuração visual do produto;

- Composição fotográfica para o render tridimensional; e

- Para valorizar a estética do produto.

No entanto, é evidente também que grande parte dos alunos se utiliza das ferramentas, apenas como meio de representação auxiliar na apresentação dos projetos em painéis expositivos, relatórios e pranchas para entrega dos trabalhos finais. Outras possibilidades observadas de uso e aplicação durante o processo é bem reduzida, considerando a gama de oportunidades de dispositivos e programas existentes; de aplicação das ferramentas, e que não estão presentes nas respostas dos alunos, indicando que não estão familiarizados com as tecnologias de ponta para o exercício profissional.

Um dos alunos esclarece que as disciplinas focam na história e referências do seu uso e emprego, incluídas geralmente em disciplinas teóricas, e também veem a instrumentação e um pouco de filmagem e edição na parte prática, associados a uma visão mais artística.

Na segunda questão (b) (Gráfico 7) da mesma seção, na opinião dos alunos, a linguagem fotográfica e do vídeo podem sim desenvolver um papel preponderante no processo de projeto - $95,7 \%$ contra apenas 4,3\% que não acreditam em seu potencial como uma das ferramentas de grande relevância para o campo. É possível identificar o quanto é claro para o aluno, a importância da linguagem fotográfica para o processo de projeto.

Gráfico 7 - Respostas para a questão: A linguagem fotográfica e do vídeo pode desenvolver papel preponderante no processo de projeto?

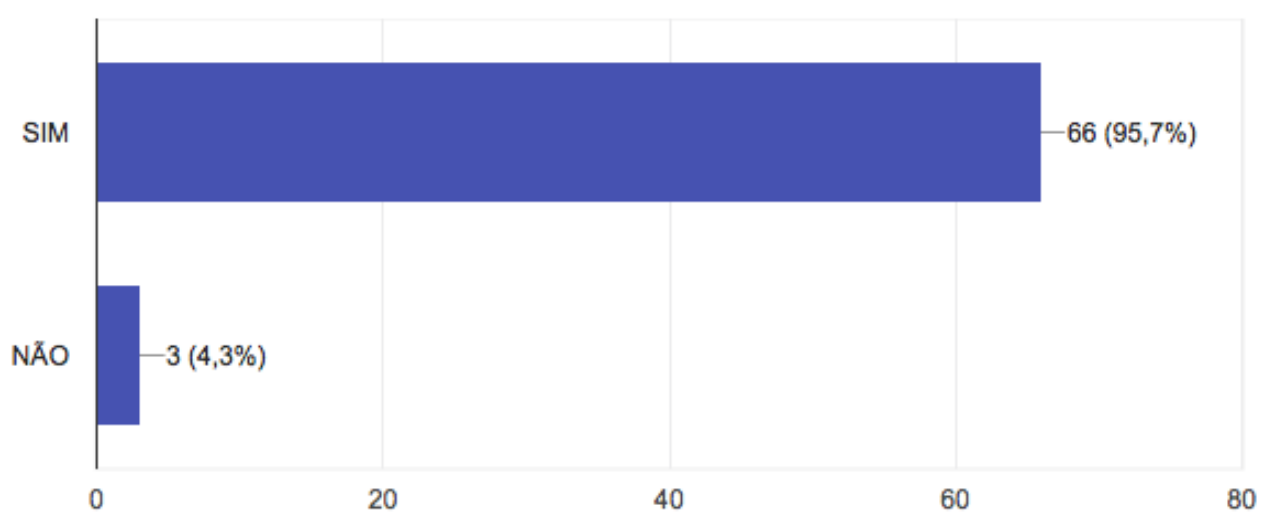

Fonte: elaborada pelo autor (2017). 
$\mathrm{Na}$ terceira questão (c) da mesma seção é evidente que metade $(52,2 \%)$ dos alunos não se utiliza das ferramentas em outras disciplinas que não sejam as de projetos, demonstrando assim, que conteúdos e práticas sobre fotografia e vídeo, não são considerados com importância, como ferramenta auxiliar para os processos de projeto (Gráfico 8).

Gráfico 8 - Você utiliza a linguagem fotográfica e do vídeo em outras aplicações dentro do curso?

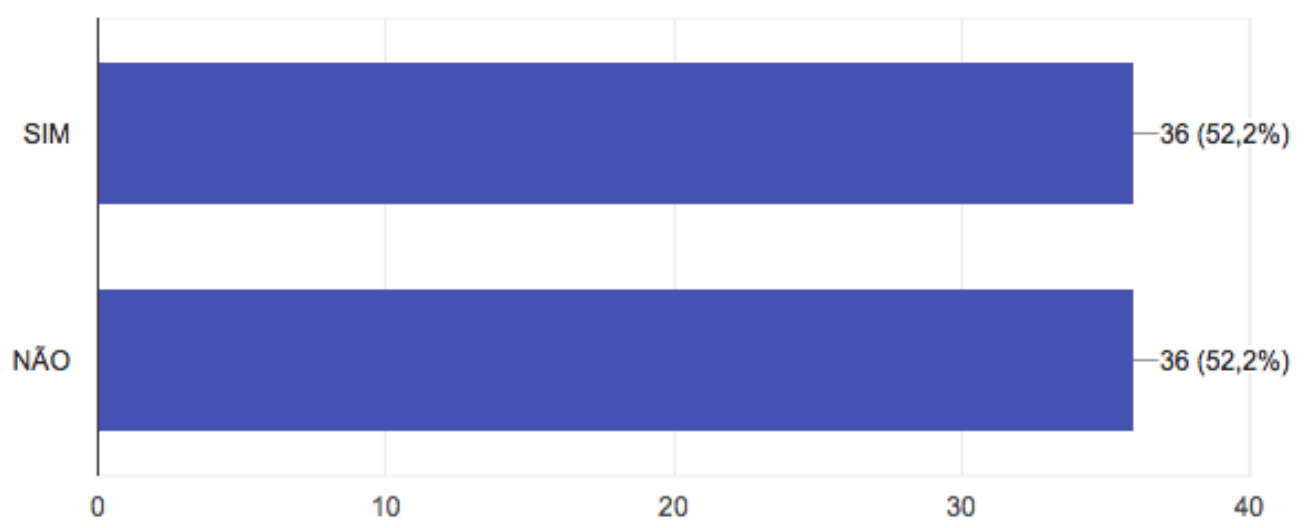

Fonte: elaborada pelo autor (2017).

Isso implica que em outras disciplinas os docentes não estão exigindo do aluno, um alto nível de utilização das ferramentas para auxiliar no desenvolvimento das atividades por eles desenvolvidas.

$\mathrm{Na}$ questão aberta os respondentes indicam uma diversidade de possibilidades de como a linguagem pode ser utilizada em outras aplicações dentro do curso

- Utilização da imagem como referência;

- Análise para engenharia reversa;

- Composição da representação do projeto;

- Utilização do vídeo para apresentar esquemas e conceitos;

- Processos de criação;

- Vídeo promocional;

- Para observar ações e movimentos de sujeitos e da natureza;

- Stopmotion para comunicação de processos;

- Intervenção artística;

- Nas disciplinas de projeto; e 
- Digitalização de rascunhos.

Nesta questão não foi possível identificar a utilização de laboratórios ou estúdios, ou até mesmo pesquisas em andamento na instituição que favoreçam a utilização de novas ferramentas da fotografia e do vídeo. Mesmo tendo uma diversidade de possibilidade de utilização é claro o uso de forma artística, para o campo do design Gráfico, como referência e como representação.

Na seção 5, questão 3 (Gráfico 9), a maior parte dos alunos concorda (94,2\%) que a fotografia e o vídeo no sistema digital viabilizam e agilizam o desenvolvimento de projeto em Design, contra $7,2 \%$ dos alunos que não concorda. desenvolvimento do projeto de design na atualidade?

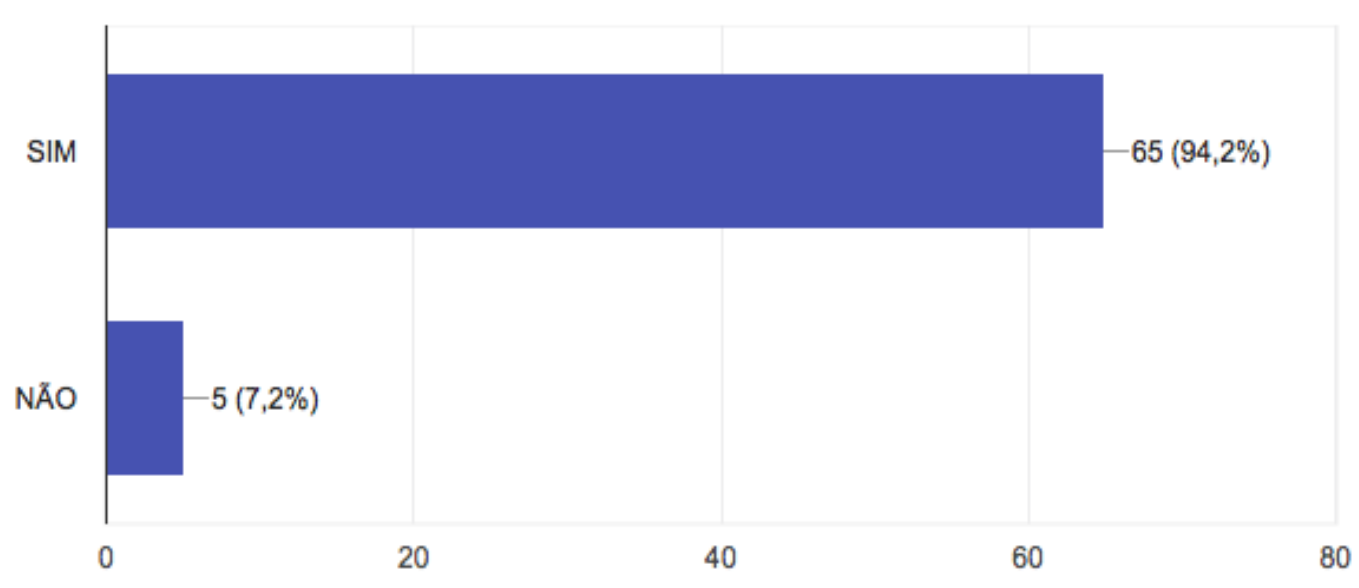

Fonte: elaborada pelo autor (2017).

Nessa questão é possível identificar que o aluno acredita no potencial das ferramentas, devido principalmente às necessidades de atuação profissional, onde o indivíduo desenvolve e aplica determinadas habilidades e conteúdo para atender ao mercado. Entretanto, tais disciplinas, com conteúdo e exercícios práticos, não estão sendo abordadas, se forem consideradas as respostas obtidas. Nos currículos das instituições pode-se perceber uma ampliação de disciplinas de cunho abrangente e formação generalista, enquanto a carga horária de cursos específicos para fotografia e vídeo, vem sendo reduzida, atendendo apenas um dos semestres da grade curricular. 
Na seção 6, questão 4 (Gráfico 10), quando perguntados sobre cursos extras ou complementares, grande parte $(76,6 \%)$ dos alunos não busca realizar cursos ou workshops de fotografia em outras instituições. Apenas 23,2\% busca participar em conjunto (concomitante) com a graduação, para ter uma base mais sólida do conhecimento das ferramentas e da linguagem.

Gráfico 10 - Já realizou algum curso ou workshop de fotografia ou de vídeo em outra instituição?

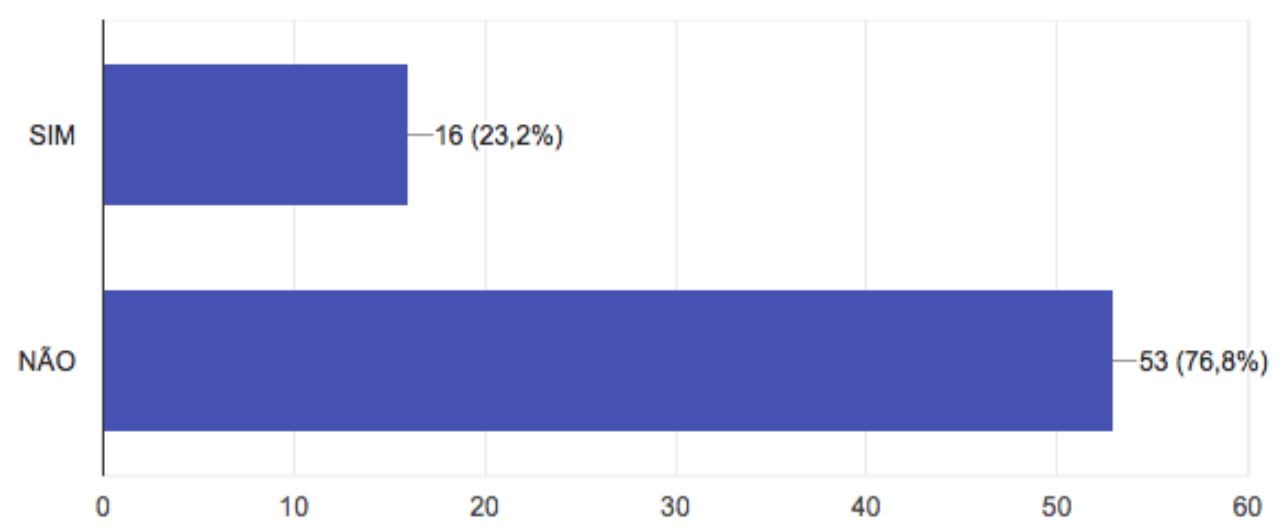

Fonte: elaborada pelo autor (2017).

$\mathrm{Na}$ questão aberta, dos que participaram de cursos ou workshops em outras instituições, foi solicitada a indicação sobre o local em que desenvolveram as atividades:

- Introdução a fotografia com câmeras semiprofissionais;

- Curso de Fotografia - SENAC;

- Disciplina de Comunicação Visual - ETEC;

- Disciplina de Audiovisual e Fotografia - ECA-USP;

- Fotografia Analógica - curso técnico;

- Fotoramance - SESC;

- Foto Documentário;

- Fotografia - ABRA; e

- Premiere e After Effects - SAGA.

A grande maioria dos cursos apresentados pelos alunos é de curta duração e tem como critério apresentar técnicas de utilização do equipamento fotográfico e 
formas de composição, com maior aproximação às artes e não ao projeto, mas que possibilita adquirir conhecimentos técnicos de manipulação das ferramentas, o que é muito importante para realizar a captura, contribuindo positivamente para que o aluno possa manipular qualquer ferramenta que tenha os princípios de captura ótica, seja bidimensional, tridimensional, térmica e outras possibilidades de espectros de luzes não visíveis ao olho humano.

Entretanto, grande parte desses workshops estão voltados ao mercado publicitário e para o seguimento de eventos sociais, que lidam com a ferramenta para atender esses nichos de mercado.

A base de instrumentação e uso de ferramentas mais modernas em termos de tecnologias é importante para que o aluno possa aprimorar suas habilidades para utilização no campo, e devem ser inseridas durante a graduação.

Com o constante desenvolvimento tecnológico, foram colocadas à disposição, novas ferramentas para a utilização em novos processos, sendo fundamental que durante a formação acadêmica, o aluno tenha contato experimental e conheça as possibilidades dos recursos oferecidos pelos diversos dispositivos e programas digitais (e analógicos) de captura para que, posteriormente, saiba eleger ou até mesmo modificar as possibilidades de representações existentes, auxiliando e ampliando a sua capacidade de percepção visual, acompanhando a evolução das técnicas aprendidas.

Os cursos existentes no Estado de São Paulo, sejam eles estaduais ou municipais, assim como os particulares, não acompanham 0 ritmo do desenvolvimento tecnológico da indústria que se encontra em constante expansão e aprimoramento, demonstrado nestas pesquisas, situação que pode ser agravada pelo alto investimento representado na aquisição e disponibilização de equipamentos, programas e recursos como laboratórios e oficinas, interferindo no campo de conhecimentos dos meios e representação visual.

Nesse sentido, considerando as respostas dos alunos pesquisados, colocamse em dúvida as condições de um estudante vir a adquirir as qualidades e competências na sua formação, necessárias para uma atuação de excelência no mercado, sem os conteúdos fundamentais representados por novas ferramentas da fotografia e do vídeo, indicando ser necessária uma reformulação das estruturas, aportes pedagógicos e instrumentais para atender as novas demandas e exigências do mercado atual. 
O Design de Produto tem como uma de suas principais características o exercício projetual, atividade inerentemente ligada à criação e ao desenvolvimento de produtos, e atua com a contribuição e na interface com os campos da Engenharia e Arquitetura; Artes, Comunicação e Economia. Durante a formação do designer, observa-se que o método projetual constitui o alicerce para a formação e alimenta o desenvolvimento de novos projetos.

Tradicionalmente, o Design usa técnicas inventivas, amparadas por sistemas analógicos, digitais, mecânicos, elaboração de desenho e ilustrações manuais, desenhos técnicos, e em diversos tipos de suporte (sistemas computacionais; e auxílio de ferramentas e equipamentos para a execução em oficina), além de insumos para a construção de modelos e protótipos. Para os estudos e testes de simulação, são confeccionados protótipos através de habilidades manuais e intelectuais, unidos às ferramentas tradicionais de representação (imagens em papel, computador, e outros recursos projetados) para auxiliar no processo de projeto.

Assim, na modalidade do produto, a pesquisa de campo observou que nas ações pedagógicas para o exercício de projeto na graduação, os estudantes são orientados, para o desenvolvimento e uso de métodos fundamentados em fases sequenciais e contínuas ou experimentais e, desta forma, ele necessita se utilizar de ferramentas que o auxiliem durante essas fases.

Para ter um maior contato com a realidade vivenciada pelo corpo discente e docente, houve a oportunidade de acompanhar a etapa de Estágio Supervisionado em Docência do Programa de Aperfeiçoamento de Ensino junto à Disciplina AUP2404 - Projeto de Produto II - ministrada aos alunos de graduação da Faculdade de Arquitetura e Urbanismo da Universidade de São Paulo (USP). Foram observadas as dificuldades dos discentes em diversas fases do projeto. Os primeiros problemas já iniciavam na visualização e no entendimento das próprias propostas (principalmente na apreensão tridimensional das partes e componentes dos produtos idealizados); na pesquisa de dados e de referências projetuais; e mesmo existindo uma liberdade durante o processo de desenvolvimento, o discente ficava preso a regras formais mencionadas pelos docentes, o que o impossibilitava ir além do já estabelecido.

Desta forma, o aluno fica condicionado a referências visuais pré-conhecidas (de matérias primas às tecnologias; e de produtos existentes) sem ampliar repertório. Considera-se ser necessário ir além de dados que estão disponibilizados na internet, 
abrindo outros caminhos para a criatividade, que acreditamos ser ferramental ideal e possível para ampliar a capacidade e o repertório visual; para aumentar o conhecimento sobre outras iniciativas de projeto e produção no tema, colaborando para considerar uma visão expandida acerca do produto a ser elaborado. Contudo, foi observado também que o processo de desenvolvimento é pautado por geração de ideias dos discentes, muitas delas já concebidas para o meio, poucas delas baseadas em pesquisas aprofundadas e quase sempre utilizando o referencial já adquirido.

Nesse sentido um dos problemas investigados e obtidos nas respostas dos alunos nos questionários, foi a perda da base física, material, da manipulação e do uso do processo analógico (mecânico), sendo possível concluir que isto prejudicou os procedimentos de ensino e de aprendizagem, devido principalmente a falta de investimentos em tecnologia e equipamentos, e a perda de docentes (e de técnicos) capacitados para realizar a transição para o sistema digital (eletrônico).

Grande parte dos docentes e das instituições pesquisadas demorou a aceitar essas mudanças e a incorporar e introduzir as novas tecnologias digitais embarcadas em equipamentos e programas, retardando a observação sobre as potencialidades aplicadas ao campo do projeto, chegando a manifestar uma descrença com as novas tecnologias. Muitos mantiveram o sistema analógico ativo, como pratica pedagógica, devido aos conhecimentos e práticas anteriormente adquiridos e acumulados em processos técnicos, mecânicos da linguagem, de captura com câmeras manuais e filmes em preto e branco, ao mesmo tempo em que as mudanças tecnológicas eram implementadas, o sistema vigente foi se tornando obsoleto e de certa forma, oneroso; colaborando para manter o interesse dos alunos baixo em relação ao contexto atual, representado por uma geração de graduandos bem familiarizados e usuários do sistema digital.

As instituições não realizaram os investimentos necessários para que, tanto os docentes quanto os alunos, adquirissem os novos conhecimentos e habilidades proporcionados pelas novas ferramentas digitais para auxiliarem nos processos de projeto. Outro aspecto é o de que grande parte dos docentes permanece transmitindo conhecimentos introdutórios da linguagem fotográfica, dirigidos somente (ou prioritariamente) para os conteúdos e práticas necessárias apenas à atuação em Design Gráfico. Essa dificuldade de encontrar possibilidades e experiências didáticas para atender as novas necessidades do designer de produto 
(comparativamente as que foram criadas ao longo do tempo com o processo fotoquímico) está impedindo novas experimentações e aplicações com as ferramentas disponíveis para a área. Esta constatação pode levar a inferência de uma falha de formação e de base para os profissionais que atuarão em Design de Produto.

O sistema digital abriu perspectivas fascinantes que não estão sendo aplicadas no ensino de Design nas instituições pesquisadas, representando atualmente, uma defasagem prejudicial à prática da fotografia e do vídeo relacionadas aos sistemas digitais, que ultrapassam a ação da captura do click automático, embarcado nos dispositivos móveis, isto é, sem usar os recursos, técnicas e programas que facilitem as etapas do processo de projeto.

Essa expertise de conhecimentos aplicados auxilia nas potencialidades para aplicação das diversas ferramentas de captura e de manipulação de imagem existentes. Considera-se que a linguagem fotográfica tem a mesma importância que outras formas de representação tradicionais utilizadas no campo, entretanto, o aluno não tem buscado complementar esse conhecimento com cursos ou workshops de Fotografia ou de Vídeo em outras instituições, para ampliar o conhecimento e a experimentação com determinadas técnicas.

Uma das alternativas para minimizar essa defasagem em relação aos conteúdos atualizados, melhorando assim, as habilidades e competências do aluno é a realização de parcerias com a indústria, considerando que grande parte das instituições não vai conseguir acompanhar a evolução e a substituição constante de maquinas e equipamentos e/ou reciclá-los de forma rápida.

O que é discutido entre os docentes é que o meio digital facilitou demais a obtenção de imagens, tornando o processo automatizado, e assim, nota-se que os alunos perderam o interesse em obter conhecimento aprofundado ou mais técnico, das habilidades necessárias para sua melhor aplicação no campo.

É indiscutível que uma revisão e aprimoramento dos programas educacionais de Design, possam fomentar e ampliar as competências para a formação a área, resgatando o papel da linguagem fotográfica e ampliando as possibilidades de exercício profissional, principalmente pela hibridização das novas ferramentas.

Entretanto, com tantas possibilidades que a tecnologia digital oferece, o aluno necessita ainda, criar uma relação mais estreita e forte com a linguagem fotográfica e de vídeo e compreender que as ferramentas e tecnologias atuais proporcionam 
auxílio no processo projetual, assim como outras ferramentas já tradicionais, além do domínio do aluno, que se mostra limitado apenas aos processos de documentação, conforme identificado na pesquisa realizada.

No relato dos docentes é possível identificar que a linguagem fotográfica esta também inserida diretamente na aplicação prática em observar os usuários e identificar como eles estão manipulando ou modificando os objetos, e ainda o que eles gostam ou não, além das suas dificuldades de uso.

Também foi constatado que as investigações ligadas ao ensino da Fotografia e do Vídeo não são de interesse de grande parte dos pesquisadores, o que leva a acreditar que os temas não são evidentes, nem considerados ferramentas auxiliares e de criação importantes no processo de projeto. O levantamento sobre técnicas e ferramentas mostrou uma diversidade de aplicações específicas, derivadas ou que usam o procedimento fotográfico, que são importantes mecanismos para a atuação em pesquisa, análises, avaliações e projeto, tais como a termografia, o escaneamento tridimensional, a fotogrametria, a biofotogrametria, a realidade aumentada e a holografia.

Assim, é irreversível o uso da linguagem fotográfica, baseada em tecnologia aprimorada de ponta, com aplicações tanto na captura de imagens; na pesquisa de referenciais semânticos e visuais; na análise de produtos e de materiais; na simulação, na prospecção e na manipulação de projeto de produtos, além da documentação e da divulgação de ideias.

Essas modalidades existentes e observadas nas ferramentas, não estão sendo abordadas, instrumentadas nem aplicadas dentro das instituições ensino, sobretudo nas suas possibilidades de experimentação, pois oferecem processos inesgotáveis de constituição, manipulação e aplicação em imagens, com uma contribuição efetiva aos processos projetuais e de modelagem; de análise e redesenho de objetos; de avaliações de produto simuladas e em uso, entre outras, e que podem/devem ser ampliados junto ao domínio computacional e de programação.

Fica claro que grande parte dos alunos apenas utiliza a ferramenta como meio de representação auxiliar na apresentação dos projetos e em painéis expositivos, além de relatórios e pranchas para entrega dos trabalhos finais. Uma fração muito pequena dos discentes a utiliza para a simulação de uso do produto; para testes; e na fase de pesquisa e problematização, de maneira a compreender os planos de configuração visual do produto e valorizar a estética do mesmo. 
É possível identificar que pequenos fragmentos das técnicas sobre a linguagem fotográfica vêm sendo apresentados aos alunos de modo distribuído nas diversas disciplinas da grade curricular, para atender parcialmente as necessidades de conhecimento e prática sem representar um papel preponderante para todo o processo de projeto.

Durante o levantamento com os docentes que ministram a disciplina de Projeto de Produto não surgiu nenhum dado relevante sobre a aplicação ou a transferência de conhecimentos, utilizando softwares tanto de gerenciamento de projetos como de tratamentos, de captura e de projeção de imagens, seja bidimensional ou tridimensional, sendo que grande parte dos pesquisados ainda não está familiarizado com os sistemas de captura e representação fotográfica em três dimensões.

Verificou-se que a contribuição da linguagem fotográfica em viabilizar e auxiliar o desenvolvimento do processo de projeto fica evidente para o aluno, que acredita que o sistema digital tem esse potencial a oferecer para o campo do Design. Mas, para que seja potencializado é necessário oferecer técnicas e ferramentas, com conteúdos conceituais e ações praticadas e exercitadas, aplicadas ao procedimento projetual, dentro das instituições.

Também foi visto que, mesmo contando com uma diversidade de técnicas de captura e manipulação a ser aplicado no Design de Produto, o aluno ainda as utiliza de forma majoritariamente artística, aplicadas e direcionadas para a formação em Design Gráfico, conforme identificado tanto na entrevista com docentes como na entrevista com os alunos. Esta evidência corrobora para inferir que, talvez este direcionamento se sobreponha ao avanço em questões que são proeminentes para - Design de Produto como: a pesquisa, a criação, geração de alternativas; possibilidades de geração de alternativas; modelagem e a captura do protótipo/modelo; simulações, análises e avaliações digitais e na comunicação; e projeção dos resultados.

As técnicas de captura podem ser direcionadas também para a manipulação e a experimentação de acabamentos e formas, das cores e texturas dos objetos; a análise e a avaliação de materiais por fotogrametria, biofotogrametria; o escaneamento tridimensional e a realidade aumentada; holografia, além de outras possibilidades existentes. É necessária uma maior familiarização com as ferramentas e suas técnicas, na formação, colocando o aluno à frente dos desafios projetuais. 
Nota-se assim, que atualmente existe uma fragilidade no acesso ao conhecimento e a instrumentação dentro da instituição, que requer parcerias com a indústria e órgãos de fomento para ajustar-se à realidade tecnológica atual.

Sem pesquisa; sem ações de atendimento a sociedade por atividades de extensão; sem contar com docentes ou técnicos especializados em linguagem, as instituições ficam à margem da obtenção de recurso ou financiamento; parcerias com órgãos públicos e privados, indústria ou empresas, dificultando ao aluno, a sua familiarização e experiência com as tecnologias vigentes. Isto o conduz, caso seja necessário, a buscar conhecimento ou especializações fora da instituição de ensino.

Mesmo que grande parte dos alunos identifique a importância da linguagem fotográfica para o processo de projeto como ferramenta auxiliar e acredite em seu potencial para o campo, mais da metade dos entrevistados não conseguem visualizar sua utilização nas disciplinas de Projeto. Neste caso, o que se pode deduzir é que a utilização das ferramentas de fotografia e de vídeo, não é mencionada, instrumentada, incentivada e requisitada pelos docentes. Observou-se que as linguagens fotográficas são mais valorizadas apenas nas apresentações finais dos projetos.

Consideramos que, para atender as questões aqui colocadas, a proposição de uma disciplina específica sobre linguagem fotográfica (apoiada, ou em consonância com o processamento, ou ainda a programação computacional), aplicada ao projeto de produto, poderia suprir parte das necessidades de conhecimento e instrumentação, ao lado de outros recursos didáticos, como a participação em oficinas e/ou laboratórios. 


\section{PREMISSAS PARA FORMATAÇÃO DE DISCIPLINA E CONTEÚDOS SOBRE LINGUAGEM FOTOGRÁFICA}

É possível identificar até aqui, lacunas relacionadas à linguagem fotográfica na formação em Design de Produto que podem ser minimizadas se forem adotadas iniciativas que considerem ou resgatem os fundamentos, as possibilidades de uso e aplicação no projeto de produto, considerando a integração entre teoria e prática (em ações multi, inter e transdisciplinares).

Dados da pesquisa de campo e levantamentos sobre os cursos nas instituições de ensino revelam situações e entraves relativos a processos já cristalizados, às vezes resistentes ou lentos à modificações, visto que o acompanhamento dos avanços tecnológicas e das necessidades de aportes financeiros para tal, demandam decisões e ações complexas, que dependem de múltiplas implicações pedagógicas e financeiras dentro das instituições.

O levantamento realizado junto aos docentes e alunos revelam aspectos gerais concernentes ao contexto institucional; a atuação docente manifestada por diferentes visões em relação ao papel da fotografia para o ensino; e do ponto de vista dos discentes, trazem uma aproximação ao estágio de conhecimento e práticas sobre esta questão, identificando as deficiências, fornecendo insumos e indicando possíveis caminhos do que seria uma desejável aplicação da linguagem fotográfica no campo do Design, com o foco no projeto. Entretanto, para a constituição de premissas sobre quais os conteúdos e práticas fundamentais e/ou mínimos, mas essenciais para o campo, é necessário definir quais competências e habilidades são necessárias para a formação do profissional.

Este capítulo não tem por objetivo a elaboração de um projeto pedagógico para um curso de Design, mas sim, estabelecer proposições e bases para desenvolver conteúdos e práticas sobre e linguagem fotográfica aplicada ao Projeto de Produto, como contribuição para a formulação de uma disciplina básica na graduação, acompanhada de outras ações complementares, distribuídas ao longo do curso, onde conteúdos e práticas podem estar contempladas.

Considera-se que os cursos de design são constituídos de estruturas variadas, conforme suas diretrizes internas e nos formatos (ou desenhos) de grade, matrizes, por projeto ou temas, entre outras versões, contendo disciplinas básicas 
(obrigatórias) e outras eletivas (optativas) que podem ser semestrais ou anuais, e onde o discente geralmente deve contabilizar créditos para constituir a totalidade necessária para a habilitação e diploma. Estas estruturas ou planos (dentro dos projetos político pedagógicos) dos cursos de graduação, dão ao aluno maior ou menor possibilidade para a escolha de disciplina (ou projetos) por temática; por interesse; por habilidade e/ou futura aplicação profissional, entre outros aspectos. Somam-se a estas exigências, ou requisitos básicos, outros eventos paralelos de aprendizagem que podem ser adquiridos e/ou experimentados em laboratórios, oficinas e outros recursos das instituições de ensino ou (conveniadas), além de trabalhos extracurriculares complementares que podem ser realizados em concomitância ao curso, como atividades de pesquisa e extensão universitária.

Diante dessa complexidade e da variabilidade das estruturas e disciplinas; das experiências mencionadas por docentes e alunos nas entrevistas de campo, coloca-se como proposta e contribuição desta tese, um elenco de conteúdos e ações, com o objetivo de inserir a linguagem fotográfica nos cursos de graduação em Design de Produto, apontando competências e habilidades adequadas e atualizadas para sua futura atuação, tanto na instituição (como docente, pesquisador) como no mercado. Inclui-se também, a necessidade da experimentação e/ou de prática em exercícios aplicados pelo discente, em ações efetivas ao longo da graduação, como fundamento para o aprendizado vivenciado, aproximando-o de situações reais e concretas, e mesmo de simulações para cenários e necessidades prospectivas no campo do Design.

Para elencar as necessidades da formação de competências e das habilidades distribuídas em disciplinas, foi realizada uma articulação crítica sobre as análises dos resultados dos subproblemas 1, 2 e 3 (figura 56). Nesse sentido, foi possível compreender e estabelecer as necessidades, a partir da grade curricular decorrente do levantamento nos cursos de graduação do Estado de São Paulo e de dados sobre linguagem fotográfica, ensino e projeto, abordados nos capítulos 2, 3 e 4, elegendo pressupostos e diretrizes para inserção de conteúdos e ações nas disciplinas e nos recursos de apoio e funcionamento dos cursos. 
Figura 56 - Diagrama considerado para a proposta de desenho de conteúdos e práticas para planos de ensino

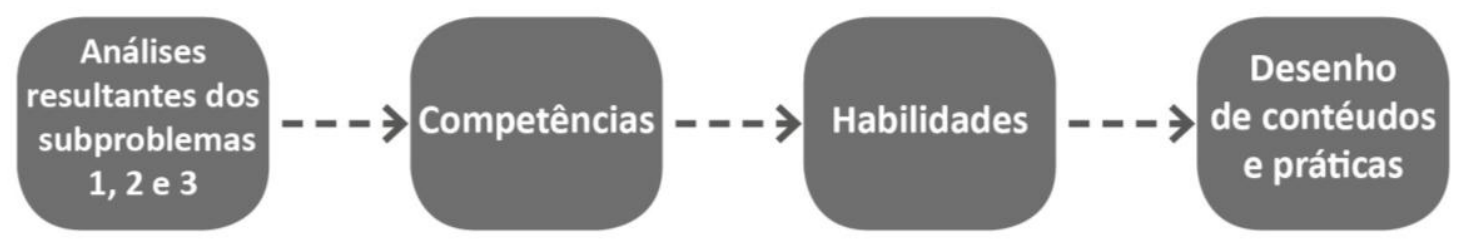

Fonte: Elaborado pelo autor (2017)

$\mathrm{Na}$ figura 56 observa-se o processo percorrido para a síntese dos dados levantados em todos os estágios de pesquisa, incluindo cursos e laboratórios, docentes e discentes que alimentam a proposta de conteúdos e práticas relativas à linguagem fotográfica aplicada principalmente ao projeto de produto. Foi identificado também, os indícios, tanto do tipo de instrumentação necessária e existente no campo da representação, quanto as possibilidades de captura, transmissão e análise computadorizada das imagens, a fim de constituir uma disciplina.

Considera-se como princípio que cada instituição tem 0 seu plano pedagógico; atende a uma estrutura ou desenho de curso, conta com recursos próprios ou colaboração de outras instituições (como laboratórios, centros de pesquisa, entre outros) e que atuam dentro de um quadro de ensino brasileiro complexo, atendendo normativas federais, estaduais e municipais (tendo como mínimo, o currículo mínimo nacional). Considera-se que a espinha dorsal dos cursos seja em projeto, e que os conteúdos gravitem em torno deste exercício, do início ao final do curso, considerando as diferentes estruturas ou planos pedagógicos.

Outra questão a se considerar são as diretrizes necessárias para a atuação e a composição dos laboratórios como contribuição para a instrumentação e a autonomia do aluno em Projeto de Produto (considerando a linguagem fotográfica).

No modo tradicional de ensino, as técnicas de revelação e ampliação por processos analógicos atendiam mais a propostas de meios e recursos para representação de ideias e projetos na interface arte - design e se tornaram, ao longo do tempo, parte fundamental do ensino formal da Fotografia e do Vídeo tanto para o Design de Produto como para o Design Gráfico. Hoje, devido ao alto custo dos equipamentos e processos, essas técnicas são cada vez menos utilizadas, sem dar 
lugar às novas possibilidades tecnológicas (ferramentas, programas e recursos digitais) direcionadas à formação.

Em se tratando de linguagem fotográfica, considera-se que o melhor aprendizado se dá em aulas práticas ${ }^{43}$, que não prescindem, entretanto, de conteúdos teóricos e conceituais, mas que possibilitem exercitar os aprendizados em propostas, projetos, exercícios concretos, que podem contar com o apoio ou, estarem associadas aos laboratórios, oficinas e estúdios.

Nesse sentido, é desejável a interação de meios e recursos pedagógicos, facilitando aos docentes, ou técnicos de laboratórios ou de estúdios, a possibilidade de criar conexão entre a teoria e as habilidades e competências necessárias, valorizando as resoluções de problemas com a experimentação de ferramentas disponíveis para a representação durante as atividades e os projetos desenvolvidos.

Verificando a realidade de carga horária disponível e a distribuição das disciplinas na grade curricular das instituições do Estado de São Paulo, é possível propor uma disciplina obrigatória no ciclo básico, ou inserida nos primeiros anos do curso, abrangendo conteúdos dos fundamentos, conceitos, técnicas e aplicações da linguagem fotográfica para projeto de produto, de modo semestral ou anual (contemplando mais aspectos envolvidos).

Essa disciplina básica pode ser complementada com outros conhecimentos do assunto, distribuídos em outras disciplinas, exercícios, projetos ao longo do curso, e/ou ser praticado em laboratórios que abordem aspectos específicos.

Desta forma, é desejável (e pode constituir pré-requisito) o aluno passar por uma disciplina alocada no curso básico (obrigatório) de fundamentos da linguagem fotográfica, enfocando os métodos e ferramentas disponíveis para empregá-los com o máximo de resultado, ao lado do uso simultâneo de outras técnicas e procedimentos como o desenho ou outras formas de expressão.

\subsection{Elementos de destaque para a proposta de disciplina sobre linguagem fotográfica aplicada ao projeto de produto}

\footnotetext{
${ }^{43}$ Para o ensino da linguagem fotográfica é necessário ir além do modo tradicional de aprendizagem que faz uso exclusivo de aulas verbais. Para o aprendizado de novos conceitos e técnicas considera-se que esse modelo tradicional dificulta a formação do aluno, não permitindo a importante liberdade e autonomia para que seja capaz de resolver problemas com a experimentação das ferramentas.
} 
A disciplina básica tem por finalidade fornecer, instrumentar os alunos com vista a ter:

- Capacidade de adquirir técnicas necessárias para manipular a ferramenta;

- Capacidade de criar uma imagem fotográfica de qualidade;

- Aumentar os níveis e técnicas de produção;

- Capacitar o aluno a utilizar os elementos da linguagem;

- Capacitar o aluno a analisar imagens fotográficas;

- Capacidade projetual e organizacional de imagem fotográfica; e

- Capacidade projetual e organizacional de imagem em movimento.

As estratégias da disciplina são fornecer relações e ligações diretas e indiretas entre teoria e prática, para apoiar os principais problemas de representação por meio das tecnologias da fotografia e do vídeo, verificando a evolução do aluno durante o semestre através da proposição de exercícios desenvolvidos em sala de aula (e, ou ir a campo); podendo adotar processos avaliativos sequenciais das atividades e do percurso do discente durante todo o curso, verificando ao final da disciplina, a compreensão e a autonomia do aluno por meio das imagens técnicas (aplicadas a projetos, planos, etc.).

Os recursos necessários às atividades são equipamentos de fácil acesso como os smartphones e tablets, que além de serem familiares e usuais, são de grande importância para as práticas desenvolvidas em sala de aula, contendo toda tecnologia necessária e de qualidade para o ensino. Atualmente os recursos da fotografia, vídeo, termografia e o escaneamento tridimensional já estão inseridos de forma hibridizada nessas ferramentas, que possuem grande facilidade na extração dos dados e aplicativos apropriados para tratamento. Também podem ser usados equipamentos específicos - maquinas fotográfica e filmadora, se a instituição colocar a disposição dos alunos e professores, estes recursos.

Nesse sentido, os objetivos da disciplina de Fundamentos da Linguagem Fotográfica, são o de apresentar os elementos da linguagem fotográfica e as novas tecnologias e sistemas de representação, hoje disponíveis, tendo em vista que boa 
parcela dos cursos, atualmente não atendem a esses objetivos conforme verificado em levantamento da pesquisa.

Seguido de:

- Capacitar o aluno a compreender os elementos básicos e suas variáveis do equipamento;

- Apresentar os dois sistemas de captura (analógico e digital), as matrizes da linguagem fotográfica e principalmente e sua plataforma/interface;

- Familiarizar-se com as propriedades da luz e óticas tanto para fotografia como para vídeo; e

- Apreender os elementos da linguagem fotográfica, e por fim as novas tecnologias e sistemas de representação.

É importante mencionar que essa etapa é considerada fundamental, fornecendo ferramental auxiliar para as disciplinas projetuais e que pode ser a única possibilidade de o aluno ter contato de técnicas necessárias.

Os conteúdos das disciplinas são voltados à ampliação de repertório sobre o campo de conhecimento dos fundamentos da linguagem fotográfica podendo tratar de: a linguagem fotográfica no passado e no presente (analógico e digital) ou seja uma revisão histórica e sua importância para o campo do Design; dispositivos e ferramentas; os elementos técnicos da linguagem como: sistema de foco (modos de focalização), abertura do diafragma (diâmetro da abertura das lentes); velocidade do obturador (tempo de exposição); sensibilidade do sensor ou do filme (ISO ${ }^{44}$ ); exposição (componentes); luz (natural e artificial) que são essenciais e que continuam presentes para o conhecimento do aluno até hoje, identificados como conteúdo não abordado ou ausente das disciplinas atuais pesquisadas nos levantamentos realizados.

Também podem ser incluídos outros elementos de captura da linguagem como: os planos da linguagem e os anatômicos (planos hipotéticos para dividir o corpo humano - sagital, frontal, transversal); proporção; simetria; movimento; forma; ângulo; cor; textura; iluminação; aberrações; perspectiva; profundidade de campo; imagem em movimento; equilíbrio e composição, que não foram identificados em situações e aplicações nos levantamentos realizados.

\footnotetext{
${ }^{44}$ Termo utilizado para se referir à sensibilidade de superfícies fotossensíveis (sensíveis à luz).
} 
Há a possibilidade de parte dos conteúdos mencionados acima estarem presentes em outras disciplinas como Fundamentos e história; Linguagens e meios de representação de ideias; Projetos; Modelagem (física e virtual) e Tecnologia e técnicas, onde podem ser praticadas na aquisição de repertório; na pesquisa; para a geração de ideias, que podem trazer à tona elementos e riqueza de informações que possibilitem gerar alternativas para o auxílio do projeto.

Quando os cursos que não utilizam estrutura curricular em sequência, ou não adotam disciplinas básicas, é possível trabalhar por temas ou projetos (curtos ou anuais) auxiliados por outros recursos como os laboratórios. Como exemplo, citamos por base, o currículo da Escola de Design - Politécnico de Milão que insere os Laboratórios (incluindo o de fotografia) a disposição desenvolvendo atividades próprias no início do curso (fonte: http://www.design.polimi.it/ acesso em 14 de fevereiro de 2018).

\subsection{Elementos para a proposta de distribuição de conteúdos de linguagem fotográfica nas disciplinas dos cursos de design de produto}

Outra proposta seria incorporar o conteúdo da LF em disciplinas distribuídas no curso, inseridas nas estruturas e eixos curriculares, e oferecer disciplinas eletivas; participação em pesquisa; participação em projetos de extensão universitária como complementação de conhecimentos sobre linguagem fotográfica.

Nesta perspectiva os conteúdos sobre linguagem fotográfica estão inseridos em disciplinas na grade curricular, que permitam que o aluno fique apto a identificar, analisar, enfrentar e solucionar problemas com o uso das ferramentas durante seu percurso acadêmico criando a tradição de uso para os processos de projeto.

Com o levantamento sobre meios, recursos e aplicações da fotografia e do vídeo no projeto de produto, que foi detalhado no capítulo quatro foram extraídos elementos que contribuem para a construção de um quadro (figura 57) identificando algumas das áreas com possibilidades de abordagem interdisciplinar onde os conteúdos e práticas de LF podem estar contempladas, como representado. 
Figura 57 - Interdisciplinaridades com as disciplinas da área.

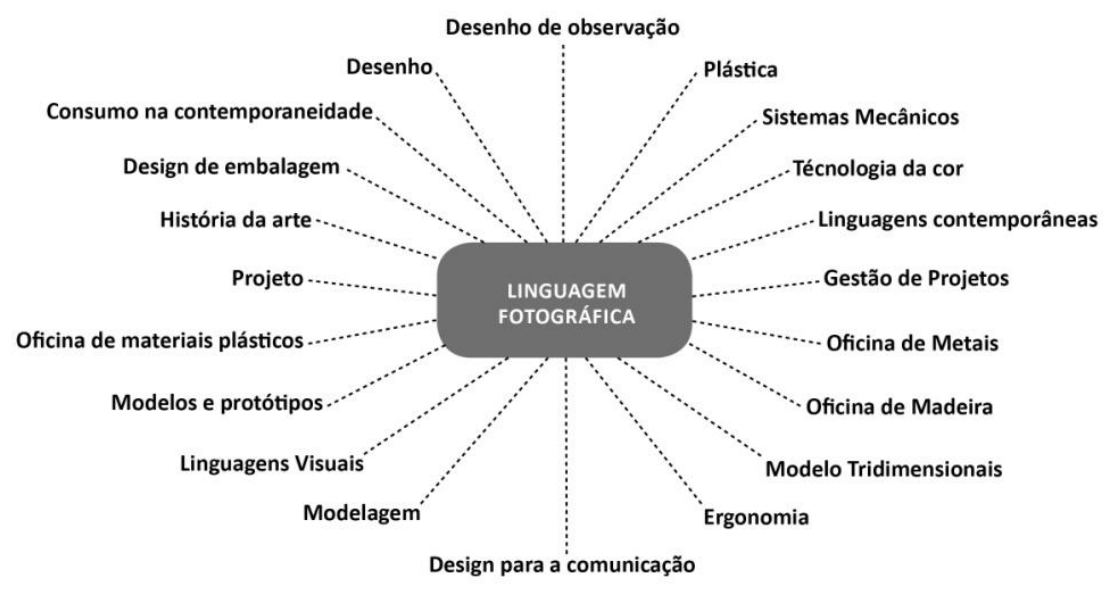

Fonte: Elaborado pelo autor (2017)

Ressalta-se que não se viu nas Instituições participantes da pesquisa, práticas verdadeiramente interdisciplinares, sendo que Neves (2009) menciona que vários podem ser os motivos que impedem a adoção dessas práticas, dentre elas falta de preparo do professor, falta de apoio do grupo de professores ou da coordenação e falta de um currículo que possibilite a prática.

Ao mesmo tempo, nota-se que um dos avanços por parte das instituições é que grande parte das estruturas de cursos tendem a oferecer diversidade de escolha para os alunos nas disciplinas optativas, que permitem também a alocação de carga horária docente; uma formação generalista para o discente, mas com linhas convergentes claras; e outras possibilidades de escolhas direcionadas para campos de atuação profissional específicas, como as dirigidas para atividade social em projeto em tecnologias assistivas, próteses e órteses; design de games (ou jogos digitais); design de ferramentas e equipamentos; design para setores automobilísticos ou de aeronaves; design de moda, etc.

Durante as entrevistas com os docentes foi possível notar que utilizam do modelo tradicional de ensino separando conteúdos de natureza teórica da aplicação pratica em projetos, e execução (física) de produtos.

Desta forma, o aluno procura sozinho criar essa ponte entre os conceitos adquiridos e as habilidades e competências técnicas, sem a mediação do docente ou de um sistema interdisciplinar que esteja formatado para esse tipo de aprendizagem. Fica evidente no questionário on-line que o aluno sabe da 
importância da teoria, mas que sozinho tem dificuldades de relacioná-la com a prática do Design.

As disciplinas de linguagem fotográfica necessitam e carecem de aulas teóricas, oficinas e laboratórios, como elemento-chave para ligação com a produção industrial, desenvolvendo no aluno competências de técnicas de forma integradas. Através desta ligação prática/teórica o aluno aplica conhecimento e desenvolve habilidades para projetar e realizar objetos, facilitando a experimentação das técnicas existentes, e preparando - o para uma capacitação profissional mais próxima a produção industrial.

Para compreender o processo de interação das competências da linguagem fotográfica com diversas outras disciplinas do curso, gerando as competências necessárias para a sua formação e que são estruturadas pelas abordagens Representacionais (fotografia; vídeo), Projetual (técnica; processos) e Relacional (ferramentas; tecnologia).

Figura 58 - Competências representacionais, projetual e relacional.

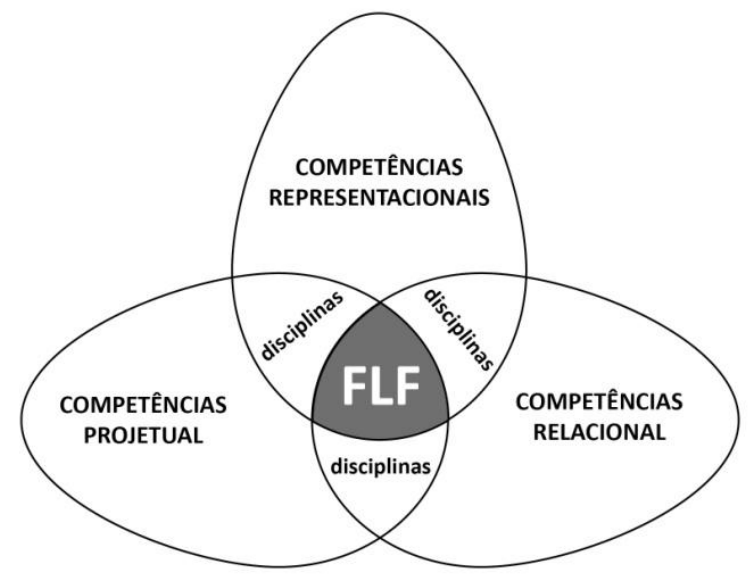

Fonte: Elaborado pelo autor, a partir de Silva (2017, p.253).

Conforme os objetivos de cada disciplina distribuída no plano de ensino das instituições de ensino do Estado de São Paulo, foi possível identificar quais as competências necessárias da linguagem fotográfica (Quadro 5 e 6) para ampliar o conhecimento do aluno sobre conceitos e ações que colaboram para a linguagem e a representação em projeto de produto. 
Quadro 5 - Sugestão de inserção da linguagem fotográfica nos eixos de conhecimento para o Design. Fonte: Elaborado pelo autor (2017). 


\section{Fundamentos e história}

- Fundamentos da linguagem fotográfica

- Sistemas analógicos e digitais

- Novas técnologias de representação

- Matrizes da Linguagem fotográfica

- Sistemas de representação

- Sistemas de reprodução

- Ética das imagens

- Evolução Técnologica

- Perspectiva

- Visualização

\section{Linguagens e meios de} representação de ideias

- Espaço bidimensional

- Espaço tridimensional

- Luz e sombra

- Formas e volumes

- Imagens Técnicas

- Documentação do projeto

- Técnicas para representação

- Painel semântico

- Referência visual

- Sistemas de projecção

- Sistemas tridimensionais

- Simetrias fotograficas

- Técnicas de composição

- Documentação das influencias do ambiente

\section{Projetos}

- Registro dos planos anatômicos

- Análise e pesquisa de uso

- Análise e prospecção de uso

- Análise através do vídeo

- Propriedades óticas

- Escala humana

- Sistemas de planejamento visual

- Documentação do processo

- Pesquisa e criação

- Processo criativo

- Biomimética e Biônica

- Fotografia publicitária

- Laboratório de Representação digital

\section{Modelagem (física e virtual)}

- Modelagem bidimensional

- Modelagem tridimensional

- Prototipagem virtual

- Referência em escala

- Referência da imagem explodida do produto

- Modelos tridimensionais

- Modelo Virtual

- Imagens técnicas

- Simulação computacional
- Técnica fotográfica

- Técnica de representação

- Técnicas audiovisuais

- Colorimetro

- Smartphone

- Tablet

- Termografia

- Escaneamento tridimensional

- Biofotogrametria

- Fotogrametria

- Holografia

- Realidade Aumentada

- Chiaroscuro

- Lightpaint

- Timelapse

- Motion Capture

- Stop Motion

- Fotografia Still

- Softwares de tratamento 
Quadro 6 - Síntese das propostas - linguagem fotográfica para o design de produto. Fonte: Elaborado pelo autor (2018). 


\section{DISCIPLINA}

\section{FUNDAMENTOS DA \\ RÁFICA}

(básica-obrigatória)

\section{LINGUAGEM FOTOGRÁFICA I}

Pode ser oferecida de forma:

- Eletiva

- Oficina

- Laboratório

- Concentrada

- Pesquisa

- Participação em projetos de extensão Universitária

\section{LINGUAGEM FOTOGRÁFICA II}

Pode ser oferecida de forma:

- Eletiva

- Oficina

- Laboratório

- Concentrada

- Pesquisa

- Participação em projetos de extensão Universitária

\section{COMPETÊNCIA}

\section{EMENTA}

- Capacitar o aluno a compreender os - Capmentos básicos e suas varí́vis do equipamento;

- Aferir os conceitos introdutórios da - Apresentar as ferramentas necessár

- Analisar a finalidade da imagem e sua

potencialidade;

- Aplicar conceitos e técncias em

exercícios, ou projetos de produto.

- Reconhecer as técnicas e ferramentas;

- Reconh

- Reconhecer e selecionar qual técnica/ ferramenta e a mais adequada para capturar e mat

- Domínio de técnicas de coleta e de tratamento de dados, geração avaliação de alternativas, configuração de solução e comunicação de resultados através de imagens fixas ou em movimento;

- Utilizando-se de técnicas e processos para documentação; e

- Utilizar técnicas e processos para documentação e comunicação de resultados

\section{- Capacidade de interagir com} especialistas de outras áreas de modo a utilizar a LF para a comunicação dos dados;

- Conhecer e manipular imagens em softwares para o tratamento dos dados obtidos;

- Utilizar a LF no projeto de produto - da criação ao desenvolvimento comunicação de resultados; e

- Utilizar a LF em análises simulações, e avaliações de materiais, projetos e de produtos.
- Apresentar os dois sistemas de captura (analógico e digital);

- Apresentar as matrizes da linguagem fotográfica e sua plataforma/interface;

- Familiarizar-se com as propriedades da luz e óticas; e

- Apreender os elementos básicos da linguagem Fotográfica; e

- Listar os conceitos técnicos pertinentes a LF.

- Capacitar o aluno para o domínio da linguagem expressando conceitos e soluções com o uso de ferramentas apropriadas para auxiliar em projetos, de acordo com as diversas técnicas e ferramentas envolvidas;

- Aprimorar os elementos da linguagem fotográfica;

- Desenvolver a capacidade de observar a forma bidimensional; $\mathrm{e}$

- Capacidade de propor soluções representacionais.

\section{(2)}

- Capacitar o aluno para a interpretação e manipulação de imagens em softwares para o tratamento dos dados obtidos;

- Apontar soluções inovadoras e ferramentas para diversos problemas; e

- Desevolver a capacidade de observar pesquisar a forma tridimensional;

- Domínico de softwares específicos.

\section{OBJETIVOS}

- História da fotografia, pautado no Design de Produto;

- Equipamentos fotográficos analógicos e digitais;

- Elementos técnicos da LF;

- Planos da linguagem e anatômicos;

- Luz; e

- Interface - Smartphone e Tablet.

\section{- Fotometria;}

- Iluminação;

- Estúdio e forma;

- Cor e composiçao (colorímetro)

- Fotografia de produto;

- Fotogrametria; e

- Biofotogrametria.

\section{- Termografia}

- Escaneamento Tridimensional;

- Holografia; e

- Realidade Aumentada.
Espera-se que o aluno, ao final da disciplina, seja capaz de:

Conhecer a Linguagem fotográfica Capacidade de adquirir técnicas necessárias para manipular as ferramentas;

- Capacidade de criar uma imagem fotográfica e cinematográfica de qualidade;

- Conhecer os principais elementos da linguagem; $\mathrm{e}$

- Diferenciar as especialidades da linguagem fotográfica no design.

- Ampliar os níveis e técnicas;

- Capacitar o aluno a utilizar os

elementos da linguagem;

- Capacitar o aluno a analisar imagens fotográficas;

- Capacitar o aluno com ferramentas expecificas;

- Desenvolver habilidades de representação da forma e dimensções;

- Aplicar técnicas específicas de representação por meio da linguagem fotográfica.

\section{- Capacidade projetual e organizaciona} da imagem fotográfica;

- Capacidade projetual e organizaciona da imagem em movimento; e

- Distinguir técnicas para determinados problemas; e

- Possuir visão analítico-reflexivo sobre as novas ferramentas e sua aplicação no Design de Produto;

- Indicar softwares específicos;

Manipular imagens sejam bidimensionais ou tridimensionais. 
Destaca-se que há abordagens conceituais, bibliográficas e práticas que podem estar em mais de um eixo dos agrupamentos.

Podem estar nas disciplinas de projeto de produto, os elementos da linguagem fotográfica que auxiliam no processo para uma documentação de qualidade, pesquisa e criação, na compreensão e busca de referências visuais, nas possibilidades de espacialidade, na construção de mapas visuais com foco no projeto com a seleção sistêmica das imagens, na aquisição de imagens para a análise, pesquisa e prospecção de uso de produtos; na conformação de imagens técnicas e na análise de forma, constitutiva e estrutural, e de acabamento dos produtos.

Os meios e ferramentas para a pesquisa, criação e representação em projeto de produto, podem estar distribuídos em áreas de história; linguagens e meios de representação; tecnológicas e de técnicas; laboratoriais/experimentais. Sendo que aspectos técnicos (Termografia, Biofotogrametria, Fotogrametria, Holografia e Realidade aumentada) de aplicação de determinadas ferramentas podem ser inseridas durante os projetos de produto realizados no curso e também podem estar contemplados em optativas (eletivas); ocorrer paralelamente ao tempo da graduação em cursos de férias ou oficinas ministradas por docentes; ou convidados, com ênfase em determinadas tecnologias e técnicas de domínio complexo.

Outros projetos ou pesquisas nos cursos de graduação podem estar dirigidos e mais próximos às realidades e situações encontradas profissionalmente, possibilitando aprofundamento no uso de ferramentas como, por exemplo, da termografia ou da realidade aumentada, oferecendo ao aluno, experiências vivenciadas e com possibilidade de aferição de resultados práticos (o que é mais improvável de ocorrer em disciplinas ou exercícios curtos e parciais).

Já nas optativas dirigidas ou livres, os fundamentos e instrumentações básicas podem ser aprofundados em projetos; processos avaliativos; análises de redesenhos que podem ainda estar sediados nos laboratórios; como também ser complementados em pesquisas, projetos e execuções de curta duração; autônomas; continuas, sequencias, ou intermitentes.

Espera-se com essas premissas para avançar as discussões sobre a importância da linguagem fotográfica no currículo dos cursos de Design de Produto, sugerindo uma reformulação no modelo estrutural para atender às demandas da sociedade atual. 
Recomenda-se para pesquisas e trabalhos futuros, o estudo e a proposição de uma reformulação nas disciplinas de representação, considerando novas propostas curriculares com inserções e experimentações de novas ferramentas de linguagem e de representação, que possam auxiliar no processo de projeto. 
CAPÍTULO 08 


\section{CONSIDERAÇÕES FINAIS}

Em seu processo evolutivo, desde o seu surgimento até os dias atuais, a fotografia e o vídeo vêm sendo estudados e aprofundados em diversas incursões teóricas e práticas, que se intensificaram nas últimas décadas em função das mudanças ocorridas na tecnologia (analógico/mecânico x digital/eletrônico), e passaram a ser utilizadas com grande potencial e qualidade nos produtos visuais (além de meios e recursos consistentes para a análise, diagnósticos, e demais processos avaliativos) pelos diversos profissionais e áreas do conhecimento. No Design de produto destacam-se as aplicações usuais no registro, memória, referência, documentação, mas também outros recursos contemporâneos que incorporam tecnologia digital, auferindo potencial como linguagem, e não somente como meio de representação.

Entretanto, tal mudança não foi acompanhada adequadamente pelas instituições de ensino, principalmente aquelas situadas no Estado de São Paulo, deixando de contribuir com esse conhecimento sobre linguagem fotográfica, se considerarmos todas as possibilidades que esta proporciona para uma atuação plena e completa para a formação de designers.

O desenvolvimento da fotografia e vídeo representa na atualidade um papel importante e significativo nas possibilidades de linguagem e representação, como visto nos levantamentos apresentados sobre as ferramentas e recursos tecnológicos, associados ou não a programas e meios digitais aplicados a captura, manipulação, tratamento, e proposições de ideias para o design de produto, no quesito da comunicação por imagens. Observou-se ainda que, quando associados a recursos e programas gráficos eletrônicos, podem potencializar as aplicações no design, colaborando como recurso desde a pesquisa de imagens, passando pelo projeto, a modelagem e a prospecção de alternativas de soluções para o projeto, além de abrir e, ou consolidar outras aplicações na análise e na avaliação de soluções ou de produtos em uso, confirmando as colocações iniciais mencionadas nas hipótese desta tese.

Vimos também que parte dos docentes reconhece a contribuição técnica, criativa e imaginética que a linguagem fotográfica pode conferir ao projeto de produto, mas que os recursos pedagógicos nas instituições de ensino, estão aquém 
das tecnologias disponíveis atualmente no mercado. Poucas instituições e docentes estão atualizados em relação aos recursos e tecnologias desenvolvidos em termos de fotografia e vídeo, e colocam a disposição do ensino estes conhecimentos e oportunidades de práticas em exercícios pedagógicos. Em algumas narrativas e respostas dos entrevistados se percebe que, usam a fotografia no modo padrão, isto é com o ajuste e as variáveis embarcadas nos dispositivos móveis, sem explorar as possibilidades de controle sobre a imagem pesquisada, projetada, ou prospectada. A tecnologia digital potencializou e criou novas formas de acesso à linguagem fotográfica, principalmente devido a hibridização dos equipamentos como é o caso dos smartphones e tabletes que incorporam as possibilidades de captura tradicional (fotografia e vídeo), além de outros mais sofisticados que oferecem meios para a apreensão e o trabalho na escala tridimensional; termográfica, na realidade aumentada, associadas às vezes, à diversos acessórios, como é o caso do projetor holográfico. Possibilidades que impulsionam novos conhecimentos e novas perspectivas para campo e consequentemente, para a linguagem, ampliando as estratégias e processos de ensino e aprendizagem. As pesquisas de campo com docentes e alunos confirmam as suposições iniciais formuladas na hipótese referente ao estado atual do ensino e das instituições.

Também se constata que as iniciativas em atualização de docentes; em aquisição e disponibilização de recursos nas instituições de ensino de graduação são pontuais, ou inexistentes.

Nos levantamentos realizados se procurou reunir e explicitar as principais técnicas e recursos disponíveis e que usam de processos fotográficos (e de vídeo), mostrando as possibilidades de uso e aplicação no projeto de produto, sem desconsiderar que se tratam de tecnologias em constante processamento e mudanças, em função de descobertas e de atualizações, e da oferta de aplicações práticas e viáveis para o mercado. Não se esgota, aqui, portanto neste trabalho, todas as possíveis inserções técnicas e de serviços para o design de produto, mas aponta-se para a abertura à novas pesquisas que foquem as especificidades de determinados processos tecnológicos, acompanhadas de explorações das suas aplicações.

No campo das pesquisas, espera-se que as produções científicas que versem a respeito da linguagem fotográfica para o campo do Design, possam ser ampliadas, principalmente em função da atualização sistemática de tecnologias e avanços nos 
dispositivos e programas eletrônicos, e que os resultados apresentados nesta tese, permitam contribuir para que os docentes e designers ampliem seus conhecimentos e habilidades na linguagem fotográfica, abrindo novas perspectivas, aplicações e abordagens para a formação e a pesquisa. Espera-se ainda colaborar para a formação do aluno considerando os exercícios em projeto do produto nas disciplinas oferecidas nos cursos, trazendo insumos e conhecimentos para a sua atuação profissional.

No ensino, constatou-se que as disciplinas ligadas à fotografia e ao vídeo, principais responsáveis pelo ensino da linguagem fotográfica, que dispõem de carga horária própria destinada a este conjunto de conhecimentos foi reduzida, ou retirada do plano de ensino, ou ainda se apresenta pouco evidente e diluída em outras disciplinas formativas (nas vertentes de história, projeto ou tecnologia em design) durante a graduação do aluno).

Face às possibilidades de atuação ofertadas pelas tecnologias apresentadas no decorrer da tese, é importante constituir e fomentar novas estratégias de ensino que possam instrumentar os alunos a respeito das possibilidades da linguagem, considerando que a substituição das tecnologias nas Instituições de ensino, envolve equacionar custos onerosos; e enfrentar as dificuldades de manutenção, de espaço e de profissionais especializados para manter (ou não) ambos os processos analógicos e digitais, sendo que a disponibilidade de docentes especializados e de laboratórios é um dos pontos cruciais para essa formação. Para a obtenção de recursos, a política interna de cada instituição poderia estar voltada para o compartilhamento dos laboratórios existentes, (intra e extra instituições); contando com a participação de professores de outros cursos, associados ou não a recursos e a instituições privadas, ou buscando fomento através de pesquisas, ganhando velocidade requerida pelas atualizações e mudanças neste setor.

Ainda em relação às instituições de ensino, observou-se também nas entrevistas com os docentes, a confirmação de atuação em currículos engessados já há alguns anos, afetando indiretamente, a disponibilização de laboratório específico de Linguagem Fotográfica (estúdio para captura e laboratório digital para manipulação e tratamento), associado ou apoiando ou não as disciplinas; oficinas, ou o uso pela comunidade acadêmica, sendo que algumas ainda mantêm o laboratório analógico, mas sem recursos ou técnicos para a sua operação plena. Outros formatos como a existência de laboratórios associados a programação digital 
que suportem aulas e atividades presenciais com ferramentas apropriadas e voltadas ao Design de Produto, e ainda docentes e técnicos especializados para atender as competências e habilidades necessárias para a formação, não foram mencionados nos levantamentos.

Desta maneira, os docentes participantes da pesquisa compreendem a necessidade da existência de pelo menos uma disciplina na grade curricular, para trabalhar com competências e habilidades visando à instrumentação formativa para a futura atuação do aluno enquanto profissional no mercado. A proposta de elaborada nesta tese de idealizar premissas para disciplinas de Linguagem Fotográfica, pontuando sínteses em termos de conteúdos e práticas (em três formatos - sendo uma de fundamentos obrigatórios), vem colaborar nesta perspectiva.

Mesmo adotando o foco da formação em projeto do produto, não se descarta a importância de levar ao discente também, os conteúdos e práticas para os estudos, a pesquisa e a atuação nas áreas visuais (isso é, no design gráfico, além das mídias digitais), que também participam dos planos pedagógicos e estratégias de ensino em design, mas que escapam ao escopo desta tese. Estes conhecimentos e práticas também deveriam (ou poderiam) estar configurados em disciplinas, oficinas, workshops, entre outras atividades acadêmicas e de extensão igualmente importantes para a graduação.

Uma das possibilidades identificadas na pesquisa é a integração entre o Design de Produto, a Arquitetura e a Engenharia, de modo inter ou multidisciplinar para utilização em conjunto de ferramentas e laboratórios voltados a técnicas e métodos da linguagem fotográfica, necessárias para ambas as formações, como já acontece de forma embrionária em algumas instituições.

O cenário analisado do ensino do Design de Produto no Estado de São Paulo possibilitou vislumbrar e afirmar as diversas possibilidades da Linguagem Fotográfica, em prol da formação, identificando os projetos pedagógicos, grades curriculares, técnicas e processos envolvidos durante as disciplinas. Mostrou que a tecnologia digital ainda caminha paralelamente com a analógica, não exclusivamente nas ferramentas, mas na forma que os docentes estão ministrando as disciplinas.

Remetendo ao objetivo principal da tese, ou seja, o de "examinar o emprego das linguagens fotográficas em processos de criação e simulação de projeto de 
produto, procedimentos de busca de informações, testes e verificação, que emergem de práticas de projeto em relatos na literatura especializada em Design de produto e em experiências nas instituições de ensino de Design também desta região" acredita-se que foram atendidos, chegando a proposição de premissas para as competências e habilidades da LF.

Quanto aos objetivos específicos elencados, acredita-se terem sido percorridos cada um deles nos capítulos, auxiliando decididamente com contribuições efetivas para este estudo; para a linguagem fotográfica, e para a necessidade imediata de promoção de melhorias no ensino tendo como meta as atividades do Designer de Produto.

Como fechamento desse estudo considera-se que este tema não esgota aqui, mas ao contrário, oferece a abertura para novas incursões no universo fascinante da Linguagem Fotográfica e sua contribuição para o Design (de produto; visual e de serviços), sendo que outra investigação pode ser levada a cabo atingindo demais regiões do país. As instituições de ensino superior, docentes e pesquisadores da área também poderão se valer desse estudo para rever, reconsiderar, e qualificar estruturas e planos curriculares; abrir novas frentes de formação, considerando a integração com áreas como Arquitetura e Engenharia; Comunicações, Economia Administração, compartilhando experiências, recursos, meios e conhecimentos.

$\mathrm{O}$ autor ainda pretende testar tais premissas, após o doutoramento, para rediscussão dos currículos, juntamente com outros docentes que ministram disciplinas de meios de representação. 
REFERÊNCIAS 
ARCHER, Bruce. Método sistemático para diseñadores. Londres: The Design Council, 1963.

AGUILAR, J. H. A.; LÓPEZ, L. M. Holografia básica. México: Instituto Politécnico Nacional, 2004. Disponível em: <http://www.libros.publicaciones.ipn.mx/PDF/1495.pdf>. Acesso em 22.04.2015.

ALENCAR, F. de et al [Orgs.]. Solidworks: uma abordagem pedagógica para o Design. In Ensaios em Design: arte, ciência e tecnologia. Bauru, SP: Canal 6, 2010.

ALEXANDER, Christopher. Notes on the synthesis of form. Cambridge: Harvard University Press, 1964.

ALONSO, C. E. Percepção tridimensional, representação bidimensional. 1994. 131F. Tese (Doutorado em Arquitetura e Urbanismo) - Faculdade de Arquitetura e Urbanismo, Universidade de São Paulo, São Paulo, 1994.

AMADIO, Alberto Carlos; DUARTE, Marcelo. Fundamentos biomecânicos para a análise do movimento humano. São Paulo: Laboratório de Biomecânica/EEFUSP, 1996.

ARAÚJO, M. C. M. Uso de técnica de engenharia reversa para reconstrução tridimensional de fósseis através de fotografias. Dissertação de Mestrado Apresentada ao Programa de Pós-graduação em Engenharia Civil, da Universidade Federal do Rio de Janeiro. Rio de Janeiro: COPPE/UFRJ, 2010. Disponível em: <http://www.coc.ufrj.br/index.php/dissertacoes-de-mestrado/110-2010/1547marcosco utinho-monnerat-araujo\#download >>. Acesso em: 01.06.2012

ASIMOW, M. Introdução ao Projeto de Engenharia. São Paulo: Ed. Mestre Jou, 1968.

AZUMA, R. et al. Recent Advances in Augmented Reality. IEEE Computer Graphics and Applications, v .21, n.6, p. 34-47. 2001.

BAUHAUS-ARCHIV, Museum für Gestaltung, Stiftung Bauhaus Dessau, Klassik Stiftung Weimar, Museum of Modern Art (New York, N.Y.), and Martin-GropiusBau (Berlin, Germany). Bauhaus: a conceptual model. (Ostfildern: HatjeCantz), 2009.

BARCELLOS, Ekaterina El et al. Holografia: Inovação e Metáfora de Interatividade na Comunicação e na Representação Ótica. Blucher Design Proceedings, v. 2, n. 2, p. 569-582, 2015.

BARROS, R.M. L; BRENZIKOFER, R.; LEITE, N.J; FIGUEROA, P. Desenvolvimento e avaliação de um sistema para análise cinemática tridimensional de movimentos humanos. Rev. Bras Eng Biomed, v. 15, n. 1-2, p. 79-86, 1999.

BARTHES, Roland. A câmera Clara: nota sobre a fotografia. Rio de Janeiro: Nova Fronteira, 1984. 
BAZZO, Walter Antonio.Ciência, tecnologia e sociedade: e o contexto da educação tecnológica. Editora da UFSC, 1998.

BAXTER, Mike. Projeto de Produto. Guia prático para o desenvolvimento de novos produtos. São Paulo: Edgard Blücher, 1998,

BONSIEPE, Gui; RIBEIRO, Darcy. A" tecnologia" da tecnologia. Edgard Blucher, 1983.

. Design como prática do projeto. Blucher, 2012,

. Design: do material ao digital. São Paulo: Blücher, 2015.

. Design, cultura e sociedade. São Paulo: Blücher, 2011.

. Design, cultura e sociedade. São Paulo: Blücher, 2015.

BOMFIM, Gustavo Amarante. Sobre a possibilidade de uma teoria do design in. v. 2, n. 2 dos Anais P\&D Design 94. Rio de Janeiro: Aend e "Estudos em Design", 1994.

BOMFIM, Gustavo Amarante; NAGEL, Klaus-Dieter; ROSSI, L. Mônica. Fundamentos de uma metodologia para desenvolvimento de produtos. Rio de Janeiro: Coppe/UFRJ, 1977.

BRAMSTON, D. Basics. Product Design 01: Idea Searching. V. 1, Ava Publishing, 2008.

BÜRDEK, Bernhard E. Design: história, teoria e prática do design de produtos. São Paulo: Edgard Blücher, 2006.

CAPOZZO, A.; CAVANAGH. P. R. One hundred years of me asurement of human motion. In: SYMPOSIUM CHARACTERIZATION AND MEASUREM ENT OF MOTION, 1994. Annals. Amsterdan: p. 148.

CARVALHO, Ana Paula Coelho de. O ensino paulistano de Design: a formação das escolas pioneiras. 2012. Dissertação (Mestrado em Design e Arquitetura) Faculdade de Arquitetura e Urbanismo, Universidade de São Paulo, São Paulo, 2012. 10.11606/D.16.2012.tde-18062012-144626. Acesso em: 2017-07-05.

CARVALHO, Juliana Guimarães; MONTE, Luiz Augusto D. S. do; SILVEIRA, Nathalie Barros da Mota. Metaprojeto como Instrumento de Gestão da Complexidade no Design, p. 145-158 . In: . São Paulo: Blucher, 2017.

CARA, Milene Soares. Do Desenho Industrial ao Design: uma crítica para a disciplina. 2008. 182f. Dissertação (Mestrado - área de concentração Design e Arquitetura) - Faculdade de Arquitetura e Urbanismo, Universidade de São Paulo, São Paulo, 2008. 
CARPES, J.R; WIDOMAR, P. Introdução ao Projeto de Produtos. Bookman Editora, 2014.

CARDOSO, Rafael. Design para um mundo complexo. São Paulo: Cosac Naify, 2012.

CARDOSO, Alexandre et al. Tecnologias e ferramentas para o desenvolvimento de sistemas de realidade virtual e aumentada. Editora Universitária UFPE, p. 1-19, 2007.

CHAVES, lana Garófalo. Estudo, análise e proposta de diretrizes a serem consideradas no projeto do produto óculos para o público infantil. 2014. Dissertação (Mestrado em Design e Arquitetura) - Faculdade de Arquitetura e Urbanismo, Universidade de São Paulo, São Paulo.

COELHO, L. A. L. Adjetivando o Método. In: Virginia Pereira Cavalcanti (Org.). II Seminário de Metodologia em Design. Recife: Editora Zoludesign, 2010.

CURDES, G. Die Abteilung Bauen an der hfg Ulm: eine Reflexion zur Entwicklung, Lehre und Programmatik. Club Office Ulm, 2001.

CUYPERS, W., VAN GESTEL, N., VOET, A., KRUTH, J.-P., MINGNEAU, J., \& BLEYS, P. Optical measurement techniques for mobile and large-scale dimensional metrology. Optics and Lasers in Engineering, 2009. 47(3-4), 292-300. https://doi.org/10.1016/j.optlaseng.2008.03.013.

DANTAS, P. V. D. F; RIBEIRO, T. R. R; SILVA, F. P. D; BRUSCATO, U. M. Protótipo de dispositivo facilitador para digitalização 3D por fotogrametria com smartphones. Blucher Design Proceedings. Blucher, 2016.

DENIS, Rafael Cardoso et al. Uma introdução à história do Design. Editora Edgard Blucher Ltda., 2008.

DIAS, Maria Regina A. C. Ensino do Design. 2004, 163f. Dissertação (Mestrado em Engenharia de Produção) - Programa de Pós-Graduação em Engenharia de Produção, Universidade Federal de Santa Catarina, Florianópolis, 2004.

DISCHINGER, M. C. T. Metodologia de análise sensorial tátil em diferentes classes de materiais e texturas para aplicação no Ddesign de Produtos. Dissertação (Mestrado) - Universidade Federal do Rio Grande do Sul, Escola de Engenharia e Faculdade de Arquitetura. Programa de Pós-Graduação em Design, Porto Alegre, 166. 2009.

DURAND, Gilbert. A imaginação simbólica. Lisboa: Edições, 70, 2000.

EISSEN, Koos; STEUR, Roselien. Sketching: drawing techniques for product designers. Bis, 2007.

ERTO, Pasquale. Statistics for innovation. Springer Milan, 2009. 
ESCOREL, A. L. As Linguagens do Design. In: LIMA, G. C. Design: Objetivos e perspectivas. Rio de Janeiro: PPDESDI UERJ, 2005.

FABRIS, Annateresa. Redefinindo o conceito de imagem. Revista Brasileira de História. São Paulo, v. 18, n. 35, 1998. Disponível em: <http://www.scielo.br/>. Acesso em: 19.03.2017.

FAGGIANI, Katia. 0 poder do Design: da ostentação à emoção. Thesaurus Editora, 2006.

FERNANDES, B. C. A; SÁNCHEZ, J. F. Realidade aumentada aplicada ao Design. Holos, v. 1, 2008.

FERROLI, P. C. M.; LIBRELOTTO, L. I. A Inclusão da Sustentabilidade (Tríade ESA Econômica, Social e Ambiental) em Métodos e Ferramentas Projetuais para Design. In: I Encontro de Sustentabilidade em Projeto do Vale do Itajaí ENSUS 2007, 2007, Balneário Camboriú. Ensus 2007. Balneário Camboriú : Univali, 2007.

FLICK, U. Introdução à pesquisa qualitativa. Porto Alegre: Artmed, 2009.

FLICK, Uwe. Triangulation revisited: strategy of validation or alternative? Journal for the theory of social behaviour, v. 22, n. 2, p. 175-197, 1992.

FLICK, Uwe. Triangulation in qualitative research. A companion to qualitative research, p. 178-183, 2004.

FLICK, Uwe. Entrevista episódica. Pesquisa qualitativa com texto, imagem e som: um manual prático. Petrópolis: Vozes, p. 114-136, 2002.

FLUSSER, Vilém. Filosofia da caixa preta: ensaios para uma futura filosofia da fotografia. Rio de Janeiro: Relume Dumará, 2002.

FONTCUBERTA, J.; Costa, J. Foto-diseño. México: Ed. CEAC, p.260, 1988.

FRIESE, S. Qualitative data analysis with ATLAS.ti. 2 ed. London (UK): Sage; 2014.

FONTOURA, A. M. As manifestações Pós-modernistas no Desenho Industrial e suas repercussões no ensino do projeto de produto. Curitiba. 1997. 188p Dissertação (Mestrado em Educação) - Área de concentração: Pedagogia Universitária, Universidade Católica do Paraná,1997.

FONTOURA, I. 20 anos de Design na UFPR. Editora da UFPR: Curitiba (PR), 1995.

GIACOMIN, J. What is Human Centred Design? In: X CONGRESSO BRASILEIRO DE PESQUISA EM DESIGN, São Luís - MA, Anais... São Luís: EDUFMA, 2012, p.148-161. GODOY, A. S. A pesquisa qualitativa e sua utilização em administração de empresas. Revista de Administração de Empresas, v.35, n.4, p.65-71, 1995.

GOMES, J. F. Design do objeto: bases conceituais. São Paulo: Escrituras, 2006. 
GOMBRICH, E.H. Meditações sobre um cavalinho de pau ou as raízes da Forma Artística. In: Meditações sobre um cavalinho de pau e outros ensaios sobre a teoria da arte. Geraldo Gerson de Souza (trad.) São Paulo: EDUSP, 1999.

GONÇALVES, L. C. C. Desenho industrial brasileiro? Crítica ao espaço e à forma de atuação. Curitiba: Editora da UFPR, 1981.

HAMILL, J.; KNUTZEN, K. M. Fundamentos do movimento humano. Hamill J, Knutzen K M. Bases Biomecânicas do Movimento Humano. 2 ${ }^{a}$ Ed. São Paulo. Manole, p. 10-14, 2008.

HEIPKE, CHRISTIAN. (2001). A Review of the State-of-art for Topographic Application: Digital Photogrammetric Workstations.GIM International, Vol.15 No. 3.

HEDGE, Alan (Ed.). Ergonomic Workplace Design for Health, Wellness, and Productivity. CRC Press, 2016.

HSUAN-AN, Tai. Design: Conceitos e métodos. São Paulo: Blucher, 2017.

HOCHMAN, Bernardo; NAHAS, Fabio Xerfan; FERREIRA, Lydia Masako. Fotografia aplicada na pesquisa clínico-cirúrgica. Acta Cirúrgica Brasileira, 2005.

HUDSON, Jennifer. Process: 50 product designs from concept to manufacture. Laurence King, 2008.

INTERNATIONAL COUNCIL OF SOCIETIES OF INDUSTRIAL DESIGN - ICSDI. Definition of design. Disponível em: <http://bit.ly/9YDndi>. Acesso 10.12.2017.

KASSER, M., \& EGELS, Y. (2002). Digital photogrammetry. London; New York: Taylor \& Francis. Retrieved from http://site.ebrary.com/id/5003410. Acesso em: 10.12.2017.

KLINKER, G., DUTOIT, A. H., BAUER, M., BAYER, J., NOVAK, V., MATZKE, D. Fata Morgana - A Presentation System for Product Design. Proceedings of the International Symposium on Mixed and Augmented Reality (ISMAR'02), 2002.

KRIPPENDORFF, Klaus. Design centrado no ser humano: uma necessidade cultural. Estudos em design, v. 8, n. 3, p. 87-98, 2000.

Linder, W. (2009). Digital Photogrammetry. Berlin, Heidelberg: Springer Berlin Heidelberg. Retrieved from http://link.springer.com/10.1007/978-3-540-92725-9

LOBACH, Bernd. Desenho Industrial: Base para a configuração dos produtos industriais. Tradução de Freddy Van Camp. São Paulo: Edgard Blücher, 2001)

LODOVICO, A.; RICIERI, D.V.; TRENTINI, D.; BARAÚNA M.A. Angular photogrammetric analysis of respiratory movements of the chest wall and its corrletion with respiratory and anthropometric variables. In: INTERNATIONAL CONGRESS OF WORLD CONFEDERATION OF PHYSICAL THERAPY, 14, Barcelona/ESP, 2003. Annals... Barcelona/ESP, 2003. 1CD-ROM. 
MACHADO, A. A fotografia como expressão do conceito. Revista Eletrônica Studium,n. 2. Disponível em: <www.studium.iar.unicamp.br>. Acesso em: 01.01.2013.

MALDONADO, T. El diseño industrial reconsiderado . México/Barcelona: Gilli, 1993. MALDONADO, T. Design Industrial. Portugal: Edições 70, 2001.

MICHAELIS, Dicionário. Disponível em< http://michaelis. uol. com. $\mathrm{br} / \mathrm{moderno} /$ portugues/index. php? lingua $=$ portuguesportugues\&palavra $=$ cartilha $>$. Acesso em, v. 10, n. 05, 2009.

Minayo MCS. Fundamentos, percalços e expansão das abordagens qualitativas. In: Souza DN, Costa AP, Souza FN. Investigação qualitativa: inovação, dilemas e desa os. Oliveira de Azeméis (PT): Ludomedia; 2016.

MUNARI, B. Das coisas nascem as coisas. Portugal: Martins Fontes, 2002. Milton, Alex, and Paul Rodgers. Product design. Laurence King, 2011

MORRIS, R. Fundamentos de design de produto. Tradução de Mariana Bandarra. Porto Alegre: Bookman, 2010.

NIEMEYER, Lucy. Design no Brasil: origens e instalação. 2ab, 1998.

NIEMEYER, L. Design no Brasil: origens e instalação. 3. ed. Rio de Janeiro: 2AB, 2000. $128 \mathrm{p}$.

NORMAN, Donald A. Emotional design: Why we love (or hate) everyday things. Basic Civitas Books, 2004.

OLIVEIRA, A.R. Fotografia Médica. J Bras Med, v. 39, n. 5, p. 25-34, 1980.

ÖZCAN, A. Agrindustrial Design: 2nd International Product and Service Design Congress and Exhibition on Agricultural Industries-Mediterranean/Food/Design Proceedings. (2016).

PANTANALI, S.B. Análise biofotogramétrica da postura e sua correlação com a composição corporal e sexo em escolares entre 8 e 10 anos. 93f. Monografia (Especialização em Fisioterapia Ortopédica e Traumatológica) - Colégio Brasileiro de Estudos Sistêmicos, Curitiba/PR, 2004.

PAZMINO, Ana Veronica. Como se cria: $\mathbf{4 0}$ métodos para design de produto. São Paulo: Blucher, 2015.

PARSONS, Tim. Thinking: Objects: Contemporary approaches to product design. AVA publishing, 2009, p. 40 e 41.

PIRES, Julie A.; RIBEIRO, Marcelo G.; Processo de criação: complexidade e interpretações, p. 450-459. In: . In: C. G. Spinillo; L. M. Fadel; V. T. Souto; T. B. P. Silva \& R. J. Camara (Eds). Anais do $7^{\circ}$ Congresso Internacional de Design da Informação/Proceedings of the 7th Information Design International Conference | CIDI 2015 [Blucher Design Proceedings, num.2, vol.2]. São Paulo: Blucher, 2015. 
POSSATTI, Giovana Marzari; LINDEN, Júlio Carlos de Souza Van Der; SILVA, Régio Pierre da; Reflexões sobre as relações entre design e complexidade, $p$. 386-397 . In: Anais do 11ํ Congresso Brasileiro de Pesquisa e Desenvolvimento em Design [= Blucher Design Proceedings, v. 1, n. 4]. São Paulo: Blucher, 2014.

RESENDE, Iara Barbosa; SILVA, André Carvalho Mol; Design e Complexidade: quadro comparativo da complexidade em diferentes demandas projetuais. $p$. 1395-1402 . In: Anais do 12ำ Congresso Brasileiro de Pesquisa e Desenvolvimento em Design [= Blucher Design Proceedings, v. 9, n. 2]. São Paulo: Blucher, 2016.

ROSSI, M. C. d. B; LIMA, A. G. G; ALONSO, C. E., Junior, G. G., Grinfeld, F. F., \& NASCIMENTO, M. d. A. BI para TRI: As conexões perceptivas. Universidade Presbiteriana Mackenzie. 2014.

RUBIN, Jeffrey; CHISNELL, Dana. Handbook of usability testing: howto plan, design, and conduct effective tests. John Wiley \& Sons, 2008.

RINKER, D. (Org.) Catálogo da exposição 'modelos de Ulm - modelos pós-ulm'. São Paulo, 2006.

RICIERI, Denise da Vinha et al. Princípios processuais da Biofotogrametria e sua adaptação para medidas em estudos sobre movimentos respiratórios toraco abdominais. Tese de Doutorado. Universidade Federal do Paraná, 2008.

RICIERI, D.V. Avaliação dos tempos respiratórios através da Análise Cinemática. In: SIMPÓSIO INTERNACIONAL DEFISIOTERAPIA RESPIRATÓRIA, 12, Ouro Preto/MG, 2004a. Anais. Ouro Preto/MG: Hotel Estalagem das Minas Gerais, 2004a. 1 CD-ROM.

RICOEUR P. Teoria da interpretação: o discurso e o excesso de significação. Lisboa (PT): Edições 70; 2016.

ROOZENBURG, N. F. M.; EEKELS, J. Product design: fundamentals and methods. Chichester: John Wiley \& Sons, 1995.

SANSONI, Giovanna; TREBESCHI, Marco; DOCCHIO, Franco. State-of-the-art and applications of 3D imaging sensors in industry, cultural heritage, medicine, and criminal investigation. Sensors, v. 9, n. 1, p. 568-601, 2009.

SEVERINO, Antonio Joaquim. Metodologia do trabalho científico. 23a Edição revista e atualizada $2^{a}$ reimpressão. 2007. SIEBENBRODT, Michael; SCHÖBE, Lutz. Bauhaus. Parkstone international, 2012.

SILVA, D. E. N. O Design Industrial e as engenharias: uma possibilidade de integração por intermédio da engenharia reversa. 2014. 392 f. Tese (doutorado) Universidade Estadual Paulista Júlio de Mesquita Filho, Faculdade de Arquitetura, Artes e Comunicação. Bauru: UNESP, 2014.

SILVA, D. C. Evolução da Fotogrametria no Brasil. Revista Brasileira de Geomática, v. 3, n. 2, p. 81-96, 2015. 
SUDJIC, Deyan. A linguagem das coisas. Rio de Janeiro: Intrínseca, 2010.

SPITZ, R. Hfg UIm: the view behind the foreground: the political history of the Ulm School of Design, 1953-1968. Edition Axel Menges, 2002.

STANTON, Neville A. Human Factors and Ergonomics in Consumer Product Design: Methods and Techniques. CRC Press, 2011.

VASSÃO, Caio Adorno. Arquitetura livre: complexidade, metadesign e ciência nômade. 2008. Tese (Doutorado em Design e Arquitetura) - Faculdade de Arquitetura e Urbanismo, Universidade de São Paulo, São Paulo, 2008. doi:10.11606/T.16.2008.tde-17032010-140902. Acesso em: 2018-02-22.

VELA, João Carlos. Design de Produto: as concepções de formação pela perspectiva de seus docentes. São Paulo: Ed. Blucher, 2010.

VIANNA, W.; CAMPOS, J. L. Fotografia, linguagem, design: uma rápida digressão. Agitprop (São Paulo), Ano IV, n. 38, 2011.

VAN DER LINDEN, J. C. de S.; LACERDA, A. P. Metodologia projetual em tempos de complexidade. In Martins, R. F. de F e Van der Linden, J. C. de S. [Orgs.]. Pelos caminhos do design: metodologia de projeto . Londrina: EDUEL, 2012.

VALENTE, Vânia Cristina Pires Nogueira; PEREIRA, Tamires Trindade. Aprimoramento da capacidade de visualização espacial com a utilização de hologramas. Technology Education for the Future: from simple Growth to Sustainable Quality of Living, p. 142-146, 2015.

WINGLER, Hans Maria. La Bauhaus: Weimar, Dessau, Berlim 1919 - 1933. Barcelona: Ed. Gustavo Gili, 1975.

WICK, Rainer. Pedagogia da Bauhaus. São Paulo: Martins Fontes, 1989.

WHITERS, J. Avaliação angular da mobilidade toraco abdominal durante o uso de incentivadores respiratórios em diferentes posturas. $122 \mathrm{f}$. Monografia (Especialização em Fisioterapia Respiratória do adulto) - Departamento de Fisioterapia, Pontifícia Universidade Católica do Paraná, Curitiba/PR, 2002. 


\section{APÊNDICE A - Entrevista aplicada no meio acadêmico.}
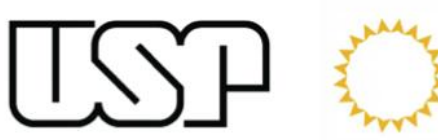

FAUUSP
UNIVERSIDADE DE SÃO PAULO FACULDADE DE ARQUITETURA E URBANISMO PROGRAMA DE PÓS-GRADUAÇÃO EM ARQUITETURA E URBANISMO

\section{Entrevista}

Instrumento de coleta de dados de campo aplicada no meio acadêmico para a tese de Doutorado "Papel de representações fotográficas em procedimentos de projeto em design de produto".

Nome do Entrevistado:

Ano de Nascimento: Gênero: M( ) F ( )

Cidade: Estado:

Data da entrevista: Local da Entrevista:

Formação do Entrevistado

Graduação:

Mestrado:

Doutorado:

Pós-Doutorado:

Atuação no(s) cursos de:

Em qual disciplina(s) o entrevistado atua na graduação:

Em qual disciplina(s) o entrevistado atua na pós-graduação:

Em qual departamento, núcleo ou espaço similar o entrevistado está alocado:

Tempo de atuação como docente: Campo de atuação:

Duração da entrevista:

1. O que é a linguagem fotográfica para você? $\mathrm{O}$ que se relaciona com as palavras linguagem fotográfica?

2. Qual foi sua primeira experiência com a aplicação da linguagem fotográfica? Poderia, por favor, falar sobre isto?

3. Qual foi a sua experiência mais significativa com o uso da linguagem fotográfica? Poderia, por favor, falar-me desta situação?

4. O que você associa hoje com as palavras linguagem fotográfica? Quais dispositivos utilizam a linguagem fotográfica?

5. Que espaço ocupa a linguagem fotográfica em suas praticas didáticas em sala de aula? Poderia por favor, contar uma situação que deixe isso claro para mim?

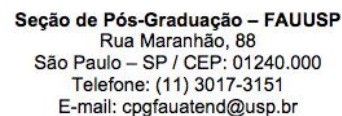



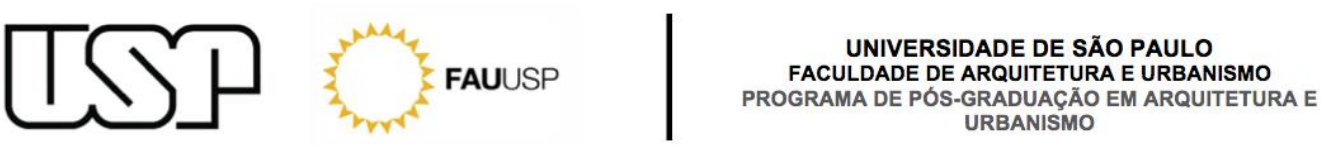

6. Que espaço ocupa a linguagem fotográfica em sua experiência acadêmica? Poderia, por favor, citar uma situação que deixe isso claro para mim?

7. Em que momento no processo de projeto a linguagem fotográfica é apresentada ao aluno como procedimento auxiliar para o projeto. Poderia, por favor, falar sobre isto?

8. O curso que você atua tem alguma disciplina projetual que pode ser trabalhada integrada a linguagem fotográfica ou vice e versa? Poderia, por favor, discorrer sobre a possibilidade desta integração?

9. Se olhar para as instituições de ensino de design, que papel tem a tecnologia fotográfica, e o que ela mudou? Poderia, por favor, expor uma situação que seja um exemplo disso?

10. Já teve oportunidade de usar, conhecer os dispositivos como a simulação fotográfica, escaneamento e do registro fotossensível? Poderia, por favor, contar essa situação para mim?

11. Se pensar no processo projetual, que papel tem a tecnologia fotográfica, e o que ela mudou? Poderia, por favor, mencionar uma situação que seja um exemplo disso no ensino dos meios de representação?

12. Na sua opinião, em que situação ou ocasião a linguagem fotográfica desempenha ou pode desempenhar papel preponderante no processo de projeto? Fale sobre esse fato, por favor.

13. Você já participou de algum desenvolvimento de produto de modo integrado com profissionais de outras áreas? Poderia por favor discorrer sobre essa integração?

14. Na sua vida profissional você já utilizou alguma técnica fotográfica especifica? Poderia mencionar qual técnica utilizada?

15. Quando a linguagem fotográfica torna-se um problema no processo de projeto? Poderia por favor, falar-me de uma situação deste tipo?

16. Você acha que as tecnologias de representação hoje desempenham um papel maior do que as analógicas? Poderia, por favor, discorrer sobre uma situação em que a tecnologia ocupa mais espaço do que antigamente?

17. Que desenvolvimentos você espera na área fotográfica em um futuro próximo? Por favor, imagine estes desenvolvimentos e descreva para mim uma situação que os exemplifique.

18. O que não apareceu na entrevista que lhe teria dado uma oportunidade de expressar seu ponto de vista?

19. Houve alguma coisa que lhe trouxe aborrecimento durante a entrevista?

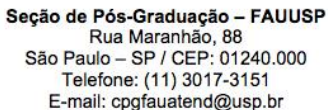




\section{APÊNDICE B - Autorização destinada às instituições de ensino}
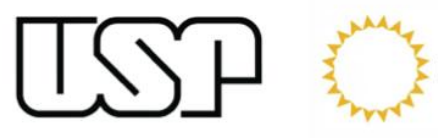

FAUUSP
UNIVERSIDADE DE SÃO PAULO

FACULDADE DE ARQUITETURA E URBANISMO PROGRAMA DE PÓS-GRADUAÇÃO EM ARQUITETURA E
URBANISMO

\section{Ao Diretor(a)}

Assunto: Autorização de Pesquisa

Senhor(a) Gestor(a) Educacional,

Estou realizando projeto de Doutorado em Design e Arquitetura da Universidade de São Paulo FAUUSP, intitulado Papel de representações fotográficas em procedimentos de projeto em design de produto, que visa o levantamento do papel da fotografia no ensino e prática de meios de projeto em design e nos procedimentos de pesquisa, e estão previstas a realização de entrevistas com docentes e assistentes ligados as áreas de representação em três etapas:

1. A aplicação de questionário (procedimento que dura em torno de 50 minutos juntamente ao docente e assistente da instituição);

2. O oferecimento de um workshop, de aproximadamente meia hora, no qual são apresentados a importância da representação fotográfica nos procedimentos de projeto em design de produto para os alunos da instituição;

3. Envio de uma entrevista on-line para os participantes do workshop.

Estou solicitando autorização desta instituição para a viabilização desta etapa, esclarecendo que os dados obtidos são para fins exclusivamente acadêmicos e científicos, sem causar qualquer constrangimento ou ônus aos docentes ou à diretoria, sendo tal projeto submetido a um Comitê de Ética em Pesquisa para apreciação das atividades, conforme recomendação do Ministério da Saúde.

Esclarecemos ainda que as atividades serão realizadas com a anuência e presença do professor ou assistente no menor tempo despendido. Cientes de contarmos com vossa colaboração, antecipadamente.

Respeitosamente,

Me. Júlio César Riccó Plácido da Silva Pesquisador Responsável / RG: 34.196.986-02

Prof. ${ }^{a}$ Dr. ${ }^{a}$ Cibele Haddad Taralli

Orientadora

de de 2015 . 


\section{APÊNDICE C - Termo de consentimento livre e esclarecido}
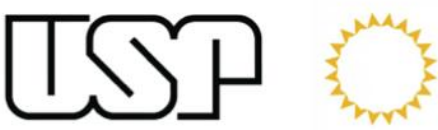

FAUUSP
UNIVERSIDADE DE SÃO PAULO FACULDADE DE ARQUITETURA E URBANISMO PROGRAMA DE PÓS-GRADUAÇÃO EM ARQUITETURA E

\section{Termo de Consentimento Livre e Esclarecido}

(Terminologia obrigatória em atendimento à Resolução 466/12 - CNS-MS)

NOME DO PARTICIPANTE:

ANO DE NASCIMENTO: GÊNERO: M( ) F（）

CIDADE: ESTADO: RG: $\mathrm{Eu}$, estou de acordo em participar como voluntário deste estudo/pesquisa, autorizando a divulgação dos dados e imagens, única e exclusivamente para fins acadêmicos e científicos, conforme proposto para levantamento.

As informações contidas nesta declaração têm por objetivo firmar um acordo por escrito, no qual o sujeito autoriza sua participação, bem como a utilização dos dados que serão obtidos, para fins exclusivamente acadêmicos e científicos, com pleno conhecimento da natureza da pesquisa, com a capacidade de livre arbítrio e sem qualquer coação.

O objetivo desse estudo é examinar o emprego das representações fotográficas em suas múltiplas modalidades, em processos de criação, procedimentos de busca de informações, metodológicos, testes e verificação, que emergem de práticas de projeto. Com isso será possível observar tanto sua importância como sua influência no processo de projeto de produto. Para tanto a entrevista como a observação participante realizada pelo pesquisador serão gravadas em vídeo digital para posterior transcrição.

Não são previstos desconfortos e/ou riscos, uma vez que os procedimentos simulados correspondem às Atividades da Vida Acadêmica e além disso, todas as variáveis da pesquisa serão esclarecidas antes, durante, e após sua execução. $O$ participante tem a garantia de indenização diante de eventuais danos decorrentes da pesquisa.

O participante poderá se recusar a participar ou retirar o seu consentimento a qualquer momento, sendo garantida e assegurada a privacidade da identificação do mesmo em qualquer fase da pesquisa, sem penalização alguma.

Este "Termo de Consentimento Livre e Esclarecido" atende a Resolução 466/12-CNS-MS.

de de 2015.

Assinatura do Participante

Me. Júlio César Riccó Plácido da Silva Pesquisador Responsável / RG: 34.196.986-02

Prof. ${ }^{a}$ Dr. ${ }^{a}$ Cibele Haddad Taralli Orientadora

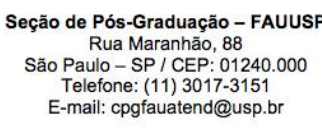




\section{APÊNDICE D - Questionário Online}

\section{Seçăo 1 de 6}

\section{Questionário para alunos de Design de Produto do Estado de São Paulo}

Instrumento de coleta de dados digital aplicada no meio acadêmico para a tese de Doutorado " 0 papel da linguagem fotográfica em procedimentos de projeto de produto".

Endereço de e-mail *

Endereço de e-mail válido

Este formulário coleta endereços de e-mail. Alterar configuraçōes

Sem título

Descriçăo (opcional)

Estou de acordo em participar como voluntário deste estudo/pesquisa, autorizando a divulgação dos dados, única e exclusivamente para fins acadêmicos e científicos, conforme proposto para levantamento. 0 objetivo desse estudo é examinar o emprego da linguagem fotográfica e de vídeo em suas múltiplas modalidades, em processos de criação, procedimentos de busca de informações, metodológicos, testes e verificação, que emergem de práticas de projeto. Este "Termo de Consentimento Livre e Esclarecido" atende a Resolução 466/12-CNS-MS. Me. Júlio César Riccó Plácido da Silva - Pesquisador Responsável / RG: 34.196.986-02 -

\section{SIM}

NÃO 
Informações do aluno

Favor preencher todos os campos.

Nome

Texto de resposta curta

Instituição de Ensino /

Texto de resposta curta

Curso *

Texto de resposta curta

Ano /

Texto de resposta curta 


\section{Questão 01}

Descrição (opcional)

No currículo do curso é oferecido a disciplina de fotografia e de vídeo ou alguma outra disciplina relacionada a estes conteúdos?
SIM
$\because \mathrm{NÃO}$

Caso sim qual o nome da disciplina e 


\section{Questão 02}

Sobre o uso da linguagem fotográfica e do video.

a. Você utiliza da linguagem fotográfica e do vídeo nos projetos do curso? *

- SIM

$\because$ NĀO

Caso sim poderia indicar como é

Texto de resposta longa

b. Na sua opinião a linguagem fotográfica e do vídeo pode desenvolver papel preponderante no processo de projeto?

1. SIM

1 NĀ̄O

c. Você utiliza a linguagem fotográfica e do vídeo em outras aplicações dentro do curso?

-1. SIM

7 NÃO

Caso afirmativo favor indicar quais 


\section{Questão 03}

Descriçäo (opcional)

3. Você acredita que o sistema digital (fotografia e vídeo) viabiliza e agiliza * no desenvolvimento do projeto de design na atualidade?
SIM
NĀO

\section{Questão 04}

Descriçăo (opcional)

4. Já realizou algum curso ou workshop de fotografia ou de vídeo em outra instituição?

SIM

NÃO

Caso afirmativo indique qual curso ou 
APÊNDICE E - Quadro sinótico da pesquisa 
SÍNTESE

De que maneira a linguagem fotográfica vem sendo utilizada em

processos e procedimentos metodológicos apresentados na literatura

especializada, em instituições de ensino selecionadas de design no

estado de São Paulo bem como em práticas pedagógicas também nesta

região?

PROBLEMA FUNDAMENTAL

Que aspectos mais relevantes do emprego da linguagem fotografica,

nas fases de concepção, criação e desenvolvimento de projeto, em

suas varias modalidades, emeregem de uma investigação de práticas

de projeto de produto divulgadas na literatura especializada, bem como

instituições de ensino de design selecionadas no Estado de São Paulo?

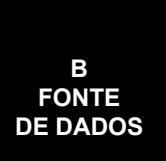

C
ÉCNICAS DE
COLETA DE COLETA DE

Subpr. 1

De que maneira o uso da fotografia e do vídeo vem sendo apresentado em processos e procedimentos metodológicos

A1

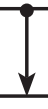

Informações que tratem do uso da fotografia e vídeo em práticas de projeto, documentadas na literatura em desgin

do produto

\section{B1a}

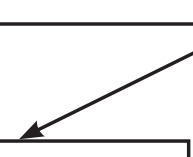

Literatura em Design de produto
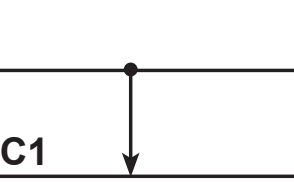

C1

Pesquisa e análise bibliográfica e documenta

\section{D1}

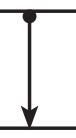

Organização e sistematização dos dados secundários coletados perante a pesquisa e análise "documental" da linguagem fotográfica empregada em processos e procedimentos metodologicos,
realizando um exame do potencial dos dados selecionados.

\section{E1 e E2}

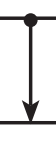

\section{B1b}

Artigos em anais de congresso, "ivros, periodicos e revistas expositivas de design de produto

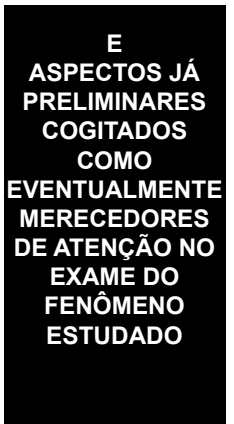
comunicação e informação nos processos de projeto? (Entre outras questões.)

\section{Subpr. 2}

De que maneira o uso da fotografia e do vídeo vem sendo apresentado em processos e procedimentos metodológicos

A2

Informações que tratem do uso da fotografia e vídeo em práticas de projeto, observadas em práticas pedagógicas em escolas de design

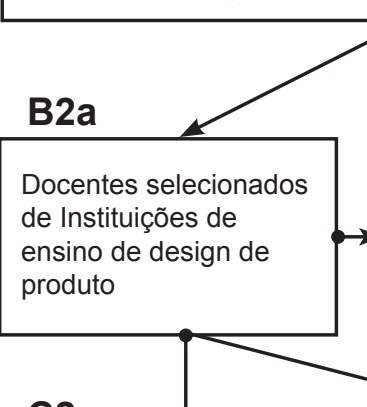

C2a

Entrevistas

em profundidade

semiestruturadas -

Episódica

D2

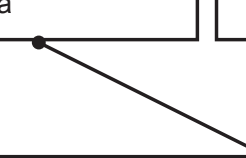

Organização e sistematização dos dados brutos coletados perante a pesquisa e análise junto as "instituições de ensino de design", da linguagem fotográfica, empregada em processos e procedime
metodológicos, buscando padrôes abstratos de associação.

\section{B2b}

Linguagem fotográfica, empregadas em processos e procedimentos de design

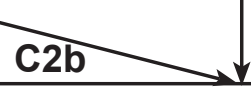

Observação participante e não participante; fotografias $e$ gravação em vídeo e áudio práticas pedagógicas, em escolas

Exemplos de possíveis indagações exploratórias que não esgotam alguns dos mais sensíveis aspectos a observar na coleta e tratamento de dados: 1. Como a ferramenta fotográfica e de vídeo vem sendo utilizada em práticas pedagógicas no campo do Design de Produto? 2. Como a ferramenta fotográfica e de vídeo vem sendo utilizada no campo do Design de Produto? 3. Como o conhecimento técnico sobre linguagem fotográfica é aplicado por docentes no campo do Design de Produto? 4. Houve mudanças fundamentais do papel da fotografia no (a) de Design de Análise? 8 . Quais são as diversas técnicas de captura e manipulacão de imagem oferecidas e a disposicão no Design de lnvestigacão? 9. Como a fotografia e o vídeo gera interferências nas ações dos processos de projeto? 10. Quais técnicas de imagem e representação contribuem para que o designer otimize a atividade projetual? 11. Existe a necessidade do aluno estar familiarizado com a as diversas ferramentas para a produção de imagens? 12. De que forma a fotografia e o video tem sido aplicados como suporte nos processos e procedímentos em Design de Produto? (Design Análise e Design investigação) 13. A linguagem fotográfica no design perdeu o seu papel fundamental de fomentar e socializar a

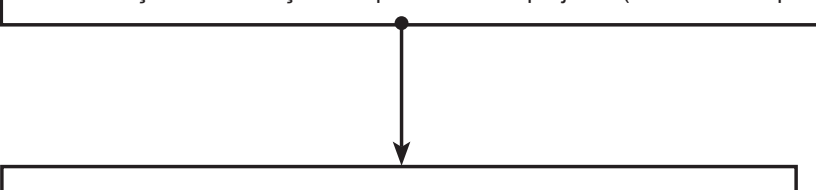

Relato de dados e análises correpondentes ao subproblema 1

Relato de dados e análises correpondentes ao subproblema 2

(alunos)

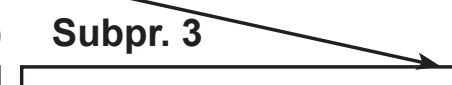

De que maneira o uso da fotografia e do vídeo vem sendo apresentado em processos e procedimentos metodologicos

A3

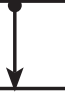

Informações que tratem do uso da fotografia e vídeo em praticas academicas por alunos de design do produto

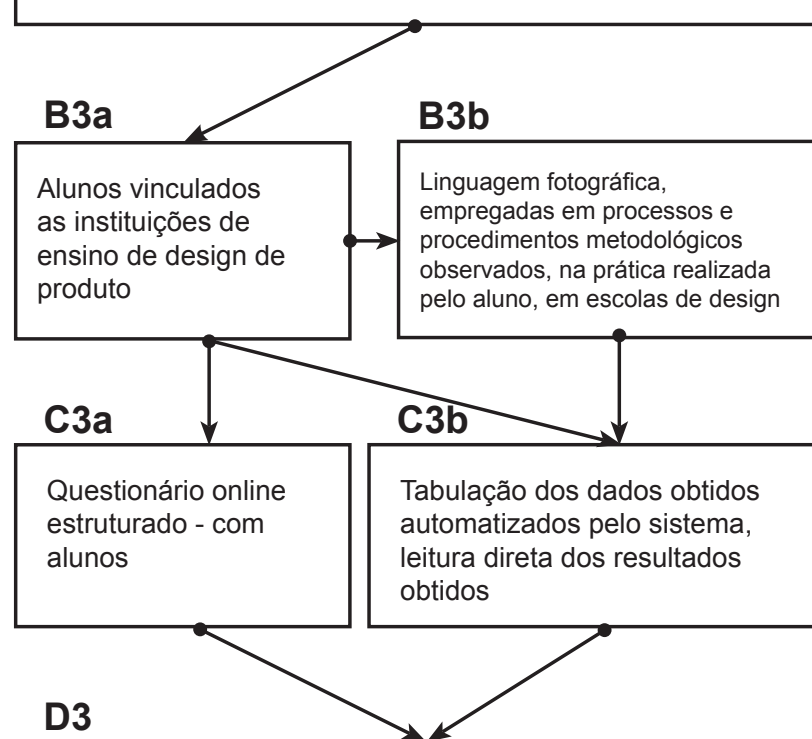

Organização e sistematização dos dados coletados perante a pesquisa e análise junto aos "alunos", da linguagem fotográfica, pedrões a proces de

E3

Exemplo de possíveis indagações exploratórias : 1. Os resultados produzidos nos subproblemas 1 e 2 se complementam? 2. A perspectiva dos docentes sobre as situações de 3 A visão complementar do pesquisador difere do exposto plus docentes e alunos?

Inicio das articulações críticas dos resultados obtidos no subproblema 1,2 e 3

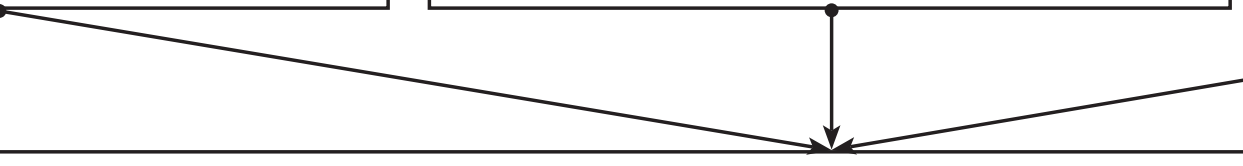

Sistematização das análises resultantes dos subproblemas 1, 2 e 3, buscando apreender padrões ainda mais abstratos e abrangentes de associação 
APÊNDICE F - Breve cronologia da história da fotografia pautada pelo ensino da fotografia no Design 

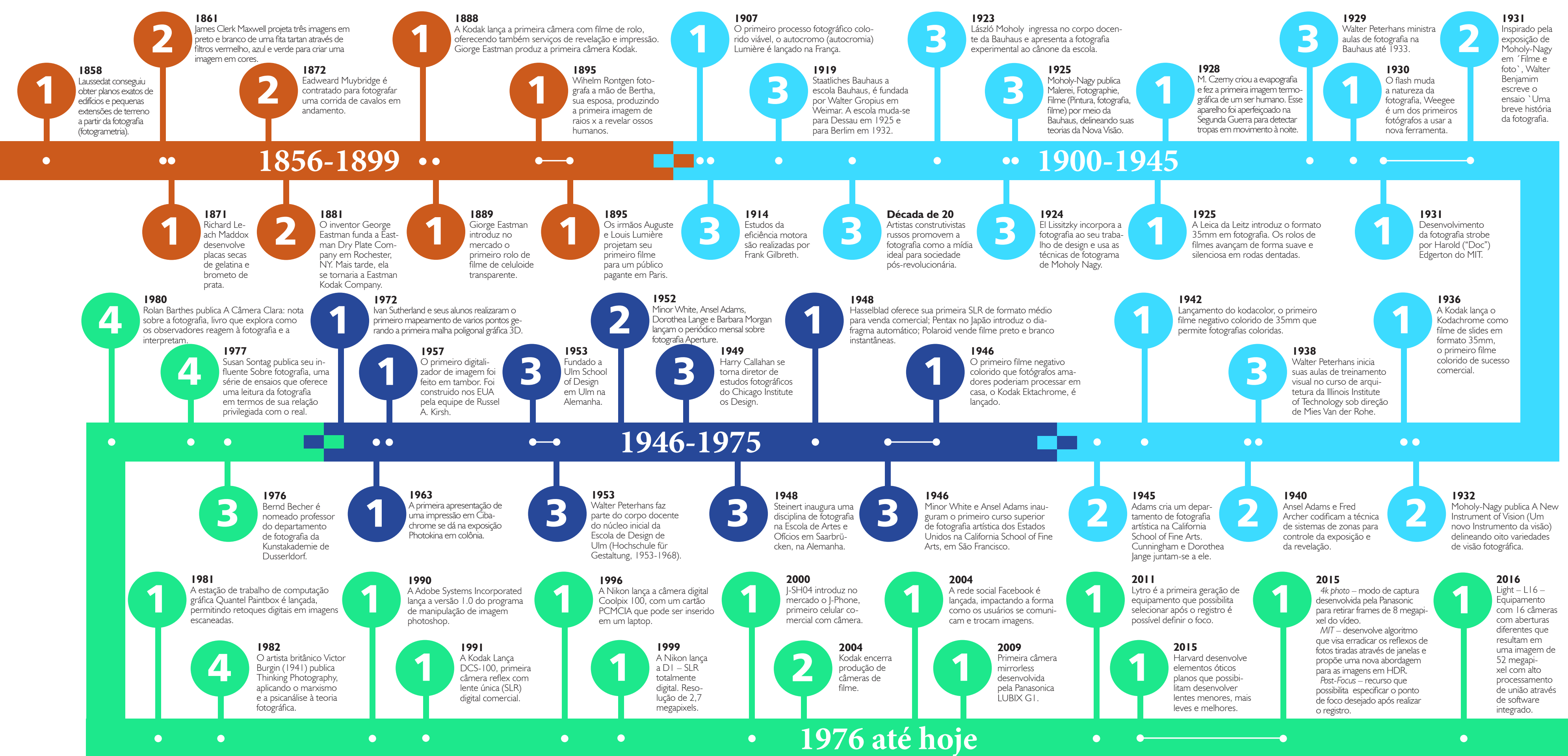

(1) Processos inventivos 2 Ampliação no processo de uso 3 Aspectos históricos de uso da fotografia no design 4 Pensamento e raciocinio na fotografia 


\section{APÊNDICE G - Cruzamento de dados Atlas.ti}

Aspectos já preliminares cogitados como eventualmente merecedores de atenção no exame do fenômeno estudado

$1 \mathrm{~A}$ - Como a ferramenta fotográfica e de vídeo vem sendo utilizada em práticas pedagógicas no campo do Design de Produto?

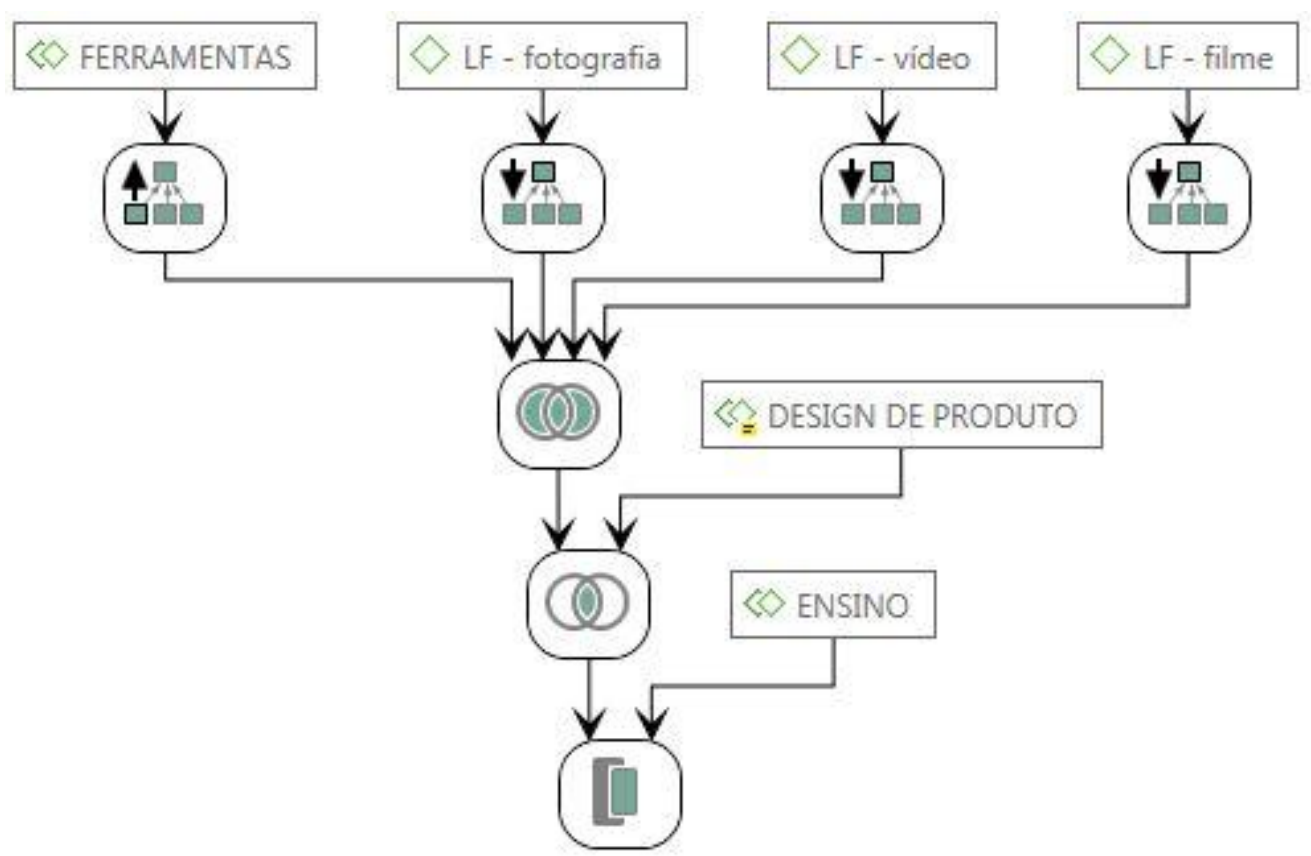

1B - Como a ferramenta fotográfica e de vídeo vem sendo utilizada no campo do Design de Produto?

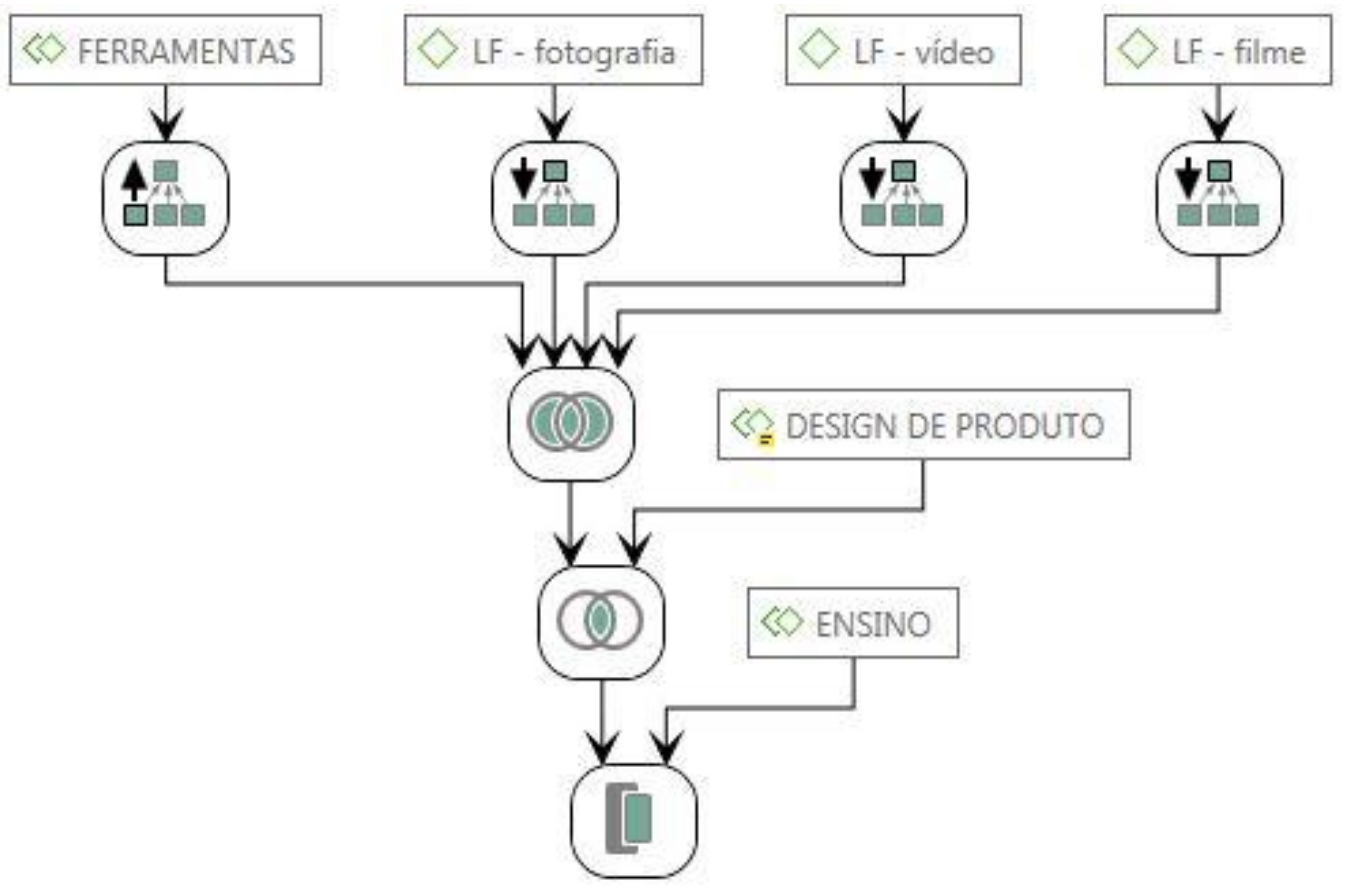


2 - Como o conhecimento técnico sobre linguagem fotográfica é aplicado por docentes no campo do Design de Produto?

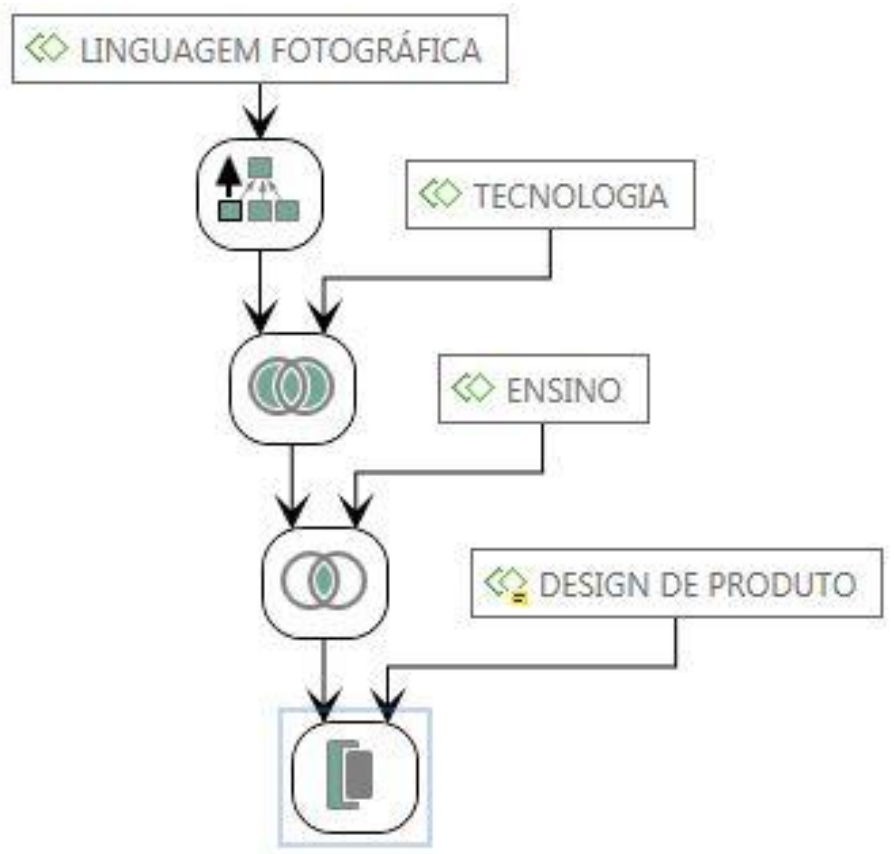

3 - Houve mudanças fundamentais do papel da fotografia no processo projetual, contextualizada na evolução da tecnologia?

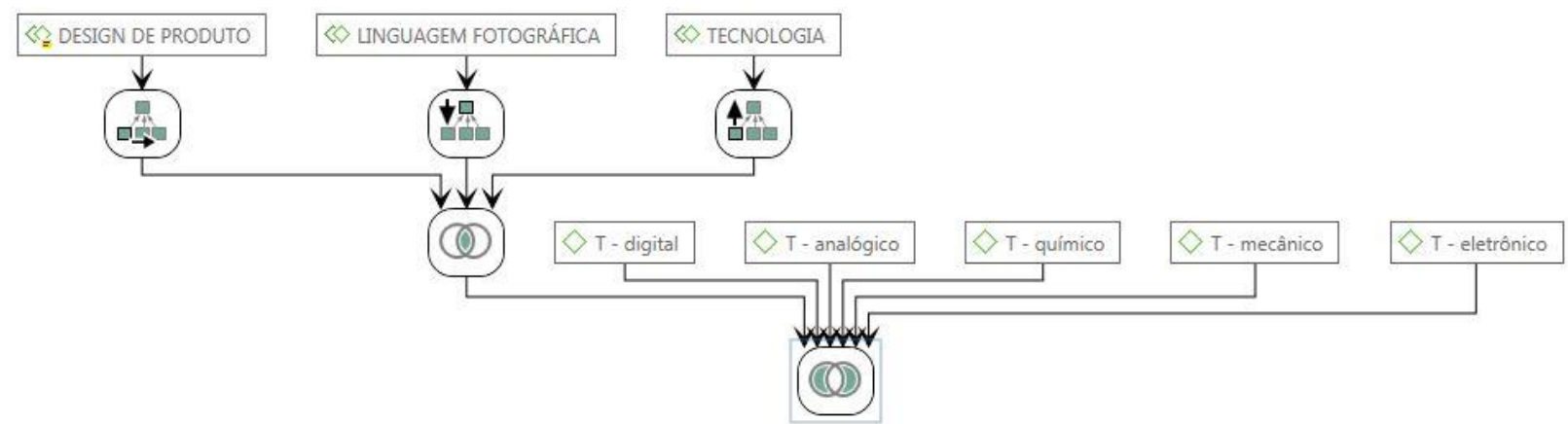

4 - Considerando a fotografia e o vídeo como meios tecnológicos, como ela tem sido empregada como recurso projetual em design?

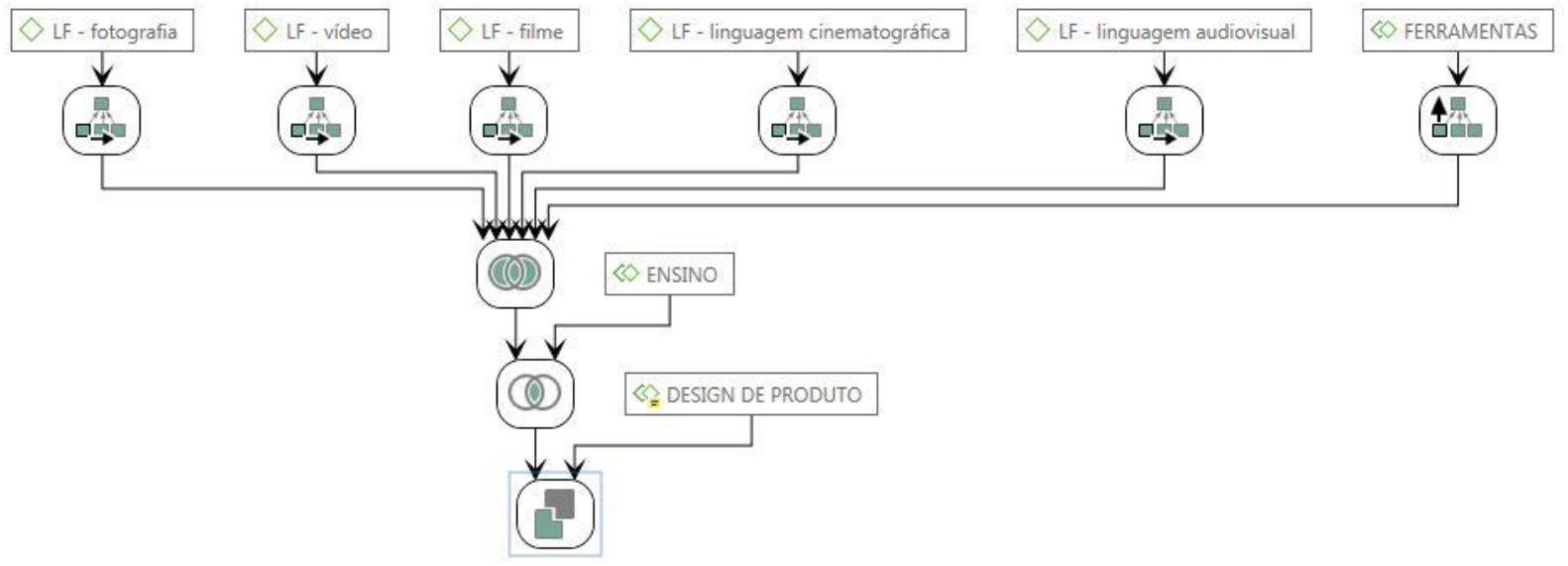


5A - Quais são as diversas técnicas de captura e manipulação de imagem oferecidas e a disposição no ensino de Design de Produto?

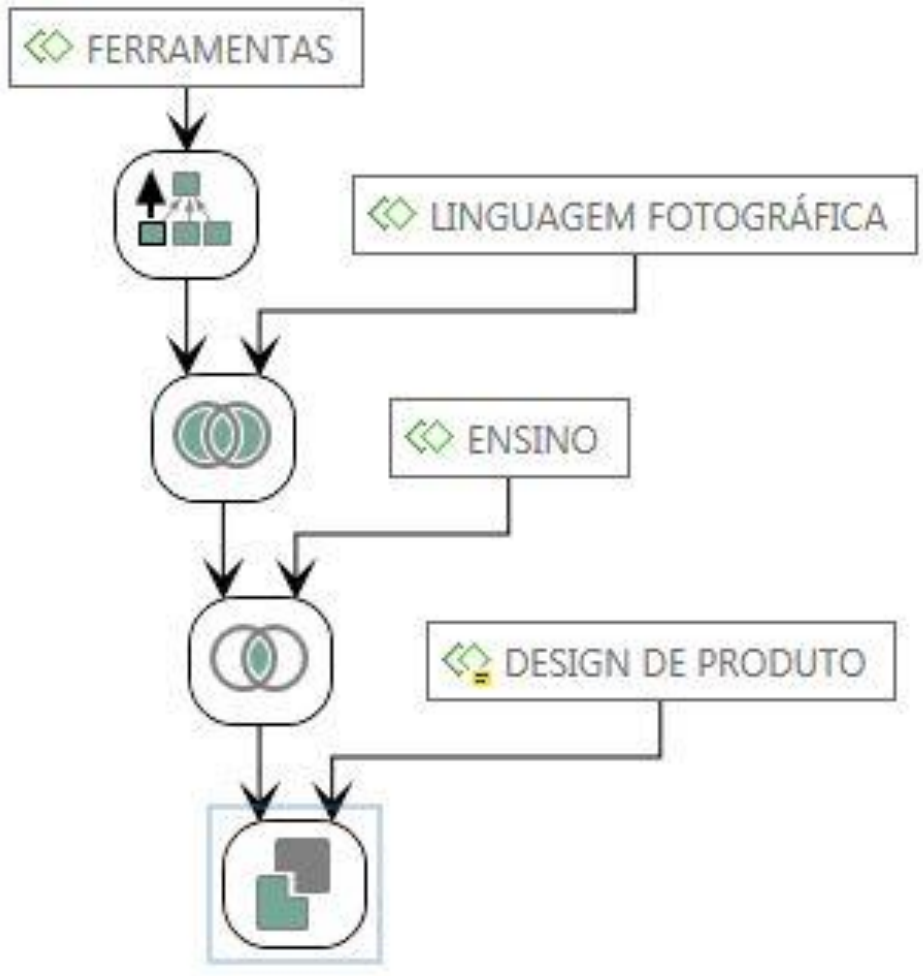

5B - Quais são as diversas técnicas de captura e manipulação de imagem oferecidas e a disposição no ensino de Design de Produto? (Design Análise)

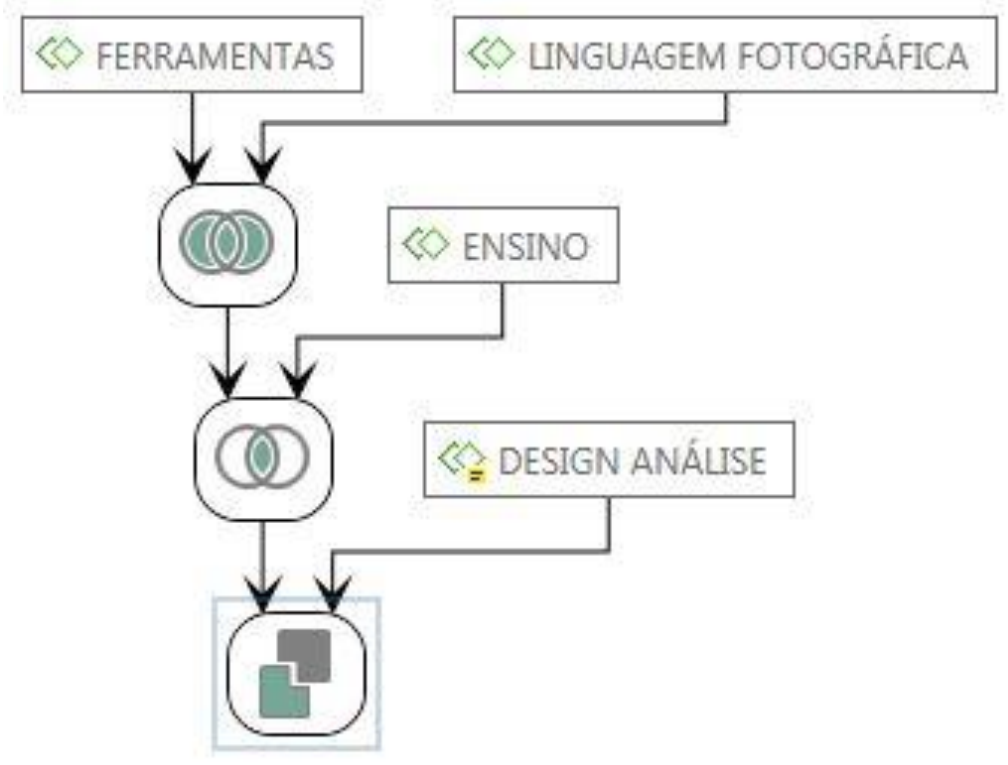


5C - Quais são as diversas técnicas de captura e manipulação de imagem oferecidas e a disposição no ensino de Design de Produto? (Design Investigação)

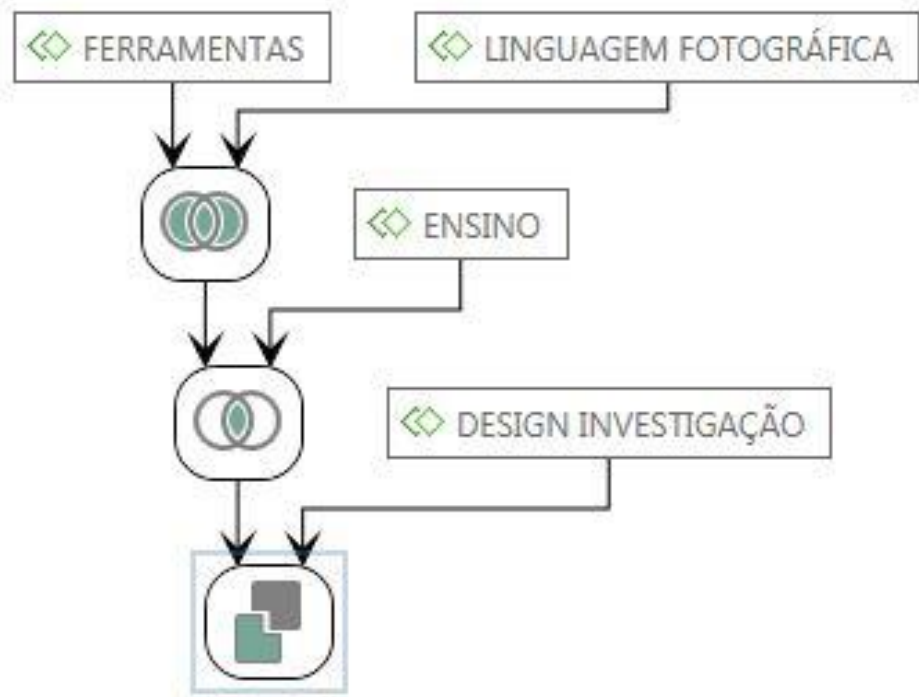

6A - Como a fotografia e o vídeo gera interferências nas ações dos processos de projeto?

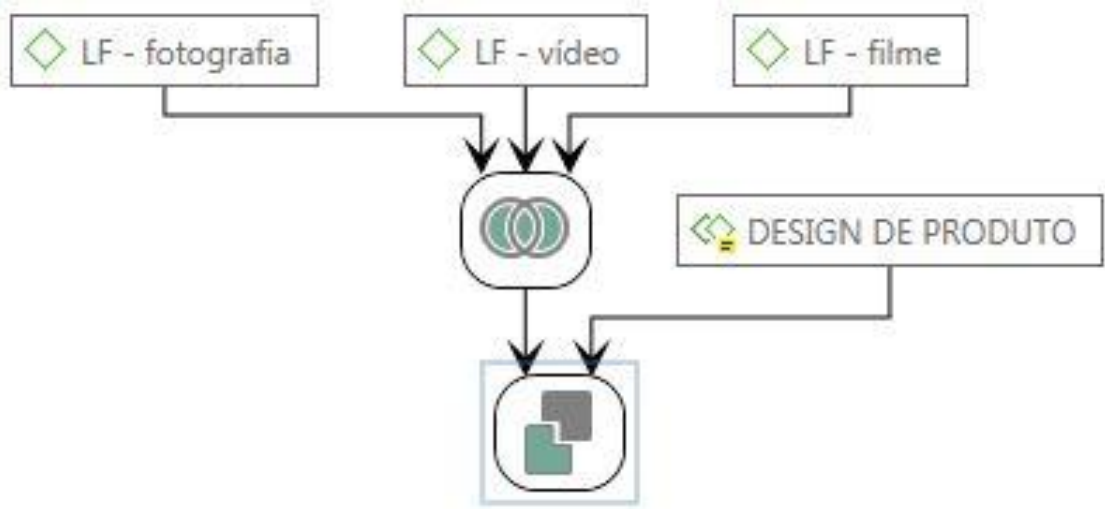

6B - Como a fotografia e o vídeo gera interferências nas ações dos processos de projeto? (Representação)

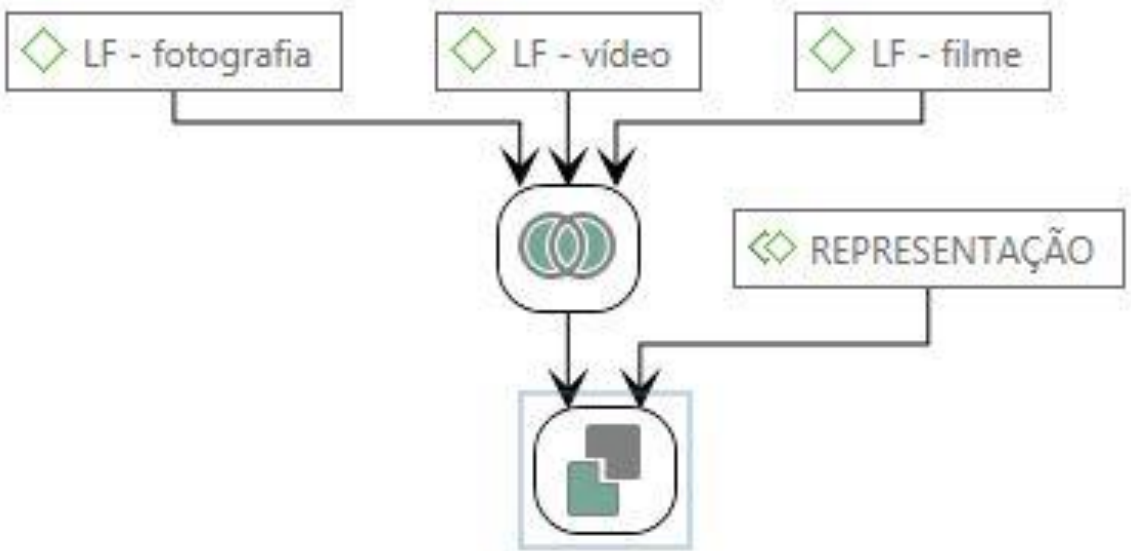


7 - Quais técnicas de imagem e representação contribuem para que o designer otimize a atividade projetual?

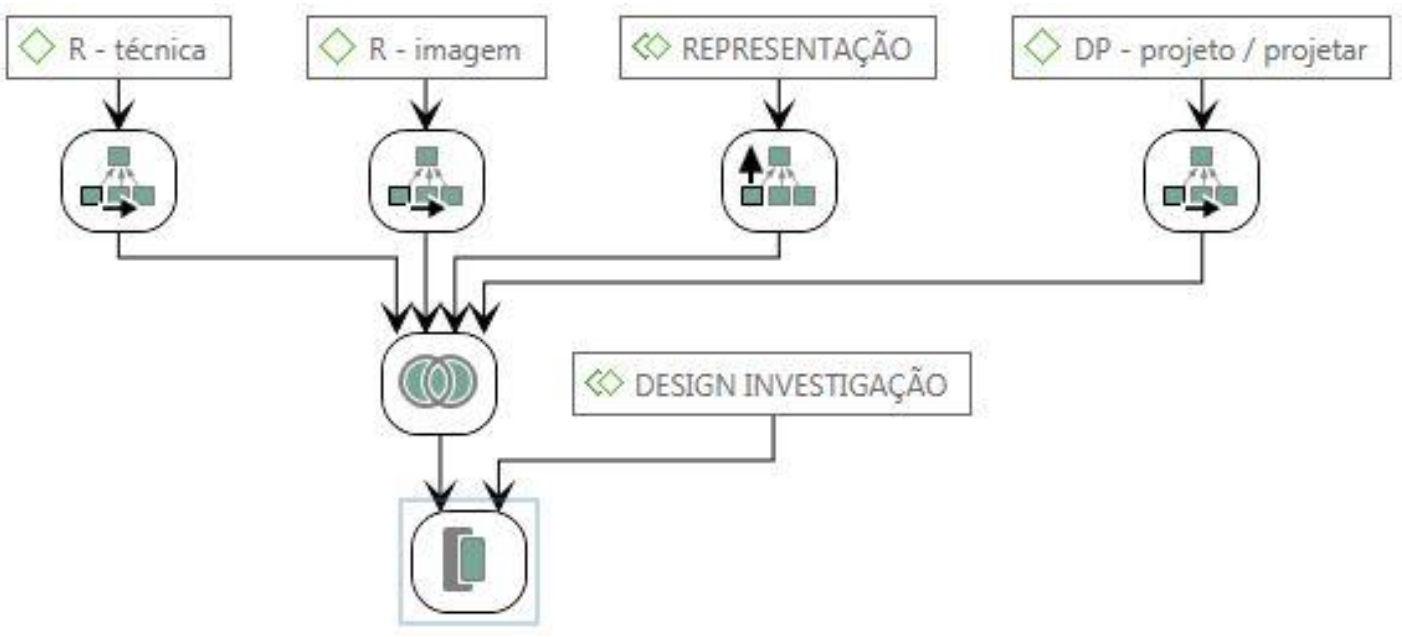

8 - Existe a necessidade do aluno estar familiarizado com a as diversas ferramentas para a produção de imagens?

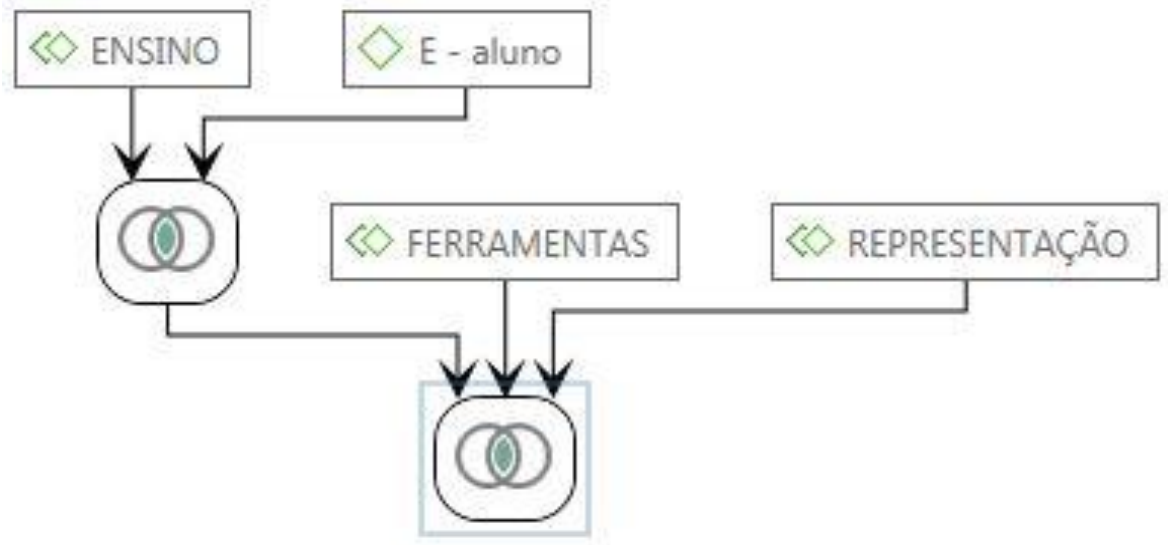

9A - De que forma a fotografia e o vídeo tem sido aplicados como suporte nos processos e procedimentos em Design de Produto? (Design Análise)

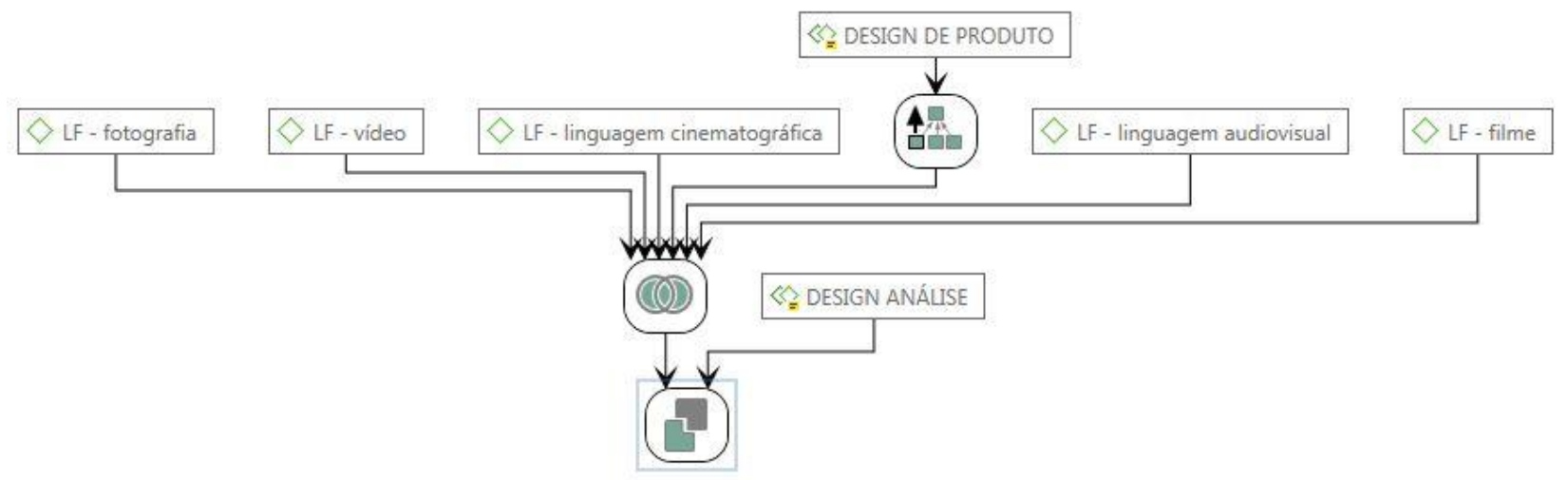


9B - De que forma a fotografia e o vídeo tem sido aplicados como suporte nos processos e procedimentos em Design de Produto? (Design investigação)

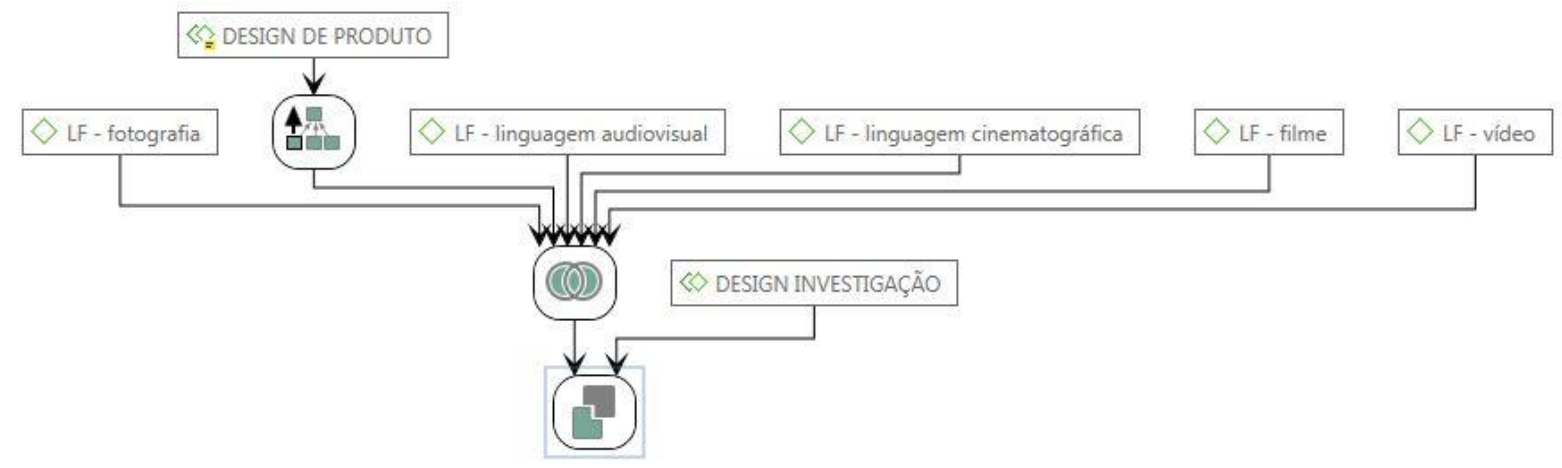

10 - A linguagem fotográfica no design perdeu o seu papel fundamental de fomentar e socializar a comunicação e informação nos processos de projeto?

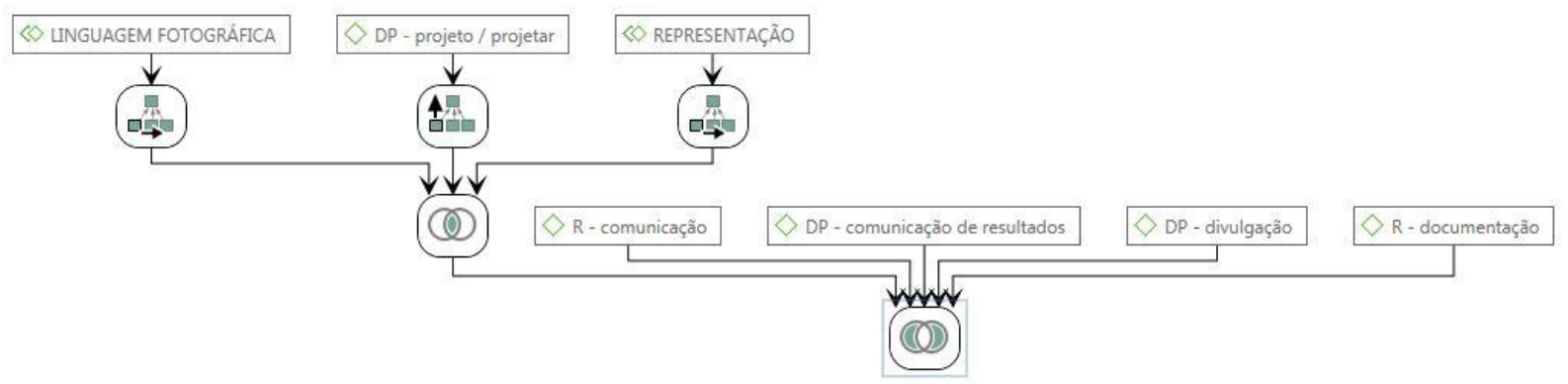




\section{APÊNDICE H - Grupos de documentos para tabulação de informações}

Década de nascimento de cada entrevistado
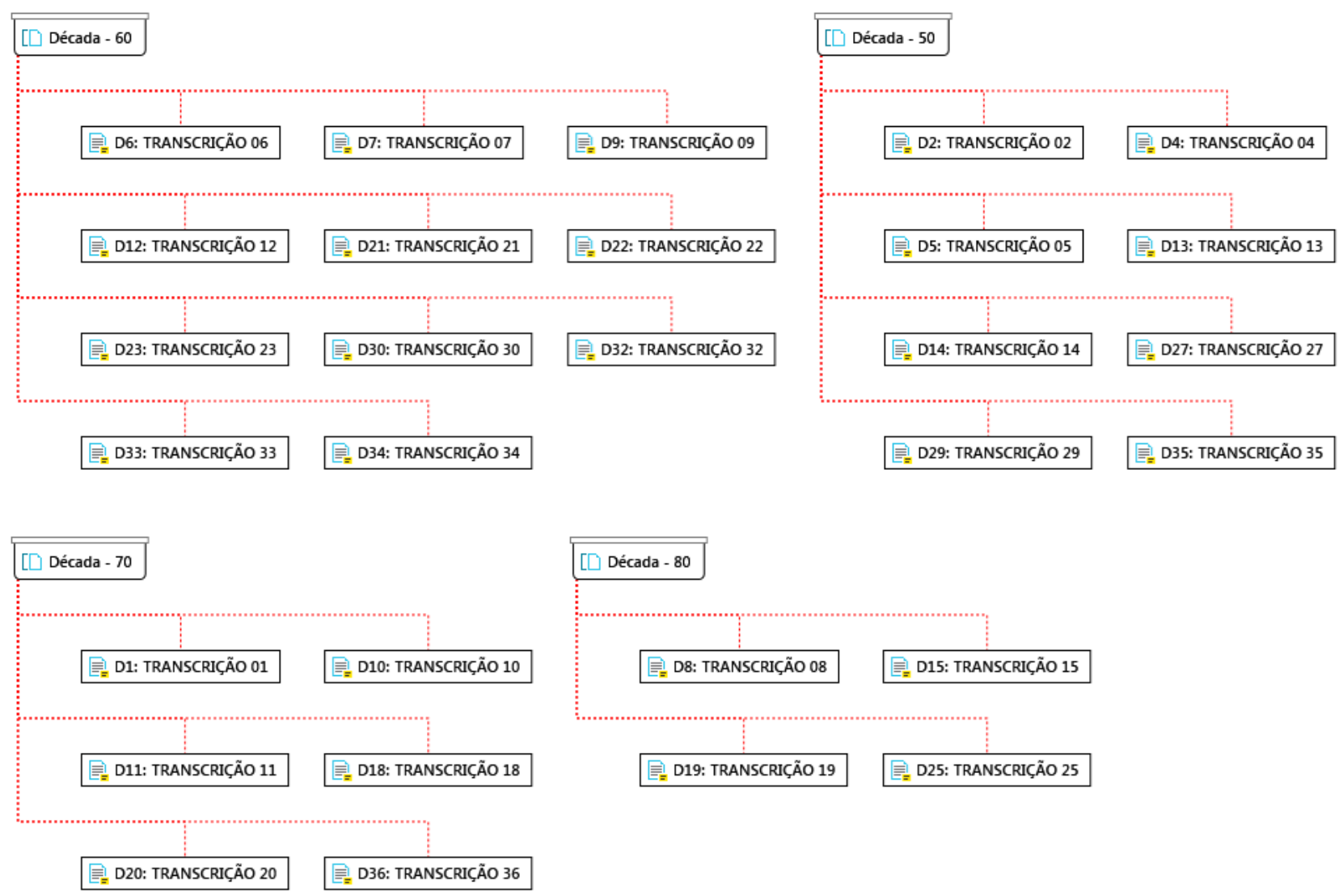

$[\square$ Década - 40

言= D3: TRANSCRIÇÃO 03 
Gênero do entrevistado

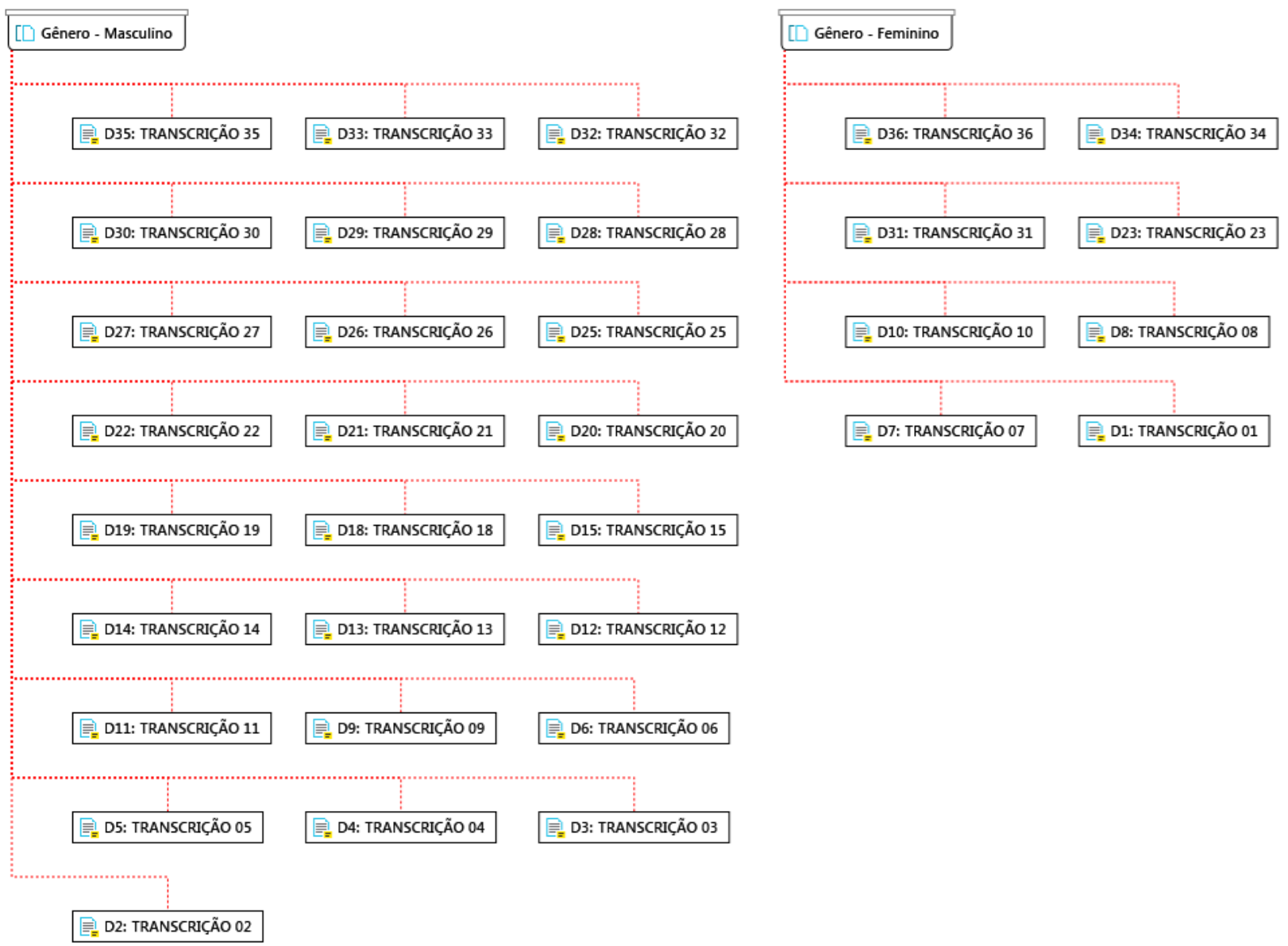




\section{Qual graduação realizou}

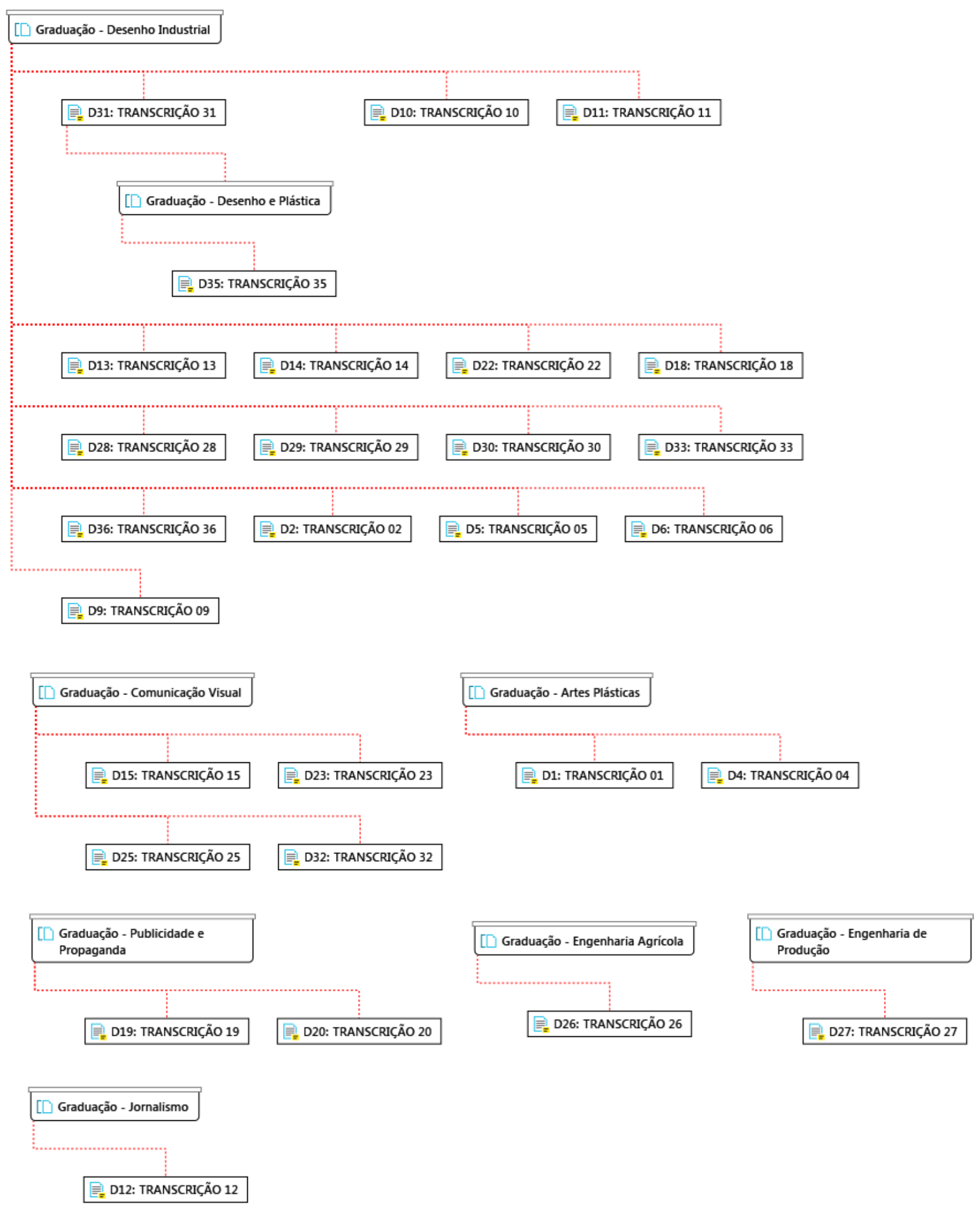




\section{Titulação máxima}
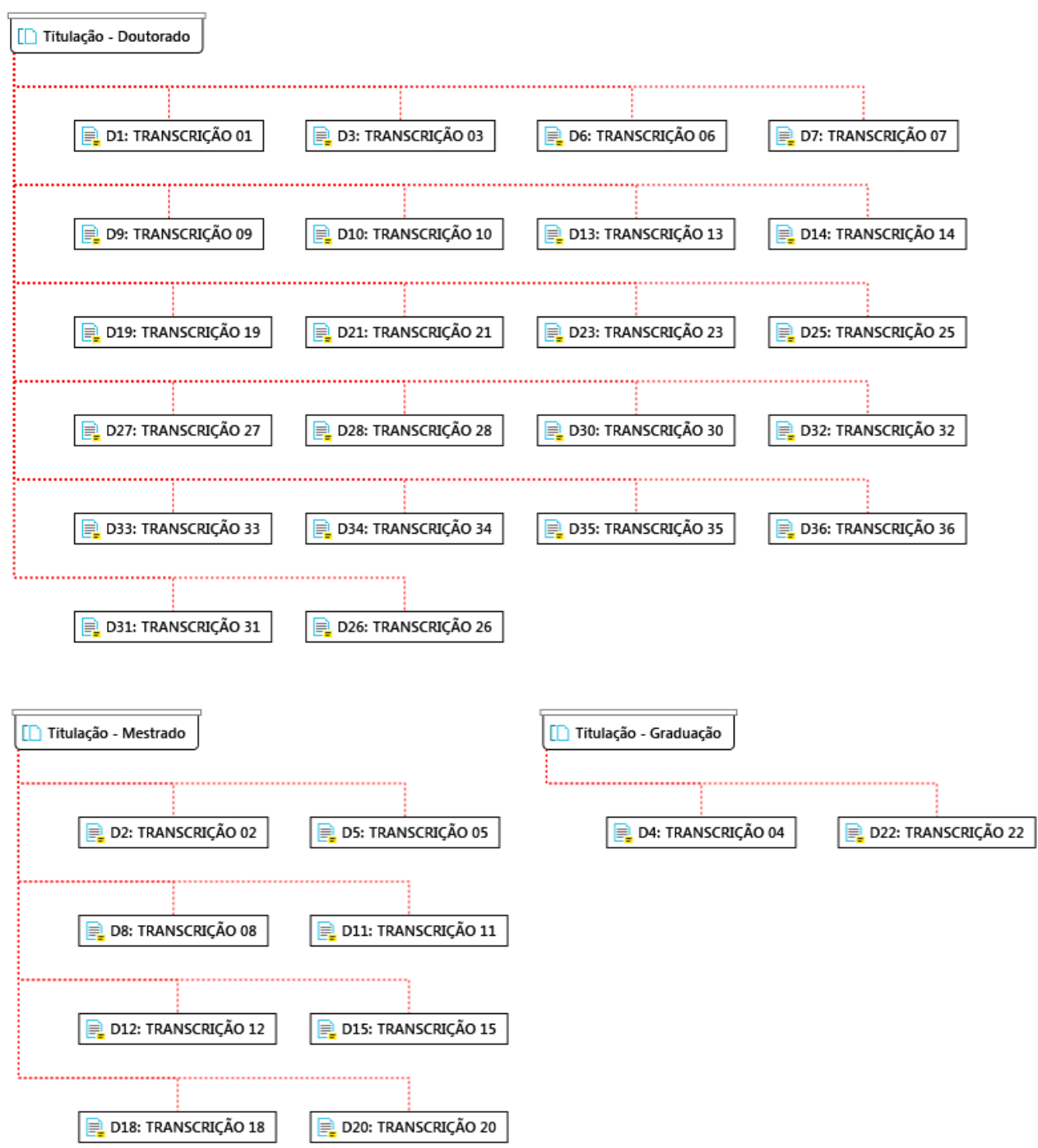

[D] Titulação - Especialização 


\section{Qual modelo de instituição pertence}
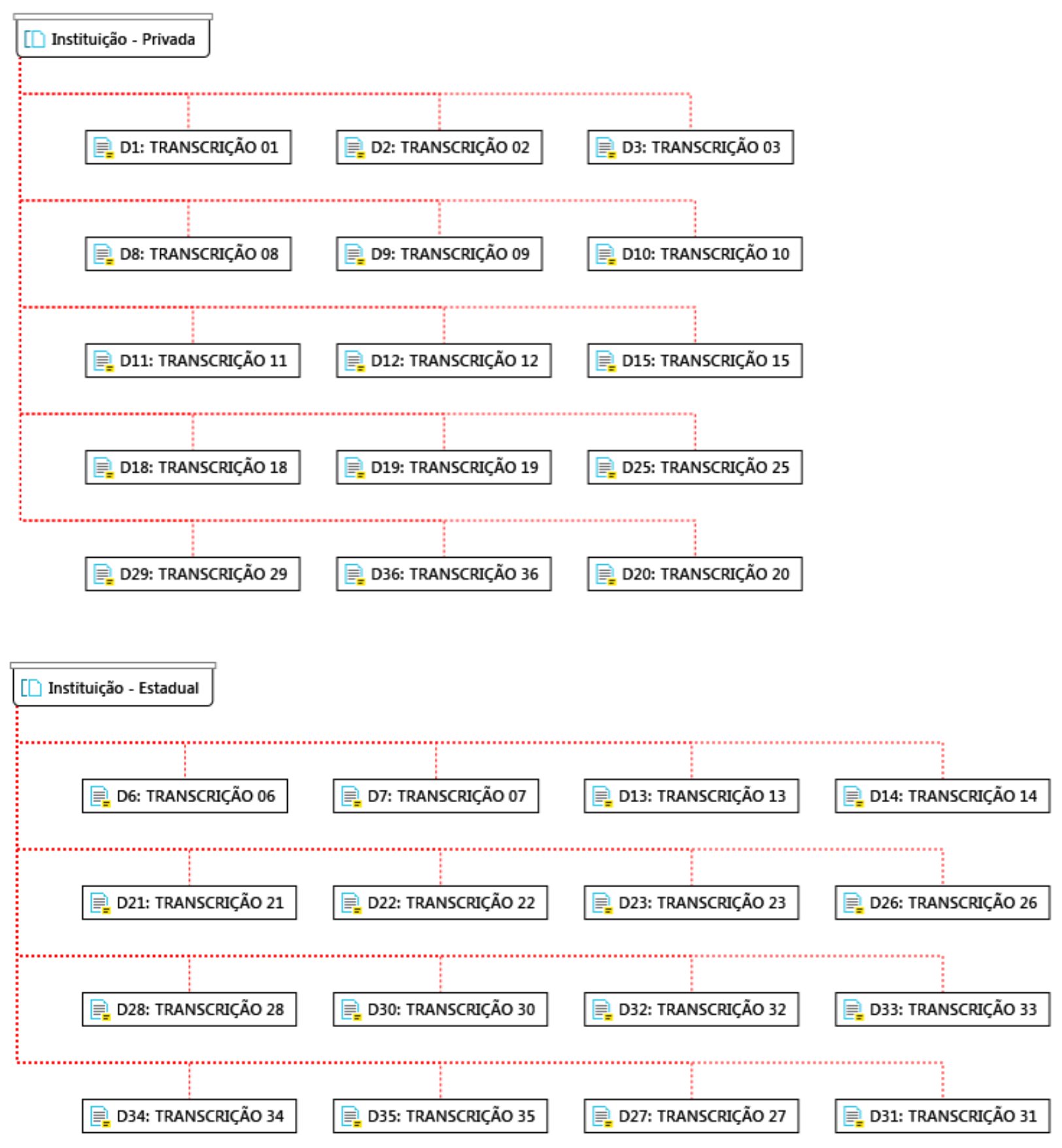

[D] Instituição - Municipal

D4: TRANSCRIÇÃO 04 产 D5: TRANSCRIÇÃO 05 
Apêndice I - DVD - Documentário e entrevistas 